\title{
COMMUNICATION AND CONTROL
}

A DISSERTATION SUBMITTED TO THE GRADUATE DIVISION OF THE UNIVERSITY OF HAWAI'I AT MÄNOA IN PARTIAL FULFILLMENT OF THE

REQUIREMENTS FOR THE DEGREE OF .

(4)

DOCTOR OF PHILOSOPHY

IN

POLITICAL SCIENCE

DECEMBER. 2014

By

John Maus

Dissertation Committee:

Michael J. Shapiro, Chairperson

Kathy Ferguson

Nevzat Soguk

Sankaran Krishna

Jaimey Hamilton 
The hours that hold the figure and the form

have run their course within the house of dream.

-Walter Benjamin

The root goal, after all, is "decriminalization by infinity-of-spectrum in easily publically accessible physics," i.e., enhancing the impossibility of control, rather than "making teh dro0gz" themselves. If nothing else, you can probably methelenate and then char into benzodioxole.

- BungHole, 06-02-2010, 06:38 AM, Zoklet.net 


\section{Acknowledgements}

I thank the University of Hawai'i for admitting me and for all of its kind assistance. I thank the faculty and staff of the University of Hawai'i at Mānoa's Political Science department, especially Laurie Onizuka for helping us keep it all together. I thank my fellow students: Jason Adams, Amy Donahue, Brianne Gallagher, Bianca Isaki, Rohan Kalyan, Ashley Lukens, Richard Pope, Chad Shomura, Lorenzo Rinelli and Noah Viernes. I thank the members of my committee: Kathy Ferguson, Jaimey Hamilton, Sankaran Krishna, Michael Shapiro, and Nevzat Soguk. I greatly appreciate the patience, open-mindedness, and forbearance they demonstrated in relation to my presence and work. I thank Anna Rice for helping me with the section on molecular biology, Dr. Amari Barash for helping me with the section on music, R. Sundararajan for helping me with the section on math, and Dr. Geoffrey Shullenberger, Dr. Merrie Bergman, as well as Kika Karadi, for helping me organize and edit the manuscript. Finally, I thank G. Adonian, N. Amato, J. Jones, A.M. Rosenberg, and my family. 


\begin{abstract}
The information age has been marked by complex advancements in the technologies of social management. Many of these advancements have been discussed in recent political theory. However, a thorough engagement with their mechanism and historical resonance remains necessary in order to substantiate such discussion. In this dissertation, I situate and analyze the increasingly informatic, molecular, and distributed technologies of power characteristic of "control societies" on a thoroughly substantive level. My research substantiates a number of claims made in recent political theory regarding control societies, and indicates that only a politics of positive feedback is adequate to the mechanism of such societies.
\end{abstract}




\section{Table of Contents}

Acknowledgements .............................................................................................................

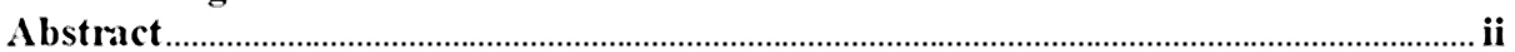

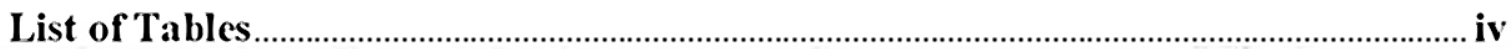

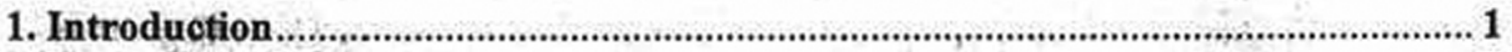

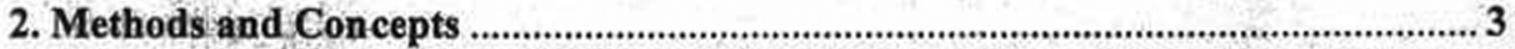

2.1. Introduction

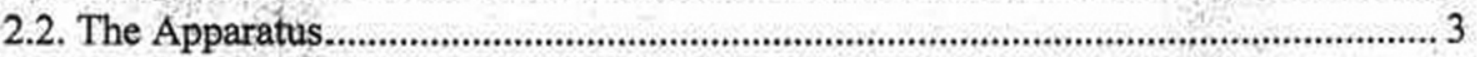

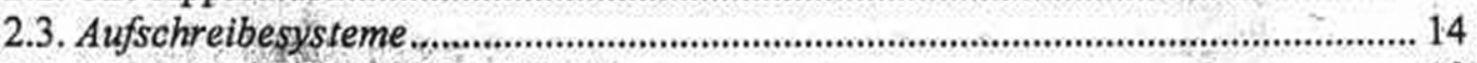

2.4. Sovereignty, Discipline, Control ................................................................. 18

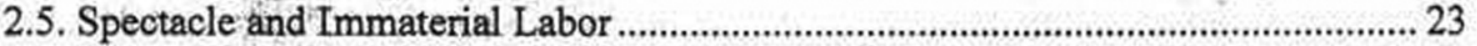

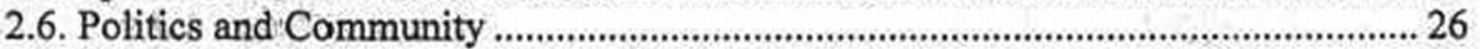

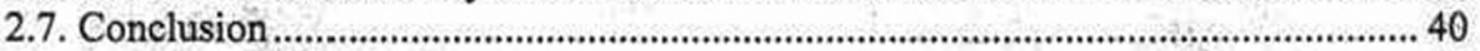

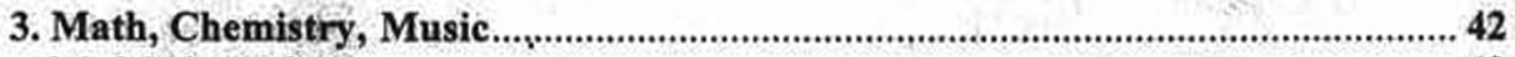

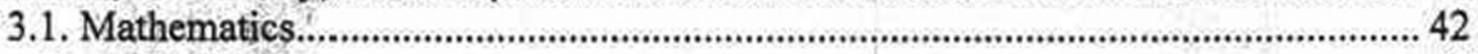

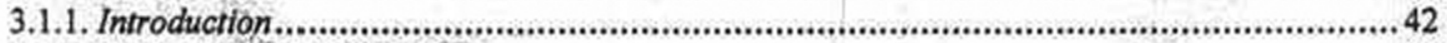

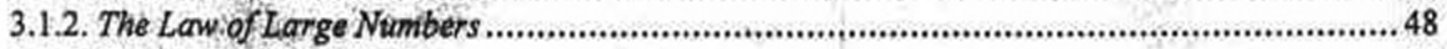

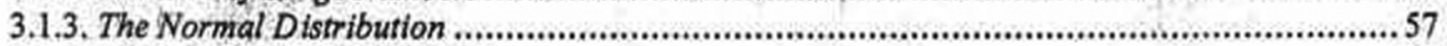

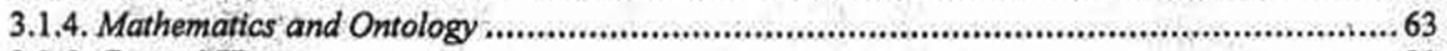

3.1.5. Control Theory ...................................................................................................... 81

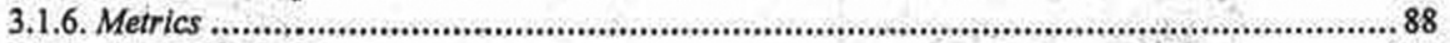

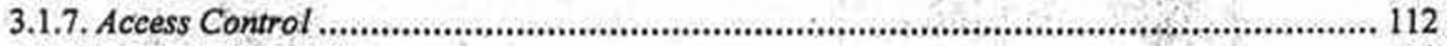

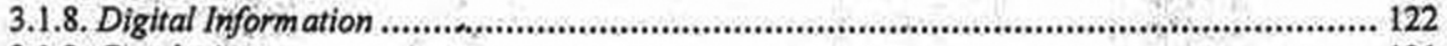

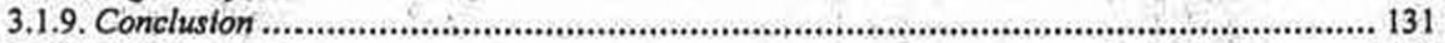

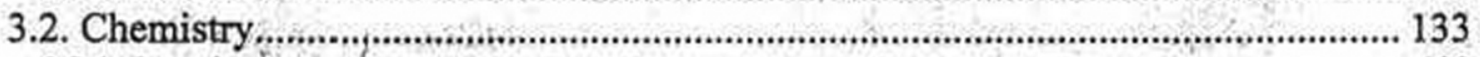

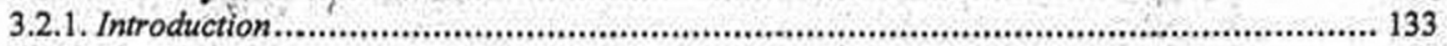

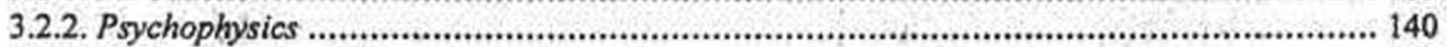

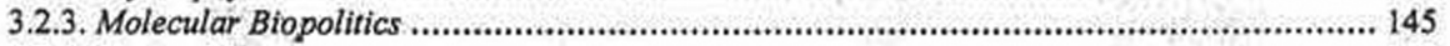

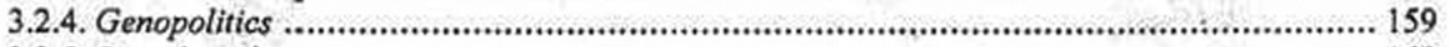

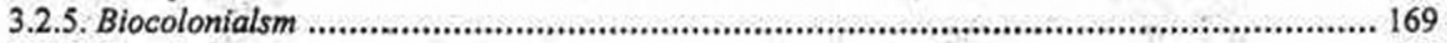

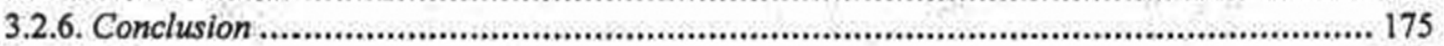

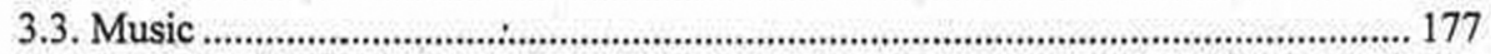

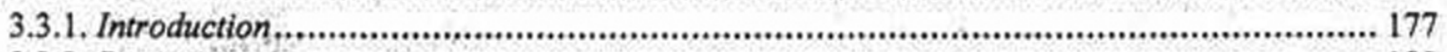

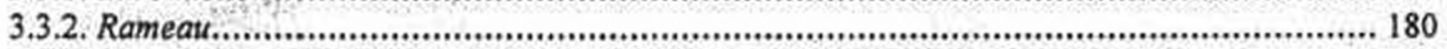

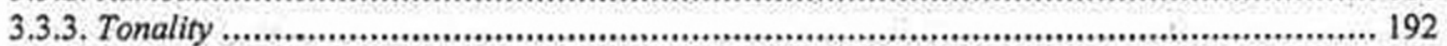

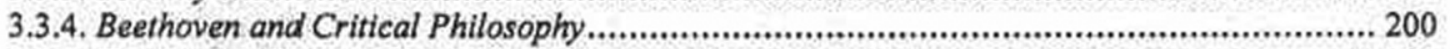

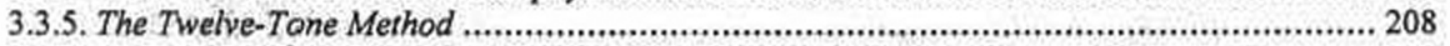

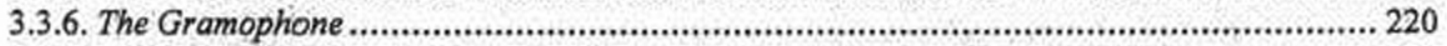

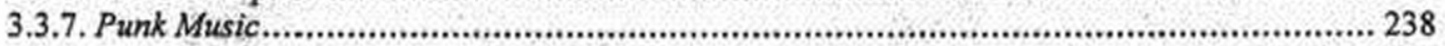

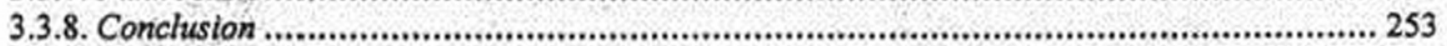

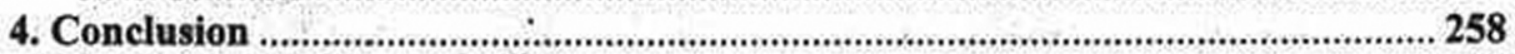

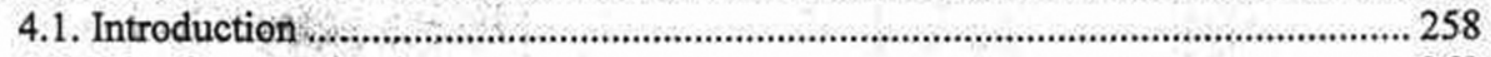

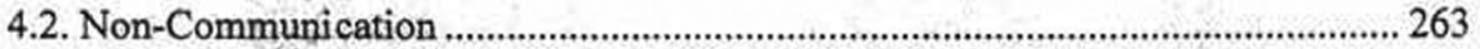

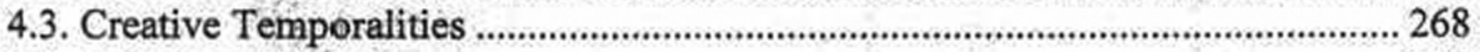

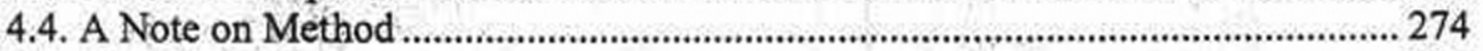

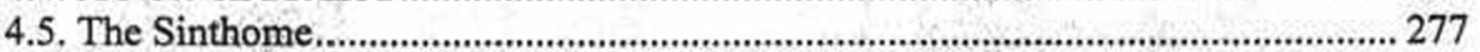

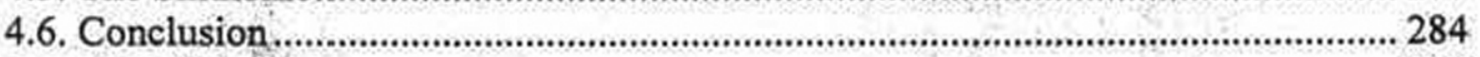

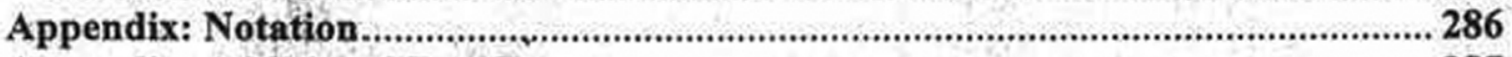

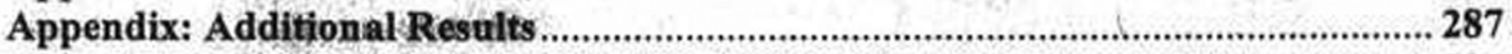

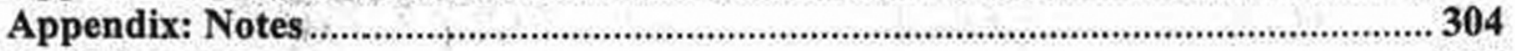

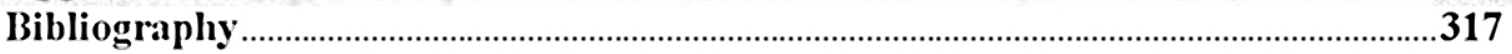


Table 1. Access Control Model

Table 2. Binary Numbers

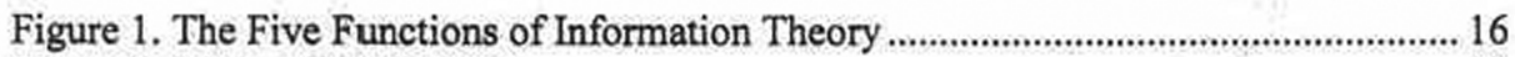

Figure 2. Conceptual Diagram..................................................................................4 40

Figure 3. Situation in Relation Being ………............................................................. 72

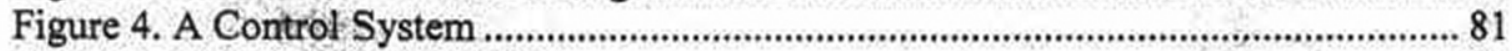

Figure 5. Google Autocomplete.............................................................................. 97

Figure 6. Level Scheme of a GATE Corpus ................................................................... 107

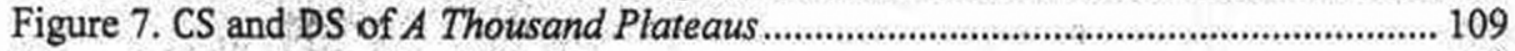

Figure 8. CS and DS of Anti-Oedipus..................................................................... 110

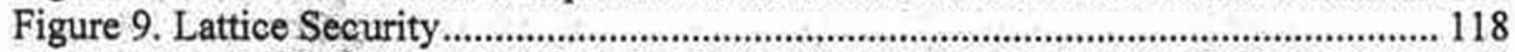

Figure 10. The KEGG: Phenylalanine, Tyrosine, and Tryptophan Biosynthesis.......... 145

Figure 11. D-Erythrose 4-phosphate and PEP ………….............................................. 146

Figure 12. Reaction (R01826)........................................................................... 147

Figure 13. Reaction (R03083)............................................................................ 147

Figure 14. Phenylalanine, Tryptophan, and Tyrosine ................................................. 148

Figure 15. Dopamine, Serotonin, and Norepinephrine ................................................ 148

Figure 16. Phenylethylamine and Tryptamine ............................................................ 153

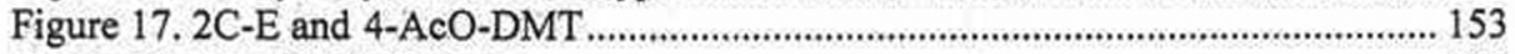

Figure 18. Fundamental Bass................................................................................ 185

Figure 19. The Overtone Series ................................................................................ 187

Figure 20. Beethoven, Symphony No. 1 in C major, Op. 21 (1801)........................... 195

Figure 21. Intervallic Symmetry of Webern's Op. 24 ................................................. 231

Figure 22. Ariel Pink, "White Freckles".................................................................. 240

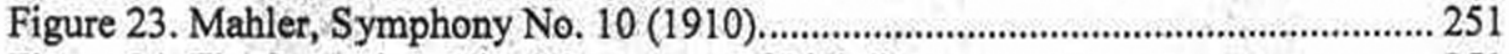

Figure 24. The Sensations Fix, "Fragments of Light".................................................. 251 


\section{Introduction}

In 1989, the Berlin Wall fell. This was also the year that Tim Berners-Lee proposed a "World Wide Web," Neil Papworth sent the first cell phone text message, and USA-35, the first operational global positioning satellite, was put into orbit. On Chang'an Avenue in Beijing, an unknown protestor, "Tank Man," stood in front of a column of military tanks. The year witnessed a series of events signaling a systematic reconfiguration in the technologies of power and the emergence of a new type of society: the "society of control,"

"Postscript on the Societies of Control," written two years later by philosopher Gilles Deleuze, provides the first outline of "control societies" and remains indispensable to their analysis. The title of the article is appropriate; the article is a brief note appended to the corpus of the author's lifework. The mood of the article is epitaphic; it refers to "young people" as laughing heirs, leaving them with the responsibility to "discover what they are being made to serve, just as their elders discovered, not without difficulty, the telos of the disciplines." The article then concludes with the cryptic phrase: "The coils of the serpent are even more complex than the burrows of the molehill. \#finger for address." The "molehill" here is that navigated by Marx's "old mole," the proletarian revolutionary; the revolutionaries of the future, suggests Deleuze, must discover new pathways.

Deleuze was not alone among post-war intellectuals in suggesting that the politics of young people would need to be something other than the grubbing of Marx's "old mole." In the 1960s, filmmaker Jean-Luc Godard was "waxing ironic about the children

1. Gilles Deleuze, "Postscript on the Societies of Control," October 59 (1992): 3.

2. Ibid. 
of Marx and Coca-Cola," ${ }^{3}$ while poet Paul Celan wrote that the efforts the generation of poets following him would confront would be the "efforts of those who, with man-made stars flying overhead, unsheltered even by the traditional tent of the sky, exposed in an unsuspected, terrifying way, carry their existence into language, racked by reality and in search of it." ${ }^{4}$ The critical theorist Guy Debord recognizes something like a possibility in the situation of young people. "In all that has happened in the last twenty years," writes Debord, "the most important change lies in the very continuity of the spectacle. [...] The spectacle's domination has succeeded in raising a whole generation molded to its laws. The extraordinary new conditions in which this entire generation has effectively lived constitute a precise and comprehensive summary of all that, henceforth, the spectacle will forbid; and also all that it will permit." ${ }^{5}$ Debord's remarks imply that an analysis of the conditions that have effected this generation of young people suffices to delineate certain of their horizons of possibility in relation to these conditions, and so this analysis already approaches the relative complexity of the serpentine coils that "Postscript on the Societies of Control" mentions in its cryptic, concluding phrase.

How do the children of the spectacle, of "Marx and Coca-Cola," bring their existence into this "serpentine" network of technologies in a way that will render thinkable the possibilities of their situation? In this dissertation, I situate and analyze the increasingly informatic, distributed, and molecular technologies of power in societies of control. My method is primarily descriptive, and so the contribution I provide to political theories of social management in control societies is primarily one of substantiation.

3. Jacques Rancière, The Emancipated Spectator, trans. Gregory Elliott (London: Verso, 2009), 32.

4. Paul Celan, Collected Prose, trans. Rosmarie Waldro (New York: Routledge, 2003), 35.

5. Guy Debord, Comments on the Society of the Spectacle, trans. Malcolm Emrie (London: Verso, 1998), 7. 


\section{Methods and Concepts}

2.1. Introduction

In this chapter, I discuss the concepts that frame my analyses of control societies. In Section 2.2, I detail the concept of an apparatus, a general concept of the mechanism of power in any situation. In Section 2.3, I develop this concept by way of Friedrich Kittler's method in media theory, which augments the concept's definition by emphasizing its material dimension. In Section 2.4, based on the concept of an apparatus in general, I explain the apparatuses of power particular to three types of societies, namely, societies of sovereignty, discipline, and control. In Section 2.5 , I detail the spectacular dimension of control societies. Lastly, in Section 2.6, I present and discuss some concepts related to doing politics in control societies: the free use of the proper, positive feedback, and the unworkable community.

\subsection{The Apparatus}

Michel Foucault defines the term "apparatus" (dispositif) as a "heterogeneous set consisting of discourses, institutions, architectural forms, regulatory decisions, laws, administrative measures, scientific statements, philosophical, moral, and philanthropic propositions."1 The term also implies a network between the elements of this set that implicates a characteristic "strategic function." ${ }^{2}$ The term does not appear in Foucault's research until the end of the 1960s; before that, Foucault uses the term "positivity," which

1. Michael Foucault, 1977, "The Confession of the Flesh," in Power/Knowledge: Selected Interviews and Other Writings, ed. Colin Gordon (New York: Vintage, 1980), 201.

2. Ibid. 
he adapted from the work of his "Master," Jean Hyppolite. In his analyses of the writings of the young Hegel, Hyppolite understood the term "positivity" (Positivitat) to signify the historical element of subjectivity. ${ }^{3}$

Giorgio Agamben recognizes an etymological antecedent of the term "apparatus" in the ancient Greek oikonomia, which "signifies the administration of the oikos (the home) and, more generally, management." The term oikonomia eventually provided the Greek Church Fathers with a method of conceptualizing the threefold nature of God, where God in His being is one, and in His oikonomia, the management of His creation, is triple: "Just as a good father can entrust to his son the execution of certain functions and duties without in so doing losing his power and his unity," explains Agamben, "so God entrusts to Christ the 'economy,' the administration and government of human history."" For the Greek Church Fathers, oikonomia conceptualized the event of the Son's incarnation, in addition to the economy of redemption and salvation (i.e., providential history) implicit in this event." "As often happens," continues Agamben, "the fracture that the theologians had sought to avoid by removing it from the plane of God's being, reappeared in the form of a caesura that separated in Him being and action, ontology and praxis. Action (economy, but also politics) has no foundation in being: this is the schizophrenia that the theological doctrine of oikonomia left as its legacy to Western

3. See Notes 2.1.

4. Giorgio Agamben, "What is an Apparatus?," in What is an Apparatus? And Other Essays, trans. David Kishik and Stefan Pedatella (Stanford, CA: Stanford University Press, 2009), 8.

5. Ibid., 10.

6. See Notes 2.2 . 
culture." ${ }^{7}$ The etymological relation between the terms oikonomia and dispositif is evident in the translations of the Latin Fathers, who translated the Greek oikonomia as the Latin dispositio. "The 'dispositifs' about which Foucault speaks," concludes Agamben, "are somehow linked to this theological legacy. They can be in some way traced back to the fracture that divides and at the same time, articulates in God being and praxis, the nature or essence, on the one hand and the operation through which $\mathrm{He}$ administers and governs the created world, on the other. The term 'apparatus' designates that in which and through which, one realizes a pure activity of governance devoid of any foundation in being." ${ }^{8}$

An apparatus is "literally anything that has in some way the capacity to capture, orient, determine, intercept, model, control, or secure the gestures, behaviors, opinions, and discourses of living beings." ${ }^{9}$ The relation between apparatuses and beings also involves the positive processes of "subjectification" implied by Hegel's use of the term Positivitat: an apparatus effects the subjects whose potentials it captures. This capture, similar to its theological antecedent, the oikoniomia, begins from a standpoint devoid of any foundation in being.

The apparatuses of the current phase of capitalism (i.e., control societies) "no longer act as much through the production of a subject as through the processes of what can be called desubjectification." ${ }^{10}$ The processes of subjectification (the emergence of a "new" self) particular to earlier apparatuses already implied processes of desub-

7. Ibid. See Notes 2.3 .

8. Agamben, "What is An Apparatus?," 11.

9. Ibid., 14.

10. Ibid., 20. 
jectification (the disappearance of an "old" self). ${ }^{11}$ The apparatuses particular to control societies entirely abandon the processes of subjectification for the processes of desubjectification. They "[do] not give rise to the recomposition of a new subject," explains Agamben, "except in larval or, as it were, spectral form."

Agamben exemplifies desubjectification through the cellular telephone apparatus. Contrary to the advertisements that celebrate the "connectedness" this apparatus is supposed to effect, Agamben argues that the cellular telephone "separates the living being from itself and from its immediate relationship with its environment." ${ }^{13}$ The ubiquitous image of people gathered in a public space captivated only by their phones rather than their surroundings or the other people around them provides support for Agamben's argument. The captivation of the cell phone users by the "elsewhere" of cyberspace also exemplifies the separation Agamben emphasizes in relation to the term oikonomia: "the capture and [de]subjectification of [...] desire in a separate sphere constitutes the specific power of the apparatus [my emphasis]." ${ }^{14}$ This concept of separation does not involve the metaphysics implicit in alienation in the critical theoretical sense, but rather involves a donation of potentiality that is productive of value only for the apparatus. Agamben maintains that free use of an apparatus is impossible: "If a certain process of [...] desubjectification corresponds to every apparatus," argues Agamben, "then it is impossible for the subject of an apparatus to use it 'in the right way.' [...] He who lets himself be captured by the 'cellular telephone' apparatus-

11. See Notes 2.4 .

12. Ibid,

13. Ibid.

14. Ibid., 17. 
whatever the intensity of the desire that has driven him-cannot acquire a new subjectivity, but only a number through which he can, eventually, be controlled."15

The separation of the "living being from itself" implicit in an apparatus involves the "living-dead." ${ }^{16}$ Marx's concept of the automatic system of machinery exemplifies this dimension of the living-dead. In the sixth notebook of the Economic Manuscripts, Marx details the qualitative changes of labor by the mechanics of capital. As circulating capital, labor can become a raw material or a product. As fixed capital, labor can become an instrument or a building. These qualitative changes culminate, however, in "the machine, or rather, an automatic system of machinery." ${ }^{17}$ Marx defines this system as a "moving power that moves itself $" 18$ and says that "[with] this automaton, consisting of numerous mechanical and intellectual organs, $[\ldots]$ the workers themselves are cast merely as its conscious linkages." ${ }^{19}$ To provide further definition to automatic systems of machinery, Marx contrasts them with instruments. The instrument can only change circulating labor into fixed labor. The worker operates the instrument "with his skill and strength. ${ }^{20}$ The automatic system of machinery "possesses skill and strength in place of the worker, [and] is itself the virtuoso, with a soul of its own." ${ }^{21}$ In this way, the automatic system of machinery changes labor, which always produces value, into "value

15. Ibid.

16. See Notes 2.5 .

17. Karl Marx, Grundrisse: Foundations of the Critique of Political Economy (New York: Vintage Books, 1973), 692.

18. Ibid.

19. Ibid.

20. Ibid.

21. Ibid. 
existing for-itself." 22 In the automatic system of machinery, "living" labor materially confronts not "dead" labor, but rather the "living-dead" labor of the automaton as a "ruling power and as [the] active subsumption of the [former] under itself."23

Norbert Wiener's anti-aircraft predictor provides another example of the livingdead as it relates to an apparatus. When the anti-aircraft predictor was unveiled in July 1942 , everyone present was astonished. It was as if the ruthless weapon could "foretell the future like a crystal ball. ${ }^{24}$ Warren Weaver threatened to take a hacksaw to the machine, and G. R. Stiblitz, Wiener's National Defense Research Council section chairman, remarked that "the behavior of their instrument is positively uncanny." 25 Wiener's anti-aircraft apparatus, comprised of servo-mechanisms and differential analyzers, was able to predict the movement and future location of enemy aircraft. The apparatus effected an active subsumption of the living by the living-dead because the dead aircraft would have been piloted by a living pilot. From the standpoint of Weiner's apparatus, in other words, the distinction between pilot and aircraft in relation to some category of life was abandoned. Both pilot and aircraft were inscribed as black boxes within a single control system. "The pilot behaves like a servo-mechanism," observes Wiener, "attempting to overcome the intrinsic lag due to the dynamics of his plane as a physical system, in response to a stimulus which increases in intensity with the degree to

22. Ibid.

23. Ibid.

24. Peter Galison, "The Ontology of the Enemy: Norbert Weiner and the Cybernetic Vision," Critical Inquiry 21, no.1 (Autumn, 1994): 242.

25. Ibid., 243. See Notes 2.6 . 
which he has failed to accomplish his task." ${ }^{26}$ "The core lesson that Wiener drew from his antiaircraft work," explains Peter Galison, "was that the conceptualization of the pilot and gunner as servomechanisms within a single system was essential and irreducible."27

Deleuze details the concept of an apparatus as comprising three components: lines of visibility and enunciation, lines of force, and lines of subjectification. Foucault's research into the history of sexuality exemplifies these components. Lines of visibility and lines of enunciation are the "historical nature" of an apparatus: "Visibility cannot be traced back to pre-existing objects," explains Deleuze; "it is made of lines [...] that form variable shapes inseparable from the apparatus in question. ${ }^{, 28}$ Lines of visibility are the lines that "make one see": "Each apparatus has a [characteristic] way of structuring light, [of] giving birth to objects [...] and causing them to disappear, ${ }^{29}$ In a similar way, lines of enunciation are what make objects describable.

The homosexual, as a visible "case" of an individual, appears and is describable only within a specific apparatus. "As defined by the ancient civil or canonical codes," writes Foucault, "sodomy was a category of forbidden acts; their perpetrator was nothing more than the juridical subject of them. The nineteenth-century homosexual became a personage [...]. The sodomite had been a temporary aberration, the homosexual was now a species. ${ }^{30}$ Members of the same sex were creating practices of love and pleasure with

26. Galison, "The Ontology of the Enemy," 237.

27. Tbid., 238.

28. Gilles Deleuze, "What is a Dispositif?," in Michel Foucault, Philosopher, trans. Timothy J. Armstrong (New York: Harvester, 1992), 160.

29. Ibid.

30. Michel Foucault, The History of Sexuality: An Introduction, trans. Robert Hurley (New York: Random House, 2012), 43. 
each other before the mechanișms of discipline. It was the apparatus of discipline (e.g., the clinic, the analyst's couch, the index), however, that allowed the homosexual as a "case" to emerge as an object of perception and description.

"The line of force," writes Deleuze, "comes about "in any relationship between one point and another,' and passes through every area in the apparatus. [...] This is the 'dimension of power' [...] internal to the apparatus, variable to the apparatus. ${ }^{" 31}$ Lines of force operate between lines of visibility and enunciation, "acting as go-betweens between seeing and saying and vice versa, acting as arrows which continually cross between words and things, constantly waging battle between them." ${ }^{32}$ Peter Bachrach and Morton Baratz's concept of "organization" as the "mobilization of bias" exemplifies lines of force. ${ }^{33}$ To bias is to change the potentials of the variables of a system in order to optimize that system as a whole. "All forms of [social] organization," write Bachrach and Baratz, "have a bias in favor of the exploitation of some kinds of conflict and the suppression of others because organization is the mobilization of bias. Some issues are organized into [society] while others are organized out."34

In relation to homosexuality, the span of fifty years in advanced liberal societies has witnessed a remobilization of bias, a line of force between seeing and saying. The treatment of homosexuals as diseased has mostly been abandoned in favor of their treatment as a protected and celebrated interest group. In 2012, for example, when an

31. Deleuze, "What is a Dispositif?," 159.

32. Ibid., 160.

33. Peter Bachrach and Morton S. Baratz, "Two Faces of Power," American Political Science Review 56, no. 4 (1962): 952.

34. Ibid., 949. 
Evangelical Christian stated on a U.S. cable news station that homosexuality was "gravely unnatural," scandal and controversy ensued. ${ }^{35}$ The shifting value of the statement that homosexuality is "gravely unnatural," which was accepted as fact only fifty years earlier, provides an example of lines of force as they operate within an apparatus.

Lines of subjectification are the "production of subjectivity in a social apparatus. ${ }^{36}$ A subjectification "has to be made," suggests Deleuze, "inasmuch as the apparatus allows it to come into being or makes it possible. ${ }^{37}$ Lines of subjectification emerge when any variable within an apparatus ceases to be well behaved in some particular way. ${ }^{38}$ This definition of subjectification corresponds to philosopher Jacques Rancière's definition of politics as an activity of les sans-part. ${ }^{39}$ Political events escape the codes of knowledge; analogous to the singularities or attractors of nonlinear dynamical systems, these invisible nonentities or lines of subjectification are only implied by way of deviations in the trajectories of visible entities.

Continuing the example of homosexuality, lines of subjectification approach the term "queer" as it is mobilized by queer theorists. Lee Edelman, for example, defines the queer as "a zone of possibilities in which the embodiment of the subject might be

35. Noah Michelson, "Kirk Cameron Tells Piers Morgan Homosexuality Is 'Unnatural,' 'Ultimately Destructive'," The Huffington Past, February 3, 2012, http://www.huffingtonpost.com/2012/03/03/kirkcameron-piers-morgan-homosexuality-unnatural_n_1318430.html.

36. Deleuze, "What is a Dispositif?," 160.

37. Ibid.

38. See Notes 2.7.

39. Jacques Rancier, "Dissenting Words: A Conversation with Jacques Ranciere," Diacritics 30, no. 2 $(2000): 124$. 
experienced otherwise. ${ }^{, 40}$ Teresa De Lauretis suggests that the rubric of the queer makes it possible "to recast or reinvent the terms of our sexualities, to construct another discursive horizon, another way of thinking the sexual. ${ }^{, 41}$ Jack Halberstam defines queer as "nonnormative logies and organizations of community, sexual identity, embodiment, and activity." ${ }^{42} \mathrm{He}$ details "counterintuitive and patently queer forms of negative knowing, ${ }^{, 43}$ such as stupidity, forgetting, failure, and illegibility. ${ }^{44}$ Petra Eckhard asserts that these ways of knowing are always "anti-communitarian, self-shattering, and antiidentitarian productions of a counter-intuitive but crucial shift in thinking away from projects of redemption, reconstruction, restoration and reclamation and towards what can only be called an anti-social, negative and anti-relational theory of sexuality. ${ }^{45}$ In queer theory, the term "queer" does not signify an interest group such as would be sanctioned by the identity politics of liberal pluralism. The queer involves something unworkable in relation to the apparatuses of liberal pluralism. In contrast with the processes of individualization defined by Foucault, lines of subjectification correspond to the creation of new forces, visibilities, and enunciations in an apparatus.

40. Lee Edleman, Homographesis: Essays in Gay Literary and Cultural Theory (Hoboken, NJ: Taylor and Francis, 2013), 114.

41. Teresa De Lauretis, Queer Theory: Lesbian and Gay Sexualities (Bloomington: Indiana University Press, 1991), iv.

42. Judith Halberstam, "Queer Temporality and Postmodern Geographies," in In a Queer Time and Place: Transgender Bodies, Subcultural Lives. (New York: New York University Press, 2005 ), 6.

43. Judith Halberstam, "The Politics of Negativity in Recent Queer Theory," PMLA 121, no. 3 (2006): 823.

44. See Notes 2.8 .

45. Petra Eckhard, "A Queer Reading of Moby Dick," in Landscapes of Postmodernity: Concepts and Paradigms of Critical Theory, eds. Petra Eckhard, Michael Fuchs, and Waiter W. Hobling (Berlin: Verlag, 2010), 179. 
The management of sexuality in the prototypical oikonomia exemplifies the queer as a line of subjectification. The theology of the body implicit in this economy orders sexuality to the sacrament of heterosexual matrimony and the mystery of procreation. In terms of this apparatus, queers are "called to chastity," because their "homosexual acts" are "gravely contrary to the dignity of persons and human sexuality," that is, they present something unworkable from the standpoint of this apparatus.

In a 1991 conversation, philosopher Toni Negri asked Deleuze about lines of subjectification: "In Foucault and in The Fold, processes of subjectification seem to be studied more closely than in some of your other works [...]. What are the political consequences of this conception of the subject? If the subject cannot be reduced to an externalized citizenship, can it invest citizenship with force and life? [...] What politics can carry into history the splendor of events and subjectivity? How can we conceive a community that has real force but no base, that isn't a totality but is $[\ldots]$ absolute?"46 Deleuze's answer to Negri is instructive:

It definitely makes sense to look at the various ways individuals and groups constitute themselves as subjects through processes of subjectification: what counts in such processes is the extent to which, as they take shape, they elude both established forms of knowledge and the dominant forms of power. This has nothing to do with going back to "the subject," that is, to something invested with duties, power, and knowledge. One might equally well speak of new kinds of event, rather than processes of subjectification: events that cannot be explained by the situations that give rise to them, or into which they lead. They appear for a moment, and it's that moment that matters, it's the chance we must seize. ${ }^{47}$

46. Gilles Deleuze and Toni Negri, "Control and Becoming," in Negotiations, trans. Martin Joughin (New York: Columbia University Press, 1990), 176.

47. Ibid. 
Deleuze continues, "Or we can simply talk about the brain, the brain is precisely this boundary of a continuous two-way movement between an Inside and Outside, this membrane between them. ${ }^{, 48}$.

Lines of visibility and enunciation, lines of force, and brains detail the concept of an apparatus. Only brains, however, can carry the "splendor of events and subjectivity into history." 49

\subsection{Aufschriebesysteme}

"Foucault developed discourse analysis as a reconstruction of the rules by which the actual discourses of an epoç would have to have been organized in order to exclude, for example, insanity." ${ }^{\text {a }}$ Kittler's statement provides a gloss on Foucault's suggestion that "enunciative analysis [...] must make it possible to raise the transcendental obstacle that a certain form of [...] discourse opposes to all analyses of language, in the name of the being of that language and of the ground from which it should derive its origin." 51 The phrase "transcendental obstacle" signifies whatever general potentiality an apparatus captures as a particular actuality. Foucault's genealogical method seeks to discover these potentialities, in addition to characterizing the strategic function involved in their capture

48. Gilles Deleuze, Cinema II: The Time-Image, trans. Hugh Thomlinson and Robert Galeta (Minneapolis: University of Minnesota Press, 1989), 212. See Notes 2.9.

49. Ibid.

50. John Armitage and Friedrich A. Kittler, "From Discourse Networks to Cultural Mathematics: An Interview with Friedrich A. Kittler," Theory, Culture \& Society 23 (2006): 18.

51. Michel Foucault, Archaeology of Knowledge, trans. A. M. Sheridan Smith (London: Routledge, 2002), 127. 
by an apparatus, in the name of the "being of language" or the "ground" that is potentiality in general.

Kittler's concept of an Aufschreibesystem supplements Foucault's concept of an apparatus and provides this "ground" more definition by emphasizing its positive or material dimension. ${ }^{52}$ Kittler details the concept of an Aufschreibesystem as involving a "free application of Claude E. Shannon's information theory." 53 "What is wrong with Foucault's The Order of Things," explains Kittler, "is that it merely describes the production of discourses. There are, for example, no descriptions in Foucault's book of the source of these discourses, of the channels or the receivers. ${ }^{.54}$ In contrast, Shannon's theory provides an "engineering or technical model" for conceptualizing "information source, information channel and information receiver [...] informational inputs, transmission and outputs." ${ }^{\text {"S }}$ The material dimension of these mediators or mediums or media (e.g., transmitter, carrier, receiver), where this material dimension would be approached as such, provides a ground for the concept of an apparatus.

Political theory generally neglects the material dimensions and mechanics of communication apparatuses (e.g., handwriting, alphabetization, typewriters, computer codes), despite the fact that these can be seen to determine the conditions of politics. As Galloway and Thacker suggest, the "networks of FedEx [and] AT\&T are arguably more important than that of the United States in terms of global economies, communication,

52. See Notes 2.10

53. Armitage and Kittler, "From Discourse Networks to Cultural Mathematics," 18.

54. Ibid.

55. Ibid. 
and consumerism.." ${ }^{, 56}$ In the context of examples such as data surveillance, biotechnology, and information warfare, the "seemingly innocuous details of data packets, network protocols, and fire walls, become politically charged indeed." ${ }^{57}$ In relation to this neglected importance, contemporary political theories must, argues Kittler, "integrate into their materialism the standards of the second industrial revolution." 58

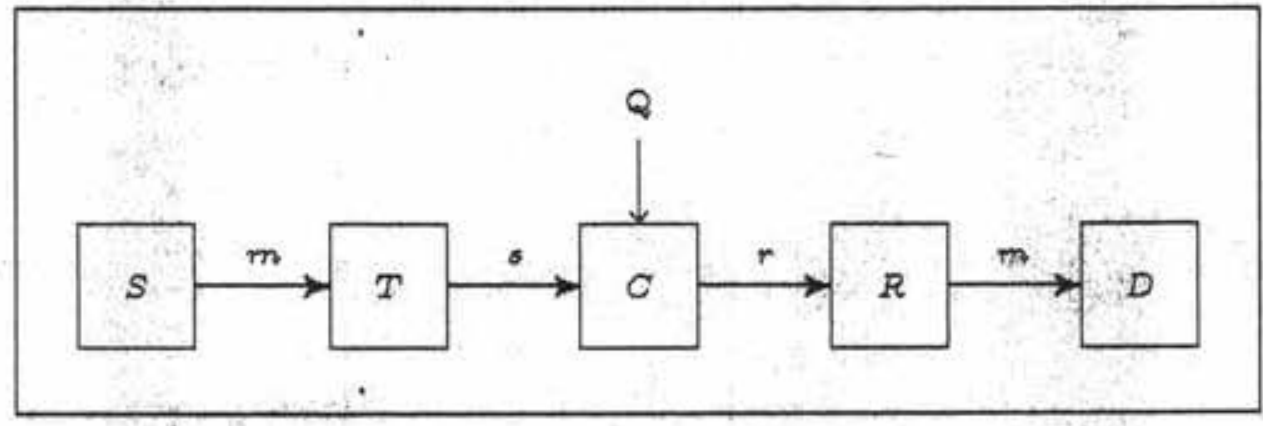

Figure 1. Five Functions of Information Theory. $S$ is the source; $m$ is the message; $T$ is the transmitter; $s$ is the signal; $C$ is the channel; $Q$ are the queers or the brains or the noises in the channel; $r$ is the received signal; $R$ is the receiver; $m$ is the received message; and $D$ is the destination. Adapted from Shannon and Weaver $(1949,2)$.

Kittler explains that Shannon's five functions of information theory-source, transmitter, channel, receiver, and destination (see Figure 1)-"can be occupied or left vacant by various agents." ${ }^{59}$ In addition to materiality (i.e., "communicational technique"), Kittler's method emphasizes contrast (i.e., "systemic differentiation") ${ }^{60}$ In

56. Alexander Galloway and Eugene Thacker, The Exploit: A Theory of Networks (Minneapolis: University of Minnesota Press, 2007), 9.

57. Ibid.

58. Friedrich Kittler, Discourse Nerworks 1800/1900, trans. Michael Metteer and Chris Cullens (Stanford, CA: Stanford University Press, 1990), 370.

59. Ibid.

60. Ibid. 
his book Aufschreibesysteme. 1800/1900, "universal alphabetization circa 1800 and technological data storage circa $1900^{\prime \prime 61}$ are the apparatuses Kittler defines in their materiality by way of contrast.

Tiziana Terranova's Network Culture also begins from the hypothesis that "an engagement with information theory is rich in analytical insights into the features of contemporary cultural politics where such informational dynamics are increasingly foregrounded." ${ }^{\prime 62}$ Such an intervention allows us to "free up the concept of information from two prejudices that have actually hindered our understanding of informational dynamics: the idea that information is 'the content of a communication;' and the notion that information is "immaterial." ${ }^{63}$ To this end, Terranova provides an overview of Claude Shannon and Warren Weaver's mathematical theory of communication. In terms of this theory, and in response to the first prejudice she mentions, Terranova defines the term "information" as something altogether different from whatever content or meaning it might be said to contain. In response to the second prejudice, and again in terms of information theory, Terranova suggests that information subsists within the materiality of its channels, transmitters, and receivers, rather than existing (as if from or by way of itself) in some abstract or immaterial "phantom zone," that is, some place like the disembodied phantom zone conventionally understood to be the locus of cyberspace.

61. Ibid.

62. Tiziana Terranova, Network Culture: Politics for the Information Age (Ann Arbor: University of Michigan Press, 2004), 10.

63. Ibid., 3. 


\subsection{Sovereignty, Discipline, Control $^{64}$}

Deleuze's "Postscript" defines control societies primarily by way of contrast with societies of sovereignty and societies of discipline ${ }^{65}$ In societies of sovereignty, power operates primarily as fiat over the life and property of its subjects. In disciplinary societies, power operates primarily by way of disciplines and enclosures that effect docile individuals who are made to function on their own in accordance with the power. Finally, in control societies, power operates primarily as a set of feedback mechanisms that effect ever more molecular and optimal "dividuals." 66

In relation to societies of sovereignty, consider the introduction to Foucault's Discipline and Punish, "The Body of the Condemned," which provides a detailed description of the execution of Robert-François Damiens by drawing and quartering. The book includes this description to exemplify the mechanics of power in societies of sovereignty as evident in their characteristic "penal style." ${ }^{167}$ In societies of sovereignty, power is primarily evident in punishment, specifically, the punishment of crimes against the sovereign. The subject's body is "the major target of penal repression," 68 and its public torture is a "ceremonial by which a momentarily injured sovereignty is reconstituted [...] by manifesting it at its most spectacular." ${ }^{169}$ Here public torture and

64. See Notes 2.11 .

65. See Notes 2.12 .

66. See Notes 2.13 .

67. Michel Foucault, Discipline and Punish: The Birth of the Prison, trans, Alan Sheridan (New York: Vintage Books, 1995), 7 .

68. Ibid., 8.

69. Ibid., 48 . 
execution do not "re-establish justice" so much as "reactivate power," by "mak[ing] everyone aware, through the body of the criminal, of the unrestrained presence of the sovereign."70

There is a reversal in the mechanics of power in disciplinary societies. In place of the sovereign's spectacular exercise of power, disciplinary societies operate under a supposition that the "perfection of power should render its actual exercise unnecessary." The mechanics of power shift from punishment for crimes against the sovereign towards the secret and diffuse administration of the "soul": "The expiation that once rained down upon the body must be replaced by a punishment that acts in depth on the heart, the thoughts, the will; the inclinations." ${ }^{72}$ A "micro-physics of power" emerges in place of the spectacular physical violence exercised against the criminal in full view of the public, "effect[ing] its domination" by way of "dispositions, maneuvers, tactics, techniques, functionings" that comprise "a network of relations, constantly in tension, in activity." 73 Institutions and enclosures such as the school, the hospital, the prison, and the barracks. exemplify the mechanics of power in disciplinary societies. In these institutions, the systematic observation of the minutiae of behavior constitutes individuals as "docile bodies" that "function on their own" in accordance with the designs of government. Foucault famously locates the ideal image of disciplinary societies in Jeremy Bentham's Panopticon, a prison in which a centrally located guard tower renders the actions of inmates visible at all times to the authorities. This apparatus "induce[s] in the inmate a

70. Ibid., 49.

71. Ibid.

72. Ibid., 16.

73. Ibid., 26. 
state of conscious and permanent visibility that assures the automatic functioning of power." 74

In the transition from sovereignty to discipline there is also a "reversal of the political axis of individualization." ${ }^{75}$ The archival evidence Foucault provides indicates that details about the life of a person in societies of sovereignty are "ascending." These details appear in heroic accounts, hagiographies, and legends: the prototypes of modern biography. In societies of discipline, however, details about the case of an individualhis or her sexuality, his or her pathology, his or her race, and so on-are "descending." "As power becomes more anonymous and more functional, those on whom it is exercised tend to be more strongly individualized." ${ }^{, 76}$ The surveillance and administration of the lives of the insane, the sick, the criminal, and the poor effect a massive literature detailing every dimension of their existence and thereby constituting them as individual cases. Whereas the societies of sovereignty tend to individualize the ideal and the normative, the societies of discipline individualize the aberrant and exceptional: "[T] he child is more individualized than the adult, the patient more than the healthy man, the madman and the delinquent each more than the normal and the non-delinquent." institutions and enclosures - the clinic, the prison, the barracks-delineate a line of force aiming "[to] concentrate; to distribute in space; to order in time; [and so] to compose a productive force within the dimension of space-time whose effect will be greater than the

74. Ibid., 201.

75. Ibid., 192.

76. Ibid., 193.

77. Ibid. 
sum of its component forces." 78

In disciplinary societies, the term "government" can be used in place of the term "power"-provided that government is understood, following Foucault's analyses, as "the conduct of conduct": the stabilities, rationalities, and consistencies in the behavior of persons within any historical situation. Wendy Brown discusses this concept of government through an analysis of Foucault's related neologism, "governmentality,"79 which exemplifies several characteristics of government in societies of discipline. Firstly, states Brown, governmentality involves capturing potentialities. This capture is evident because these potentialities may have been actualized otherwise-anarchically, destructively, creatively—or may have remained pure potentialities (i.e., simply unproductive). Secondly, this capture is not necessarily one of explicit rule or violent domination. The capture of a potentiality by government can be an act of free donation. ${ }^{80}$ Finally, as the "conduct of conduct," government can operate by way of mechanisms seemingly unrelated to governance. Areas as disparate as molecular biology, information management, and popular culture become no less effective in their "governmental" function than law, policy, and statecraft.

In addition to the disciplinary mechanisms of government that increasingly constituted the governed as individual cases, another novel object of government appeared in the societies of discipline: the population. "After a first seizure of power over the body in an individualizing mode, we have a second seizure of power that is not

78. Deleuze, "Postscript on the Societies of Control," 7.

79. Wendy Brown, "Power After Foucault," in The Oxford Handbook of Political Theory, eds. John S. Dryzek, Bonnie Honig, and Anne Phillips (Oxford: Oxford University Press, 2008), 73.

80. See Notes 2.14 . 
individualizing but, if you like, massifying, that is directed not at man-as-body but manas-species. After the anatomo-politics of the human body established in the course of the eighteenth century, we have, at the end of that century, the emergence of something that is no longer anatomo-politics of the human body, but what I would call a 'bio-politics' of the human race." ${ }^{81}$ When government began administering the individual's health, sexuality, behaviors, and so on, it was often by way of the individual's place in relation to the population: "[W]here discipline is the technology deployed" to make individuals behave, to be efficient and productive workers," explains Foucault, "biopolitics is deployed to manage population; for example, to ensure a healthy workforce." ${ }^{, 2}$

In the fallout of World War II, the enclosures of discipline and the biopolitics of population began to disintegrate, and a new informatic and molecular physics of social management appeared. Networked mechanisms replace the strategies of administration of life carried out in disciplinary societies, that is, the eugenic strategies, health mandates, population statistics; and so on. The biopolitics of the unified clinical body becomes less tenable as a swarming of the disciplines inscribes the body's organs into networks of procurement and transplantation, its reproductive fluids into banks for indefinite storage, its cell tissues into laboratories for cultivation and modification, and so on, towards the end of optimization and control. Predictive analytics, mobile devices, EEO satellites, and related technologies determine the capacities and trajectories of this new molecular body to a probable certainty. In place of governmental administration to the individual case, a mechanics Foucault details in relation to disciplinary societies, the mechanics of social

81. Michel Foucault, Society Must Be Defended: Lectures at the Collège de France, 1975-76, trans. David Macey (New York: Macmillan, 2003), 243.

82. Ibid. 
management in control societies effect an endless modulation of the increasingly molecular "dividual."

\subsection{Spectacle and Immaterial Labor}

Guy Debord refers to control societies as "societies of the spectacle": "The spectacle," Debord explains, "is capital to such a degree of accumulation that it becomes an image." ${ }^{83}$ In societies of the spectacle, the fetish of the commodity determines the conditions and horizons of possibility, especially in relation to communication. This effects something approaching the "separation" discussed by Agamben (see above) in relation to apparatuses.

There are many critics of Debord's analyses. Steven Shaviro, for example, suggests that there 'was [never] a time when life was 'directly lived,' instead of being diverted into representations; there never was a 'unity of life,' as opposed to the separation imposed by the detaching of images from their original contexts. The unity of a life directly lived is a fiction." ${ }^{84}$ Jacques Rancière argues that "the theoretical foundations of the critique of the spectacle are borrowed, via Marx, from Feuerbach's critique of religion. The basis of both critiques consists in the Romantic vision of truth as non-separation." ${ }^{85}$ However, Debord's critique-for example, his suggestion that "passive identification with the speetacle supplants genuine activity" ${ }^{\mathrm{96}}$-is not an appeal

83. Guy Debord, The Society of the Spectacle, trans. Ken Knabb (Berkeley: Bureau Of Public Secrets, 2013), 32 .

84. Michael Shaviro, Connected (Minneapolis: University of Minnesota Press, 2003), 71.

85. Jacques Rancière, The Emancipated Spectator, trans, Gregory Elliott (London: Verso, 2009), 6.

86. Debord, Society of the Spectacle, 12. 
to any metaphysical category of the "genuine." Rather, it involves the disparity between material and immaterial labor.

Post-war capitalism effẹcts a massive dematerialization of production in advanced economies, corresponding to the change from disciplinary enclosures to controlled modulations. "Postscript" mentions the shift from the gold standard to floating rates of exchange, from manufacturing to "higher-order production," from the factory to the multinational corporation. ${ }^{87}$ These changes exemplify a line of force towards modulation and dividualization. In relation to this line of force, the spectacular dimension of control societies involves the transformation of an "individual's principal work $[\ldots]$ into a realm of non-work, of inactivity. This inactivity, however, is by no means emancipated from productive activity; it remains in thrall to that activity, in an uneasy and worshipful subjection to production's needs and results." ${ }^{88}$

Maurizio Lazzarato defines this immaterial labor as the "activity that produces the 'cultural content' of the commodity." 89 Immaterial labor "involves a series of activities that are not normally recognized as 'work' [...] the kinds of activities involved in defining and fixing cultural and artistic standards, fashions, tastes, consumer norms, and, more strategically, public opinion. ${ }^{.90}$ In control societies, labor is often nothing more than what Mark Andrejevic describes as "instrumentalized hyper-sociality."91 This labor

87. Notes, 2.15 .

88. Ibid., 21.

89. Maurizio Lazzarato, "Immaterial Labor," in Radical Thought in Italy: A Potenticl Politics, trans. Paul Colilli and Ed Emory (Minneapolis: University of Minnesota Press, 2006), 133.

90. Ibid., 137.

91. Mark Andrejevic, "Surveillance and Alienation in the Online Economy," in Surveillance and Society 8, no. 3 (201i): 280. 
is both voluntary and instrumental to power, which is why Tiziana Terranova defines it as "free labor": "Free labor is the moment where this knowledgeable consumption of culture is translated into productive activities that are pleasurably embraced and at the same time often shamelessly exploited." ${ }^{92}$ Zwick, Bonsu, and Darmody suggest that this consumer cocreation, as a practice of marketing, is an increasingly effective apparatus of social management. They argue that websites that rely on user-generated content "expropriate the cultural labor of the masses and convert it into monetary value: each in their own specific way, but all according to the same general logic." ${ }^{93}$ It is in this way that "consumers are asked to pay for the surplus extracted from their own work." 94

The spectacular dimension of control turns marketing into both a generalized feature of social relations and a necessary characteristic of the dividual. In relation to this process, Thomas Thoburn suggests that "[c]apital still operates through the enforced splitting of producers and consumers but the flows and relations of production are continually enriched through processes outside of the immediate sphere of work: the product is enriched through the intervention of the consumer, and is therefore in permanent evolution." ${ }^{95}$ Streaming videos on the Web, for example, often have advertisements, similar to television commercials. In contrast with television viewers, however, Web users are supposed to "select the ad experience they prefer." This allows the advertising software involved to calculate an increasingly detailed and efficient

92. Tiziana Terranova, "Free Labor: Producing Culture for the Digital Economy," Social Text 63, no, 18 (2000): 37 .

93. Samuel K. Bonsu, and Aron Darmody, Detlev Zwick, "Putting Consumers to Work: 'Co-Creation' and New Marketing Governmentality," Jóurnal of Consumer Culture 8, no. 163 (2008): 180.

94. Ibid., 186.

95. Nicholas Thoburn, Deleuze, Marx, and Politics (London: Routledge, 2003), 99. 
profile for the user. The constant obligation to "express oneself $[\ldots]$ to speak, communicate, cooperate, and so forth $[\ldots]$ leads to a situation where every aspect of subjectivity $[\ldots]$ becomes productive of value. ${ }^{.96}$ Thoburn continues:

This immaterial labor constitutes itself in forms that are immediately collective, and we might say that it exists in the form of networks and flows. The organization of the cycle of production of immaterial labor [...] is not obviously apparent to the eye, because it is not defined by the four walls of the factory. The location in which it operates is outside in the society at large [...]. The cycle of production comes into operation only when it is required by the capitalist; once the job has been done, the cycle dissolves back into the networks and flows that make possible the reproduction and enrichment of its productive capacities. ${ }^{97}$

Labor always produces an excess in its reproduction of social relations. Capitalism must recuperate this excess because it is both its condition of possibility and a potential ground for freedom from its mechanisms. The lines of force towards immaterial labor in control societies only intensify this ambivalence, which leaves open the question of what it would mean to "escape" this capture. ${ }^{98}$

\subsection{Politics and Community}

Agamben suggests that a practice of politics adequate to control societies requires approaching their spectacular đimension as a language, as the "very communicativity or linguistic being of humankind." ${ }^{99}$ The spectacular dimension of control societies forecloses any possibility of an actively political practice of community because it is "directed not only toward the expropriation of productive activity, but also and

96. Ibid., 100.

97. Ibid.

98. Bonsu, Darmody, and Zwick, "Putting Consumers to Work."

99. Giorgio Agamben, Means without Ends: Notes on Politics, trans. Vincenzo Binetti and Cesare Casarino (Minneapolis: University of Minnesota Press, 2000), 2. 
principally toward the alienation of language itself $[\ldots]$, of that logos, which one of Heraclitus's fragments identified as the Common. ${ }^{100}$ The spectacle, Agamben suggests, captures the very "means of constructing a community that might free itself from a logic of exclusion and violence."101 "For the same reason," however, it "retains something like a positive possibility that can be used against it." 102

Leland de la Durantaye discusses Agamben's analyses of the spectacular dimension of control as a language: "The spectacle reaches not only into our homes through the ideological messages transmitted by our media," writes Durantaye, "but also into our very 'mediality,' our capacity to communicate what we have in common."103 Jean-Luc Nancy develops this analysis when he suggests that the spectacular dimension of control is "being-with" "subsumed within the generalized equivalence of all the representations of itself that it gives itself to consume." ${ }^{104}$ Nancy continues:

Capital's violent inhumanity displays nothing other than the simultaneity of the singular (but the singular posing as the indifferent and interchangeable particularity of the unit of production) and the plural (itself posing as the system of commodity circulation). The "extortion of surplus value" presupposes this concomitance between the "atomization" of producers (of "subjects" reduced to being-productive) and a "reticulation" of profit (not as an equal redistribution, but as concentration that is itself more and more complex and delocalized). One could say that capital is the alienation of being singular plural as such. [...] Capital is the "alienation" of Being in its being-social to the extent that it puts this being into play as such. ${ }^{105}$

100. Ibid., 80 .

101. Ibid., 174.

102. Ibid.

103. Leland Durantaye, Giorgio Agamben: A Critical Introduction (Stanford, CA: Stanford University Press, 2009), 174.

104. Jean-Luc Nancy, Being Singular Plural, trans. Robert D. Richardson and Anne E. O'Byrne (Stanford, CA: Stanford University Press, 1996), 49.

105. Ibid., 73. 
To suggest that the spectacle puts being-with as such into play is also to suggest that, by way of the spectacle, being-with as such (i.e., the common, the proper) positively appears, but in an inversion. Analyses of the spectacle "not only [provide] clarity about the extremity of our situation, but also the means through which we might reverse it."106 Agamben details this positive possibility by way of the relation between the "matter of language and the thinking of potentiality"; the relation involves the concept of an experimentum linguae, a "pure experience of language"107 — not a use of language, but correspondence with the materiality or pure potentiality of language. Agamben explains:

It is not language in general that marks out the human from other living beings $[\ldots]$ but the split between language and speech, between semiotic and semantic (in Benveniste's sense), between sign system and discourse. Animals are not in fact denied language; on the contrary, they are always and totally language. [...] Animals do not enter language, they are already inside it. Man, instead, by having infancy, by preceding speech, splits this single language and, in order to speak, has to constitute himself as the subject of language- he has to say $I^{108}$

An experimentum linguae would recapture the pure potentiality exemplified by the language of the animal and the infant (i.e., those who "are always and totally language"). The political matter here is not that of a "higher end" but that of "being-in-language itself." 109 The experimentum linguae is an "experience of the potentiality of thought,"110

106. Giorgio Agamben, The Coming Community, trans. Michael Hardt (Minneapolis: University of Minnesota Press, 1993), 175.

107. Ibid., 178.

108. Giorgio Agamben, Infancy and History: Essays on the Destruction of Experience, trans. Liz Heron (London: Verso, 1993), 51.

109. Agamben, Means Without End, 117.

110. Durantaye, Giongio Agamben, 180, 
an experience that is "constructed as an experiment concerning the very matter, or the potentiality, of thought [my emphasis]."111

When Agamben discusses the "expropriation of language" by the spectacle, he details it as a "rendering common of what one thought of as one's own, and only as one's own, province or property." ${ }^{\text {112 }}$. In relation to characterizing a ground for doing politics, this capture approaches a "first step toward a truly 'free usage' of that which is most common: our means of communication." 113 When a dividiual communicates by way of consumption or in the guise of an identity in accord with the mechanics of the spectacle, the spectacle captures that dividual's potential, especially its potential to be in common. The common in control societies, in other words, is not grounded on a transcendental presupposition (e.g., God, the Truth, the Nation). It is precisely because the common is no longer grounded on a transcendental presupposition, however, that its free use becomes possible: "The era in which we live is also that in which for the first time it is possible for humans to experience their own linguistic being, not this or that content of language, but language itself."114

The work of Martin Heidegger and of poet Paul Celan anticipates this concept of free use in relation to control societies. Heidegger describes the absence of any transcendental presupposition characteristic of control societies (i.e., "the world's night") as a "default of the gods." 115 "Because of this default," writes Heidegger, "there fails to

111. Agamben, Means Whithout End, 116.

112. Ibid., 181.

113. Ibid.

114. Agamben, Coming Community, 83.

115. Martin Heidegger. "What are Poets For?," in Poetry, Language, Thought, trans. Alfred Hofstadter 
appear for the world the ground that grounds it."116 This concept of abyss (Abgrund) also "characterizes [Celan's] poetics," "117 suggests Antti Salminen, who draws attention to this statement by Celan: "Like the human, the poem has no adequate ground $[. .$.$] . Yet maybe:$ the poem has its ground in itself; with this ground it reposes above, in the groundless."118 This statement corresponds with others from Celan's writings on poetry:

Poetry is perhaps this: an Atemwende, a turning of the breath. Who knows, perhaps poetry goes its way-the way of art-for the sake of just such a turn? And since the strange, the abyss and Medusa's head, the abyss and the automaton, all seem to lie in the same direction-it is perhaps this turn, this Atemwende, which can sort out the strange from the strange? ${ }^{19}$

Celan explains the abyss and the "breathturn" (Atemwende): the "abyss is the direction taken by the poem and writing. Like the breathturn, the moment between inhaling and exhaling, the abyss comes between the strangeness of Medusa's head and that of the automaton. [...] The gesture, a kind of Mobian loop, which inside turns outside, is both bodily and poetic." ${ }^{120} \mathrm{He}$ approaches how the breathturn, both bodily and poetic, can provide an experience of the abyss through a discussion of Buchner's novella fragment, Lenz, whose eponymous character remarks that it is "unpleasant not to be able to walk on

(New York: Harper and Row, 2002), 101.

116. Ibid.

117. Antti Salminen, "Falling Upwards: Paul Celan's Poetics," in Partial Answers: Journal of Literature and the History of Ideas 10, no. 2 (June 2012): 223.

118. See Notes 2.16 .

119. Paul Celan, Selections: Paul Celan, trans. Pierre Joris, eds. Pierre Joris and Jerome Rothenberg (Berkeley: University of California Press, 2005), 47, translated and quoted in Salminen, "Falling Upwards," 225.

120. Salminen, "Falling Upwards," 225. 
his head." ${ }^{121}$ Celan explains, "whoever walks on his head, ladies and gentlemen, whoever walks on his head sees the sky below, as an abyss."122

For both Heidegger and Celan, the abyss (Abgrund) is the "foundation of thought in nothingness." In Der Satz vom Grund, where "nothing is without ground," Heidegger "builds on a paradox: an enduring foundation for language and thought has to be a nonfoundation, not to be founded on an arche."123 In his Meridian speech, Celan alludes to one of Heidegger's texts, "Language"; the relevant passage from "Language" reads: "The sentence, 'language is language,' leaves us to hover over an abyss as long as we endure what it says [...]. If we let ourselves fall into the abyss demoted by this sentence, we do not go tumbling into emptiness. We fall upward, to a height. Its loftiness opens up a depth. The two span a realm in which we would like to become at home, so as to find a residence, a dwelling place for the life of man." ${ }^{124}$ Celan, who had read "Language" in 1959, also approached this sense of a homecoming in his Meridian speech, dated October 1960: "One of the ways: others, coming from the ungrounded, lead back into the ungrounded; for them the abyss is home; their language is their being-underway; no longer." $" 125$

By way of this "abyss above," Heidegger and Celan anticipate Agamben's argument that an experience of the groundlessness of all things, an experimentum

121. See Notes 2.17 .

122. Celan, Selections, 161, translated and quoted in Salminen, "Falling Upwards," 225.

123. Salminen, "Falling Upwards," 229.

124. Martin Heidegger, "Language," in Poetry, Language, Thought, trans, Alfred Hofstadter (New York: Harper and Row, 2002), 189-90, quoted in Salminen, "Falling Upwards," 229.

125. Paul Celan, Der Meridian, 62, quoted in Salminen, "Falling Upwards," 230. 
linguae, is an experience of their proper ground. The concepts of the breathturn and the abyss above point the way towards an experimentum linguae, which Heidegger terms the "free use of the proper." Philosopher and Heidegger exegete Christopher Fynsk explains that Heidegger adopted this phrase ("free use of the proper") from a letter of Hölderlin's in which Hölderlin suggested, "nothing is more difficult to learn than the 'free use of the proper [er-eignend-brauchende Be-wëgung]." ${ }^{126} \mathrm{~A}$ free use of the proper is free, explains Fynsk, because it implies a release onto its own groundlessness, or precisely what always escapes control. ${ }^{127}$ Use (Brauch) involves an engagement with the common (i.e., the proper), or what we are used to (Brachtum; i.e., the idiomatic), by way of a relation to "the 'lack' of commonality from which all speech communities proceed and to which they return whenever their essential relations are communicated $[. .$.$] , where what$ it means to be comes into question." ${ }^{128}$ The proper "carries it back to the earth and physis, defining [free use] as the bodily that emerges in showing." 129 Elsewhere Heidegger explains the "bodily that emerges in showing." In contrast with the challenging-forth of the earth by modern technology (e.g., as a standing reserve of energy to be exploited), Heidegger suggests that the artwork uses the earth (i.e., what "loves to hide"), which is its origin, but does not exploit it in this setting-forth. "A kind of intervention, even a violence, is required in this letting emerge," suggests Fynsk, "but such usage never exhausts what 'loves to hide.' A free use of the proper will thus be impelled always to

126. Christopher Fynsk, Heidegger: Thought and Historicity (Ithaca, NY: Cornell University Press, 1993), 198.

127. Christopher Fynsk, Language and Relation: That There is Language (Stanford, CA: Stanford University Press, 1996), 130.

128. Tbid.

129. Ibid. 
further usage, will invite further usage." ${ }^{130}$ In anticipation of Agamben's suggestion that a free use of the proper is an "experiment concerning the very matter language," Fynsk concludes that "it is almost as though we must start from the body, $[\ldots]$ in learning a free use of the proper, $[\ldots]$ from $[\ldots]$ speech and writing conceived as a use of the body. Learning free use will mean learning thought and following the heart. But at the most proximate horizon there is the bodily."131

Kittler adopted the idiosyncratic term Aufschreibesystem from Daniel Paul Schreber's Memoirs of my Nervous Illness, which Schreber wrote while institutionalized under the care of psychiatrist Paul Flechsig. Schreber explains the term:

The mentioned Aufschreibesystem is extraordinarily difficult to explain to other people even vaguely $[\ldots]$. Books or other notes are kept in which for years have been written-down all my thoughts, all my phrases, all my necessaries, all the articles in my possession or around me, all persons with whom I come into contact, etc. I cannot say with certainty who does the writing down. As I cannot imagine God's omnipoțence lacks all intelligence, I presume that the writingdown is done by creatures given human shape on distant celestial bodies after the manner of the fleeting-improvised-men, but lacking all intelligence; their hands are led automatically, as it were, by passing rays for the purpose of making them write-down, so that later rays can again look at what has been written. ${ }^{132}$

"By appealing to the notion of Aufschreibesysteme," explains Kittler, "the madman sought to imply that everything he did and said within the asylum was written down or recorded immediately and that there was nothing anyone could do to avoid it being written down, sometimes by good angels and occasionally by bad angels." ${ }^{133}$ In this way, Schreber's concept of Aufschreibesystem corresponds with the concept of an apparatus.

130. Ibid., 130-31.

131. Ibid., 131.

132. Daniel Paul Schreber, Memoirs of My Nervous Illness, trans. Ida Macalpine and Richard A. Hunter (New York: New York Review of Books Classics, 2000), 123.

133. Armitage and Kittler, "From Discourse Networks to Cultural Mathematics," 18. 
Firstly, it captures and directs the potentiality of Schreber's "gestures, behaviors, opinions, and discourses" into a determinate and unified archive, enabling his surveillance and control. Secondly, corresponding to the ancient oikonomia, it is an apparatus devoid of any foundation in being; the "creatures" who perform the writingdown stand at an ontological remove from Schreber and "lack all intelligence." Lastly, the capture of Schreber's potentiality by the Aufschreibesystem increases its effectiveness: It enables the "rays" to "again look at what has been written."

Schreber's Memoirs can not only be analyzed as an exemplification of an Aufschriebesystem; additionally, they obediently enact "soul murder." 134 In this sense, it also exemplifies the free use of the proper. To develop this argument, Kittler draws attention to a passage from the work of poet Rainer Maria Rilke: "[T]wo "completely similar' knives bought by two schoolboys on the same day are only 'remotely similar' a week later. To use therefore means to wear down: out of industrial guaranteed similarity come broken, but singular things. Because these things, only a little worse for the wear, gather together whole case histories at once."135 Analogous to the boys' free use of the knives, Kittler argues that Schreber's Memoirs mark a breath turn: an explosion onto the groundlessness of their awn broken, singular address by way of beginning from where the danger comes.

Freud's suggestion that "there is more truth in Schreber's delusion than other people are yet prepared to believe" ${ }^{136}$ provides evidence of this explosion. Schreber's

134. Schreber, Memoirs of My Nervous Illness, 9.

135. Ibid., 280.

136. Sigmund Freud, "Psychoanalytic Notes on an Autobiographical Account of a Case of Paranoia," in Three Case Histories (New York: Simon and Schuster, 2008), 154, quoted in Schreber, Memoirs of My Nervous Illness, 291. 
Memoirs provided the founder of psychoanalysis with the very ground of his libido theory, and Freud himself remarked that the "details of Schreber's delusional structure sound almost like endopsychic perceptions of the processes whose existence I have assumed." ${ }^{.137}$ According to Kittler, Schreber's Memoirs "depict a nerve-diseased body as the theater for whole theomachies, where divine nerve rays invade and retreat, destroy organs and extract brain fiber, lay down lines of communication and transmit information-a psychic information system that Freud takes at its word rather than as mania." 138 The correlation of the human mind with an information system renders the psychotic text as a nonmetaphoric truth: "The corpus of the psychotic text provides psychoanalysis with its indispensable but undiscoverable basis: a body"; without this "body," psychoanalysis would have remained "empty speculation."139

Kittler maintains that Schreber's Memoirs "respond to Flechsig's psychophysics with psychophysical nonsense." ${ }^{140}$ Schreber's Memoirs use Flechsig's neurophysiological language "in order to demonstrate in the latter's own territory that Schreber's purported hallucinations are facts effectuated by the discourse of the Other." ${ }^{141}$ The fact that this use of language (i.e., this free use of the proper) seemed to indicate nothing but madness to Schreber's doctors "simply demonstrates once more how indistinguishable pathology

137 Freud, "Psychoanalytic Notes " quoted in Ibid.

138. Ibid., 292.

139. Ibid.

140. Ibid., 301.

141. Tbid., 297. 
and experiment are. God makes an imbecile of someone who resists the onslaught with imbecility." 142

I am Sitting in a Room (1970), a musical work by Alvin Lucier, provides a useful analogy for the free use exemplified by Schreber's Memoirs. Lucier's piece consists of a brief statement spoken by the composer and recorded onto magnetic tape. This "original" recording is then played through a loudspeaker into a room, and rerecorded by way of a microphone onto a second tape recorder. This results in a second recording of the original. This process is repeated until a fiftieth-generation tape is recorded. As a result, the natural resonant frequencies of the room become increasingly reinforced with each successive generation of the tape. I am Sitting in a Room, therefore, uses a kind of acoustic positive feedback. While the tape is played and rerecorded repeatedly in the same room, this feedback process reinforces the resonant frequencies of the room to the point that the composer's voice is annihilated and only the medium in its materiality can be heard. Control systems are designed precisely to minimize this sort of noise and achieve a bounded output for a bounded input. "If 'control," explains Kittler, "or, as engineers say, negative feedback, is the key to power in this century, then fighting that power requires positive feedback. Create endless feedback loops until VHF or stereo, tape deck or scrambler, the whole array of world war army equipment produces wild oscillations of the Farnborough type. Play to the powers that be their own melody."143

In his analysis of Heidegger, Fynsk refers to "free use" as giving "hints of a relation to the 'lack' of commonality from which all speech communities proceed and to

142. Ibid., 301 .

143. Friedrich Kittler, Gramophone, Film, Typewriter, trans. Geoffrey Winthrop-Young and Michael Wutz (Stanford, CA: Stanford University Press, 1999), 110. 
which they return whenever their essential relations are communicated." ${ }^{144}$ This corresponds with Agamben's concept of the "coming community" (i.e., the "community of singularities"), in addition to Nancy's closely related concept of the "inoperative community" (La communauté déscuvrée) and Maurice Blanchot's concept of the "unavowable community" (La communauté inavouable). ${ }^{145}$ Agamben develops this concept of an unworkable community as follows:

The novelty of the coming politics is that it will no longer be a struggle for the conquest or the control of the State, but a struggle between the State and the nonState, an insurmountable disjunction between whatever singularity and the State organization. This has nothing to do with the simple affirmation of the social in opposition to the State that has often found expression in the protest movements of recent years. Whatever singularities cannot form a societas because they do not possess any identity to vindicate nor any bound of belonging for which to seek recognition. In the final instance the State can recognize any claim for identityeven that of a State identity within the State. What the State cannot tolerate in any way, however, is that the singularities form a community without affirming an identity, that humans co-belong without any representable condition of belonging (even in the form of a simple presupposition). The State, as Alain Badiou has shown, is not founded on a social bond, of which it would be the expression, but rather on the dissolution, the unbinding it prokibits. For the State, therefore, what is important is never the singularity as such, but only its inclusion in some identity, whatever identity. ${ }^{146}$

In his description of the unworkable community as the impossible community of whatever [quodlibet] "singularities [...] without [...] identity, or any representable condition of belonging (even in the form of a simple presupposition)," Agamben's "whatever," he suggests, "relates to singularity not in its indifference with respect to a common property (to a concept, for example: being red, being French, being Muslim), but only in its being such as it is [...]. In this conception, such-and-such being is

144. Christopher Fynsk, Language and Relation, 130.

145. See Notes 2.18 .

146. Agamben, Coming Community, 85-86. 
reclaimed from its having this-or-that property, which identifies it as belonging to this-orthat set, to this-or-that class (the reds, the French, the Muslims)-and it is reclaimed not for another class nor for the simple generic absence of any belonging, but for its beingsuch, for [the possibility of belonging]."147

Nancy provides examples of this community, of sharing through a "lack of identity," in passages from The Inoperative Community. Here, the presentation of beingwith as such by way of a free use of the proper would take upon itself and inscribe in itself the impossibility of community. Nancy writes:

The thinking of community as essence-is in effect the closure of the political. Such a thinking substitutes closure because it assigns to community a common being, whereas community is a matter of something quite different, namely, of existence inasmuch as it is in common, but without letting itself be absorbed into a common substance. Being in common has nothing to do with communion, with fusion into a body, into a unique and ultimate identity that would no longer be exposed. Being in common means, to the contrary, no longer having, in any form, in any empirical or ideal place, such a substantial identity, and sharing this "lack of identity."148

Nancy's mention of "articulations" suggests that the elements of this unqualified multiple are all possessed of a voice: a voice that is "no longer to be heard except as the communication of the incommunicable singularity/community. I no longer (no longer essentially) hear in it what the other wants to say (to me), but I hear in it that the other, or some other speaks and that there is an essential archi-articulation of the voice and of voices, which constitutes the being in common itself." 149

147. Ibid., 1-2.

148. Jean-Luc Nancy, The Inoperative Community, trans. Peter Connor (Minneapolis: University of Minnesota Press, 1990), xxxviii.

149. Nancy, Inoperative Community, 76. 
The free use of the proper, as Nancy understands it, follows Heidegger's original distinction between artwork and technology: The work appears, and by way of the work, so too does the proper. When this event enters into a constellation with other such events, they form a community "with nothing in common," because

the interruption of myth does not make up a myth, the being-in-common of which I am speaking - and that many of us are trying to speak about, that is to say, to write - has nothing to do with the myth of communion through literature, nor with the myth of literary creation by the community. But if we can say, or if we can at least try to say, while remaining fully conscious of its unsuitability, that being-incommon is literary, that is, if we can attempt to say that it has its very being in "literature" (in writing, in a certain voice, in a singular music, but also in a painting, in a dance, and in the exercise of thought), then what "literature" will have to designate is this being itself [...] in itself. In other words, it would designate that singular ontological quality that gives being in common, that does not hold it in reserve, before or after community, as an essence of man, of God, or of the State achieving its fulfillment in communion, but that rather makes for a being that is only when shared in common, or rather whose quality of being, whose nature and structure are shared (or exposed). ${ }^{150}$

A community of singularities comes only by way of communication, if the latter term is defined as a free use of the proper, as an activity of brains, rather than the "communication" monetized by the spectacular dimension of control. Defined in terms of free use, communication begins from the unworkable. When its members are "always already enacted," no community is possible. In this situation, beings can only experience "coincidences and factual partitions" among themselves. "We can communicate with others only through what in us-as much as in others-has remained potential, and any communication [...] is first of all communication not of something in common but of communicability itself."

150. Ibid., 64.

151. Agamben, Means without Ends, 10. 


\subsection{Conclusion}

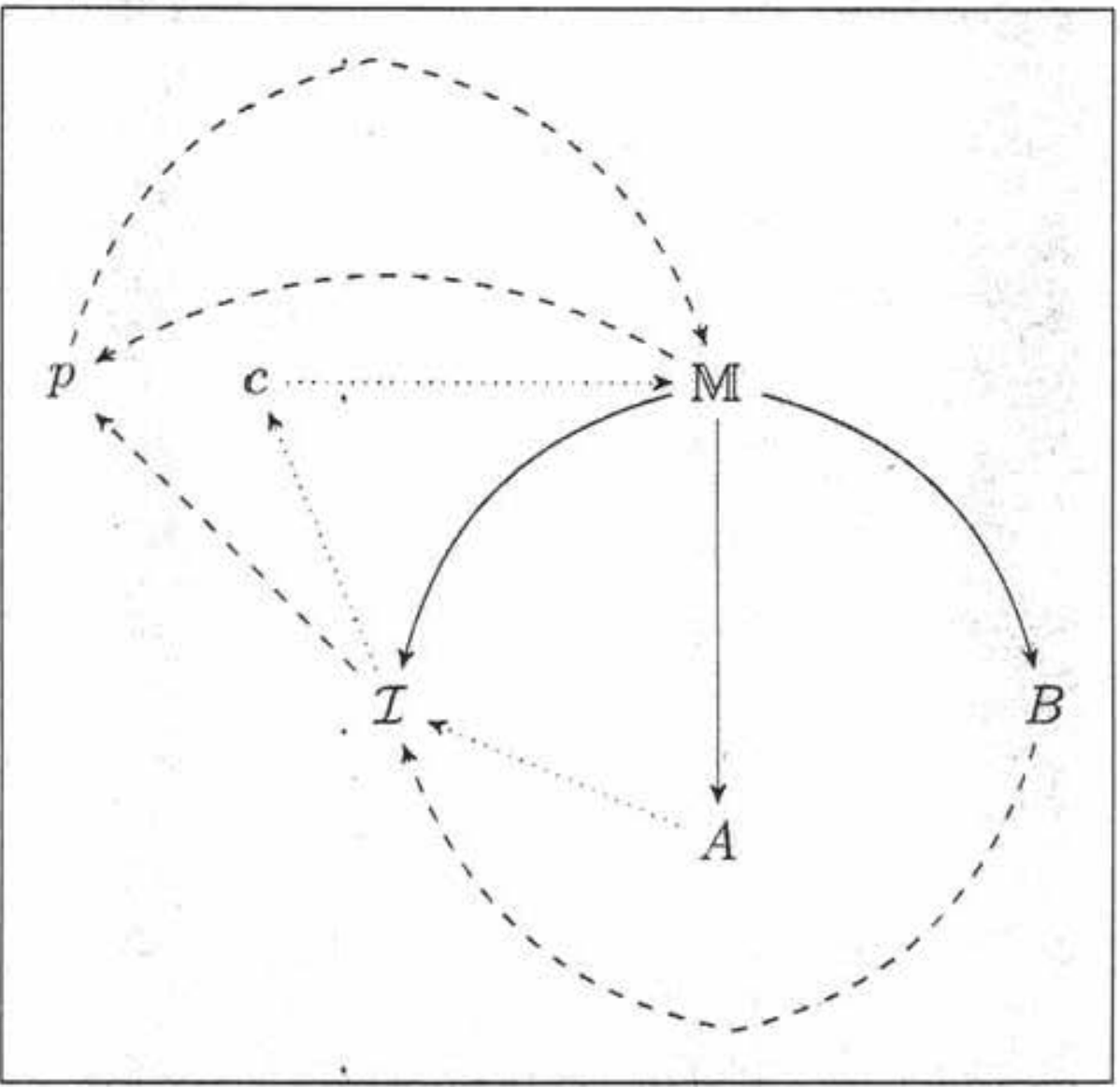

Figure 2. Conceptual Diagram. $B$ are brains; $\mathbb{M}$ is materiality; $A$ is an apparatus; $J$ is inscription; $c$ is control; and $p$ is positive feedback or the free use of the proper. Double-stroked characters represent the ground of the process; calligraphic characters represent how this ground is used; regular upper-case characters represent by what it is used; and lower-case characters represent why or to what end.

Figure 2 is a directed graph representing the concepts I presented in this chapter. It is not well-formed; I provide it simply in order to help clarify the relations between these concepts. ${ }^{152}$ The solid paths from $\mathbb{M}$ to $J, A$, and $B$ indicate that inscription $(\mathcal{J})$, apparatuses $(A)$, and brains $(B)$ have a necessary condition of possibility in 
materiality (M; e.g., writing requires some material instrument, such as a pencil or a typewriter; a prison is partly steel and concrete; and brains are partly organic matter). The dashed path from $B$ through $J, p$, and $\mathbb{M}$ indicates a free use of the proper or positive feedback, that is, any political path, any path that is not bound by control. The dotted path from $A$ through $\mathcal{J}, c$, and $\mathbb{M}$ indicates the sovereign, government, or social management, that is, the negative feedback or strategic function of an apparatus. In other words, $((A \rightarrow J(M)) \rightarrow(c(M))$, or: apparatuses inscribe materiality to the end of controlling materiality. In addition, $((B \rightarrow J(\mathbb{M})) \rightarrow((p(\mathbb{M})) \rightarrow(p(\mathbb{M})) \rightarrow \cdots))$, or: brains inscribe materiality to the end of materiality as such. This path is a positive feedback loop: $B$ inscribes $\mathbb{M}$ to the end of $p$, which implies more of $\mathbb{M}$, which in turn implies more of $p$, and so on. 


\section{Math, Chemistry, Music}

\subsection{Mathematics}

\subsubsection{Introduction}

The two sections of Kittler's Aufschreibesysteme 1800/1900 correspond to the two centuries in the book's title. As translator Stephanie Harris notes, Kittler "selects a mathematical formula to serve as an epigraph to each section"1:

$$
\begin{gathered}
\text { 1800: } e^{i x}=\cos x+i \sin x-\text { Leonhard Euler }{ }^{2} \\
\text { 1900: } y=(+a)+(-a)+(+a)+(-a)+\cdots-\text { Bolzano }^{3}
\end{gathered}
$$

"The first of these [1800]," explains David Wellbery, "can be interpreted as an algorithm of 'growth,' the movement of 'progressive augmentation that characterizes the discourse network of 1800 . The second [1900] formalizes the pulse of differential alternation that permeates the modernist discourse network." ${ }^{4}$

Euler's formula equates the trigonometric functions, known since antiquity, with the complex exponential function, some components of which remained undeveloped until the sixteenth century. The formula was necessary for the development of Fourier analysis, which represents complex functions as a synthesis of trigonometric functions. Described as "uncanny and sublime," "filled with cosmic beauty," and "reach[ing] down

1. Stefanie Harris, Mediating Modernity: German Literature and the "New" Media, 1895-1930, (University Park: Pennsylvania State University Press, 2009), 39.

2. Kittler, Discourse Networks, 1.

3. Ibid., 175 .

4. David Welbery, forward to Kittler, Discourse Networks 1800/1900, xxvi. 
into the very depths of existence," Euler's formula exemplifies the strategic function of power in disciplinary societies. By way of this formula, part is sublated into whole and whole is determined by part, and so it exemplifies the "organismistic" character, for example, of Hegel's philosophy, frequently summarized using the image of the acorn that finds its truth in the oak; a magnificent tapestry woven as so many sublations of part into whole. $^{6}$

Bolzano's "pathological" function differs from Euler's formula. The function first appears in Bolzano's 1817 paper on the intermediate value theorem, where he writes, "There are also series whose values, however far they may be continued, never exceed a certain quantity. The series:

$$
a-a+a-a+\ldots
$$

is of this type; its value, however far it is continued, is always either 0 or $a$ and therefore never exceeds a." Functions of the type Bolzano describes here are known today as "everywhere continuous, nowhere differentiable" functions. Nineteenth-century mathematicians regarded such functions as anomalies. Twentieth-century scientists and mathematicians, however, rediscovered Bolzano's equation as they sought new mechanisms to frame the increasingly complex phenomena under their consideration. French chemist Jean Perrin, for example, invoked Bolzano's function in an effort to visualize the physics of Brownian motion, which he compared to the coast of Brittany: As one approaches the curves of the shoreline, they only endlessly decompose into smaller

5. Crease, Robert P., The Greatest Equations Ever, Physics World (Oct 6, 2004), np.

6. See Notes 3.1.1.

7. Bernard Bolzano, A Translation of Bolzano's Paper on the Intermediate Value Theorem, trans. S. B. Russ (San Diego: Academic Press, 1980), 170. 
curves. "[O]ne cannot trace a tangent," writes Perrin, "even approximately, at any point on the trajectory. It is one of those cases where we are reminded of these continuous, nowhere differentiable functions that were wrongly seen as mathematical curiosities, since nature can suggest them just as well as differentiable functions." ${ }^{8}$ The intimate relationship of Bolzano's formula to Brownian motion explains Kittler's use of the function to represent "1900." "Under the conditions of information technology," writes Kittler, "the old-European despot disintegrates into the limit value of Brownian motion, which is the noise in all channels." Everywhere continuous and nowhere differentiable, that is, Bolzano's function exemplifies the "noise in the channels" at the ground of media technology in the Aufschreibesysteme of "1900."

Kittler also attached a mathematical epigraph to his article "Computer Graphics: A Semi-Technical Introduction." This mathematical epigraph was presumably intended to designate the twenty-first century, 2000:

$$
\left.I\left(x, x^{\prime}\right)=g\left(x, x^{\prime \prime}\right)\left[\varepsilon\left(x, x^{\prime}\right)+\int_{s} p\left(x, x^{\prime}, x^{\prime \prime}\right) I\left(x^{\prime}, x^{\prime \prime}\right) d x^{\prime \prime}\right)\right]-J . T \text { Kajiya }{ }^{10}
$$

Kittler explains this equation by way of Heidegger's "nearsighted" definition of phenomenology as legein ta phainomena, "the gathering of that which appears." The equation inscribes the behavior of light to the limit of "what appears unseen-the optical partial values of quantum-physically distributed particle dynamics." as it would be absorbed, reflected, diffused, and so finally inseribed within any three-

8. Jean Perrin, "Mouvement brownien et realité moléculaire,"Annales de chimie et de physique. 8, no. 8, (1909): 5-114, 79 .

\section{Kittler, Discourse Networks 1800/1900, 356.}

10. Kittler, "Computer Graphics: A Semi-Technical Introduction," trans. Sara Ogger, Grey Room no. 2 (Winter, 2001): 30 .

11. Ibid., 44. 
dimensional space — can be simulated without any "real" light or "real" space and, most importantly, without any "real" observer. "In the farsightedness of computer graphics," remarks Kittler, "such gathering no longer requires any Dasein, for illuminating radiosity surfaces can be reduced to the easiest projection surfaces, while radiant points of light can be reduced to the most expedient raytracing path. Projectiles have relegated subject vs. object, this simplest of all oppositions, to the grave." ${ }^{12}$ Kittler concludes his discussion of the equation by way of radar screens, the precursors of computer monitors: "Our eyes are thus not just scattered around the world in the Hs $293 \mathrm{D}^{16}$ and its cruisemissile children; as a result of Kajiya's rendering equation our eyes may expect that, some unspeakable day, the world itself, at least in the magic disguise of microchips, will project their image $[$ Bild $]$. Legein ta phainomena, the gathering of that which appears, will be made no easier." ${ }^{13}$ In control societies, mathematics can inscribe matter in a way that is optically convincing down to the level of quantum noise, regardless of whether there is any "observer," and so relegate dichotomies such as subject and object, real and imaginary, "to the grave."

Kittler provides a perspective on the social function and power of numbers. "Numbers are the only kind of information that remains relevant beyond all minds," he suggests, "whether insane or professorial: as an inscription in the Real."14 Here, Kittler follows some enigmatic remarks made by Lacan in his article "Lituraterre." "What is evoked of jouissance insofar as a semblant is broken," states Lacan, "this is what in the

12. Ibid., 42.

13. Ibid., 44.

14. Kittler, Discourse Networks 1800/1900, 206.

15. Jacques Lacan, "Lituraterre," trans. Jack W. Stone, Ornicar? 41 (April, 1987): 5-13. 
Real presents itself as a furrowing. It is from the same effect that writing is in the Real the furrowing of the signified, which has more of the semblant insofar as it makes the signifier. Writing does not trace (décalque) the signifier, but its effects of language (langue), what is forged by whoever speaks it. It only climbs back in taking a name there, as happens in those effects among things that the signifying battery names (dénomme) to have them numbered (dénombrées)."16 When some jouissance fractures or interrupts some Imaginary ordering of the Real, that is, fragments some fantasy, which through force of desire anchors an otherwise meaningless network of floating signifiers upon their signifieds, this implies an encounter with the Real. These explosions of the Imaginary order are always momentary in the sense that the signifier will inevitably be reanchored on some new meaning. In relation to "numbering," then, an inscription is made in the Real such that it can "climb back" into the Symbolic, interrupting or disturbing its present imaginary sense and replacing it with some new one. For example, if someone were to maintain that the answer to " $2+2$ " was 5 and were subsequently made to see that it is in fact 4 , so that they could no longer imagine it as they had previously, it would follow that their Imaginary order had been fractured, they had encountered the Real, or some furrow in the Real had "climbed up" and interrupted their previous fantasy in relation to the equation.

The argument that numbers are "relevant beyond all minds" might appear to contradict contentions that they are determined by broader discursive fields that are the condition of possibility for all thought. Alternatively, we can view the paradoxical relationship between the determination of numbers by the social and the numerical determination of the social as in a kind of torsion. Apparatuses of this kind emerge within 16. Ibid., 6 . 
a situation in accord with its strategic ends, but after having arisen there, they proceed to take on a power of their own "beyond all minds."

In this section, I follow Kittler's procedure of analyzing mathematics as an apparatus of social management, however different its form may be from one situation to another. In Sections 3.1.2 and 3.1.3, I consider the law of large numbers and the normal distribution. The "count" of which these are a part, that is, the lines of visibility and enunciation corresponding to the advent of social statistics and science, is driven by a biopolitical line of force. Counting was such an effective apparatus of government and social management that machines, specifically, the prototypes of the modern computer (e.g., Babbage's difference engine and the Hollerith machine), were designed in order to carry out the counting. These technologies effectively enabled the discovery of "population," the management of the new biopolitical economies of race, health, and degeneracy.

In Section 3.1.4, I provide an analysis of foundational mathematics. This analysis is important to the extent that $\mathbb{Z F C}$ set theory-or some set of axioms resembling those comprising it - ean be and often is used as the axiomatic basis of the countable in addition to the computable, and in this way, in control societies, it is also the axiomatic basis of the controllable. I follow Alain Badiou's argument that mathematics is ontology, which corresponds to recent research in the field of information management on what is known as "ontological engineering." The line of force in information management towards universals of communication and portability has led to a renewed interest in formalized abstract ontologies, which, as formalized, must operate by the very same axioms Badiou claims are the "thought of being." 
In Section 3.1.5, I discuss control theory. The purpose of control in control theory is to eradicate any and all "singularities" or "perturbations" in the system through various negative feedback designs. In contrast with disciplinary power, from the perspective of control theory, external behavior is more important than interior constitution and casuality. InSection 3.1.6., I discuss stylometrics. I suggest that the material "essence" of the dividual is precisely a vector of feature sets. In Section 3.1 .7 , the access control models I discuss allow me to demarcate the spaces and temporalities to which such dividuals are bound. Lastly, I conclude in Section 3.1.8 by considering the "substance" of dividuals as digital information.

\subsubsection{The Law of Large Numbers}

Nikolas Rose's study of disciplinary and control societies, Powers of Freedom: Reframing Political Thought, addresses the constitutive interrelationship between mathematics and modern government. Counts such as the census guarantee the legitimacy of authorities and institutions, just as statistics align nation-states and populations through the formulation and administration of policy. Because mathematics can quantify "types" of human beings, it enables the disciplinary mechanisms of hierarchical observation, individualization, categorization, and normalization.

Already by the end of the nineteenth century, social management had mostly abandoned recourse to eternal laws in favor of the calculation of statistical probabilities. The evidence suggests that this change resulted partly from the increasing amount of available numerical information. Ian Hacking's archival research indicates that the period between 1820 and 1840 witnessed an exponential increase in the amount of numerical 
information that was recorded and published. This "avalanche of numbers,"17 as Hacking calls it, offered social scientists and officials access to statistics concerning race, deviance, poverty, and sickness. "Galilean science had once said that the world was written in mathematical language," writes Hacking, "[b]ut geometry and algebra [only] furnished [a] model. [Not until] the nineteenth century did empirical numbers assume their paramount role. It had finally become a task of the natural scientist to measure."18

During this period, fields such as engineering, navigation, and accounting all began drawing up tables. The human specialists who carried out the necessary mathematical computations were known as "computers." These human computers inevitably made mistakes. By 1820 , Charles Babbage, the "father of the computer," had become frustrated by widespread errors in the humans' accuracy, and so he drew up plans for a machine that would automatically calculate these tables.

The characteristic mathematical techniques that acquired new importance during the nineteenth century facilitated both the discovery and the effective management of the population. As Foucault argues, the "population"19 appeared as an object of governance along the same line of force he characterizes as "biopolitics," defined by Thacker and Galloway as "the strategic integration of biology and informatics toward the development of techniques of organization and control over masses of individuals, species groups, and populations." ${ }^{20}$ The "population" as an entity to be statistically managed by the state

17. Ian Hacking, The Taming of Chance (Cambridge, England: Cambridge University Press, 1990), 46.

18. Ian Hacking, "How Should We Do the History of Statistics?" in The Foucault Effect: Strudies in Governmentality, eds. Graham Burchell, Colin Gordon, and Peter Miller (Chicago: University of Chicago Press, 1991), 186.

19. Foucault, Security, Territory, Population, 67.

20. Thacker and Galloway, The Exploit, 72. 
emerged alongside concrete mathematical mechanisms designed to carry out that management. When, for example, Foucault describes the phenomena that accompanied the appearance of the population as "aleatory and unpredictable when taken in themselves or individually, but which, at the collective level, display constants that are easy, or at least possible, to establish, ${ }^{21}$ he describes what, in 1837 , mathematician S. D. Poisson called "la loi des grandsnombres." ${ }^{22}$ As the number of cases of any phenomena that are collected and observed increases, the difference between the probable and the actual in relation to those cases almost surely converges to zero:

THE (WEAK) LAW OF LARGE NUMBERS. Let $X_{1}, X_{2}, \ldots$, be a finite sequence of independent and identically distributed random variables with a finite expected value of $E\left(X_{1}\right)=E\left(X_{\dot{2}}\right)=\cdots \mu<\infty$ The average $\bar{X}_{n}$ converges in probability $\stackrel{P}{\rightarrow}$ towards an expected value $u$ as the collected number $n$ of cases inereases:

That is, for all $\varepsilon>0$,

$$
\bar{X}_{n} \stackrel{P}{\rightarrow} u \text { when } n \rightarrow \infty \text {. }
$$

$$
\lim _{n \rightarrow \infty} \mathrm{P}\left(\left|\bar{X}_{n}-u\right| \geq \varepsilon\right)=0.23
$$

As an example of this law, suppose that $X$ deviants have been captured, and that some information $u$ about these deviants is needed in order to identify the deviants still remaining among the normal population. Suppose that all of these deviants, both those captured and those remaining among the normal population, are qualified as such under some supposition $\varepsilon$. Then the' more deviants that are captured by $\left|\bar{X}_{n}-u\right|$, the more

21. Michel Foucault, Society Must Be Defended: Lectures at the College De France, 1975-76, (New York: Picador, 2002), 246.

22. S. D. Poisson, Probabilité des jugements en matière criminelle et en matière civille, précédées des règles générales du calcul des probabiliniés (Paris: Bachelier, 1837).

23. Michel Loève, Probability Theory l, 4th ed. (Berlin: Springer Verlag, 1977), 14. 
convergence there is when estimating $u$ to a probable certainty.

The use of statistics to track deviancy figures among its earliest applications. "One name for statistics," observes Hacking, "especially in France, had been 'moral science;' the science of deviancy, of criminals, court convictions, suicides, prostitution, divorce [...]. [A]bove all [it was] the science that studied, empirically and en masse, immoral behavior [...]. From the time of Quetelet [1796-1874] to that of Willcox [18611964] social facts simply became facts that are statistical in character." ${ }^{24}$ Hacking also provides the example of recidivism as a category that was set in place by the collection of numerical data. The "recidivist" first appeared when the quantitative study of crime began in 1820 . "New kinds of people came to be counted," writes Hacking; "the categories of the census, and of other bureaucracies such as the Factory Inspectorate in England and Wales, created $[\ldots]$ the official form of class structure in industrial societies. ${ }^{25}$ The law of large numbers implies a consequent avalanche of expected values, which is exactly what occurred in relation to the health and welfare of the population.

Bruce Curtis summarizes the "sciences of the state" as follows: "As an object of knowledge, population is primarily a statistical artifact. The establishment of practical equivalences means that population is connected to the law of large numbers, which causes individual variation to disappear in favor of regularity. In its developed forms, population is bound up with the calculus of probabilities. Population makes it possible to identify regularities, to discover 'things which hold together,' and such things may be

24. Hacking, "How Should We Do A History of Statistics?," 182.

25. Ibid., 183. 
both analytic tools and objects of intervention." ${ }^{26}$ The continuous nature of statistical distributions and the statistical use of mathematical mechanisms such as the mean and the average ground the continuity of individual and population in the terms of the emerging apparatuses of government. The mathematical concept of the normal distribution, for example, becomes a mechanics that abstracts the relations of individuals into populations. The spread of the statistics of population enables a rationalization of social relations. Though individuals seem to act in irregular ways, the collective facts about the behavior of those same individuals now present themselves as regular and constant.

Rose examines the addition of several new sample questions to the United States census during the early nineteenth century, in addition to the novel governmental strategies that the information collected through these questions permitted. He indicates that before the period identified by Hacking (c. 1820), proposals for a census that was anything other than a simple population count had proven controversial. Many viewed the nation as an organic whole and the object of government as the pursuit of an indivisible common good. By 1820 , however, a new understanding of the nation began to take shape, which "viewed society as consisting in multiple and diverse interests." ${ }^{27}$ The government of such a society, accordingly, required complex information about the population. The sample questions added to the census subdivided the nation into disparate classes. "The common good was being broken into constituent parts," Patricia Cline-Cohen writes, "and the social order could now be comprehended through

26. Bruce Curtis, "Foucault on Governmentality and Population: The Impossible Discovery," Canadian Journal of Sociology 27 (2002): 508.

27. Nikolas Rose, Powers of Freedom: Reframing Political Thought (Cambridge, England: Cambridge University Press, 1999), 220. 


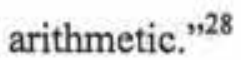

A calculus of race figured in the United States census from its inception. The infamous "Three-Fifths Compromise" determined representative apportionment based on the number of all free persons except Indians who were not taxed and "three-fifths of all other persons." The census initially determined the boundaries of electoral districts based on this count and had only four questions. By 1840 , however, "amongst those who had become objects of [...] statisticalization," writes Rose, "were the mad." ${ }^{29}$ Rose continues:

The 1840 census added'a count of the insane and idiots, distinguished by race and by mode of support, to the counts of the blind, deaf and dumb, that had been included in 1830 . When the results of the census were published in 1841 , the total number of those reported as insane or feeble-minded in the United States was over $17,000[\ldots]$. Nearly 3,000 were black, and the rate of insanity amongst free blacks was eleven times higher than that of slaves and six times higher than that of the white population. ${ }^{30}$

The potential effect of these statistics was actualized only in the service of government.

Rose provides the example of vice president John C. Calhoun, for whom these numbers were proof that slaves were better off in chains. In the first session of the twenty-eighth Congress, 1843, Calhoun declared:

The census and other authentic documents show that, in all the two races, the condition of the African, instead of being improved, has become worse. They have been invariably sunk into vice and pauperism, accompanied by the bodily and mental inflictions incident thereto- - deafness, blindness, insanity, and idiocy - to a degree without example; while, in all other states which have retained the ancient relation between them, they have improved greatly in every respect-in number, comfort, intelligence, and morals-as the following facts, taken from such sources, $[\ldots]$ serve to illustrate. ${ }^{31}$

28. Patricia Cline-Cohen, A Calculating People: The Spread of Numeracy in Early America (Chicago: University of Chicago Press, 1982), 160.

29. Rose, Powers of Freedom, 220.

30. Ibid.

31. Vice President Calhoun, April 18, 1844 Congress, Ist Session, vol. vi, 51. 
At the end of the nineteenth century, General Francis Amasa Walker, founder of the United States immigration restriction movement, used statistics in a manner similar to Calhoun. Walker's article "Restriction of Immigration" reveals the intimate relationship between the statistics of population and the key biopolitical doctrines of eugenics and social Darwinism. "New England was settled almost exclusively by one branch of the great Teutonic race," writes Walker, "from which has proceeded almost every invention and mechanical discovery of the past two centuries. Of that Teutonic race, it was that branch, the English, which had long shown itself pre-eminent in mechanical insight, that colonized this coast." 32 "It was to their experiences," continues Walker, "extending through many generations upon these inhospitable shores, that their descendants were to owe the development of a mechanical faculty which was to place them as far ahead of the English as the English are ahead of any other branch of the Teutonic race; as the Teutonic race is ahead of the Slavic or the Celtic." ${ }^{33}$ Throughout the article, Walker makes use of statistics-for example:

Only a short time ago, the immigrants from southern Italy, Hungary, Austria, and Russia together made up hardly more than one per cent of our immigration. Today the proportion has risen to something like forty per cent, or even more. The entrance into our political, social, and industrial life, of such vast masses of peasantry, degraded below our utmost conceptions, is a matter which no intelligent patriot can look upon without the gravest apprehension and alarm. These people have no history behind them which is of a nature to give encouragement. They have none of the inherited instincts and tendencies which made it comparatively easy to deal with the immigration of olden time. They are beaten men from beaten races; representing the worst failures in the struggle for existence. Centuries are against them, as centuries were on the side of those who formerly came to us. They have none of the ideas and aptitudes which fit men to take up readily and easily the problem of self-care and self-government, such as

32. Ibid.

33. Ibid. 
those who are descended from the tribes that met under the oak-trees of old Germany to make laws and choose chieftains. Their habits of life [...] are of the most revolting kind. Read the description given by Mr. Riis, of the police driving from the garbage dumps to the miserable beings who try to burrow in those depths of unutterable filth and slime in order that they may eat and sleep there $!^{34}$

Walker was the superintendent of the 1870 and 1880 censuses. The new techniques he introduced for monitoring changes in the population and representing these in population maps and population density maps supported his statistical arguments that new immigrants were breeding faster than old immigrants. Walker's arguments ultimately led to the passage of the legislation that restricted immigration to the United States along racial lines in 1920. During the second half of the nineteenth century, America's population grew by $35 \%$ each decade. The country's exploding population began making the American census an all too complex affair. The 1880 census had taken seven years to tabulate, and by the time the figures were available, they were obsolete. The growth of the United States population from 1880 to 1890 , largely on account of the immigration, led to estimates that the 1890 census would take 13 years to complete. A more efficient technique was necessary.

"There ought to be a machine," one census agent, John Shaw Billings, suggested to his colleague Herman Hollerith; as Hollerith recalled it, "[Billings] said to me there ought to be a machine for doing the purely mechanical work of tabulating population and similar statistics $[\ldots]$ his idea was something like a type distributing machine. He thought of using cards with the description of the individual shown by notches punched on the edge. ${ }^{35}$ Hollerith immediately began work on his tabulating machine. His first approach,

34. Ibid.

35. Geoffrey D. Austrian, Herman Hollerith: Forgotten Giant of Information Processing (New York: Columbia University Press, 1982), 24. 
which used a continuous strip of paper, only worked when every record was to be read consecutively. As he characterized it, "The trouble was that, if $[\ldots]$ you wanted any statistics regarding Chinamen, you would have to run miles of paper to count a few Chinamen! ${ }^{36}$ To solve the problem, Hollerith developed the punch card. Hollerith explains: "I was traveling in the West and I had a ticket with what I think was called a punch photograph $[\ldots]$ the conductor $[\ldots]$ punched out a description of the individual, as light hair, dark eyes, large nose, etc. So you see, I only made a punch photograph of each person. ${ }^{37}$ The resulting punch card, based on his recollection of the punch photograph, provided a standardized and easily interchangeable unit for the recording of information. As Hollerith's biographer Geoffrey Austrian notes, Hollerith often applied the analogy of photography to census-taking itself. The enumeration corresponded to the exposure of the photographic plate, while the compilation of the census was equated with development: "As the first flow of the development brings out the prominent points of our photographic picture, so, in the case of a census, the first [census] tabulations will show the main features of our population. As the development is continued, a multitude of detail appears in every part while at the same time, the prominent features are strengthened and sharpened in definition, giving, finally, a picture full of life and vigor." ${ }^{38}$

Hollerith described his first design in an 1884 patent application. "Various statistical items for a given person," Hollerith explains, "are recorded by punching suitable holes in a line across the strip, being guided by letters on the guide plate (a

\footnotetext{
36. Ibid., 14.

37. Ibid., 43.

38. Ibid., 56.
} 
template superimposed over the tape). The position of the hole indicated whether a person was a male or female, native born or foreign-born, and white or colored, in addition to his or her age category. ${ }^{, 39}$ Hollerith's machine was used for the 1890 census, with the cards coded for age, state of residence, gender, and other information. Clerks used keypunches to enter information from the returns by punching holes in the cards. The census results were "finished months ahead of schedule and far under budget."

Just as Walker's remarks resemble those made about North America in Mein Kampf, Hollerith machines were an important instrument in implementing the genocidal programs of Nazi Germany. In 1911, Hollerith sold his shares in the Tabulating Machine Company. Hollerith's former company merged with three others and, led by salesman Thomas Watson, grew into a major supplier of business equipment. In 1924, Watson renamed the enterprise "International Business Machines" (IBM). The Nazi regime used Hollerith machines supplied by the German subsidiary of IBM to carry out the task of ethnic identification. In other words, the modern digital computer appeared along the line of force characteristic of the biopolitical enterprises of modernity.

\subsubsection{The Normal Distribution}

The "normal distribution" calculated by Carl Friedrich Gauss has had many different names, including the "law of errors," the "law of facility of errors," "Laplace's second law," and the "Gaussian law." Gauss was the first to use the term "normal" in relation to the "normal equations" involved in its applications, where "normal" has the

39. Ibid., 43.

40. Ibid., 44 . 
technical meaning of "orthogonal" rather than the colloquial meaning of "usual" or "typical." By the end of the nineteenth century, however, some authors had begun using the name "normal distribution" with the implication that Gaussian distribution was typical, common, and therefore "normal." The Belgian astronomer Quetelet, in addition to his fundamental role in preparing the Belgian census of 1840 , became convinced that Gauss's bell-shaped "law of errors" could model the distribution of human social and biological traits. Quetelet was the first to apply the Gaussian error curve, the "bell curve," to social relations, in his book Sur l'homme et le dévelopement de ses facultés, ou Essai de physique sociale, using the expanding collection of social data available at that time. This extension of the mathematical law of error to social objects ushered in the nineteenth-century era of "social arithmetic," "social mathematics," and "social physics." It also signaled the advent of the quantitative social sciences. Quetelet supposed that the mean of the normal distribution should have the same kind of error-canceling accuracy when applied to social entities as it had for the astronomical objects he had studied. Quetelet also proposed that the sum of the means of the height, weight, intelligence, and other features of a group would paint a mathematical portrait of the "average man."

To calculate a normal distribution, one begins by calculating the familiar arithmetical mean. First, one takes an entity included in some general class and places that entity into some particular class. One takes a petson, for example, from the class of "people in general" and places that person into the class of "particular people." Second, one divides the size of that particular class by the size of the general class. One divides the number of "particular people," for example, by the number of "people in general." Already from the beginning, then, one has shifted ontological registers twice: first, from 
any entity to some particular class, and second, from the particular class to the ratio of that particular class to some more general class. One has decided, in the first instance, not only to include certain people in some class of "particular people," but also, from the standpoint of that particularity, that these "particular people" are more or less equivalent. In the second instance, one has decided that the ratio of "particular people," $i$, to "people in general," $n$, reveals something intelligible, the mean $\mu$ :

$$
\mu=\frac{1}{n} \sum_{i=1}^{n} \mu_{i}
$$

If two out of five people in general are particular, then on average, $40 \%$ of people in general are particular. "In effect," writes Remi Lenoir, "What appears in the form of a 'fact of population' or of a 'demographic structure' is the result of a double social construction: demographic data are constructed in keeping with the bureaucratic categories of modern states which aim to identify individuals and define groups $[\ldots]$ and the principle of construction of these categories is itself constructed as based in nature. ${ }^{n+1}$ After having calculated the mean, in order to calculate the normal distribution, one must next calculate the variance. To calculate the variance, continuing with the example above, one divides the sum of the difference between particular people and the mean of particular people squared by the sum of people in general:

$$
\sigma^{2}=\frac{1}{n} \sum_{i=1}^{n}\left(x_{i}-\mu\right)^{2}
$$

Having calculated the mean $\mu$ and the variance $\sigma^{2}$, we now come to the normal sciences socials, (2000): 96-97, quoted in Bruce Curtis, "Foucault on Governmentality and Population," 531. 
distribution, a function that indicates the probability of any case falling between two limits. In other words, the normal distribution is the only distribution all of whose cumulants beyond the first two (i.e., other than $\mu$ and $\sigma^{2}$ ) are zero:

$$
f(x, \mu, \sigma)=\frac{1}{\sigma \sqrt{2 \pi}} e^{-\frac{(x-\mu)^{2}}{2 \sigma^{2}}}
$$

In her article "Foucault and Social Measure," Mary Beth Mader draws attention to the questionable presuppositions involved in the normal distribution, for example, that the term "particular" should retain the same sense across all these different ontological registers. Mader writes

The specifically ontological shift indicated here is significant because the adjectival and arithmetic assimilation effected in these kinds of cases does the conceptual labor of homogenization that is subsequently found in discourses of social and political comparability in the form of claims purported to be merely and innocently descriptive and representative ones. So, aside from the oft-noted problem of actually crafting the definitions [of particularity] under which observed phenomena will be classed [...], and the problem of the norm's equivocal descriptive or prescriptive status, there is also the problem of the sort of overlooked equivocations on the ontological or conceptual "level.,"42

Mader's analyses suggest that if we follow the levels of abstraction in going from person to person in general, from person in general to person in particular, from the ratio of people in particular to people in general, from people in general divided by the difference between particular people and the ratio of people in general to people in particular squared, the dubious equivalences that emerge with the widespread use of social statistics can be seen with greater clarity. The normal distribution is one example of a highly elaborate apparatus for presenting and coordinating the multiple quantitative relations with respect to population. In the novel apparatus of the normal distribution, the

42. Mary Beth Mader, "Foucault and Social Measure," Journal of French Philosophy 17, no. 1 (Spring 2007): 8. 
individual is inscribed by way of a general feature relative to the total population, while this general feature is partially derived from the value of any given individual value, since it is the mean of all the individual values aggregated. The most common value, then, becomes the point of reference for the location of every value that is represented. The complexity of the multidimensional space of comparability activated by the normal curve permits multiple kinds of comparisons through the intermediary of the mean of the curve. ${ }^{43}$

Quetelet, as Hacking observes, "transformed the theory of measuring unknown physical quantities, with a definite probable error, into the theory of measuring ideal or abstract properties of a population. Because these could be subjected to the same formal techniques, they became real quantities." ${ }^{44}$ And so, Mader argues, "[I]t is the properties endogenous to mathematical objects that create the alleged comparability and continuities of populations and other social phenomena constituted as the objects of social statistics. The conceptual sleight that performs this conversion seems today still to pass undetected. ${ }^{45}$ What is involved here is more than merely semantic; social statisticians over the course of the nineteenth and early twentieth centuries formalized the normal: norms could be calculated for populations, and individuals could be individualized by comparing their characteristics-height, weight, circumference of skull, and later intelligence and moral worth-with those of the population as a whole. The capacity to identify, measure, instill, and regulate through the apparatus of the norm becomes a

43. Tbid.

44. Ian Hacking, The Tarming of Chance (Cambridge, England: Cambridge University Press, 1990), 108.

45. Mary Beth Mader, Sleights of Reason: Norm, Bisexuality, Development (Albany: SUNY Press, 2012), 59. 
crucial technique of government.

Georges Canguilhem points to a fundamental distinction between social (technological, economic, juridical) norms and organic norms: "Between 1759, when the word 'normal' appeared, and 1834, when the word 'normalized' appeared," Canguilhem argues, "a normative class had won the power to identify-a beautiful example of ideological illusion - the function of social norms, whose content it determined, with the use that that class made of them." 46 From this point on, the norm would become that which is socially worthy, statistically average, scientifically healthy, and personally desirable. Normality was natural, but those who were to be civilized would have to achieve normality through wQrking on themselves, controlling their impulses in their everyday conduct and habits, and inculcating norms of conduct into their children, under the guidance of scientific experts who claimed to ground their norms and codes of conduct in objective standards and measures. Under their tutelage, free individuals would become governable - in a range of different ways and with varying consequences-as normal subjects. To be free, in this modern sense, is to be attached to a polity that identifies certain modes of conducting one's existence as normal and simultaneously to be bound to those "engineers of the human soul" who define the norm and direct individuals towards normality. The formulae that underpin these apparatuses show themselves to be materially effective mechanisms of government.

46. Georges Canguilhem, On the Normal and the Pathological, trans. Carolyn R. Fawcett (Cambridge, MA: Zone Books, 1989), 151. 


\subsubsection{Mathematics and Ontology}

For Jacques Rancière and Alain Badiou, to be "counted" in a system is to be bound to that system's stabilities and so bound to actuating the design of its control. The "count" binds potentialities to an "ensemble of well-defined parts, places and functions [...], an ordered distribution of the visible and the invisible, noise and speech, etc." ${ }^{\text {,47 }}$ Politics proper, or rather, that for which Rancière and Badiou "reserve" the name politics, is what remains irreducible to these boundaries of "common and private, visible and invisible, audible and inaudible., ${ }^{, 48}$ This definition of politics, emphasizes Rancière, implies the "action of supplementary subjects, subjects that are not reducible to social groups or identities but are, rather, collectives of enunciation and demonstration surplus to the count of social groups. [...] Political subjects are supernumerary collectives which call into question the counting of the community's parts and the relations of inclusion and exclusion which define that count." ${ }^{49}$ The count entails boundaries, while politics proper entails an activity that is out-of-bounds, evident only as a disturbance of such boundaries from some position in the boundless.

This conceptualization of politics in terms such as "count," "supernumerary," "relation," and "inclusion" proceeds from Badiou's thesis in Being and Event that "mathematics is ontology." For Badiou, mathematics, specifically set theory, is the pure thought of multiplicity. If being qua Being is nothing other than pure multiplicity, then mathematics, because it is the only thought of generic multiplicity, is also the only

47. Jacques Rancière, "Introducing Disagreement," Angelaki 9, no. 3 (2004): 6.

48. Ibid.

49. Ibid., 7. 
thought of Being. The speculations in Being and Event figure in my analyses only to the extent that they demonstrate a free use of a formal language in place of instrumentalizing a formal language over some empirical field, as with the quantitative social sciences. Set theory, or some set of axioms resembling those comprising it, grounds several of the mechanisms deployed by government and social management since the birth of biopolitics into societies of control. Therefore, an analysis of set theory is also a critique of horizons of possibility in relation to these mechanisms.

Mathematician Georg Cantor created the "algebra of sets" in his 1874 paper "On a Characteristic Property of All Real Algebraic Numbers." ${ }^{50}$ Cantor introduced the theory in order to prove his formulation of the real numbers, a formulation he needed before he could approach the more pressing question of whether the trigonometric series expressing complex functions could in each case be proven unique. The algebra of sets, in other words, first emerged from Cantor's interest in the ceaseless multiplication of illogical exteriorities. By the time of his 1899 correspondence with Dedekind, Cantor distinguished two types of multiplicities (Vielheiten). The first, which he called "inconsistent multiplicities," are multiplicities that when taken as a unity (Einheit) imply a paradox (e.g., the set of all sets that do not contain themselves). The second, which he called "consistent multiplicities" or "sets" (Menge), are multiplicities that when taken as a unity do not imply a paradox (e.g., the set of all natural numbers). ${ }^{51}$ Cantor concluded that "almost all" multiplicities are inconsistent multiplicities.

50. Georg Cantor, "Ober eine Eigenschaft des Inbegriffes aller reellen algebraischen Zahlen," in Journal fir die reine und angewandte Mathematik, 77 (1874): 258-62.

51. Georg Cantor, "1899 Letter to Dedekind," in From Frege to Godel: A Source Book in Mathematical Logic, 1879-1931, ed. J. Van Heijenoort (Cambridge, MA: Harvard University Press, 2002), 113-17.

52. See Notes 3.1.2. 
In place of understanding mathematics as a language game or as an apparatus that can objectively apprehend the empirical world, Badiou's philosophy discerns an ontology of police and politics in the formal language of set theory. This project is appropriate in many ways. In control societies, the processes of dividualization and modulation, which mathematical apparatuses often enable, are grounded upon axioms such as those comprising $\mathbb{Z F C}$. For example, computability, Turing machines, complexity classes, and so on, are all formally defined by way of such axioms. Moreover, the equation of set theory and ontology also relates to the work undertaken by "ontological engineers" in the field of information management.

In his 1991 conversation with Negri, Deleuze states, "Compared with the approaching forms of ceaseless control in open sites, we may come to see the harshest confinement as part of a wonderful happy past. The quest for 'universals of communication' ought to make us shudder." ${ }^{, 53}$ Not coincidentally, that same year, the Knowledge-Sharing Effort (KSE); a consortium to develop such universals, submitted its first progress report. The Defense Advanced Research Projects Agency (DARPA), the Air Force Office of Scientific Research (AFOSR), the Corporation for National Research Initiative (NRI), and the National Science Foundation (NSF) sponsor the KSE. In the report, the KSE addresses "the impediments to knowledge sharing and corresponding needs for the development of technology to overcome these impediments." ${ }^{54}$ In the interests of developing such a technology, the report calls for the development of robust

53. Deleuze and Negri, "Control and Becoming," 14.

54. Ramesh Patil, Don Mckay, Tim Finin, Richard Fikes, Thomas Gruber, Peter F. Patel-Schneider, and Robert Neches, "The DARPA Knowledge Sharing Effort: Progress Report," in Readings in Agents, eds. Michael N. Huhns and Munindar Paul Singh (Burlington, VT: Morgan Kaufman, 1998), 243-255, 243. 
"ontologies," which are defined as "pre-fabricated foundations for application of specific knowledge bases in a particular topic area." 55

The World Wide Web (WWW), for example, is an information system of interlinked hypertext documents that is accessed by way of the Internet every time one uses the prefix "www" to access an Internet resource. The main international standards organization for the WWW is the World Wide Web Consortium (W3C). The Semantic Web was first described by Tim Berners-Lee, chairman of the W3C, in a 2001 Scientific American article. Slow in coming but inevitable, the Semantic Web is a standard "metadata data model" that will soon encompass the Web. By encouraging the inclusion of semantic content on web pages, the Semantic Web will convert the current WWW into a universally portable "web of data." According to the W3C, "The Semantic Web provides a common framework that allows data to be shared and reused across application, enterprise, and community boundaries." 56 "The Semantic Web," explain Tim Berners-Lee, James Hendler, and Ora Lassila, "is not a separate web but an extension of the current one, in which information is given well-defined meaning, better enabling computers and people to work in cooperation." 57

The Semantic Web is built on the Resource Description Framework (RDF), which has come to be used as the general framework for the conceptual description or modeling of information of resources on the WWW. RDF statements, known as triples, consist of a subject (the resource itself), a predicate (an attribute or a relation), and an object (not to

55. Ibid.

56. Ivan Herman, "W3C Semantic Web Activity," W3C, accessed October 13, 2013, http://www.w3.org/2001/sw/.

57. Tim Berners-Lee, James Hendler, and Ora Lassila, "The Semantic Web," Scientific American 284 (2001): 34 . 
be confused with "object" in the ordinary sense, "object" here denotes the value of the predicate). The RDF schema provides a "metadata data model," so that instead of simply requesting a resource, as one would by clicking on a hypertext link or visiting a resource through its uniform resource locator (URL), one can also request other resources in terms of a semantic web of which that resource is only a part. For example, the semantic web would involve the "class" to which a resource is supposed to belong, its properties, and so on. By extension, other resources can be requested in terms of these classes, properties, and relations.

Following the KSE's progress report and the subsequent growth of the Semantic Web, numerous academic papers in information management began to appear with the intention of developing ontologies in the RDF. According to the W3C Web Ontology Working Group charter, "An ontology defines the terms used to describe and represent an area of knowledge." 58 Ontologies are the basic component of the Semantic Web. They define and relate concepts that can be used for resources on the WWW, which are then accessible through semantic interconnection among different resources. One of the numerous articles that appeared on the development of these ontologies, Thomas Gruber's "A Translation Approach to Portable Ontology Specifications," contains the following:

[In this paper] we discuss how the translation approach to portability addresses several technical problems. One problem is how to accommodate the stylistic and organizational differences among representations while preserving declarative content. Another is how to translate from a very expressive language into restricted languages, remaining system-independent while preserving the computational efficiency of implemented systems. ${ }^{59}$

58. Jeff Heflin, "OWL Web Ontology Language: Use Cases and Requirements," last modified November 22, 2009, http://www.w3.org/TR/webont-req/.

59. Thomas R. Gruber, "A Translation Approach to Portable Ontology Specifications," Knowledge 
Gruber's article details the obstacles to achieving universals of communication, including impediments to portability, translatability, and abstract equivalence. Information management literature, in other words, presents the development - of standardized "upward" ontologies as a promising way to overcome impediments to universals of communication.

Most articles in this area begin with a brief nod to the term "ontology" as it has been understood in philosophical and theoretical contexts, as in the article "Ontologies and Knowledge-Bases":

Aristotle defined Ontology as the science of being as such: unlike the special sciences, each of which investigates a class of beings and their determinations, Ontology regards "all the species of being qua being and the attributes which belong to it qua being" (Aristotle, Metaphysics, IV, 1). In this sense, Ontology tries to answer to the question: What is being? or, in a meaningful reformulation: What are the features common to all beings? ${ }^{60}$

From the perspective of most serious philosophical work done in ontology in the twentieth century, leaps such as the one made in this quotation would be seen as problematic. In the fundamental ontology of Heidegger, for example, the question "What is being?" cannot be reformulated as the question "What are the features common to all beings?" "All ontology," writes Heidegger, "remains fundamentally blind and perverts its innermost intent if it has not previously classified the meaning of being sufficiently and grasped this clarification as fundamental to its task [my emphasis]."

Acquisition 5, no. 2 (1993): 199.

60. Nicola Guarino and Pjerdaniele Giaretta, "Ontologies and Knowledge Bases Towards a Terminological Clarification," in Towards Very Large Knowledge Bases: Knowledge Building \& Knowledge. Sharing, ed. N. J. I. Mars (Amsterdam: IOS Press, 1995), 26.

61. Martin Heidegger, Being and Time, trans. Joan Stambaugh (Albany: State University of New York Press, 1996), 9. 
revealing" used by these ontological engineers orders beings in terms of taking them to be what Heidegger refers to in his essay on technology as a "standing-reserve." Such systems of classes, subclasses, transitivity, equivalences, and so on, according to Heidegger, leave ontological difference- the difference between Being and beingsunthought. They attest to the "forgetting of what is thought provoking" within the course of development of a Western Logocentric, that is, "metaphysical" thought, which takes thinking to be "an assertion of something about something." ${ }^{62}$ In such thematizations, formalizations, and quantifications, meaning is reduced to what is objectively either "classifiable," "countable," or “measurable."

The contrast between ontology as a philosophical project and ontology as a project of information management helps reveal the presuppositions of each enterprise. Guarino and Giaretta state, "Ontology is concerned not so much with the bare existence of certain objects, but rather the rigorous description of their forms of being, i.e. their structural features. ${ }^{163}$ This statement should be placed into constellation with the existential analytic from Heidegger's Being and Time and the decades of scholarship following that project, especially the work of Jacques Derrida and Jean-Luc Nancy. This latter body of scholarship not only attempts to preclude any presuppositions regarding the "features common to all beings"; it also suggests that what should remain our paramount concern is precisely "bare existence," that is, precisely what would resist any universal equivalence.

The article "State-of-the Art: A Comparative Analysis of Ontology Matching

62. Martin Heidegger, What is Called Thinking?, trans. J. Glenn Gray (Now York:_Harper \& Row, 1968), 139.

63. Guarino and Giaretta, "Ontologies and Knowledge Bases," 26. 
Systems," provides another example of a tacit nod to the philosophical discipline of ontology by "ontological engineers":

Ontology is derived from the two Greek words namely ontos which means "to be" and logos meaning "word." The term ontology is also derived from the philosophy field which refers to a systematic approach to explain the existence of things in the world. Ontology typically provides a vocabulary that describes a domain of interest and a specification of the meaning of terms used in the vocabulary. They are generally used to provide a uniform conceptualization of terms. $^{64}$

As Iroju, Soriyan, Gambo, and Ikono make clear, the ontologies of information management are designed to provide uniform conceptualizations in order to facilitate universal portability. In contrast, the philosophical discipline of ontology, as it played out over the twentieth century, was interested in exactly what always resists such portability, bearing witness to it, and deçonstructing the "uniform conceptualizations" that would bind this resistance to any equivalence or portability.

The ontologies of the ontological engineers, designed to facilitate universals of communication, in addition to mathematical apparatuses such as the normal distribution, are today grounded upon some set of axioms such as those comprising $\mathbb{Z F C}$. An analysis of these axioms allows us to unpack their effective mechanism, which becomes increasingly important in relation to the computer. The details and limits of these axioms reveal the details and limits of the count, both in general and in relation to the digital apparatuses of control societies.

AXIOM OF EXTENSIONALITY. If $X$ and $Y$ have the same elements, then $X=Y$ :

$$
\forall u(u \in X \leftrightarrow u \in Y) \rightarrow X=Y .
$$

As mathematicians Thomas Jech and Michael Potter both emphasize, the axiom of 64. O. Iroju , A. Soriyan, I. Gambo, and R. Ikono, "State-of-the Art: A Comparative Analysis of Ontology Matching Systems," African Journal of Computing \& ICT 5, no. 4 (June, 2012): 81. 
extensionality establishes the basic idea of a set: a set is determined by its elements. ${ }^{65}$ Badiou also emphasizes the axiom's extensional form. By way of extension, the axiom's determination of a set also establishes the basic idea of an element; an element (a member of a set) is determined by way of its indifference in relation to belonging:

$$
X=\{\varnothing,\{u\}\} \wedge Y=\{\varnothing,\{u\}\} \rightarrow X=Y, 66
$$

The axiom implies that $u$ is extensibly (i.e., from $X$, from $Y$, from $X$ and $Y$ ) the same, but only in the element of its belonging. We can say nothing about $u$ as such, only, if $u$ already belongs to both $X$ and $Y$, then it is the same $u$ in $X$ and $Y$ : the same is always only the same in terms of a count. Badiou explains, "[B]eing an 'element' is not a status of being, an intrinsic quality, but the simple relation to-be-an-element-of, through which a multiplicity can be presented by another multiplicity."

AXIOM SCHEME OF SEPARATION. Let $\varphi(u, p)$ be a formula. For any $X$ and $p$, there exists a set $Y=\{u \in X: \varphi(u, p)\}$ :

$$
\forall X \forall p \exists Y \forall u(u \in Y \leftrightarrow u \in X \wedge \varphi(u, p)) .
$$

The scheme above produces an axiom for each formula $\varphi(u, p)$, and the set $Y$ in the scheme is unique by extensionality. ${ }^{68}$ The scheme of separation, emphasizes Potter, axiomatizes all the second-order separations (involving quantification of relations) that can be formulated in the first-order language (involving only the quantification of

65. Thomas Jech, Set Theory: The Third Millennium Edition (New York: Springer, 2002), 6; Michael Potter, Set Theory and its Philosophy: A.Critical Introduction (Oxford: Oxford University Press, 2004), 31.

66. Jech, Set Theory, 6.

67. Badiou, Being and Event, 46.

68. Jech, Set Theory, 7. 
variables over a range of elements). ${ }^{69}$ Badiou makes a similar point: an axiom of separation must, in the first place, assume the existence of all those $u$, which only then, in the second place, are said to satisfy $\varphi(u)$. In addition to this assumption, the formula $\varphi$ may also depend on more than one parameter $p$ (i.e., more than one auxiliary variable). These assumptions and possible dependencies imply that the existence of any set (or the assumption thereof) is fundamentally anterior to its formulaic (i.e., linguistic) determination. "What is induced by $[\ldots]$ language," writes Badiou, "is not directly an existence, a presentation of multiplicity, but rather —on the condition that there is already a presentation - the 'separation,' within that presentation, and supported by it, of a subset constituted from the terms which validate the formula [see Figure 3]"70:

\begin{tabular}{cccc|}
\hline \multicolumn{4}{c|}{ Implied } \\
$\uparrow$ \\
$\forall X \quad \forall p \quad \exists Y \quad \forall u$ & $\forall \in \in Y \leftrightarrow u \in X \wedge \varphi(u, p))$ \\
$\downarrow$ & $\downarrow$ & $\downarrow$ & $\downarrow$ \\
& Presupposed & Language \\
\hline
\end{tabular}

Figure 3. Situation in Relation to Being. The separations and classifications of language (formal or otherwise, i.e., any second-order quantifications) are anterior to the multiples they would inseribe in that they already presuppose the existence of these multiples. Adapted from Badiou (2005), 46.

The power set, union, and replacement axioms all require similar assumptions. ${ }^{71}$ "The purely conditional character of existence," Badiou emphasizes, "is marked by the logical structure of these axioms, which are all of the type 'for all $X$, there exists a $Y$ such

69. Potter, Set Theory and its Philosophy, 42.

70. Alain Badiou, Being and Event, trans. Oliver Feltham (New York: Continuum, 2005), 46.

71. See Notes 3.1.3. 
that.","72

Before addressing the axiom scheme of separation, Jech introduces the informal concept of a class, ${ }^{73}$ which is important because it is only upon the basis of this informal concept that many of the operations of set theory can be carried out. If $\varphi\left(x, p_{1}, \ldots, p_{n}\right)$ is a formula, then

$$
C=\left\{x: \varphi\left(x, \mathrm{p}_{1}, \ldots, p_{n}\right)\right\}
$$

is a class. Members of the class $C$ are all those sets $x$ that satisfy $\varphi\left(x, p_{1}, \ldots, p_{n}\right)$ :

$$
x \in C \rightarrow \varphi\left(x, p_{1}, \ldots, p_{n}\right) .
$$

Every set can be considered a class, and a class that is not a set is a proper class. Using this definition of a class, Jech defines inclusion ( $C$ is a subclass of $D$ ):

$$
C . \subset D \rightarrow \forall x, x \in C \rightarrow x \in D \text {. }
$$

The concept of a class also provides the basis for operations such as intersection, union, and complement:

$$
\begin{gathered}
\text { Intersection: } C \cap D=\{x: x \in C \wedge x \in D\} \\
\text { Union: } C \cup D=\{x: x \in C \vee x \in D\} \\
\text { Complement: } C-D=\{x: x \in C \wedge x \notin D\} .
\end{gathered}
$$

The distinotion between belonging and inclusion (i.e., between set and class) is also important in relation to many of the claims made in Being and Event. "One cannot underestimate," writes Badiou, "the conceptual importance of the distinction between belonging and inclusion., ${ }^{74}$ Inclusion (c) implies that each set must be included in itself (e.g., $C \subset C$ ), that is, inclusion is reflexive. Belonging $(\epsilon)$, however, is not reflexive:

72. Ibid., 62.

73. Jech, Set Theory, 5-6.

74. Badiou, Being and Event, 82. 
$\{x\} \subset\{x\}$ is true, but $\{x\} \in\{x\}$ is false, because the only member of $\{x\}$ is $x$, not $\{x\}$. The difference lies in the position of the count in relation to the counted. "In the one case (the case $\epsilon$ ), the multiple falls under the count-as-one which is the other multiple. In the other case (the case $\subset$ ), every element presented by the first multiple is also presented by the second. But being-mutliple remains completely unaffected by these distinctions of relative position." ${ }^{75}$ In relation to its belonging, a multiple has already been counted, that is, presented in a situation. In relation to its inclusion in some class (and a class that is always and additionally included in itself), there is a count of this initial count, a representation of this initial presentation, which Badiou calls the "State of a situation."

On the basis of this distinction between State and situation, Badiou distinguishes three types of multiple: the excrescent type, which is an element such that it does not belong to a set but is a class in which that set is included (e.g., a proper class); the normal type, which is an element such that it belongs to both a set and to a class in which that set is included; and finally, a singularity, which is an element such that it belongs to a set but is not included in a class in which that set is included:

$$
\begin{gathered}
\text { Excrescence: } \forall X \forall C \exists Y:(Y \notin X \wedge X \subset C \rightarrow Y \subset C) \\
\text { Normality: } \forall X \forall C \exists Y:(Y \in X \wedge X \subset C \rightarrow Y \subset C) \\
\text { Singularity: } \forall X \forall C \exists Y:(Y \in X \wedge X \subset C \rightarrow Y \subset C))^{76}
\end{gathered}
$$

He draws an example of this tertiary scheme from Marx and Engels: "The bourgeoisie is a normal term (it is presented economically and socially, and re-presented by the State), the proletariat is a singular tèrm (it is presented but not re-presented), and the State

75. Ibid.

76. The material I describe and formalize in this paragraph appears in ibid., 93-103. 
apparatus is an excrescence." 77 The domain of the State is the proper class - the State, in other words, "guarantees that the [count] holds for inclusion." ${ }^{78}$ The situation, however, is what "holds for belonging." "Put more precisely," clarifies Badiou, "given a situation whose structure delivers consistent one-multiples, there is always a meta-structure-the State of the situation-which counts as one any composition of these consistent multiplicities." ${ }^{80}$

Commentators on Badiou's ontology have illustrated this point with the example of undocumented residents. ${ }^{81}$ Who or what is included or re-presented by the U.S. or any other nation state is obviously conditional upon citizenship status, financial status, criminal history, social connections, and other factors. The presence of undocumented residents, however, as they are present without re-presentation, poses an open question with respect to the legitimacy of that re-presentation. Within the legal framework of the U.S. or any other nation state, undocumented residents exceed the mechanisms of inclusion. "Their status is thus undecidable from the position of the situation," explains Gillespie, "they belong, they are not included; they are presented, but not represented." ${ }^{82}$ The concept of "citizenship" then, in any case, is an excrescence, a purely representational mechanism without any foundation in being (i.e., a proper class). The

77. Ibid, 109.

78. Ibid.

79. Ibid.

80. Ibid., 97.

81. Peter Hallward, Badiou: A Subject to Truth (Minneapolis: University of Minnesota Press, 2003), 118; Sam Gillespie, The Mathematics of Novelty: Badiou's Minimalist Metaphysics (Prahran: re.press, 2008), 71. See Notes 3.1.4.

82. Gillespie, The Mathematics of Novelty, 79. 
citizen in good-standing, by contrast, because he or she both belongs and is included within these re-presentational mechanisms, is a normal element. Finally, the undocumented resident, because he or she belongs but is not included, is a singularity. A reformist or liberal objection might suggest that undocumented residentș are not so much indiscernible singularities as they are bound to re-presentations that are "less equal" or more restricted. Undocumented residents, such a viewpoint suggests, are-included in the situation, but are not included in the way they ought to be included. The answer to this ought, then, according to liberalism, is more equality, better accommodation, and a form of inclusion that works. For Rancière and Badiou, however, politics is not liberal democratic negotiation but a declaration on the part of les sans parts through which the dominant logic of the situation must not only be transformed but must be abandoned entirely for some new order. This is what Rancière refers to as the "redistribution of the sensible. ${ }^{83}$

AXIOM SCHEME OF REPLACEMENT. If a class $F$ is a function, then for every set $X$, $F(X)$ is a set.. For each formula $\varphi(x, y, p)$, the formula below is an axiom of replacement:

$$
\begin{aligned}
& \forall x \forall y \forall z(\varphi(x, y, p) \wedge \varphi(x, z, p) \rightarrow y=z) \\
\rightarrow & \forall X \exists Y \forall y(y \in Y \leftrightarrow(\exists x \in X) \phi(x, y, p)) .^{84}
\end{aligned}
$$

The axiom of replacement implies that the consistency of a set does not depend on its members (i.e., what is counted). "The idea-singular, profound-is the following,"

83. Jacques Rancière, The Politics of Aesthetics: The Distribution of the Sensible, trans. Gabriel Rockhill (London: Continuum, 2004), 12-13, See also Jaeques Rancière, Disagreement: Politics and Philosophy, trans. Julie Rose (Minneapolis: University of Minnesota, 1999), 57-58.

84. Jech, Set Theory, 13. 
writes Badiou: "if the count-as-one operates by giving the consistency of being onemultiple to some multiples, it will also operate if these multiples are replaced, term by term, by others. ${ }^{n 5}$ The State does not depend in any way upon that which it is supposed to re-present. Badiou continues: "No more than the axioms of extensionality, separation, power set or union does the axiom of replacement induce the existence of any multiple whatsoever. ${ }^{186}$ The universal quantifier, as it operates within these axioms, already supposes a universe of multiples, while the existential quantifier, as it operates within these axioms, depends upon this supposition because it implicitly follows from this presupposed universe of multiples (e.g., "for any ... there exists").

AXIOM OF THE EMPTY SET.

\section{$\exists X \forall Y(Y \notin X)$.}

That is, there exists an $X$, such that for any $Y, Y$ is not a member of $X$, i.e., there exists a set with no members.

Both Jech and Potter follow general convention-rather than include the axiom of the empty set, they deduce the existence of the empty set as it follows from the axiom of separation:

$$
\emptyset=\{u: u \neq u\} .^{87}
$$

"This, of course," adds Jech, "only under the assumption that at least one set exists:" 88

$$
\exists X(X=X))^{89}
$$

85. Badiou, Being and Event, 65.

86. Ibid.

87 Jech, Set Theory, 8.

88. Ibid.

89. Ibid. 
While most mathematicians today do not include the axiom of the empty set but deduce its existence from the axiom of extensionality, for Badiou, the axiom of the empty set is necessary in order to establish the existence of any set whatsoever. Referring to the axioms of $\mathbb{Z F C}$, Badiou writes, "Amongst these statements, one alone, strictly speaking, is existential; that is, its task is to directly inscribe an existence, and not to regulate a construction which presupposes there already being a presented multiple. As one might have guessed, this statement concerns the void." $" 90$ The axiom of the empty set begins with the existential quantifier, while even with the axiom of infinity, an infinite set is only something implied through deduction. The other axioms presented above were of the form "for all $X$, there exists a $Y$ such that..." The existence of $Y$ in each of these formulas is only implicit relative to some other presupposed existence, that is, its existence is not asserted explicitly as with the axiom of the empty set. At some point, as Jech admits, the existence of at least one set must be assumed. For the pioneers of set theory, such as von Neumann and Gödel, this assumption was precisely the axiom of the empty set. Indeed, it was on the basis of this axiom that the whole of the natural numbers, or any multiplicity whatever, was established. For example, in a 1939 letter to John von Neumann, Kurt Gødel wrote: "One has to understand by 'sets' all objects obtained by building up the simplified hierarchy of types on an empty set of individuals (including types of arbitrary transfinite orders). ${ }^{\text {91 }}$ The natural numbers are established on the basis of the empty set as follows:

90. Badiou, Being and Event, 60 . .

91. Akihiro Kanamori, "Set Theory from Cantor to Cohen," in Handbook of the History of Logic, vol. 6 , eds. Dov M. Gabbay, Akihiro Kanamori. and John Woods (Amsterdam: Elsevier, 2012), 39. 


$$
\begin{gathered}
0=\emptyset \\
1=\{\varnothing\} \\
2=\{\varnothing,\{\varnothing\}\} \\
3=\{\varnothing,\{\varnothing\},\{\varnothing,\{\varnothing\}\}\} \\
\text { etc. }{ }^{92}
\end{gathered}
$$

There is a double movement here between the empty set as the basis of every count and the empty set as the only thing that is not counted. "It must certainly be assumed that the effect of structure is complete," Badiou writes, "that what subtracts itself from the latter is nothing [i.e., the empty set]. ${ }^{193}$ The atomic formula of membership, the count, leaves nothing out, and so it is only nothing, as what is not counted, that is subtracted from the "law of the count," that is, les sans parts.

The "count" with which I began this section, any count, is an operation predicated on some set of axioms such as those comprising $\mathbb{Z R C}$. In terms of $\mathbb{Z F C}$, every element that is a member of a set belangs to that set (e.g., undocumented residents belong to the situation in which they reside) ${ }^{94}$ In relation to their belonging, some, though not all, of these elements can be classified, that is, inscribed in terms of inclusion in some class (e.g., undocumented residents are not included in the State of the situation in which they reside). Not only does $\mathbb{Z R C}$ provide an image of the basis of the computable, in the sense that complexity classes, Turing machines, and the rest, including the ontologies of information management, require similar axioms in order to be defined, it is also provides a generic image of the count. In this way, it could be called the "generic thought of Being."

92. J. von Neumann, "Zur Einfuhrung der transfiniten Zahlen," Acta Scientiarum Mathematicarum (Szeged), 1, no. 4, (1922-1923): 199-208.

93. Badiou, Being and Event, 54.

94. See Notes 3.1.5. 
When we analyze the axioms of set theory, the following six points become clear. Firstly, the identity of an element is only ever its in-difference in relation to belonging. Secondly, although every member of a set belongs to that set, these members can be classified and separated, that is, included in different classes to varying degrees and in different ways, or not included at all. Thirdly, these classifications and separations are always second-order (i.e., re-presentations of some initial presentation, e.g., both documented and undocumented resident belong, but by way of a second-ordering, each is included differently, or the latter is not included at all), and the details of such classifications and separations in no way depend upon what they are supposed to be classifying and separating. In terms of the generic thought of Being (i.e., $\mathbb{Z} \mathbb{F C}$ ), and in keeping with an apparatus' lack of foundation in being, an apparatus would be the mechanism of such classifications and separations. In other words, in keeping with an apparatus' lack of foundation in being, these operations are anterior or excrescent in relation to the beings they would inscribe; second-order in nature, any axiom of the form "for every $X$ there exists a $Y$ ". already presupposes the existence of some $X$. Fourthly, only the axiom of the empty set makes an outright assertion of existence; therefore, the foundation of any count (in terms of its axiomatic basis) is nothing (i.e., the empty set, which contains nothing). Fifthly, it follows that in terms of the generic thought of being (i.e., $\mathbb{Z F C}$ ), the operations (i.e., classifications and separations) of an apparatus are always working in another direction than towards the untouchable nothing that they are supposed to inscribe, because it is precisely this nothing that is the limit of their foundation, that is, they are always working to "foreclose the void" of the empty set; operations of separation and classification work in another direction (i.e., "away from" whatever [membership] 
minimal element). Lastly, and also in terms of $\mathbb{Z F C}$, politics would be any activity that reconfigures the measure of excrescence the second-order holds over the first. "The consequence of these theses is that politics can be defined therein as an assault against the State, whatever the mode of that assault might be, peaceful or violent. It 'suffices' for such an assault to mobilize the singular multiples against the normal multiples by arguing that excrescence is intolerable." 95

\subsubsection{Control Theory}

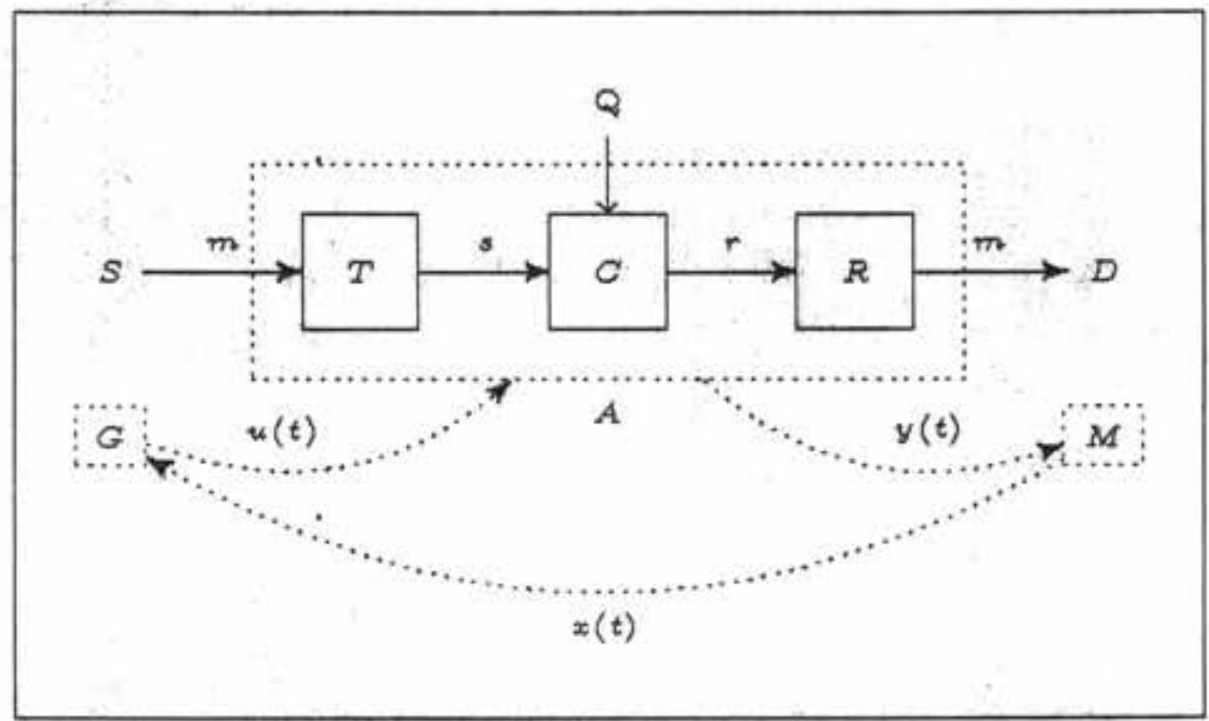

Figure 4. A Control System, shown here as the dotted lines and arrows encapsulating Shannon's five functions, which were provided in Figure 1. Here $G$ represents power (e.g., the sovereign, government, social management, etc.); $\boldsymbol{A}$ is the system or apparatus itself; and $\boldsymbol{M}$ is the quantification, measurement, or inscription of the system's variables to the end of actuating their control.

In engineering and mathematics, control theory concerns the behavior of systems. Design in control theory usually aims to achieve system stability, that is, a bounded output for a bounded input (BIBO). This objective might include disturbance rejection,

95. Ibid., 110. See Notes 3.1.6. 
input tracking, or passivity in relation to uncertain parameters. An overview of control theory, including its algebraic language of inscription, reveals correspondences between the notion of an apparatus and the concept of a "controlled" system.

Discussions of Shannon's five functions (in addition to emphasizing the fact that information theory understands information as something distinct from meaning) are found frequently in political theories about control societies. The communication mathematized within and by these functions, however, is a much less significant dimension of control societies than is the control to which such communication can be bound: a control mathematized elsewhere, and represented in Figure 4. In this figure, I underline the precedence of control over communication, in that I place the five functions within a generic control system. $T, C$, and $R$ are all in the plant (the controlled system), $A$ and $M$ are the measurement of this plant, and $G$ is the control mechanism.

A system is nonlinear if it is neither additive nor homogenous, that is, if at least one of its variables, so to speak, is a "queer," or in the language of the previous section, some multiple "standing at the edge of the void." Most systems of power (e.g., government, social management, etc.) have nonlinear components, Control theory represents a basic nonlinear control system as the state-space model:

$$
\begin{aligned}
\frac{d}{d t} x(t) & =g(x(t), u(t)) ; x(0) x_{0} \\
y(t) & =m(x(t), u(t)) .
\end{aligned}
$$

Here $x(t) \in \mathbb{R}^{n}$ is the state vector, $u(t) \in \mathbb{R}^{m}$ is the vector of input signals, and $y(t) \in \mathbb{R}^{q}$ is the output vector. This model, surprisingly, can be deployed to model and control most nonlinear systems, from particle dynamics to biology. In reference to Figure 4 , for example, the transmitter $T$, channel $C$, and receiver $R$ are all mechanisms included 
within the system, that is, within the apparatus $A$, which control theory refers to as the plant. These mechanisms are unimportant in themselves; that is, in control theory, they are regarded merely as the black boxes to be controlled, and their interiority is of no consequence whatever. Note that the queers $Q$, in addition to the sender $S$, the message $m$, and the destination $D$, remain beyond control. In relation to the control system itself, which I represent using dotted lines, there is firstly a vector of inputs $u(t)$, which are fed from the controller $G$ into the apparatus $A$. These inputs are deployed in order to control or track the queers and messages within the apparatus using negative feedback and other mechanisms, which 1 explain in detail below. The inputs are fed through the apparatus into a vector of outputs $y(t)$, which are then inscribed or measured by $M$. From this point, a vector of quantified states $x(t)$ is fed into $G$ for processing, in order to calculate the optimal input for the control of $A$. Formally, the system is a triple $(M, A, G)$, where $M$ is the set of qualification mechanisms, $A$ is the system to be quantified and controlled, and $G$ is the set of evolution or transfer functions $G: U \subset M \times A \rightarrow A$ with input $U$. These functions map the elements belonging to $A$ onto a unique image depending on $t$, called the evolution parameter apparatus, using negative feedback and other mechanisms I explain in detail below. More precisely, as $\dot{x}=g(t), y=m(x, u)$.

The term "black box" originated in the wartime research of the MIT Radiation Laboratory, where it was first used in relation to the black boxes encasing radar and electrical equipment such as amplifiers, receivers, filters, and so on. In relation to Wiener's anti-aircraft research, the significance of the term is that anything (artillery, aircraft, pilot, etc.) can be understood simply as a variable to be controlled, regardless of its inner constitution. With respect to the system in Figure 4, for example, $T, C$ and $R$ are 
black boxes, and while the behavior of these boxes might be intelligible in terms of their respective inner constitutions, control theory regards such factors as inconsequential. Control theory limits its purview to their behavior from one state to the next. "Negative feedback" designates the process of predicting and controlling a black box's action. Wiener defines negative feedback as "the property of being able to adjust future conduct by past performance." ${ }^{\prime 96}$ For Wiener, the question of teleology is not a question of causality: "[T]he concept of teleology shares only one thing with the concept of causality, a time axis. [...] Causality implies a one-way, relatively irreversible functional relationship, whereas teleology is concerned with behavior, not with functional relationships." ${ }^{97}$

The concept of equilibrium points helps explain why control theory places more importance on the behavior amongst and between black boxes than on their causes or interiority. Formally, in the nonlinear system $\dot{x}=f(x)$, a point $x_{e}$ in the state vector is an equilibrium point if $f\left(x_{e}\right)=0$. An equilibrium point is any state variable that behaves exactly as it is expected it to; that is, an equilibrium point is a fully actuated point. Following from equilibrium points, there are equilibrium pairs, equilibrium triples, and so on. In the nonlinear system $\dot{x}=f(x, u)$, for example, the pair $(x, u)$ is an equilibrium point if $f\left(x_{e}, u_{e}\right)=0$. Control theory can determine an equilibrium point relationally, as between two or more state variables, and so mobilize that newly determined point to the end of actuating the design of its control. Indeed, the problem of optimization in control theory is precisely the problem of locating these points, or finding global or local

96. Norbert Wiener, The Human Use of Human Beings: Cybernetics and Society (New York: Avon Books, 1967), 33.

97. Arturo Rosenblueth, Norbert Wiener, and Julian Bigelow, "Behavior, Purpose, and Teleology," Philosophy of Science no. 10 (1943): 377. 
extrema, that is, the global or local minima and maxima, of any system.

In the strict sense, system stability is not always achievable, and so this leads to concepts such as Lyapunov stability, where variables with an initial state near enough to some equilibrium point remain near to that equilibrium point indefinitely and so exhibit a behavior useful for their control. Lyapunov's method is the most general approach to the stability analysis of nonlinear systems. The method involves a generalized differential function with a strict minimum at some equilibrium point, or some estimate about the domain of attraction of some equilibrium point. Linearization, another method of system analysis and control design, involves the transformation of the state variables of some nonlinear system into an equivalent linear system, or an approximate linear model of the controlled system, most often through local linearization around some equilibrium point. Setting aside formal notation for the moment, linearization and other such mechanisms might collapse the behavior of the black boxes in any system into a lower-dimensional space in such a way as to render their behavior more controllable. Designs involving gain deploy linear controllers for some range or norm of gain intensity, determining the appropriate controller according to the current system state.

Control theory has recognizable applications in control societies. Ian Ayers provides the example of the American casino chain Harrah's. While guests of the casino are gambling, the company tracks their outcomes through a "total rewards loyalty card." The company then uses an algorithm that estimates each guest's personal "pain point," which is the maximum level of loss the guest can endure before leaving the casino. Before this pain point is reached, a "luck ambassador" will approach the guest: "I see you are having a bad day. I know you like our steakhouse so I'd like to take you to dinner on 
us right now." 98 In this way, the company controls behavior through the use of negative feedback.

The tracking of Web use furnishes more precise examples. The "digital footprints" generated by tracked online activity increasingly resemble the total rewards loyalty card. Andrew Pole, a statistician for the Target corporation, for example, develops software designed to calculate information related to users of the Target website. The software assigns each user a "Guest ID number," which monitors everything they purchase and more. "If you use a credit card or a coupon," explains Pole, "or fill out a survey, or mail in a refund, or call the customer help line, or open an e-mail we've sent you or visit our Web site, we'll record it and link it to your Guest ID."99 The algorithms, for example, might target expectant motherș-as Pole explains, "We knew that if we could identify them in their second trimester, there's a good chance we could capture them for years [...]. As soon as we get them buying diapers from us, they're going to start buying everything else from us too." ${ }^{100}$ A Guest ID number can link together a wide array of consumer information, including age, marital status, number of children, address, salary, Web browsing history, and more: "Target can buy data about your ethnicity, job history, the magazines you read, if you've ever declared bankruptcy or got divorced, the year you bought (or lost) your house, where you went to college, what kinds of topics you talk about online, whether you prefer certain brands of coffee, paper towels, cereal or applesauce, your political leanings, reading habits, charitable giving and the number of

98. Ian Ayers, Super Crunchers (New York: Bantam Books, 2007), 173.

99. Charles Duhigg, "How Companies Learn Your Secrets," New York Times Magazine, February 16, 2012, http://www.nytimes.com/2012/02/19/magazine/shopping-habits.html.

100. Tbid. 
cars you own."101

The world's nation-states have begun to pursue the types of data mining pioneered by corporations such as Harrah's and Target. Fusion centers form part of a surveillance system put in place as a means for streamlining intelligence between local, state, and federal agencies in the United States. There are at least seventy such centers operative in the US, at least one in every state, and their numbers are growing. By way of such centers, a surveillance camera may capture a video of someone with a pair of binoculars and a notepad outside a likely attack target and flag this as suspicious behavior. Depending on the weight of the flag, this video could then be passed along to a fusion center for more in-depth analysis. The heavily fortified $\$ 2$ billion Utah Data Center, made possible by the extremely large NSA budget awards following September 11, 2001, stores large amounts of data on everyone and everything it can, estimated to be on the order of exabytes, that is, approximately seventy-five digital compact discs of data for every person on the planet. As a result of the Edward Snowden leaks, it became widely known that the NSA freely shares this information with other federal law enforcement agencies such as the FBI and the DEA. ${ }^{102}$ The rapidly increasing amount of information that is being collected and the ever more efficient mechanisms being designed to predict and control the sources of this information are enabling increasingly effective strategies of security and calculated violence. The adjudication of military forces, explicit air, ground, and naval movements, intelligence gathering, detailed logistics modeling, and the rest are all strategically calculated using extremely large amounts of data processed through

101. Ibid.

102. Kristina Cooke and John Shiffinan, "U.S, directs Agents to Cover Up Program Used to Investigate Americans," Reuters, August 5, 2013, http://www.reuters.com/article/2013/08/05/us-dea-sodidUSBRE97409R20130805. 
attrition algorithms run on supercomputers. Data mining and the social control designs it enables serve to inscribe the social and the dividual in control societies.

\subsubsection{Metrics}

Stylometry is the computational analysis of a text in order to identify its author, that is, in order to compute an "identity" class label. The related field of affect analysis is an extension of stylometry carried out in order to identify the sentiments, opinions, proclivities, and so on, contained in any text. Finally, another related field, predictive analytics, forecasts the probable future behavior of these identities and affects on the basis of their recorded histories. These forms of textual analysis and classification grew out of earlier philological and quantitative analyses of literature. In 1851, English logician Augustus de Morgan had already suggested that authorship might be determined through the quantification of frequency distributions of word lengths amongst and between different literary works. Thomas Mendenhall later applied de Morgan's ideas to the work of Shakespeare. In 1964, stylometry enjoyed a renewed interest when Frederick Mosteller and David Wallace used a Bayesian inference algorithm to identify the authors of twelve disputed Federalist Papers.

The advent of the WWW has occasioned an explosion of stylometry, affect analysis, predictive analytics, and related fields, under the general umbrella of "data

mining." Many of the globe's largest corporations now orient their businesses around data mining strategies. The most well-known example is the Google corporation, whose original mission was to organize the massive amounts of information on the WWW for more effective searching. In 2007 , however, the company stated its future ambitions: "To 
enable Google users to be able to ask questions such as 'What shall I do tomorrow?' and 'What job shall I take?"'103 In order to realize these ambitions, Google would need to collect, collate, and process ever more personal data using ever more sophisticated algorithms.

Taking advantage of breakthroughs in data mining has become increasingly imperative for many businesses. In a recent business best seller, Competing on Analytics: The New Science of Winning, ${ }^{104}$ for example, the authors argue that by using the same machine learning algorithms that Google uses to collect information about its customers, businesses in many fields can make predictions about the future behavior of their customers. Such tracking mechanisms generate the disaggregated subject referred to by Deleuze as the dividual. "Already in the early 1990s," writes Tiziana Terranova,

[t] he marketing literature was describing the shift from new media to the Internet in terms of information targeting strategies. The Néw Economy apologists, for example, famously postulated three stages of media power: broadcasting, narrowcasting and pointeasting. The latter corresponded to a digital mode in which messages were not simply directed at groups but tailored to individuals and even sub-individual units (or as Gilles Deleuze called them, 'dividuals,' what results from the decomposition of individuals into data clouds subject to automated integration and disintegration). ${ }^{105}$

The data collected with these technologies does not represent the person as an individual case; rather, it inscribes the person as a vector of measurements: features, trajectories, class labels, and the rest. The dividual, as it is inscribed by algorithms, is pursued to the point where it becomes a set.of disparate multiplicities. "It is not simply a matter of catering for the youth or for migrants or for wealthy entrepreneurs," explains Terranova,

103. Karl Palmás, "Predicting What You'll Do Tomorrow: Panspectric Surveillance and the Contemporary Corporation," Surveillance \& Society 8, no. 3 (2011): 347.

104. Thomas H. Davenport and Jeanne G. Harris, Competing on Analytics: The New Science of Winning (Cambridge, MA: Harvard Business:Press, 2013).

105. Terranova, Network Culture, 34. 
"but also that of disintegrating, so to speak, such youth/migrants/entrepreneurs into their micro-statistical composition-aggregating and disaggregating based on better management or improved security. Web logs (blogs), for example, present what one information management article describes as a "wealth of information that can be very helpful in assessing the general public's sentiments and opinions." 106 To what end? The paper continues: "[W] study the problem of mining sentiment information from blogs [in order to] use such information for predicting product sales performance." ${ }^{107}$ Affect analysis is of special interest because, as another article explains, "affects play an important role in influencing people's perceptions and decision making." 108 In another article, the authors begin by pointing out that " $[t]$ he Internet is often used for the illegal sale and distribution of software. It also serves as an attractive medium for hackers indulging in online attacks and cyber-wars. Furthermore, internet-based communication is swarming with fraudulent schemes, including email scams." ${ }^{109}$ For example, the introduction to another article mentions "threatening or offensive messages, child pornography, and the distribution of stolen properties." 110 Another article explains the utility of developing programs capable of discerning such threats: "As the incidence of computer related crime increases it will become increasingly important to have

106. Yang Liu, Huang Xiangji, An Ajun, and Yu Xiaohui, "ARSA: A Sentiment-Aware Model for Predicting Sales Performance Using Blogs," in SIGIR'07, July 23-27, 607.

107. Ibid.

108. Ahmed Abbasi and Hsinchun Chen, "Affect Intensity Analysis of Dark Web Forums," in IEEE Transactions on Knowledge and Data Engineering 20, no. 9 (2007), 1168.

109. Ahmed Abbasi and Hsinchun Chen, "Writeprints: A Stylometric Approach to Identity-Level Identification and Similarity Detection in Cyberspace," ACM Transactions on Information Systems 26, no. 2(2008): 71.

110. Rong Zheng, Li Jiexun, Hsinchun Chen, and Zan Huang, "A Framework for Authorship Identification of Online Messages: Writing-Style Features and Classification Techniques," Journal of the Association for Information Science and Technology 57, no. 3 (2006): 378. 
techniques that can be applied in a legal setting to assist the court in making judgments." ${ }^{111}$ Articles in this area tend to present anonymity as an obstacle to be overcome.

The need to overcome anonymity has led to the development of metrics that quantify the degrees of anonymity afforded by particular communication networks. The anonymity afforded by the Tor network, for example, has made it an attractive alternative to the WWW. On the Tor network, the client automatically specifies a random path through proxies, through which any information being sent must pass before it reaches its destination. From each proxy to the subsequent proxy, this information is encrypted and reencrypted, and in any case, it only reveals the address of the next proxy and nothing in relation to its origin or final destination. As Geoffrey Goodell explains, "The successive layers of encryption shape the 'onion' analogy: each successive proxy 'unravels one layer of the onion' to expose the identity of the next proxy to which to forward the datagram. The result is that, in theory, each proxy in the chain knows nothing about the chain itself other than the identities of the previous proxy and the next proxy in the sequence."112 All manner of contraband is readily available for mail order from peer-reviewed marketplaces on the Tor network, and the use of an encrypted form of electronic currency called "bit coins" ensures anonymity on every level of these transactions. The authorities of various interested countries have been unable to do anything to shut these marketplaces down. The so-ealled "hidden services" the Tor network provides do not

111. Andrew R. Gray and Stephen G. MacDonell, "Software Forensics: Extending Authorship.Analysis Techniques to Computer Programs," in Third Biennial Conference of the International Association of Forensic Linguistics, (1997), 1.

112. Geoffry L. Goodell, Perspective Access Networks (Cambridge, MA: Harvard University Press, 2006), 62. 
have any address for these authorities to seize because their location at any given moment is known only to the network itself.

Many articles in information management explain the importance of stylometry, affect analysis, and related metrics with observations such as "[E]xtremist groups often use the internet to promote hatred and violence [providing] a ubiquitous, quick, inexpensive, and anonymous means of communication [...]. Consequently many believe that the Internet operates as an ideal method for such groups to disseminate information and spread propaganda." ${ }^{113}$ Here, "affect analysis is useful for measuring the presence of hate, violence, and the resulting propaganda dissemination across extremist groups."114 Another security concern addressed in such articles is "sock-puppetry," that is, the creation of a fake online identity in order to praise, defend, or create the illusion of support for some brand or company. An article concerning "chat bots," however, provides the most telling reason given for the necessity of developing stylometry. In this article, the authors explain that the "abuse of chat services by automated programs, known as chat bots, poses a serious threat to Internet users." ${ }^{115}$ Chat bots are programs designed to dupe people into thinking they are chatting online with another person. Such programs are most often used for marketing. They play-act at being a person, becoming "friends" with people through online social networks, only to make subtle suggestions from time to time in relation to marketing some product. These programs can be so convincing that

113. Jiexun Li, Hsinchun Chen, and Zan Huang, "A Framework for Authorship Identificationof Online Messages: Writing-Style Features and Techniques," Journal of the American Society for Information Science and Technology 57, no. 3 (2006): 378.

114. Abbasi and Chen, "Affect Intensity Analysis of Dark Web Forums," 282.

115. Steven Gianvecchio, Xie Mengjun, Wu Zhenyu, and Wang Haining, "Measurement and Classification of Humans and Bots in Internet Chat," in 17th Conference on Security Symposium (Berkeley: USENIX Association, 2008), 155. 
some people have even fallen in love with them. Robert Epstein recounted his own experience with one such program. Epstein was looking for a date online and contacted a woman named "Amélie Poulain." "She responded to my e-mail quite affectionately," explains Epstein, "[and] her e-mails [were] so warm that I continued to correspond with her." 116 By the end of their correspondence, however, Amélie was no longer able to pass the test: "[A]t that point," explains Epstein "I wrote: asdf;kjas;kjI;jkjj ;kasdkljk ;klkj 'klasdfk; asjdfkj. With love, Robert. And [she] reacted with another long letter about her mom." 117 Stylometry may be mobilized to develop programs that impersonate people, but might also be used to discern the presence of such programs on the basis of the same data.

Where stylometry would be brought to bear on such a phenomenon-for example, a stylometric feature set could be used by an natural language generation (NLG) framework in order to generate a convincing conversational "person" or used to detect whether the "person" one was conversing with was actually a chat bot-it would be done in the form of a program designed to either deceive people into thinking that it was another person through the mobilization of stylometric data or to discern the presence of such programs on the basis of the same data. With the latter of these two alternatives, we have something similar to the Voight-Kampff test imagined in Philip K. Dick's Do Androids Dream of Electric Sheep?. This test is intended to distinguish a human from an android. The Turing test, on the other hand, works in the opposite way; it is a test designed to determine whether a person and computer have become indistinguishable.

116. Robert Epstein, "From Russia, with Love," Scientific American Mind, October 2007, http://www.nature.com/scientificamericanmind/journal/v18/n5/full/scientificamericanmind1 $007-16$.html.

117. Ibid. 
For example, in the Turing test, a person engages in a conversation by way of a computer terminal, and is asked to determine whether the person he or she is conversing with by way of that terminal is really a person at all. If and when the human test subject is no longer able to tell a program from a person, the Turing test has been passed.

Given Epstein's remarks above, it is reasonable to suggest that programs capable of passing this test were already developed years ago. Even so, for the last several years a handful of "Futurists" have patiently been awaiting and speculating upon this coming event, which they call the "technological singularity." This cultural phenomenon is loosely affiliated with the popular TED (Technology, Entertainment, Design) lectures, a global set of conferences owned by the Sapling Foundation and carried out under the slogan "ideas worth spreading." One popular author who writes about the technological singularity and who recently opened a "Singularity University," Raymond Kurzweil, has given many lectures for TED. It should be mentioned that Kurzweil follows a strict regime of dietary supplements, vitamins, and other "Iongevity products," out of a conviction that the soon-to-appear technological singularity will offer him eternal life. Already in 1951, Alan Turing spoke of machines outstripping humans intellectually: "[O]nce the machine thinking method has started, it would not take long to outstrip our feeble powers. [...] At some stage therefore we should have to expect the machines to take control."118 In 1965, Irving John Good referred to this as an "intelligence explosion." Good wrote, "Let an ultraintelligent machine be defined as a machine that can far surpass all the intellectual activities of any man however clever. Since the design of machines is one of these intellectual activities, an ultraintelligent machine could design even better 
machines; there would then unquestionably be an 'intelligence explosion,' and the intelligence of man would be left far behind. Thus the first ultraintelligent machine is the last invention that man need ever make,"

In 1983, mathematician and author Vernor Vinge popularized Good's notion of an intelligence explosion, giving it the new name: "We will soon create intelligences greater than our own. When this happens, human history will have reached a kind of singularity, an intellectual transition as impenetrable as the knotted space-time at the center of a black hole, and the world will pass far beyond our understanding. This singularity, I believe, already haunts a number of science-fiction writers."120 This sort of discourse is common in control societies. In some instances, for example, such discourse suggests that people would appear to ultraintelligence as "insects appear to people." Neil deGrasse Tyson, a popular scientist, claims this is exactly how ultraintelligence would regard people, stating: "You don't walk by the worm on the street and say, 'Gee, I wonder what he's thinking.' No, you step on the worm."121

The point could be driven home with more examples, statements of other popular scientists such as Stephen Hawking and Carl Sagan, but the idea is the same in any case. Setting aside the explicitly colonial overtones for the moment-and also the objection that animals such as the blue whale already seem to regard people as people would regard a worm-not only is the meaning of "intelligence" something that is taken for granted, but degrees of intelligence are supposed to correspond to degrees of relative worth. In

119. Irving John Good, "Speculations Concerning the First Ultraintelligent Machine," in Advances in Computers, eds. Franz L. Alt and Morris Rubinoff (Waltham, MA: Academic Press, 1966), 33.

120. Vernor Vinge, "First World," Omni, (January, 1983), 1.

121. Business Insider. 2013. You Tube video, 3:32, 7/1/2013, https://www.youtube.com/watch?v=TtouVsd8tss. 
this discursive field, then, one is asked to forget the fact that being is and suppose instead that it could somehow be worth more than that. Whether worm or human, there is some minimal degree of sense involved in any biological organism (and perhaps even nonbiological objects); the supposition here, however, is that if some greater degree of sense were involved, for example, if there were some entity with twenty senses in addition to the five human senses, able to occupy one hundred more dimensions than the four known to human beings, an entity capable of instantly calling to mind every positive fact its species knows in relation to materiality and to perform calculations on them at a boundary of mathematics so vastly more complex than anything available to human beings that it would be incomprehensible to them, then that entity would somehow be more here, that is, worth more and/or more intelligent than a human being. Given such an entity, and even if such an entity knew every move a person would make before the person even moved at all, it still has not been explained how such an entity would be anymore here in the element of its sense than a person or a worm - at least, not any more than it could be supposed that literate peoples are more here than oral peoples. In addition to this, the groundwork for something unquestionably disastrous is being laid by narratives that ascribe a hierarchy of worth in terms of dubious categories such as intelligence. This notion of an ultraintelligence forms a necessary component in relation to how such things as the inevitable "conversational" interfaces of large search engines will be regarded, that is, such interfaces will almost certainly be regarded as ultraintelligences who ought to (and by right) regard human beings as human beings are supposed to regard worms.

Already, the Google corporation's search engine auto-completes search inquiries 
(Figure 5), and so it is reasonable to speculate, given the large amounts of data Google has in relation to each of its users, that its interface will soon become more conversational in nature. In the near future, using the types of technology I examine in this section, the Google search engine will almost certainly begin offering advice and opinions, making uncanny predictions, and the rest. Here, the groundwork is laid that such a thing, whether "truly self-aware" or whatever, will be regarded as an ultraintelligence within this field of discourse - the doxa around the technological singularity, intelligence, and so on - and should, by all rights, consider people as "people consider worms."

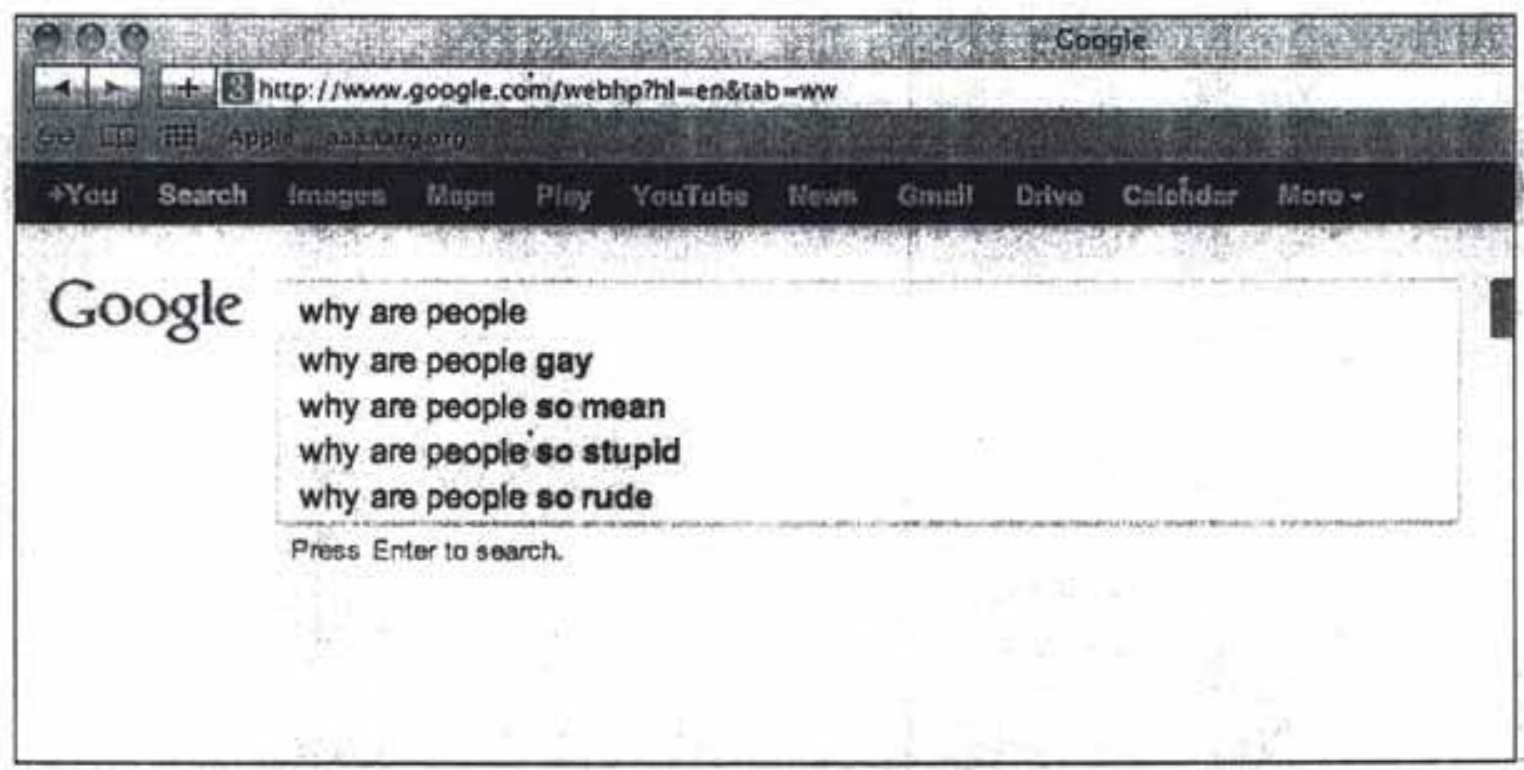

Figure 5. Google Autocomplete. The text in bold represents the suggested completion of "why are people...." Google search page, accessed 6/1/2012, http://www.google.com. Copyright 2012, by Google: "Autocomplete helps you find information quickly by displaying searches that might be similar to the one you're typing. For example, as you start to type [why are people], you may be able to pick searches for other 'why are people'-related search queries."

Affect analysis relies on the data contained on sites where users post their

122. See Notes 3.1.7. 
thoughts, reactions, beliefs, and feelings. Affect analysis programs troll the WWW, classifying the emotions of people in relation to products and events. Here the most important dimensions are speed and volume: processing as many posts and messages in real time as is possible in order to deliver "relevant and actionable answers fast." ${ }^{123}$ The goal is not comprehension; rather, it is the classification of information flows. One affect analysis company described an application that "automatically evaluates conversations based on sentiment [...] to deliver feedback about your products and brands. By automating the process, we can significantly reduce the time needed to analyze conversations." 124 The goal here is not to understand but to effect, to abstract affect from a person, to promote action, or, in some cases, to foreclose it. A sentiment analysis company, for example, promises "real time tracking of 'detractors' to minimize the impact and velocity of negative word-of-mouth." 125 A complementary application seeks out influential members of brand communities, "inspirational consumers," in order to amplify their positive reviews.

In addition to its importance for marketing and forensics (e.g., threat detection), affect analysis has assumed a central role in the design of "emotionally believable" interfaces. Joseph Bates's article "The Role of Emotion in Believable Agents" explores how emotion might be brought to bear on the design of programs. "There is a notion in the Arts," writes Bates, "of a 'believable character.' It does not mean an honest or reliable character, but one that provides the illusion of life, and thus permits the audience a

123. Mark Andrejevic, "The Work that Affective Economics Does," Cultural Studies 25, no. 4-5 (2011): 604.

124. Tbid.

125. Ibid. 
suspension of disbelief." ${ }^{126}$ The primary objects Bates explores in this study are animated characters. He quotes Disney animators Frank Thomas and Olli Johnston: "Disney animation makes audiences really believe in [...] characters, whose adventures and misfortunes make people laugh-and even cry. There is a special ingredient in our type of animation that produces drawings that appear to think and make decisions and act of their own volition; it is what creates the illusion of life." ${ }^{127}$ Bates concludes with three points: first, the emotional state of the interface must be clear at each moment; second, the visible "thought process" is what defines this emotional state; and third, the emotion must be exaggerated.

In "Computers are Social Actors," Clifford Nass, Johnathan Steur, and Ellen Tauber suggest that person-computer interactions are already social. The authors situate the utility of their article in its "numerous [...] implications for design, [and] approaches to usability testing." 128 . The article suggests that people apply "politeness norms" to computers, based on the finding that people asked by a computer about its own performance feel more compelled to be positive in their response than are users asked about the computer by another source. The authors also attempt to determine whether people apply notions of self and other to computers. They argue that people do apply such notions to computers, citing a study in which respondents regarded self-criticism on the part of the computer as "friendlier" than its criticism of others but also regarded the computer's criticism of others as more "intelligent" than its praise of others. The same

126. Joseph Bates, "The Role of Emotion in Believable Agents," Communications of the ACM 37, no. 7 (1994): 123.

127. Frank Thomas and Olli Johnston, The Illusion of Life: Disney Animation (New York: Hyperion, 1995), 12.

128. Clifford Nass, Jonathan Steuer, and Ellen R. Tauber, "Computers Are Social Actors," in SIGCHI Conference on Human Faotors in Computing Systems (New York: ACM, 1994): 75. 
study also determined that people praised by computers will perform any task in a manner superior to those criticized by the computer.

"Human-sounding" voices, Nass, Steuer, and Tauber conclude, are essential to eliciting these responses. "Voice, and not box," they write, "is the primary determinant of the locus of social attributions toward computers." ${ }^{29}$ In one study they cite, subjects consistently perceived a different computer with a different voice as a distinct social actor. "As in the politeness study," they remark, "subjects used inappropriate social rules in assessing machine behavior." ${ }^{130} \mathrm{~A}$ further study examined in the article found that users prompted by interface voice differences also "apply gender stereotypes to computers": Praise from interfaces with male voices was more convincing and likeable than praise from interfaces with female voices, while computers with female voices "knew more" about "love and relationships."131 The authors discard the conclusion that such social responses were based on a mistaken belief that subjects were interacting with some agent other than the computer, the programmer, for example. "This study demonstrates that users do make social attributions toward the computer itself," they write, "and provides some evidence that the computer referring to itself as ' $\mathrm{I}$ ' is not necessary to generate such attributions. Thus, computer users who respond socially to computers do not feel as though they are interacting with a programmer, rather, they attribute socialness directly to the computer itself. Computer self-reference using ' $\mathrm{I}$ ' is not essential to generating this response., ${ }^{132}$

129. Ibid.

130. Ibid.

131. Ibid.

132. Ibid, 
Another study uses stylometry to identify the perspective from which a given document was written. By "perspective," the authors of the study explain, "[we mean] subjective evaluation of relative significance, a point-of-view." ${ }^{133}$ The examples provided in the study are instructive: two paragraphs regarding the situation of Israelis and Palestinians. The first paragraph, the authors state, is written from an Israeli perspective, while the second paragraph is written from a Palestinian perspective: "Anyone knowledgeable about the issues of the Israeli-Palestinian conflict can easily identify the perspectives from which the above examples were written." 134 The paragraph supposedly written from the Israeli perspective, for example, mentions "Palestinian terrorists" and defends the "inadvertent killing" of Palestinian civilians as retribution for the killing of Israeli civilians by Palestinian suicide bombers. The paragraph supposedly written from the Palestinian perspective refers to the "brutality of Israel" and Israel's killing of "tens of unarmed protestors." The authors set out to determine whether computers can "learn to identify the perspective of a document given a training corpus" and to develop "algorithms for learning perspectives using a statistical framework."135

Such algorithms would remove the necessity of dealing with the interpretative challenges posed by disparate perspectives, languages, and situations. They replace the traditional imperatives of interpretation with the task of designing a program capable of measuring and quantifying such perspectives in order to enable effective prediction and management. Chris Anderson, 'the editor of Silicon Valley's Wired magazine, celebrates

133. Wei-Hao Lin, Theresa Wilson, Janyce Wiebe, and Alex Hauptmann, "Which Side Are You On? Identifying Perspectives at the Document and Sentence Levels," in Tenth Conference on Computational Natural Language Learning (Stroudsburg: Association for Computational Linguistics, 2006), 111.

134. Ibid.

135. Ibid. 
the possibility of such models and even calls for the "end of theory": "This is a world where massive amounts of data and applied mathematics replace every other tool that might be brought to bear. Out with every theory of human behavior, from linguistics to sociology $[\ldots]$. Who knows why people do what they do? The point is they do it, and we can track and measure it with unprecedented fidelity. With enough data, the numbers speak for themselves [...]. There's no reason to cling to our old ways. It's time to ask: What can science learn from Google? [my emphasis]"136

Stylometric analysis techniques can be broadly categorized into supervised and unsupervised methods. Supervised techniques require class labels, while unsupervised techniques do not require these labels. Class labels can be anything, for example, the features common to a set of documents written by the same author. Supervised techniques include support vector machines (SVMs), artificial neural networks (ANNs), decision trees, and linear discriminant analysis.

SVMs apply to a number of information management tasks. In the field of social management, for example, there is Crystal, a system for predicting the outcome of public office elections using opinions mined from the WWW. ${ }^{137}$ SVMs have been used to "mine the peanut gallery," that is, for "semantic classification of product reviews." ${ }^{\text {138 SVMs }}$ have also been used to develop humor recognition in computers. In one article on the topic, the authors claim that "through experiments performed on large data sets, we show

136. Chris Anderson, "The End of Theory: The Data Deluge Makes the Scientific Method Obsolete," Wired 16, no. 7 (2008): 24 .

137. Soo-Min Kim and Eduard Hovy, "Crystal; Analyzing Predictive Opinions on the Web," in 22nd International Conference on Computational Linguistics (Stroudsburg, PA: Association for Computational Linguistics, 2008): 473-480.

138. Dave Kushal, Steve Lawrence, and David M. Pennock, "Mining the Peanut Gallery: Opinion Extraction and Semantic Classification of Product Reviews," in /2th International Conference on World Wide Web (New York: ACM, 2003), 519. 
that automatic classification techniques can be effectively used to distinguish between humorous and non-humorous texts, with significant improvements observed over a priori known baselines." ${ }^{139}$ Finally, SVMs have even shown promise in detecting deception: "We have designed an automatic classifier based on Support Vector Machines (SVM) for the identification of deception in an ad hoc opinion corpus. [...] These findings are potentially applicable to areas such as forensic linguistics and opinion mining, where extensive research [...] is needed." 140

Artificial neural networks (ANNs) are information processing models that imitate. the biological nervous system. The network consists of a large number of interconnected nodes called "neurons," which work together in solving problems such as data classification, pattern recognition, or image understanding. ANNs learn by example and can perform adaptive learning, self-organizing, and fault tolerance. Alan Turing, when he explored the technical feasibility of machines learning to speak, assumed that speech would be learned not by mere computers but by robots equipped with sensors and effectors, that is, robots with some knowledge or embodiment within an environment. However, this environmental knowledge in robots would also remain hidden from the programmers who started them up with the initial codes. The so-called "hidden layers" in today's artificial neural networks, observes Kittler, present a good example of this obscurity: "[E]ither we write code that in the manner of natural constants reveals the determinations of the matter itself, but at the same time pay the price of millions of lines

139. Rada Mihalcea and Carlo Strapparava, "Learning to Laugh (Automatically): Computational Models for Humor Recognition," Computational Intelligence 22, no. 2 (2006): 132.

140. Angela Almela, Rafael Valencia-Garcia, and Pascual Cantos, "Seeing Through Deception: A Computational Approach to Deceit Detection in Written Communication" in Workshop on Computational Approaches to Deception Detection (Stroudsburg, PA: Association for Computational Linguistics, 2012), 17. 
of code and billions of dollars for digital hardware; or else we leave the task up to machines that derive code from their own environment, although we then cannot readthat is to say: articulate- this code."141

Unsupervised stylometric categorization techniques include principal component analysis (PCA) and cluster analysis. PCA's ability to capture essential variance across large numbers of features in a reduced dimensionality has found many uses in classifications involving large feature sets. PCA, also known as the Karhunen-Loeve transformation, is a linear transformation that chooses a new coordinate system for the data such that the greatest variance by any projection of the dataset comes to lie on the first axis (also known as the first principal component), the second greatest variance in the second axis, and so on. In this way, the invariance or the invariants that persist across these different transformations are designated as principal components. In contrast with SVMs, which separate data hyperdimensionally, PCA converges upon a principle or basis dimension through the use of matrices and linear operators similar to eigenvalues and eigenvectors, that is, operators that work to discern invariance across disparate dimensions.

Examples of the application of PCA abound in the literature. Vision-based methods of automatically detecting loiterers around "inner-city bus stops" comprise one such application:

Using a stationary camera view of a bus stop, pedestrians are segmented and tracked throughout the scene. The system takes snapshots of individuals when a clean, non obstructed view of a pedestrian is found. The snapshots are then used to classify the individual images into a database, using an appearance-based method. The features used to correlate individual images are based on short-term biometrics, which are changeable but stay valid for short periods of time; this

141. Friedrich Kittler, "Code (or, How You Can Write Something Differently)," in Software Studies: A Lexicon, ed. Matthew Fuller (Boston: MIT Press, 2008), 40. 
system uses clothing color [...]. To determine if a given individual is loitering, time stamps collected with the snapshots in their corresponding database class can be used to judge how long an individual has been present. An experiment was performed using a 30-min video of a busy bus stop with six individuals loitering about it. Results show that the system successfully classifies images of all six individuals as loitering. ${ }^{142}$

Researchers have also invested enormous effort in the automatic biometric identification of individuals using PCA vision systems. Face recognition systems such as eigenfaces and fisherfaces recognize people based on an analysis of facial features. Other methods, such as color-based models, have identified inanimate objects in constrained settings. Visual surveillance in dynamic scenes, especially for people and vehicles, is currently one of the most active research topics in computer vision and PCA. "It has a wide spectrum of promising applications," explains one research article, "including access control in special areas, human identification at a distance, $[.$.$] detection of$ anomalous behaviors, and interactive surveillance using multiple cameras, etc." ${ }^{143}$ The authors point out that biometric data (such as height, face, or walking gait) can be used to allow or deny entry into security-sensitive locations without having to rely on a security guard. In relation to person-specific identification, the authors explain that personal identification at a distance by a smart surveillance system can help the police catch suspects: "The police may build a biometric feature database of suspects, and place visual surveillance systems at locations where the suspects usually appear, e.g., subway stations, casinos, etc."144 These systems could "automatically recognize and judge" whether the

142. N. D. Bird, O. Masoud, N. P. Papanikolopoulos, and A. Isaacs, "Detection of Loitering Individuals in Public Transportation Area," IEEE Transactions on Intelligent Transportation System 6, no. 2 (June, 2005): 167.

143. Hu Weiming, "Survey on Visual Surveillance of Object Motion and Behaviors," Systems, Man, and Cybernetics 4, no. 3 (August, 2004): 334.

144. Ibid. 
people in its sights were suspects. "If yes," they explain, "alarms are given immediately. Such systems with face recognition have already been used at public sites, but the reliability is too low for police requirements." ${ }^{145}$ Finally, in relation to anomaly detection and generating alarms, the authors point out that it is "necessary to analyze the behaviors of people and vehicles and determine whether these behaviors are normal or abnormal. For example, visual surveillance systems set in parking lots and supermarkets could analyze abnormal behaviors indicative of theft." ${ }^{146}$

Surprisingly, the authors do not mention threat assessment. The U.S. Department of Homeland Security, however, has been developing technology that can detect threats before they are acted on. Precisely by detecting and monitoring changes in blood pressure, body temperature, heart rate, respiratory rate, and so on, these detectors and monitors can determine whether some person of interest is suspiciously anxious, ill, intoxicated, or otherwise anomalous. However, as Brian Massumi argues, "[P]reemption does not prevent, it effects. [...] Rather than acting in the present to avoid an occurrence in the future, preemption brings the future into the present. ${ }^{1147}$ These mechanisms of power do not merely manage a preexisting reality; they produce the object they seek to control.

In order to demonstrate how stylometry and related procedures produce the dividual through data processing algorithms, I performed an informal experiment. ${ }^{148}$ The

145. Ibid.

146. Tbid.

147. Brian Massumi, "The Future Birth of the Affective Fact," in Conference Proceedings: Genealogies of Biopolitics, (2005): 5-6.

148. See Appendix II: Additional Results. 
General Architecture for Text Engineering (GATE) is an application programming interface (API) for developing and deploying natural language processing (NLP) software components. GATE provides three types of resource: language resources (LRs), or data; processing resources (PRs), or algorithms; and visualization resources (VRs), the components of its visual interface. In GATE, documents are LRs containing text and one or more annotation sets. Corpora, another type of LR in GATE, consist of collections of documents. Using a PR, annotation sets can be encoded with different annotation types, and each of these annotation types can in turn encode features of different values:

1. Corpus

2. Document

3. Annotation Set

4. Annotation Type

5. Annotation Feature

6. Feature Value

Figure 6. Level scheme of a GATE corpus.

A corpus of 65 disciplinary familiar documents was prepared and loaded into GATE. The Tokeniser $\mathrm{PR}^{149}$ annotated each element in every document of the corpus, and the resulting "Token" annotation type included the following features: kind (word, punctuation mark, or number), length (number of characters in the word), orthography (lowercase, all uppercase, or capitalized), and string (i.e., the word or character itself). From this information, the Sentence Splitter $\mathrm{PR}^{150}$ annotated each sentence in every

149. Cunningham, Hamish, Diana Maynard, Kalina Bontcheva and Valentin Tablan. "GATE: A Framework and Graphical Development Environment for Robust NLP Tools and Applications," in $40^{\text {th }}$ Annual Meeting of the ACL (2002).

150. Ibid. 
document of the corpus, resulting in a "Sentence" annotation type. For every document in the corpus, the SUMMA TermFrequency $\mathrm{PR}^{151}$ then computed the term frequency tf for each annotation of type "Token" whose feature kind was word. Before any of this, and from a larger corpus including 3,421 additional documents, the SUMMA InvertedTable $\mathrm{PR}^{152}$ had already computed the inverse document frequency idf for each of these terms. Where each term is $t$, each document is $d$, and $D$ is the total number of documents:

$$
\operatorname{idf}(t, D)=\log \frac{|D|}{|\{d \in D: t \in d\}|} .
$$

From the tf values, and the idf values that had been computed earlier, the SUMMA VectorComputation $\mathrm{PR}^{153}$ then generated a vector $v$ for each term and by extension each sentence in every document of the corpus. Where the value for any $v$ is equivalent to the term frequency-inverse document frequency tf_idf of each term:

$$
\operatorname{tf} \text { idf }(t, d, D)=\operatorname{tf}(t, d) \cdot \operatorname{idf}(t, D) .
$$

The SUMMA NormalizeVector $\mathrm{PR}^{154}$ normalized these vectors to numbers between 0 and 1 . For every document in the corpus, and in addition to the corpus itself, the SUMMA Centroid $\mathrm{PR}^{155}$ computed a centroid vector $C$. Where $v_{1}, v_{2}, \ldots, v_{n}$ is the set of vectors:

$$
C=\frac{1}{n+1} \sum_{i=0}^{n} v_{i} .
$$

151. Horacio Saggion, "SUMMA. A Robust and Adaptable Summarization Tool," TAL 49, no. 2 (2008): 103-25.

152. Ibid.

153. Ibid.

154. Ibid.

155. Ibid. 
Finally, the SUMMA Cosine $\mathrm{PR}^{156}$ calculated the similarity of each sentence vector in every document, firstly, to the centroid vector of its document, returning a sentencedocument similarity score (DS), and secondly, to the centroid vector of the entire corpus, returning a sentence-corpus similarity score (CS). Where $x$ and $y$ are text representations based on the vector space model implemented in SUMMA, and $x_{t}$ and $y_{i}$ are the values of the term $i$ in that representation:

$$
\cos (x, y)=\frac{\sum x_{i} \cdot y_{i}}{\sqrt{\sum\left(x_{i}\right)^{2}} \times \sqrt{\Sigma\left(y_{i}\right)^{2}}} .
$$

\begin{tabular}{|c|l|c|}
\hline \multicolumn{2}{|c|}{ A Thousand Plateaus } & Deleuze, G.; Guattari, F. \\
\hline CS & However, these analyses of Marx should be enlarged upon. ${ }^{157}$ \\
\hline DS & $\begin{array}{l}\text { There is a distribution of intensive principles of organs, with their positive } \\
\text { indefinite articles, within a collectivity or multiplicity, inside an assemblage, and } \\
\text { according to machinic connections operating on a BwO. }\end{array}$ \\
\hline
\end{tabular}

Figure 7. CS and DS of $A$ Thousand Plateaus.

Figure 7 provides the CS and DS of $A$ Thousand Plateaus. The DS is the sentence "most similar" to the entire document in which it is contained, and the CS is the sentence "most similar" to the entire corpus of 75 documents of which it is only one part. Two things become apparent immediately from the CS and DS identified for this and other texts. First, the CS pivots around proper names; and not surprisingly, these names are often "Marx," "Nietzsche," and "Freud." Of the 75 CSs, 12 contain "Marx," 3 contain "Nietzsche," and 5 contain "Freud." "Kafka" appears in 4 documents, and "Bergson" also appears in 4, 3 of which are other texts of Deleuze's. The DS, on the other hand-and

156. Ibid.

157. Gilles Delueze and Fellix Guattari, A Thousand Plateaus, trans. Brian Massumi (Minneapolis: University of Minnesota Press, 1987), 447.

158. Ibid., 165. 
again, not surprisingly - features the neologisms or key concepts particular to a given document: in this case, Deleuze and Guattari's idiosyncratic lexicon of "BwO," "assemblage," "intensive," and "multiplicity," Nothing approaching a legitimate summary might be expected from such a procedure. In relation to $A$ Thousand Plateaus, however, it is not unfair to suggest that the CS in this case does indeed provide an accurate synopsis of the book's general project: an "enlarging upon" the analyses of Marx. In addition, the DS is appropriate: A Thousand Plateaus examines the intensive capacities of the BwO. The processes of dividualization, as they are approached through vector space models of language filtered through similarity functions, do appear to distill the "essence" of what they are supposed to represent. This weighting procedure "mimics the human decision making process," and, in some sense at least, this would seem to be accurate.

\begin{tabular}{|c|l|c|}
\hline \multicolumn{1}{|c|}{ Anti-Oedipus } & \multicolumn{1}{c|}{ Deleuze, G.; Guattari, F. } \\
\hline CS & $\begin{array}{l}\text { Let us recall Marx's great declaration: he who denies God does only a "secondary } \\
\text { thing," for he denies God in order to posit the existence of man, to put man in God's } \\
\text { place (the transformation taken into account). }\end{array}$ \\
\hline DS & $\begin{array}{l}\text { Yet every psychoanalyst- should know that, underneath Oedipus, through Oedipus, } \\
\text { behind Oedipus, his business is with desiring-machines. }\end{array}$ \\
\hline
\end{tabular}

Figure 8. CS and DS of Anti-Oedipus.

Figure 8 reveals the same phenomenon: for the CS, proper names ("Marx") are the focus, and for the DS, neologisms ("desiring-machines"). This outcome remained consistent for all the documents. Concerning the DS, a fair portion of Anti-Oedipus indeed sets out to demonstrate that beneath Freud's Oedipal account of the tripartite 159. Gilles Delueze and Fellix Guattari, Anti-Oedipus, trans. Robert Hurley (Minneapolis; University of Minnesota Press), 58.

160. Ibid., 63. 
subject lies a seething assemblage of desiring-machines.

Algorithms that seek to "mimic human reasoning," similar to those employed in this informal experiment, produce processable units that in turn enable further disaggregation, aggregation, and recombination. The resulting abbreviation and optimization are essential features of dividualization. Such operations differ dramatically in their functions and implications from the mechanisms inscribing the individual on a "descending axis" in disciplinary societies. Indeed, as Terranova explains, "gender, race and sexuality, the mantra of the cultural politics of difference in the 1980 s and 1990 s, have been reduced to recombinable elements, disassociated from their subjects and recomposed on a plane of modulation-a close sampling of the micromutations of the social, moving to the rhythm of market expansions and contractions." 161 This statistical modulation of information "undermines the perspectival and three-dimensional space which functions as a support for relations of mirrors and reflections as they engender subjects, identities and selves. In other words, the logic of representation presupposes a homogeneous space where different subjects can recognize each other when they are different and hence also when they are identical." ${ }^{162}$ Clough, similar to Terranova, describes this as a "shift away from logics of representation and ideological interpellation: there is no need to rely on models of reality to interpret the data, which simply 'speaks for itself." ${ }^{163}$ Pividualization in control societies takes place by way of exabytes, and implies an interactive modulation of affect and identity: a society in which feedback is not only collected, but also constantly generated: "The goal is to craft an

161. Terranova, Network Culture, 35.

162. Ibid.

163. Andrejevic, "The Work that Affective Economics Does," 12. 
interactive mediascape that triples as entertainment, advertising and probe. The promise of super crunching vast amounts of data, according to Ayres, is to 'predict what you will want and what you will do."'164

The results, however informal, are still instructive. They provide an image of the "face" of the dividual. In so-called chat speak, often used to communicate online or through cellular phone text messages, acronyms and other forms of abbreviation such as "LOL" for "laughing out loud" or "CUL8R" for "I will see you later," are used in place of conventional language. One of the more common instances of chat speak that can be found on the WWW is "TL;DR," which stands for "too long, didn't read." The societies of control place a premium on abbreviation in more than one way. Increasingly, interpretative interfaces, truncations, and summarizations stand in as place-holders for more complicated sets of information. Searching for a philosopher on Google's search engine, for example, returns not only relevant results from the WWW; it also returns a profile, that is, a photograph with a few dates and a brief synopsis of his or her ideas. Algorithms similar to the ones I used in the experiment may facilitate the generation of such place-holders.

\subsubsection{Access Control}

Andrea Brighenti examines the transition from the societies of discipline to the societies of control through the shifting topology of the wall. Just as the walls of discipline, exemplified in the work of Foucault on the clinic, the school, and the prison, replaced the medieval walled urbs of the societies of sovereignty, the disciplinary walls of closed institutions have given way to a dispersion towards the molecular. With this shift, 
observes Brighenti, new forms of segregation emerge, based on "smart" technologies that increase discriminatory control over access and mobility. "Walls become virtual," writes Brighenti; "They are pluralized and potentially everywhere. Once the technological infrastructure is implemented, it takes no more than an instant to actualize an ad hoc wall."165

Most studies of control societies as "network societies" pay particular attention to the topologies necessary to these virtual walls. Manuel Castells suggests that " $[N]$ etwork logic induces a social determination of a higher level than that of the specific social interests expressed through the networks: the power of flows takes precedence over the flows of power. Presence or absence in the network and the dynamics of each network vis-à-vis others are critical sources of domination and change in our society: a society [...] characterized by the preeminence of social morphology over social action."166 Castells emphasizes that such morphologies are inextricably tied to the logic of networks. Tiziana Terranova makes a similar suggestion: "Beyond being a concrete assemblage of hardware and software, the internetwork is also an abstract technical diagram implying a very specific production of space. [...] By modeling such open networks spatially, the Internet becomes for us more than simply one medium among many, but a kind of general figure for the processes driving the globalization of culture and communication at large. [...] The relation between the Internet and the production of space is, by no chance, crucial to all theoretical and analytical engagement with Internet culture." ${ }^{167}$

165. Andrea Brighenti, "The Wall and the Mobile Phones," in Urban Plots, Organizing Cities, eds. Claudio Coletta, Francesco Gabbi, and Giovanni Sonda (New York: Ashgate, 2012), 34.

166. Manuel Castells, The Information Age: Economy, Society, and Culture, vol. 5, The Rise of Network Society (Oxford: Blackwell, 1996), 469.

167. Ibid. 
As Qin and Atluri's article on access control makes clear, the production of space depends upon the formal abstraction afforded by set theory, category theory, group theory, and model theory. The concept-level access control Atluri and Qin propose "specifies whether a subject can perform certain actions on an object." ${ }^{168}$ This proposal also includes formalizations of these "subjects," "objects," and "privileges." The inscription of space in the societies of control goes beyond merely unfolding some abstract plane or manifold. This topology involves an increasing indistinction between itself and the matter it would otherwise only contain, to the extent that its substance is approached by way of the degrees of "privilege" this matter itself is granted. It is a topology that can be decomposed into the distinct quanta at its bounds.

The first mathematical model of a "secure" computer system was developed in 1973 by D. E. Bell and L. J. LaPadula at the MITRE corporation for the United States Department of Defense. The United States Air Force had authority over all matters relating to computer security for the Department of Defense, and so the development of the Bell-LaPadula model was prompted by James Anderson's 1972 report to the Air Force, the Computer Security Technology Planning Study: "The Contractor shall develop a comprehensive plan for research and development leading to the satisfaction of requirements for multi-user open computer systems which process various levels of classified and unclassified information simultaneously through terminals in both secure and insecure areas." 169

168. Atluri and Qin, "Concept Level Access Control," 12.

169. James P. Anderson, Computer Security Technology Planning Study, Air Force Electronic Systems Division, Hanscom Air Force Base, Bedford, MA, October, 1972, available at http://csrc.nist.gov/publications/history/ande72.pdf. 
"Every year, the Air Force came to MITRE and said 'these are the things we want you to do," explains Bell; "They would lay out projects, and within projects, tasks. Out of this came a description, and Len [LaPadula] and I got called into [Lipner's] office [...]. He showed us the description of the task: take a year, and [...] produce a mathematical model of computer security." ${ }^{170}$ The need for a mathematical model of computer security, according to the report, comes from "the fact that there are growing pressures to interlink separate but related computer systems into increasingly complex networks."171

The advent of resource-sharing systems such as computer servers, raised major security problems for the U.S. Department of Defense. These problems concerned the classification of data, user clearances, and access to resources. When users with different security clearance levels have access to resources with different security classifications that are hosted on the same server, only that server's software prevents "hostile penetration" by a "malicious user." A problem emerges when users with different security clearance levels need the ability to program that server's software. "As a malicious user is able to exercise more direct control over a computer through programming," explains the report, "he has the use of the computer as a tool to help his penetration and subsequent exploitation of the system. If he has a full programming capability using assembly or most of the higher order langiages, he has the maximum possible user control of the system, and has available all but a few of the tools needed to aid him in his penetration." ${ }^{172}$ Even the use of transactive or interpretative interfaces to sanction the

170. David Elliott Bell, OH 411, oral history interview by Jeffrey R. Yost, September 24, 2012, Reston, VA (Charles Babbage Institute, University of Minnesota, Minneapolis), http://purl.umn.edu/144024.

171. Anderson, "Computer Security Technology Planning Study," 1.

172. Ibid. 
programming capabilities of a user cannot eliminate security problems of this type. Table 1 shows the elements in most access control models.

Table 1. Access Control Model.

\begin{tabular}{|c|c|c|}
\hline Set & Elements & Semantics \\
\hline S & $\left\{\mathrm{S}_{1}, \mathrm{~S}_{2}, \ldots, \dot{\mathrm{S}}_{\mathrm{n}}\right\}$ & Subjects: processes, programs in execution. \\
\hline 0 & $\left\{\mathrm{O}_{1}, \mathrm{O}_{2}, \ldots, \mathrm{O}_{\mathrm{m}}\right\}$ & Objects: data, files, programs, subjects. \\
\hline C & $\begin{array}{c}\left\{C_{1}, C_{2}, \ldots, C_{q}\right\} \\
C_{1}>C_{2}>\cdots,>C_{q}\end{array}$ & $\begin{array}{l}\text { Classifications: clearance level of a subject, } \\
\text { classification of an object. }\end{array}$ \\
\hline K & $\left\{\mathrm{K}_{1}, \mathrm{~K}_{2}, \ldots, \mathrm{K}_{\mathrm{r}}\right\}$ & Category: special access. \\
\hline A & $\left\{A_{r}, A_{a}, A_{e}, A_{w}, A_{c}\right\}$ & $\begin{array}{l}\text { Access Attributes: read, append, execute, } \\
\text { write, and control. }\end{array}$ \\
\hline RA & $\{g, r, c, d\}$ & $\begin{array}{l}\text { Request Elements: } \\
\mathrm{g}: \text { get, give } \\
\mathrm{r} \text { : release, rescind } \\
\text { c: change, create } \\
\text { d: delete. }\end{array}$ \\
\hline $\mathrm{R}$ & $\begin{array}{c}\mathrm{S}^{+} \times \mathrm{RA} \times \mathrm{S}^{+} \times 0 \times \mathrm{L}, \\
\mathrm{S}^{+}=\mathrm{S} \cup\{\varnothing\}, \\
\mathrm{L}=\mathrm{A} \cup\{\varnothing\} \cup \mathrm{F} .\end{array}$ & $\begin{array}{l}\text { Requests: inputs, commands, requests for } \\
\text { access to objects by subjects. }\end{array}$ \\
\hline D & $\left\{D_{y}, D_{n}, D_{e}, D_{7}\right\}$ & Decisions: "yes," "no," "error," and "?." \\
\hline $\mathrm{T}$ & $\left\{t_{1}, t_{2}, \ldots, t_{n}\right\}$ & $\begin{array}{l}\text { Indices: Elements of the time set; } \\
\text { identification of discrete moments; an } \\
\text { element } t \text { is an index to request and } \\
\text { decision sequences. }\end{array}$ \\
\hline $\mathrm{F}$ & $\begin{array}{l}C^{S} \times C^{\circ} \times(\mathbb{P K})^{S} \times(\mathbb{P K})^{\circ} \\
\text { an arbitrary element of } F \text { is } \\
\text { written } f=\left(f_{1}, f_{2}, f_{3}, f_{4}\right)\end{array}$ & $\begin{array}{l}\text { Classification Vectors: } \\
\mathrm{f}_{1} \text { : subject-classification function; } \\
\mathrm{f}_{2} \text { : object-classification function; } \\
\mathrm{f}_{3} \text { : subject-need-to-know function; } \\
\mathrm{f}_{4}: \text { object-need-to-know function. }\end{array}$ \\
\hline
\end{tabular}




\begin{tabular}{|c|c|c|}
\hline $\mathrm{X}$ & $\begin{array}{l}\stackrel{\mathrm{R}^{\mathrm{T}}}{\text { an arbitrary element of } \mathrm{X} \text { is }} \\
\text { written } \mathrm{X}\end{array}$ & Request Sequences. \\
\hline $\mathrm{Y}$ & $\begin{array}{c}\mathrm{D}^{\mathrm{T}} \\
\text { an arbitrary element of } \mathrm{Y} \text { is } \mathrm{y}\end{array}$ & Decision Sequences. \\
\hline M & $\begin{array}{l}\quad\left\{M_{1}, M_{2}, \ldots, M_{n m 2}{ }^{P}\right\} ; \\
\text { an element } M_{K} \text { of } M \text { is an } \\
n \times m \text { matrix with entries from } \\
\mathbb{P A} \text {; the }(i, j) \text {-entry of } M_{K} \text { shows } \\
S_{i} \text { 's access attributes relative to } \\
O_{j}\end{array}$ & Access Matrices. \\
\hline V & $\mathrm{P}(\mathrm{S} \times 0) \times \dot{M} \times \mathrm{F}$ & States. \\
\hline $\mathrm{Z}$ & $\begin{array}{l}\qquad \mathrm{V}^{\mathrm{T}} \\
\text { an arbitrary element of } \mathrm{Z} \text { is } \\
\text { written } \mathrm{z} ; \mathrm{z}_{\mathrm{t}} \in \mathrm{z} \text { is the } \mathrm{t} \text {-th state } \\
\text { in the state sequence } \mathrm{z}\end{array}$ & State Sequences. \\
\hline
\end{tabular}

From Bell and LaPadula $(1973,11-13)$.

The Bell-LaPadula model ${ }^{173}$ distinguishes five basic types of access: read-only access, append access, execute access, read/write access, and control access. Read-only access capabilities represent a subject's read access attributes in relation to some object. Append (write-only) access capabilities represent a subject's append access attributes in relation to some object. Execute access capabilities represent a subject's access attribute in relation to executing an object (and imply the capability to execute an object on its behalf). Read/write access capabilities represent a subject's read/write access attribute in relation to some object (and imply the capability to both read and write an object). Finally, control access capabilities represent a subject's control access in relation to some object (and imply the capability to extend to another subject one or more of the other four

173. David Bell and Leonard LaPadula, "Secure Computer Systems: Mathematical Foundations and Model," in Technical Report M74-244 (Bedford: MTTRE Corp., 1973). 
access attributes it may have in relation to that object). In the Bell-LaPadula model, subjects $\mathrm{S}$ and objects $\mathrm{O}$ are always in some state, where a state $\mathrm{v} ; \mathrm{V} \in \mathrm{V}$ is a 3-tuple $\left(b, M_{K}, f\right)$. The variable $b: b \in \mathbb{P}(S \times 0 \times A)$ indicates which subjects have access to which objects in the state $v$. The variable $M_{K}: M_{K} \in M$ indicates the entries of the access matrix in the state $v$. And the variable $f: f \in F$ indicates the clearance level of all subjects, the classification level of all objects, and the categories associated with each subject and objeet in state $\mathrm{v}$. This model provides a concrete image of the state, in addition to the distribution of space and time in the societies of control.

\begin{tabular}{|l|l|c|l|}
\hline & & $O_{9}$ & \\
\hline & & $\vdots$ & \\
\hline$S_{7}$ & $\cdots$ & $\left\{A_{w}, A_{c}\right)$ & \\
\hline & & & \\
\hline
\end{tabular}

Figure 9. Lattice Security. Compare with Figure 2-1 in Bell and LaPadula (1973).

This model does not simply provide such a conerete image; it actually does the work of putting things in order within these societies. I provide the formal alphabet involved with these models because it effectively performs the task of inscription of space and the dividual. When the alphabet native to these systems of inscription is taken on its own terms, it affords a dimension of complexity that might otherwise be lost. For example, Bell and LaPadula explain their image of an access matrix as a "record-keeping device which remembers, for each possible subject object pairing, a list of access 
attributes associated with that subject-object pairing."174 They provide a simple graphic (shown in Figure 9) to illustrate this idea of lattice security:

This graphic illustrates the general idea behind lattice security. The intersection of $S_{7}$ and $O_{9}$ shows $S_{7}$ 's access attributes in relation to $O_{9}$, namely, $\left\{A_{w}, A_{c}\right\}$. A certain amount of complexity is lost in transposing this mathematical idea into such a simple graphic. Even on its own terms, however, the multiplicity of elements and relations represented by this model defy any immediate comprehension. In relation to these power sets, Cartesian products, and all the possible relations between the model's elements, the model represents a tremendous complexity that would, in its totality, always already escape any immediate human comprehension. $O_{9}$ and $S_{7}$ could just as well be comprised in matrices themselves, and these matrices could in turn represent other matrices, and so on. The management of subjects/objects enacted by such access control models can be as extraordinarily complex as is necessary.

In terms of this model, the state is conceivable only where the relative access privileges of each subject have already been established, where all subjects and objects have already been classified, and where any possible relation between these different elements has been categorically sanctioned. Indeed, the requests of any subject are handled solely on the condition that they do not contain the empty set (that is, do not trigger an error), just as in Badiou's ontology: "[W] hat the state seeks to foreclose through the power of its count is the void of the situation, and the event that in each case reveals it." ${ }^{175}$ The categories and classes native to this system are essential to its

174. Ibid., 5

175. Hallward, Badiou, 110. 
operation, and they create the space for the operation of truth and falsity in that truth and falsity become the decisions "yes" and "no." These categories and classes situate error: An error occurs when a subject attempts to relate to some object without the proper clearance in terms of the defined categories and classes.

The state transition relation, the function by which the current state becomes the next state, is determined by the previous state and the input to the current state. Informally, in this instant the model provides an image of temporality in control societies-in place of a continuous temporality, a sequence of elementally discrete moments, "unit steps," as with digital information. These moments are themselves only indices to other sequences: first, a sequence of states, as state was defined above-the classification and categorization of elements; secondly, a sequence of the requests made by these elements (each in a queue); and finally, a sequence of the decisions, where each decision is either a "yes," "no," "what?," or "error," as handed down by the system itself. The temporal dimension of this system unfolds only as a sequence of verdicts handed down by the state. There is no "going forward" until the system has reached a verdict, and the verdict is always categorical in basis. Time clicks forward, one discrete instant at a time, along an index of decisions made by the system in terms of categories and classifications. The degrees of freedom afforded in terms of the system dictate the space of any subject. The security clearance assigned to subjects by the system determines what Castells refers to as a "social morphology"; the system can modulate its topology entirely at any instant.

Access control will increasingly depend on the types of online profiles discussed in the previous section. One article, for example, formalizes a model of access control 
based on "online reputation systems." In "Reputation Systems: Facilitating Trust in Internet Interactions," Paul Resnick et al. define a reputation system as a system that "collects, distributes, and aggregates feedback about participants' past behavior." ${ }^{176}$ The primary domains where computational reputation has been explored so far include peerto-peer networks and electronic commerce. Most of these systems have limited scope and lack generalizability. Advances in user-centric identity systems such as CardSpace and OpenID, however, provide a foundation for the establishment of general-purpose online reputation systems, which depend on generalized identity systems for correlation of user actions. "In many situations where explicit authorization is either impossible or infeasible," explain Resnick eț al., "or even in situations where explicit authorization is currently in use, replacing or augmenting human-mediated authorization with calculated reputation scores can make an application more flexible and scalable."177

In the article "Using Reputation to Augment Explicit Authorization," Phillip Windley et al. provide some idea of how future access control models might deploy reputation: "Game-theoretic models show that the most efficient strategy for isolated communities is to give newcomers the minimum possible level of trust. By communicating with other contexts (by allowing some external reputation data) services avoid forcing new users to rebuild their reputation from scratch; this can increase the service's appeal, especially to users with high reputation (the users most likely to make sizable positive contributions to the social network)." ${ }^{\prime 17}$ In addition to reputation-based

176. Paul Resnick, Ko Kuwabara, Riehard Zeckhauser, and Eric Friedman, "Reputation Systems: Facilitating Trust in Internet Interactions," Communications of the ACM 43, no, 12 (2000): 45.

177. Ibid.

178. Phillip J. Windley, Devlin Daley, Bryant Cutler, and Kevin Tew, "Using Reputation to Augment Explicit Authorization," in ACM Workshop on Digital Identity Management (New York: ACM, 2007), 72. 
access control and to the ontological engineering discussed in a prerious section, some researchers have attempted to ontologically model sanctions for the access control of multi-agent systems. Pasquier, Flores, and Chaib-draa, for example, present an "ontology of sanctions and punishment philosophies which are required ingredients of any social control mechanism susceptible to fostering agents' compliance with the commitments they create." ${ }^{179}$ The article then proceeds to formalize these sanctions. Such access control models delineate the topologies that increasingly dominate social relations.

\subsubsection{Digital Information}

In the societies of control, space is no longer continuous and so, in the mathematical sense, this is an inscription of space as something that is no longer even "real," that is, in the sense that it must first of all be computable. A real number $a$ is said to be computable if it can be approximated by some terminating algorithm in the following way: given any integer $n \geq 1$, the algorithm will produce an integer $k$ such that:

$$
\frac{k-1}{n} \leq a \frac{k+1}{n}
$$

In the introduction to this chapter, I presented Euler's equation and suggested that this equation would ultimately effect the possibilities in relation to inscribing the social. The frequency domain of a signal is a representation of that signal as the sum of a possibly infinite number of trigonometric functions. The frequency domain, as a mechanism of inscription, finds a condition of possibility in Euler's equation. The initial

179. Phillippe Pasquier, Roberto A. Flores, and Brahim Chaib-draa, "An Ontology of Social Control Tools," in AAMAS '06: Proceedings of the Fifih International Joint Conference on Autonomous Agents and Multiagent Systems (New York: ACM, 2006), 1369. 
signal, both real and continuous, is encoded into some distribution of frequency components, also called its "spectrum." The inscriptive mechanism for encoding real and continuous signals is called the "Fourier transform." The output of this inscriptive mechanism is the amplitude and phase of the trigonometric functions at each frequency in the spectrum, which correspond to the signal in the time domain. The Fourier transform encodes a real and continuous function by finding the projection of the signal on the trigonometric functions at each frequency.

The digital inscription or encoding of a continuous signal is called "sampling." The digital sampling of a signal encodes it as a sequence of discrete points. In his article "Communication in the Presence of Noise," Claude Shannon calculated the exact sampling rate needed to encode a continuous signal in such a way that it could then be decoded "without any loss of information": "If a function $f(t)$ contains no frequencies higher than $W$ [cycles per second]," writes Shannon, "it is completely determined by giving its ordinates at a series of points spaced $1 / 2 W$ seconds apart." ${ }^{180}$ The sampling rate needed to decode a digital signal back into its real and continuous basis needs to be at least twice as fast as the highest frequency of the initial real and continuous function. Most continuous signals, however, are not band-limited: they contain frequency components higher than any possible $W$. The sampling of a continuous signal, even in accord with the sampling theorem explained by Shannon, entails an irrevocable loss. Indeed, most signals are filtered before they are sampled in order to comply with this theorem. Once a continuous signal has been sampled, it is quantized, that is, given a

180. Claude Shannon, "Communication in the Presence of Noise," Proceedings of the Institute of Radio Engineers 37, no. 1 (1947): 10. 
discrete value dependent on the sampling range of the inscription system involved: 8 bits per sample, 16 bits per sample, 64 bits per sample, and so on.

With these systems of inscribing or encoding the real and continuous, observes Kittler, "[f]or the first time a system of writing had been optimized according to technical criteria - that is, with no regard to semantics-[using] Code Condensers, which provided lists of words that could be abbreviated for global cable communications, thus reducing the length, and cost, of telegrams, and thereby encrypting the sender's clear text for a second time."181 With this second encryption, inscription is bound to mathematical principles rather than semantics: "The twentieth century thus turned a thoroughly capitalist money-saving device called 'code condenser' into highest mathematical stringency." 182 Such stringency has led to the development of mechanisms of compression in addition to filtering techniques.

. Table 2. Binary Numbers.

\begin{tabular}{|l|l|l|}
\hline No. & Bin. & \multicolumn{1}{|c|}{ Explanation (From Left) } \\
\hline 0 & 0 & Zero "one." \\
\hline 1 & 1 & One "one." \\
\hline 2 & 10 & One "two" and zero "one." \\
\hline 3 & 11 & One "two" and one "one." \\
\hline 4 & 100 & One "four," zero "two," and zero "one." \\
\hline 5 & 101 & One "four," zero "two," and one "one." \\
\hline
\end{tabular}

In the digital domain, as its name implies, the sampling of information requires numerical encoding. A digital audio file, for example, is a long sequence of digits encoding an audio waveform as a series of amplitude values along a regular index of time

181. Kittler, "Code," 46.

182. Tbid. 
values. The nature of Turing machines requires that these digits be binary in form. The binary system is the base 2 system, where each digit represents an increasing power of 2 , as indicated in Table 2.

By encoding the real and continuous signal as so many zeros and ones, digitization approaches a precision whose limit is determined only by the number of bits in question. Even as this code occasions the loss of something real, it also "reconstitutes" or "replaces" this loss in the digital domain through the statistical mechanics of probability.

The mathematical theory of communication-cybernetics, statistical mechanics, and the rest-already begins from uncertainty. As Terranova observes, "The closer you try to get to matter the faster your counting has to become in an attempt to catch up with the imperceptible speed of matter. Information theory accepts the existence of an 'incomplete determinism, almost an irrationality in the world $[\ldots]$ a fundamental element of chance. $"{ }^{183}$ While Wiener was busy with his research on antiaircraft ballistics, his colleagues Claude Shannon and Warren Weaver were doing telecommunications research for Bell Labs. Most acknowledge the research of Weaver and Shannon as the foundation of information science. Shannon and Weaver pivotally abandon any conception of information that relies upon meaning. "In fact," they explain, "two messages, one of which is heavily loaded with meaning and the other of which is pure nonsense, can be exactly equivalent, from the present viewpoint, as regards information." 184 Weaver and Shannon elaborate:

183. Terranova, Network Culture, 33.

184. Warren Weaver and Claude Shannon, The Mathematical Theory of Communication (Urbana: University of Illinois Press, 1949), 8. 
The word information, in this theory, is used in a special sense that must not be confused with its ordinary usage. In particular, information must not be confused with meaning. [...] To be sure, this word information in communication theory relates not so much to what you do say, as to what you could say. That is, information is a measure of one's freedom of choice when one selects a message. If one is confronted with a very elementary situation where he has to choose one of two alternative messages then it is arbitrarily said that the information associated with the situation is unity [...]. The concept of information applies not to the individual message (as the concept of meaning would), but rather to the situation as a whole, the unit information indicating that in this situation one has an amount of freedom of choice, in selecting a message, which is convenient to regard as a standard unit amount. ${ }^{185}$

Wiener, who worked closely with Weaver, likewise understond information as a statistical choice from amongst noise. As such, information implies a system with the ability to "control by informative feedback." ${ }^{186}$ Information theory comes to regard noise as that which is external to the system. Concomitant with the privileging of process and relation over structure and identity and of behavior over causality, information-in a strictly statistical sense-assumes priority over meaning.

For Terranova, the mathematical theory of communication marks a paradigm shift in the mechanisms of representation precisely in its preference for the digital over the continuous by way of the probable. "For Wiener," Terranova explains, "analogue machines, unlike digital machines, measure rather than count, and are therefore 'greatly limited in their precision,' because they operate 'on the basis of analogous connection between the measured quantities and the numerical quantities supposed to represent them.' Wiener points out how digital machines, on the other hand, provide 'great advantages for the most varied problems of communication and control...,' in as much as "the sharpness of the decision between "yes" and "no" permits them to accumulate

185. Ibid., 8-9.

186. Nobert Wiener, Cybernetics (New York: Wiley, 1948), 121. 
information in such a way as to allow us to discriminate very small differences in very large numbers." ${ }^{187}$ In terms of information theory, the quantity of "information" is equivalent to a quantity of discrete states. As an example, consider the number of all the possible twelve-tone rows: $12 !=479,001,600 .{ }^{188}$ That number is rather large, but if we reduce that number to the number of all possible unique twelve-tone rows, that is, every possible row that is not permutable into some other row through transposition, inversion, retrograde, or retrograde inversion, then we end up with the slightly more manageable number of $9,979,200$. As the digits in the binary system can only have one of two values, a binary set of $n$ bits can encode a maximum number of $2^{n}$ different messages. In my example, then, the number of bits necessary is 24 , as this number is the minimum number required in order to ensure the possibility of encoding every possible (out of the $9,979,200$ ) unique twelve-tone row-23 bits would be too few, as $2^{23}=8,388,608$, but 24 bits is more than sufficient, as $2^{24}=16,777,216$.

With 24 bits, every possible unique twelve-tone row can be encoded, whether arbitrarily or as defined in advance. For example, using an arbitrary encoding, the rows could be encoded as follows:

Table 3. 24-bit Encoding.

\begin{tabular}{|l|l|}
\hline First Row & 0000000000000000000000000 \\
\hline Second Row & 000000000000000000000001 \\
\hline Third Row & 000000000000000000000010 \\
\hline Fourth Row & 0000000000000000000000011 \\
\hline Fifth Row & 0000000000000000000000101 \\
\hline \multicolumn{2}{|c|}{ etc. } \\
\hline
\end{tabular}

187. Terranova, Network Culture, 33.

188. I explain twelve-tone rows in subsection 3.3.5. 
However, a minimal error of ope bit in the received information would lead the receiver to decode the message incorrectly. If, for example, the first twelve-tone row, that is, the 24-bit string ending in " 00 " as given in Table 3, encountered some error in its last bit during transmission and became " 01 ," then it would be received as the second row given in Table 3 rather than the first.

In order to overcome this problem, Shannon introduced redundancy as a means of detecting and correcting errors. The Shannon theorem would insure error-free communication by adding bits to the lengths of the binary strings used to encode information. For example, by using 25 bits rather than 24 bits to encode the twelve-tone rows in the example above, we could assign to every twelve-tone row additional binary strings, because the total number of strings (i.e., $2^{25}=33,554,432$ ) is much greater than twice the total number of tone rows (i.e., $2 \cdot 9,979,200=19,958,400$ ). In Shannon's mathematical theory of communication, it is precisely by way of this redundant encoding - where any one twelve-tone row would be encoded using more than one binary string - that the reliability of communication can be increased exponentially. Shannon's theorem is this: if the probability of an error in a single bit is $p$, and this probability is the same for all the bits of the message, then in order to make sure the correct message is recovered, at least $N \cdot H(p)$ redundancy bits need to be added, where $N$ is the total number of bits of the transmitted message, original bits plus redundancy bits, and $H(p)$ is a quantity that depends only or the probability of an error:

$$
H(p)=-\left(p \cdot \log _{2} p+(1-p) \cdot \log _{2}(1-p)\right) .
$$

This means that given the original number of bits $M$ and the error probability $p$, the total number of bits $N$ will be: 


$$
N=\frac{M}{1-H(p)} .
$$

Redundancy checks of this type bind communication to statistical probabilities. The redefinition of information as quantified data aids the development of social management mechanisms ever more capable of capturing the dynamic possibilities native to the social and material.

In a previous section that examined the statistical sciences of state, we saw how the normal distribution was a' generalization of so many particularities. The "average man" was not assumed to exist as such; rather, it served a strategic function for regulating the population. Terranova elaborates this point: "[L]ike the mass society that in those same years was increasingly preoccupying conservative and radical critics alike, thermodynamics and statistical mechanics too were concerned with formations such as masses, quantities such as averages and qualities such as homogeneity and heterogeneity. An average, however, can only adequately describe a low-entropy, highly structured system and its value as a descriptive measure is undermined in systems that are more fluid, hence more random and disorganized." 189 As Terranova observes, information theory allows for the quantification of these more random and disorganized systems. Its codes function on statistical constraints that mark the succession of bits according to degrees of probability, which allows a condensing that has a maximum only in the limit of information any given channel is capable of transmitting. Here, any given event is inscribed on the basis of its probability. However, Terranova writes, "The relation between the real and the probable also evokes the specter of the improbable, the fluctuation and hence the virttal. As such, a cultural politics of information somehow 189. Ibid., 32 . 
resists the confinement of social change to a closed set of mutually excluding and predetermined alternatives; and deploys an active engagement with the transformative potential of the virtual (that which is beyond measure)." ${ }^{190}$ The mathematical theory of communication implies not a relation between original and copy, but rather the reduction of a real signal to a digital set of probabilities and so to the resolution of any uncertainties through a choice from within this set. As Terranova puts it: "The political technology of information societies is crucially concerned with the organization of the field of the probable or the likely. It thus produces a sensibility to social change (and forms of subjectivity) that are informed by the relation between the real and the possible-where the real is what remains while all other competing possibilities are excluded."191

To this relation between the real and the probable, Terranova would counterpose a cultural politics of information that calls upon the virtual:

What lies beyond the possible and the real is thus the openness of the virtual, of the invention and the fluctuation, of what cannot be planned or even thought in advance, of what has no real permanence but only reverberations. Unlike the probable, the virtual can only irrupt and then recede, leaving only traces behind it, but traces that are virtually able to regenerate a reality gangrened by its reduction to a closed set of possibilities [...]. In this sense, if we can talk about a cultural politics of information at all it is not because of new technologies, but because it is the reduction of the space of communication to a space of limited and hardly effectual alternatives (as in the postmodern sign) that poses the problem of the unlikely and the unthinkable as such. The cultural politics of information is no radical alternative that springs out of a negativity to confront a monolithic social technology of power. It is rather a positive feedback effect of informational cultures as such. ${ }^{192}$

Terranova's reference to positive feedback echoes a statement of Kittler's: "If 'control,'

190. Ibid., 20.

191. Ibid., 25.

192. Ibid., 19. 
or, as engineers say, negative feedback, is the key to power in this century, then fighting that power requires positive feedback. Create endless feedback loops until VHF or stereo, tape deck or scrambler, the whole array of world war army equipment produces wild oscillations of the Farnborough type. Play to the powers that be their own melody."193 Both Terranova and Kittler call for a politics of positive feedback that multiplies the noise in the channels. Such a politics recalls Schreber's "free use" of "psychophysical nonsense" to combat Flechsig's regime of psychophysics, to which I return in the next section.

\subsubsection{Conclusion}

In this section, I examined some formal or mathematical apparatuses. Specifically, those inscribing the dividuals of control societies. I began with the antecedents of such technologies (e.g., the law of large numbers and the normal distribution) and teased out their inextricability from the biopolitical management and "discovery" of the population. Examples from the census and the deployment of statistics illustrated the effectiveness of these instruments in relation to concerns around race, degeneracy, and recidivism. The enthusiasm for this increasing effectiveness led to the development of the earliest prototypes of the modern computer. In the section on set theory, I explained the limits or axiomatic bases of these instruments, the deployment of which, as I continued to show in the section of metrics, has not changed so much since "1700." The objective of fostering and proliferating various "individualizations," whether as demographics to be marketed to or as terrorists to be tracked carefully, remains constant.

The "unworkable community" I discussed in the chapter 2 is precisely what these 193. Kittler, Gramophone, Film, Typewriter, 110. 
mechanisms aim to identify and put to work. In terms of control theory, whether something is "visible" or not, whether its potentiality remains held in reserve or not, whether it is "virtual" (in the sense we saw Terranova give this term) or not, whether it can be qualified or not, makes no difference. Even if only as some barely observable disturbance amongst what is visible, these singularities can be found and so made to serve the design of system stability. Indeed, the whole arsenal of the equations of control theory was developed precisely to such an end.

The section on metrics, access control, and digital information demarcated the "citizens" of control society in the spaces and temporalities they come to occupy. Continuously updatable stylometric feature sets comprise the essence or identity of these dividuals. In the model of a secure system, the temporal dimension to which they would universally be bound was illuminated as a queue of requests and decisions, the sum total current state of which constituting the spatial dimension to which they would universally be bound. Finally, the substance of all these dimensions was shown to be digital. In its substance, then, nothing about control societies is real, in the sense that this substance is no longer inscribed as something infinitely continuous but rather as something diserete, digital, and finally only a probable approximation of the real or infinitely continuous. 


\subsection{Chemistry}

\subsubsection{Introduction}

In the early chapters of Thomas Mann's 1943 book Doctor Faustus, the narrator, Serenus Zeitblom, relates a scene from his childhood that he will never forget. His friend Adrian Leverkuhn's father showed the narrator, Adrian, and another friend a crystallization vessel, "filled to three-quarters with a slightly mucilaginous liquid, diluted sodium silicate to be precise." Inside of this vessel, he recalls, there "rose a grotesque miniature landscape of different colored growths-a muddle of vegetation, sprouting blue, green, and brown and reminiscent of algae, fungi rooted polyps, of mosses too, but also of mussels, fleshy flower spikes, tiny trees or twigs, and here and there even of human limbs - the most remarkable thing my eyes had ever beheld [...].". Zeitblom explains that these objects were remarkable to him "not so much because of their very odd and perplexing appearance, $[\ldots]$ but because of their deeply melancholy nature." ${ }^{3}$ Father Leverkuhn asks the boys what they suppose this "grotesque miniature landscape" is, and they respond that it must be plants or algae. "No, that they're not," Father Leverkühn responds, "they only pretend to be. But don't think less of them for it! The fact that they give their best pretense deserves all due respect. ${ }^{, 4}$ Zeitblom continues:

It turned out that these growths were of purely inorganic origin and arose with the aid of chemicals [...] patassium dichromate and copper sulfate [...]. He showed us, you see, that these woeful imitators of life were eager for light, or "heliotropic," as science says of life-forms. To prove it to us, he exposed his aquarium to

1. Thomas Mann, Doctor Faustus, trans. John E. Woods (New York: Vintage, 1997), 22.

2. Ibid.

3. Ibid.

4. Ibid. 
sunlight, while shading it on three sides; and behold, within a very short time the whole dubious crew-mushrooms, phallic polyps, tiny trees, and algae meadows, plus those have formed limbs-bent toward the pane of glass through which the light was falling, pressing forward with such longing for warmth and joy that they literally clung to the pane and stuck fast there. ${ }^{5}$

One of Zeitblom's friends, Jonathan, is brought to tears by this sight, while the other friend, Adrian, commences "shaking with surprised laughter." ${ }^{16}$ Zeitblom then concludes: "[F]or my part I leave it only to the reader whether such things deserve laughter or tears. I have only this to say: phantasms of this sort are exclusively the concern of nature, and in particular of nature when she is willfully tempted by man. In the worthy realm of the humanities, one is safe from all such spooks."”

As Kittler demonstrates, the media technologies of " 1900 " initially provoked reactions similar to the reactions to the uncanny imitators of life generated by Leverkühn's father. The gramophone caused a particular disturbance because it allowed the voice to issue from a lifeless mechanical box, dissociating it from a living presence. Contemporaries perceived the early gramophones as "spooky": "They cannot bear to hear a remarkably life-like voice issuing from a box. They desire the physical presence. For want of it, the gramophone distresses them." As Kittler explains, "[O]nce the technological differentiation of optics, acoustics and writing exploded the Gutenberg monopoly around 1880 , the fabrication of so-called Man became possible. His essence escapes into apparatuses [...] So-called Man is split up into physiology and information

5. Ibid.

6. Ibid.

7. Ibid.

8. Timothy D. Taylor, Mark Katz, and Tony Grajeda (eds.), Music, Sound, and Technology in America: A Documentary History of Early Phonograph, Cinema, and Radia, (Durham, NC: Duke University Press, 2012), 16. 
technology." Media may now speak directly to each other, without mediation, similar to the two gramophones that Kafka imagined speaking to each other in lieu of a lovers' conversation: "Whereas individuals [1800] consisted of matured and unified speech and writing, individual cases [1900] are specified by the scattered debris of their language use. Uniqueness in the discourse network of 1900 is always a result of the decomposition of anonymous, mass-produced products." ${ }^{10}$ Contrary to Zeitblom's reassurance that in "the realm of the humanities, one is safe from all such spooks," of life increasingly colonize and define the realm of life in control societies.

In the discourse surrounding the gramophone, the medium assumes the qualities of a corpse. That is to say, it is not a living body in the sense that this had been understood previously, and yet it still speaks. For Kittler, Stoker's Dracula allegorizes the obliteration of "soul" by the discourse network of 1900 :

No despot can survive when a whole multimedia system of psychoanalysis and textual technologies go after him. The special forces have "scientific experience," whereas Dracula has only his "child's brain" with engrams dating back to the battle of Mahacs (1526). He does have an inkling of the power about to bring him down, for otherwise he would not throw the phonographic rolls and typescripts he finds into the fire. But the hunters have Mina and "thank God there is the other copy in the safe." Under the conditions of information technology, the oldEuropean despot disintegrates into the limit value of Brownian motion, which is the noise in all channels ${ }^{12}$

Kittler continues with his literary metaphor: "A stab to the heart turns the Undead to dust. Dracula's salaciously whispering bride, the resurrected vampire Lucy, is put to death a second time, and finally, on the threshold of his homeland, so is he. A multimedia system,

9. Friedrich A. Kittler, Gramophone, Film, Typewriter, trans. Geoffrey Winthrop-Young and Michael Wutz (Stanford, CA: Stanford University Press, 1999), 16.

10. Kittler, Discourse Networks 1800/1900, 281.

11. Ibid.

12. Kittler, Discourse Networks 1800/1900, 356. 
filmed over twenty times, attacks with typescript copies and telegrams, newspaper clippings and wax rolls (as these different sorts of discourse are neatly labeled)." ${ }^{13}$ As Kittler later remarks: "Once technological media guarantee the similarity of the dead to stored data by turning them into the latter's mechanical product, the boundaries of the body, death and lust, leave the most indelible traces."14

The dramatic advances in data storage that mortified the living voice in the gramophone both prefigured and contributed to a far more systematic transformation of the concept of life: the informątic conception of heredity at the basis of modern genetics. Two years after Watson and Crick proposed that the entirety of the biological is encoded in a sequence of discrete bases along a double helix joined by sugar phosphates, Georges Canguilhem reflected on the consequences that would follow from this "revolutionary" redefinition of life and suggested that molecular biology, which arose after World War II, had "dropped the vocabulary of classical mechanics, physics and chemistry $[\ldots]$ in favor of the vocabulary of linguistics and communication theory. Messages, information, programs, codes, instructions, decoding: these are the new concepts of the life sciences." 15 In this passage from The Concept of Life, Canguilhem proceeds along a trajectory I have underlined previously. "The science of life no longer resembles a portrait of life," writes Canguilhem, "as it could when it consisted in the description and classification of species." ${ }^{\text {16 }}$ Canguilhem refers to the elegant taxinomia of classical societies, exemplified by the binomial nomenclature of Linnaean taxonomy, which

13. Tbid.

14. Kittler, Gramophone, Film, Typewriter, 55.

15. George Canguilhem, A Vital Rationalist: Selected Writings from George Canguilhem, ed. Francois Delaporte (New York: Zone Books, 1994), 319.

16. Ibid. 
inscribes the biological along an index of genera and species. Canguilhem adds that it also "no longer resembles architecture or mechanics as it could when it was simply anatomy and macroscopic physiology," ${ }^{17}$ alluding to the macroenclosures of discipline, where the biological is inscribed by way of anatomy textbooks and visualized by the clinical gaze. The new paradigm instead binds the inscription of life, Canguilhem suggests, to "grammar, semantics, and the theory of syntax." 18

Nikolas Rose explains 'how the new system of inscribing the biological differs from its predecessors:

Most notably, it is conceived on a different scale. In the 1930s, biology came to visualize life in terms of phenomena at the submicroscopic region-between ten to the negative six and ten to the negative seven centimeters. Life, that is to say, was molecularized. This molecularization was not merely a matter of the framing of explanations at the molecular level. Nor was it simply a matter of the use of artifacts fabricated at the molecular level. It was a reorganization of the gaze of the life sciences: their institutions, procedures, instruments, spaces of operation, and forms of capitalization. ${ }^{19}$

The disintegration of macroscopic biology into molecular biochemistry parallels the shift from enclosure to vector and from individual to dividual. Restriction enzymes can dissect the genetic bases of cells and cells can also easily be explanted, while sonicators can shatter them and electrophoresis gels and affinity chromatography can separate the scattered debris. The biopolitical now implies organs without bodies: commoditized and transferable, gone to market along with tissues, blood products, sperm, macrolecithal eggs, and embryos. Rose elaborates:

17. Ibid.

18. Ibid.

19. Nikolas Rose, The Politics of Life Itself: Biomedicine, Power, and Subjectivity in the Twenty-First Century (Princeton: Princeton University Press, 2009), 44. 
Molecularization strips tissues, proteins, molecules, and drugs of their specific affinities - to a disease, to an organ, to an individual, to a species - and enables them to be regarded, in many respects, as manipulable and transferable elements or unities, which can be delocalized-moved from place to place, from organism to organism, from disease to disease. Hybrid assemblages of knowledges, instruments, persons, systems of judgment, buildings and spaces, underpinned at the programmatic level and certain presuppositions and assumptions about human beings. Thus, as many have argued, new reproductive technologies entail much more than the craft skills of doctors using new instruments and techniques. They engender certain ways of thinking about reproduction, for the subject and for the expert, certain routines and rituals, techniques of testing and practices of visualization, modes of advice giving and so on. Organ transplantation is not merely a triumph of surgical techniques but requires new sets of social relations bringing together donors and recipients across time and space, entailing and.... All of it orientated toward the goal of optimization. ${ }^{20}$

In his short article on software, Kittler writes: "[C]odes-by name and by matter-are what determine us today, and what we must articulate if only to avoid disappearing under them completely." ${ }^{21}$ Developments in the field of biological semiology underline what is at stake in Kittler's comments. The biological semiologist Marcello Barbieri, for example, maintains that the qualitative difference between the biological and the nonbiological is that the former is always encoded, that is, the biological is something that is always mediated in some way. ${ }^{22}$ For Barbieri, a code is a set of rules governing the relations between any two entities from entirely disparate domains. The qualitative difference between the biological and the nonbiological is that the behavior of the biological is irreducible to its native domain. The relations between atoms, for example, are immediate, that is, purely and precisely reactive, as with, for example, the exchange of electrons. In contrast, the synthesis of proteins within a

20. Ibid., 17.

21. Kittler, "Code," 1.

22. Mario Barbieri, The Codes of Life: The Rules of Macroevolution (New York: Springer, 2007), 25. 
biological system always requires the mediation of RNA "messengers." Fundamental interactions such as gravity are immediate, and so from this position, nonbiological, while the interactions within a nervous system are biological, to the extent that they imply every manner of mediation, channel, and transmission. Biosemiology understands codes as conventional in nature-that is, the mediated relations between the elements implicit to any code are not necessarily given in advance as some set of transcendental laws imposed from on high; rather, they are relations that emerge in dynamic ways, always sensitive to context. .

Information science is therefore becoming the primary mechanism of inscribing the biological in control societies. As Galloway and Thacker observe, "[T]he biological and the informatic become increasingly enmeshed in hybrid systems that are more than biological [my emphasis]."23 The biological is equally the informatic, that is, so many flows of information to be mapped, directed, and controlled. Galloway and Thacker continue:

One important result of this intersection of biology and informatics in biopolitics is that the sovereign form of power (the right over death and to let live) gives way to a newer "regulative power" (the right to make live and let die). In other words, biology and informatics combine in biopolitics to make it productive, to impel, enhance, and optimize the species-population as it exists within the contexts of work, leisure, consumerism, health care, entertainment, and a host of other social activities. ${ }^{24}$

The informatic has already been discussed in Section 3.1; the present section will map out the simultaneously molecular and informatic inscription of life that characterizes the biopolitical regime of control societies.

23. Galloway and Thacker, The Exploit, 28.

24. Ibid., 74 . 
I discuss the "molecularization" of life as it is inscribed by the technologies of control. After an overview of this molecular line of force, I follow and explain a KEGG pathway in order to demonstrate the extraordinarily complex manner in which life is inscribed by such technologies. I then consider the ways in which some foods, in their molecular constitution, are instrumentally mobilized to the end of actuating the designs of control, and this in addition to the similar forms of instrumentality manifest in drug legislation. Against such instrumentalization, the research of chemist Alexander Shulgin exemplifies many of the claims in relation to doing politics that I have made in my study, such as, for example, positive feedback or the "free use of the proper."

\subsubsection{Psychophysics}

Ian Hacking, applying Kittler's " $1800 " /$ " 1900 " transition to the science of memory, proposes a divide between the traditional art of memory-or memorizationand the "scientificization" of memory in the late nineteenth century in which "memory, already regarded as a criterion of personal identity, became a scientific key to the soul $[\ldots][B] y$ investigating memory (to find out its facts) one would conquer the spiritual domain of the soul and replace it by a surrogate, knowledge about memory." ${ }^{25}$ In place of the deeply respected art of memory -as Hacking tells us, "no art was more carefully studied, or esteemed" 26 - the focus would now be "factual knowledge" of memory as a

25. Ian Hacking, Rewriting the Saul: Multiple Personality and the Sciences of Memory (Princeton: Princeton University Press, 1995), 203.

26. Ibid. 
new science. ${ }^{27}$

The art of memory required "rigorous discipline and regimens." 28 "One had to practice," recounts Hacking, "the building of houses and cities in the head, and learn how best to arrange things so that one could always be sure of where one had placed each object to be remembered. Texts were remembered in this way. Any competent scholar had an immense database stored in architectural mnemonics. Usually he could not go off to the library to check a citation or saying but he had no need to do so. It was in his head."29 In this context, suggests Hacking, "the art of memory is outer-directed." ${ }^{30}$ Far more important than memory of one's own experiences was the ability to recall facts and texts, the creation of a mental image to give the thinker access to specifically external material. In German, the term in current use for technical memory-Speicher-translates as "storehouse," recalling the medieval architectural metaphor. In the late nineteenth century, this metaphor became appropriate in new ways as science began to approach the mysteries of the brain, its memory capacity, and its physical divisions. ${ }^{31}$

In 1861, Paul Broca examined a brain lesion and pronounced that it had been the cause of a patient's subsequent amnesia. Broca's conclusions about the localization of brain functions heralded a new era in the history of science-shortly thereafter, Carl Wernicke would identify the part of the brain responsible for storing words, and Théodule

27. Ibid, 3 .

28. Mary Carruthers, The Biook of Memory: A Study of Memory in Medieval Culture (Cambridge, England: Cambridge University Press, 2008). Quoted in Hacking, Rewriting the Soul, 202.

29. Hacking, Rewriting the Soul, 202.

30. Tbid.

31. Tbid. 
Ribot would begin lecturing and writing on diseases of memory. ${ }^{32}$ Tracing the movement of the concept of memory from the soul to the laboratory, Hacking writes: "On the relations between mind and brain, Ribot was no more, and no less, programmatic than most other positivist or scientistic writers of the day. 'Memory,' he wrote, 'is essentially a biological fact, accidentally a psychological fact.' The rhetoric succeeded by changing the ground on which to think about the soul. The soul was the last bastion of thought free of scientific scrutiny.",33

As set out by Hacking, the transition of memory from an imagined architectural space to a biophysical place with an identifiable, logical, and consistent set of rules marks the birth of psychophysiology. Returning to Kittler, the importance of this field, with its bodily locus, matches that of the gramophone. Man has now become a "corpse" with "nerves"-an immediately gramophonic being. It was, after all, a corpse that inspired Ramón Cajal, the "father of modern neuroscience." Kittler, referring to the transformation of souls into "nerve information systems," suggests that Schreber's psychiatrist Flechsig and his contemporaries faced an irremediable difficulty: the impossibility of physically examining the brain until after death meant that cures (clearly, for the living) could only be tentatively arrived at "through more or less composite inferences." ${ }^{34}$ For Ramón Cajal, though initially "both brain and stomach protested" upon first examining a cadaver, the possibility of witnessing "the marvelous workmanship of

32. Ibid., 203.

33. Ibid., 208 .

34. Kittler, Discourse Networks 1800/1900, 295. 
life" ${ }^{35}$ was of paramount significance.

Along with new technologies such as the gramophone and practices such as psychophysiology, Kittler sees in the work of psychologist Hermann Ebbinghaus another development that helped bring about the transition from "1800" to " 1900 ." Ebbinghaus took the romantic concept of "remembrance" and subjected it to experimentation (determining, for instance, how many random syllables in a row an experimental subject can remember). In doing this, Kittler maintains, Ebbinghaus brought about the transition from the inherited notion of "remembrance" to the notion of "recall" as a positive psychophysical capacity. ${ }^{36}$

Ebbinghaus's reduction of language to a "raw state" involving nonsense syllables devoid of association with unintentional mnemonic aids redefined the signifieds of cultural, aesthetic, and individual meaning as mere "disturbing influences." Turning his own brain into a storage facility, Ebbinghaus used emptiness and meaninglessness to "[institute] the flight of ideas." ${ }^{38}$ When Ebbinghaus repeated the experiment on himself using cantos from Byron's Don Juan under the same conditions, though, he discoveredto his own surprise-that his capacity to memorize poetry was not significantly greater than his ability with nonsensical material. "Thus," writes Kittler, "the great doctrine bestowed by the discourse network of 1800 on its reformed primers is shaken: namely, the notion that readers would learn signifieds, because of their immanence in the mind,

35. Santiago Ramón y Cajal, Recollections of My Life (Cambridge, MA: MIT Press, 1989), 169.

36. Kittler, Discourse Networks 1800/1900, 206.

37. Ibid., 208.

38. Tbid. 
with much greater speed than they would learn signifiers by rote. To the contrary, pure nonsense reveals certain specific aspects of attention that hermeneutics could not even conceive." ${ }^{39}$ If there is no correlation between understanding and memory capacity, and "if the difference between sense and nonsense dwindles, then the kingdom of sense-that is, the entire discourse network of 1800 -sinks to the level of a secondary and exceptional phenomenon. ${ }^{40}$ The path inward, the concept of recollection and making sense of things, in the end, has no real influence on memory capacity. Kittler concludes that the repercussions for signifiers as such resound throughout the " 1900 " discourse network: the importance of statistics grows manifold "if signifiers obey laws that are as fundamental as they are incomprehensible.,"41

Ebbinghaus had begun to study this phenomenon quite some time before proponents of Spracherotik determined that language must be "demolished" and its linguistic material then returned to its primordial, homogeneous, and essentially "chaotic" state. The material Ebbinghaus had used in his first set of tests was created by a random generator; naturally, it would have been impossible for "a few meaningful German words" not to appear in the series of 2,299 syllables, but these were indeed few and, in fact, claimed Ebbinghaus, had little effect on his memorization attempts-he barely noticed the potential meaningfulness of the syllables that occasionally appeared because his mind had already dismissed the notion. ${ }^{42}$ As Kittler concludes: "The discourse network of 1900 was the first to establish a treasury of the signifier whose rules were entirely based on randomness and combinatorics., ${ }^{, 43}$

39. Ibid., 209.

40. Ibid.

41. Ibid.

42. Ibid., 209-10.

43. Ibid., 210 . 


\subsubsection{Molecular Biopolitics}

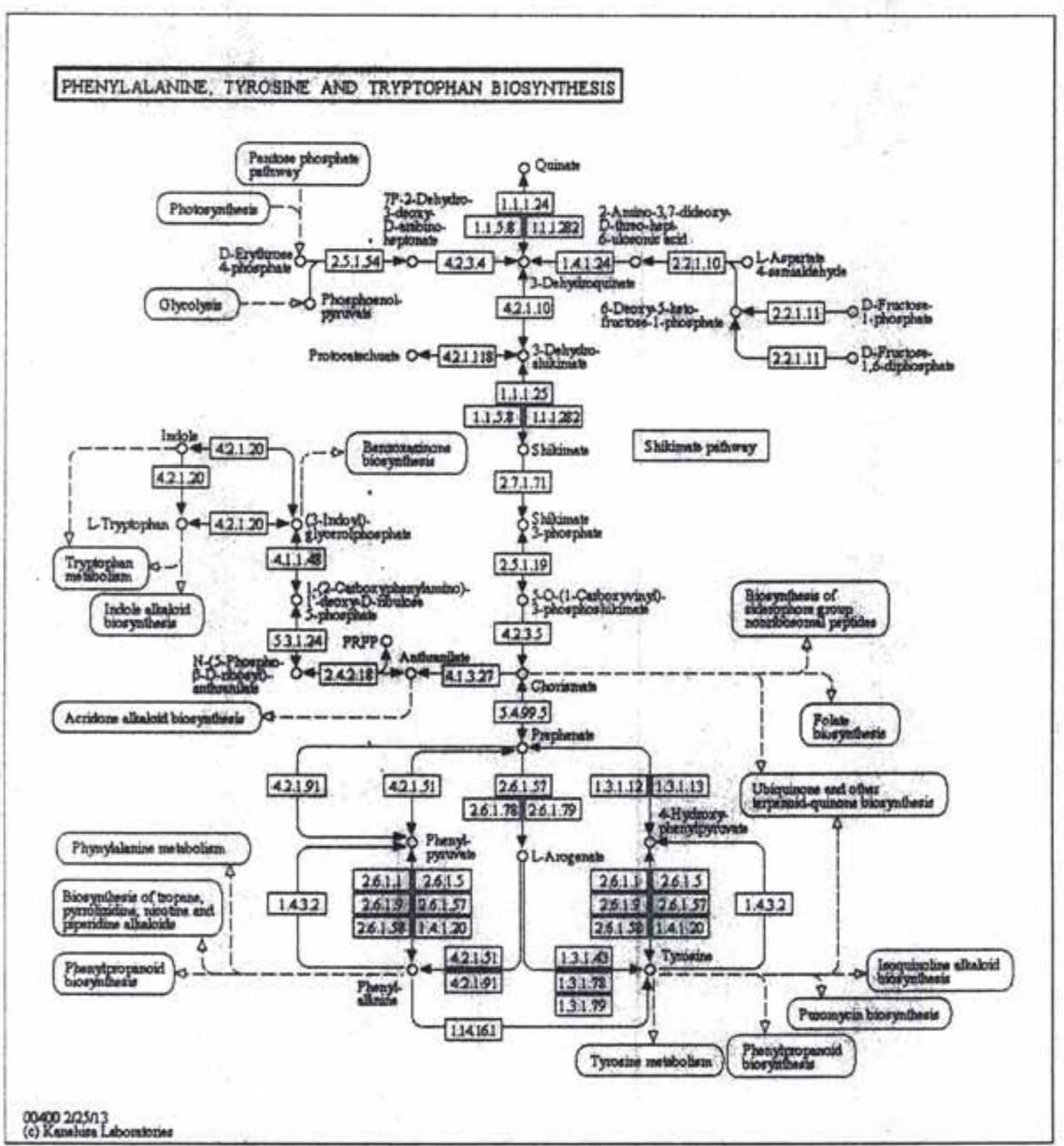

Figure 10. KEGG: Kyoto Encyclopedia of Genes and Genomes, object name "Phenylalanine, Tyrosine, and Tryptophan Biosynthesis" (map00400); accessed October 14, 2013; http://www.genome.jp/dbget-bin/www_bget?map00400. Copyright 2013 by Kanehisa Laboratories. 
There are few maps more appropriate to the cartographies of the present than those of systems biology. These maps, hosted online, expand as they are empirically verified and uploaded onto databases such as the Cyc and the Kyoto Encyclopedia of Genes and Genomes (KEGG). In reference to catalogued plants, bacteria, and other animals, they present a whole causeway of multiple entities: genes, enzymes, reactions, molecules, and so on. In place of the anatomical atlases of the societies of discipline, causeways such as these map and inscribe the biological in the societies of control.

For an example, consider Figure 10, a KEGG metabolic pathway. The rounded boxes in the top left corner of the pathway provide hyperlinks to other pathways: the pentose phosphate, photosynthetic, and glycolgenetic pathways. These other pathways, for example, the photosynthetic pathway of some plant, have yielded D-Erythrose 4phosphate (C00279) and PEP (C00074):
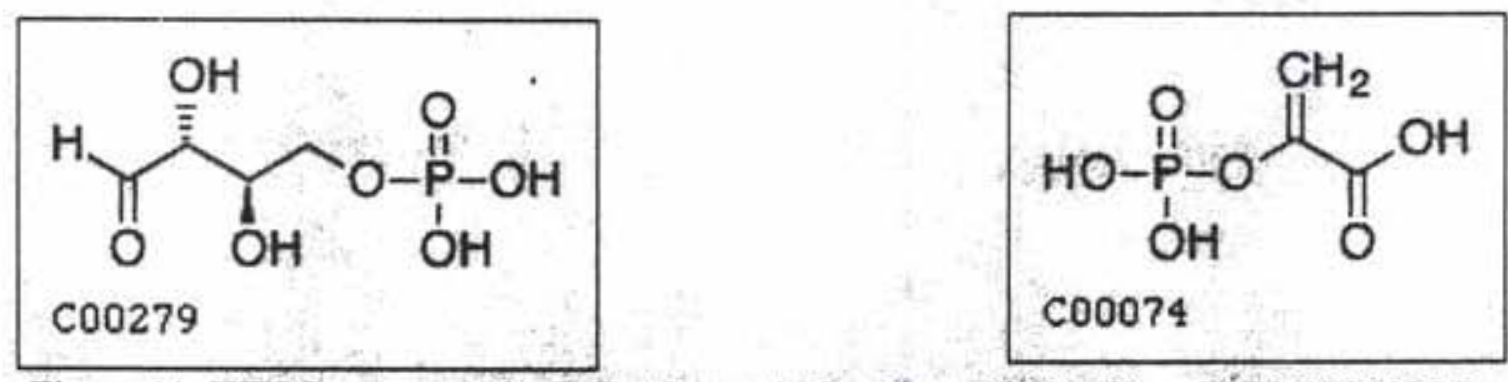

Figure 11. KEGG compounds: D-Erythrose 4-phosphate (C00279) and PEP (C000274).

Along the pathway, rectangles and the enzyme commission (EC) numbers they contain are hyperlinked to gene, enzyme, and reaction information, that is, the genetic sequence responsible for expressing that enzyme and the reaction it precipitates. Following the pathway, the two molecules in Figure 11 next encounter the 3-deoxy-7phosphoheptulonate synthase enzyme (EC: 2.5 .1 .54 ), and an enzyme reaction takes place 
(R01826):

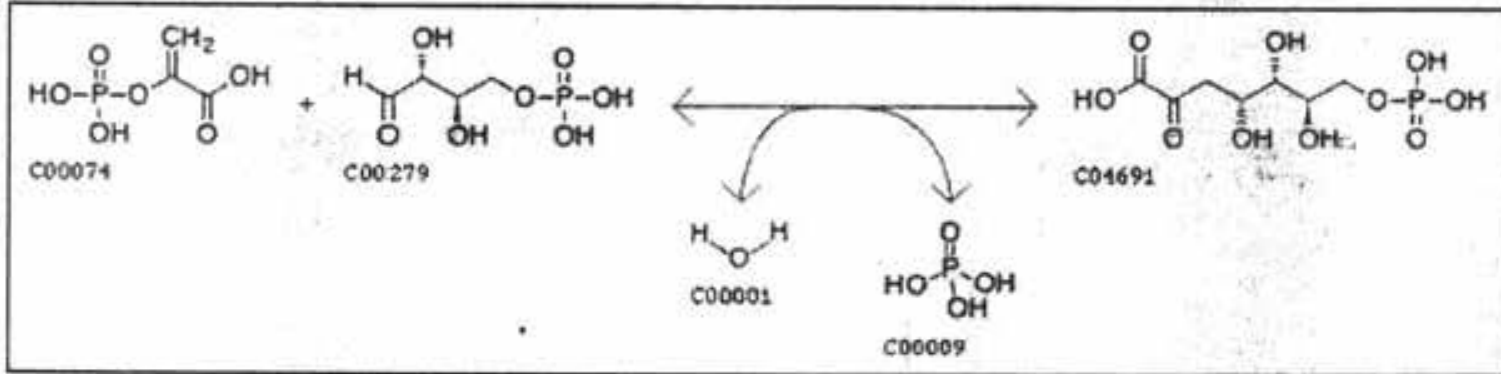

Figure 12. KEGG reaction (R01826).

A step further, the DAHP (C04691) yielded by the reaction in Figure 12 encounters the 3dehydroquinate synthase enzyme (EC:4.2.3.4) and another reaction takes place (R0383):

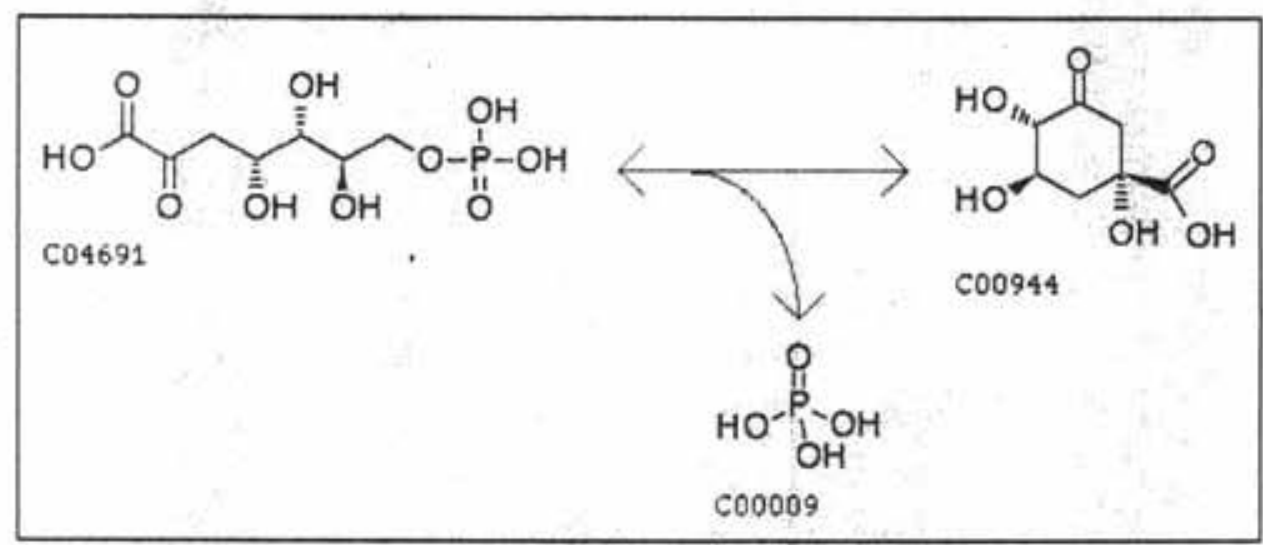

Figure 13. KEGG reaction (R03083).

Midway down the pathway, a series of various enzyme reactions have produced chorismate (C00251) from the initial compounds on the top left. Some of this chorismate arrives at its final destination by way of EC:4.2.1.20, where it becomes tryptophan (C00078). The rest of it, however, continues downward, becoming, towards the bottom of the pathway, phenylalanine (C00079) on the left, by way of EC:4.2.1.51, and tyrosine (C00082), on the right, by way of EC:1.3.1.43 or EC:1.3.1.78 or EC:1.3.1.79. 
The importance of following this pathway and of using skeletal notation becomes more evident in relation to the three molecules it has yielded, shown in Figure 14: tryptophan, phenylalanine, and tyrosine.
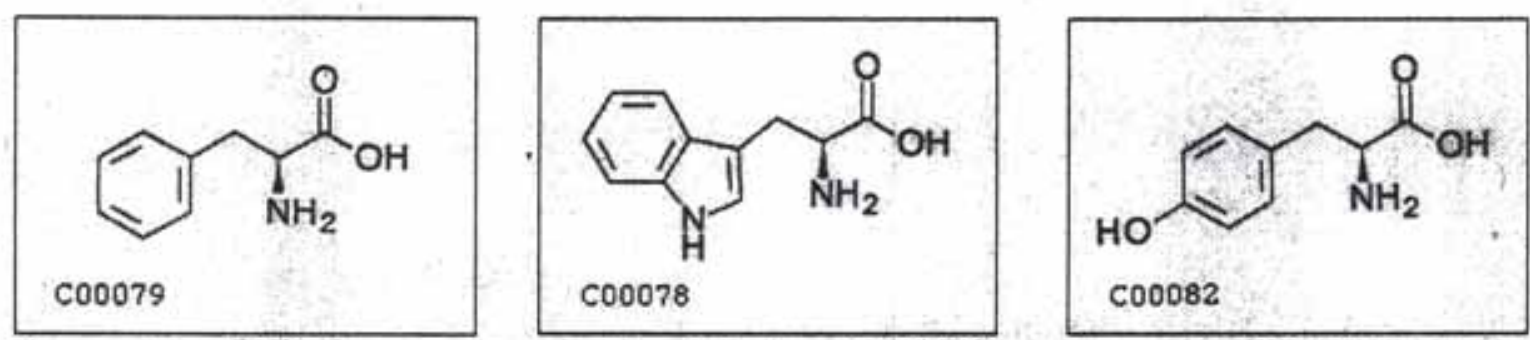

Figure 14. KEGG compounds: phenylalanine (C00079), tryptophan (C00078), and tyrosine (C00082).

These three essential amino acids enter metabolic pathways and form the basis of neurotransmitters. Tryptophan is decarboxylated into tryptamine, which is in turn hydroxylated at the 5 position into 5 -hydroxytryptamine, or serotonin; in similar ways, phenylalanine and tyrosine become dopamine and norepinephrine.
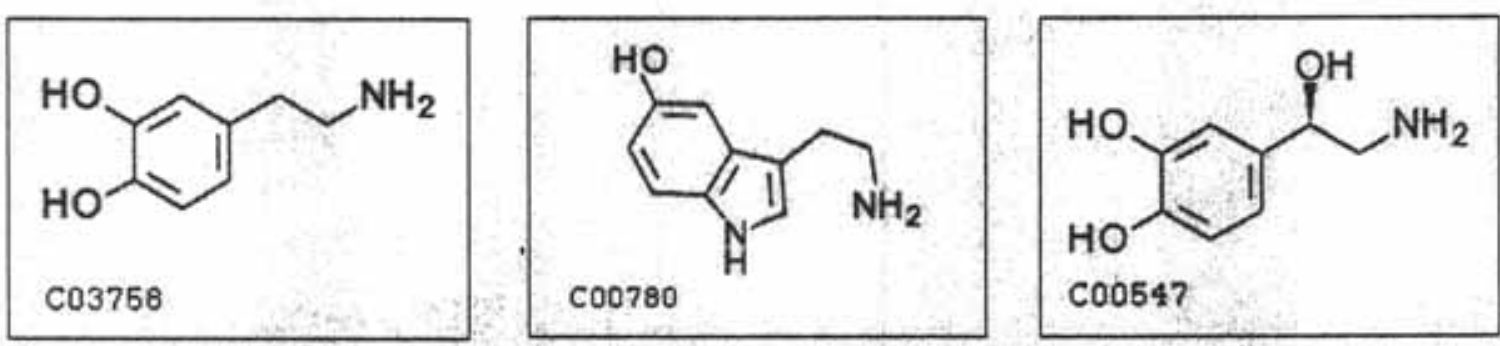

Figure 15. KEGG compounds: dopamine [2,5-Dimethoxy-4-ethyl-phenethylamine] (C03758), serotonin [5-Hydroxy-tryptamine] (C00780), and norepinephrine (C00547).

These three molecules, serotonin, dopamine, and norepinephrine, function as "transmitters" in the neural networks of brains. As a system of inscription, this cartography maps out a domain newly opened for power in control societies: the domain of the molecule. 
To elucidate this point, I turn to the research by molecular biologists on nutrition and the constitution of behavior. ${ }^{44}$ Researchers have observed various nutrients affecting the mature nervous system, including but not limited to tryptophan, phenylalanine, and tyrosine. The biologists suggest that increasing the availability of tyrosine and tryptophan-two amino acids that act as neurotransmitter precursors - can change the rate and amount at which these neurotransmitters are generated. The biologists' research indicates that changes in mood and sleep patterns may occur after the administration of tryptophan, a precursor to serotonin. They have also studied tyrosine for its impact on the production of dopamine, norepinephrine, and epinephrine. Their evidence suggests that administering tyrosine can stimulate the production of these catecholamine neurotransmitters.

The regulation and use of dietary supplements illustrates Galloway and Thacker's observation that, in control societies, informatics and biology combine to "impel, enhance, and optimize the species-population as it exists within the contexts of work, leisure, consumerism, health care, entertainment, and a host of other social activities." ${ }^{45}$ Many dietary supplements contain large quantities of the amino acids discussed above. In the US, "dietary supplements" are on a juridical schedule of substances, first defined in the Dietary Supplement Health And Education Act (DHEA) of 1994. Utah Republican senator Orrin G. Hatch introduced the DHEA. Hatch received "hundreds of thousands of dollars in campaign contributions, political loyalty and corporate sponsorship" ${ }^{, 46}$ from the

44. E. Wurtman, "Tyrosine: Effects on Catecholamine Release," Brain Research Bulletin 21, no. 3 (1988): 473-77; J. D. Fernstrom, "Can Nutrient Supplements Modify Brain Function?," American Journal of Clinical Nutrition 71, no, $6(2000)$ : 1669-75.

45. Galloway and Thacker, The Exploitt, 26. 
many corporations manufacturing such supplements in his home region, which is nicknamed "the Silicon Valley of the nutritional supplement industry.,"47 The act restricted the Food and Drug Administration's ability to regulate these supplements: It can now only regulate such substances as a category of food, and not as a category of pharmaceuticals. The 5-Hour Energy dietary supplement, a form of supplement also known as an "energy shot," sells seven to nine million bottles a week in the US. ${ }^{48}$ A single 5-hour Energy contains $8333 \%$ of the recommended daily allowance of Vitamin B12, an important cofactor in enzyme reactions. In relation to the amino acids above, that is, the precursors for these same enzyme reactions as they would pertain to neurotransmitter production, a 5-hour Energy supplement is roughly the equivalent of $200 \mathrm{~g}$ worth of soy protein isolate.

The television commercials for 5-hour Energy make their intended purpose and use clear enough: work. If an employee is lacking in energy, then the employee can consume $57 \mathrm{~mL}$ of a liquid containing concentrated amounts of the precursors and cofactors necessary for their biological systems to provide them with more energy. Standing in front of a cubicle and a dozing worker, the spokesman in one 5-hour Energy television commercial begins by asking: "You know what 2:30 in the afternoon feels like, right?" He turns to the worker: "Sleepy?" The spokesman then appears in a board room meeting of some kind, and turning to a yawning man sitting at the conference table, he asks: "Groggy?" Next, out in the hallway of the office building, he asks: "What do you

46. Eric Lipton, "Hatch a 'Natural' Ally of Supplements Industry," New York Times, June 20, 2011.

47. Ibid.

48. Clare O'Connor, "The Mystery Monk Making Billions with 5-Hour Energy," Forbes, February 27, 2012. 
do? Run for a coffee? Grab a soda? But how long does that last before you're back for more?" Finally, the spokesman comes to the point: "Try this instead, take one 5-hour Energy, then see what the rest of your day feels like...." Each of the previously tired-out workers are then shown again, newly enlivened and focused on their jobs. The spokesman concludes, "Sure won't feel like 2:30."

Four hundred thirty-six $\mathrm{mg}$ of caffeine and $44 \mathrm{~g}$ of high fructose corn syrup are not sufficient stimulants for the producers of the post-industrial commodity in control societies. And while discourse and culture are necessary fields for the manufacture of the dividual, the available positive molecular techniques and tactics are becoming ever more precise. If the worker is too "groggy," he or she can take an "energy shot" with phenylalanine and tyrosine coupled with the cofactors necessary for converting these amino acids into the desired neurotransmitters, such as dopamine and norepinephrine. Upon the employee's returning home from work, perhaps overstimulated, "chill shots" are also available with enough melatonin and tryptophan to insure relaxation until the next workday. Molecular biologists suggest that the dopaminergic system, as one example, influences everything from locomotion and endocrine regulation to cognition, emotion, arousal, motivation, and reward. Dopamine is a much more effective motivator than the browbeating managers of the disciplinary factory.

As governments have prioritized the management of the molecularized body, creative scientists have converted their own zoē into a field of experimentation. Agamben provides the example of "Wilson" from one of Paul Rabinow's studies. Wilson was a biochemist who decided to make his own body and life into a laboratory after discovering that he suffered from leukemia. Since Wilson was accountable only to himself, the 
barriers between ethics and law disappeared; scientific research freely and fully coincided with biography. His body was no longer private, since it was transformed into a laboratory; but neither was it public, because it was his own body. "Experimental life,"” explains Agamben, "is the term Rabinow uses to define Wilson's life. It is easy to see that 'experimental life' is a bios that has, in a particular sense, so concentrated itself on its own $z o e \bar{a}$ as to become indistinguishable from it., ${ }^{49}$

Another exemplar of this "experimental life" is chemist Alexander Shulgin. The 1,000 pages of Shulgin's Phenethylamines I Have Known and Loved (PiHKAL), and the 800 pages of its follow-up, Tryptamines I Have Known and Loved (THHKAL), present a manner of "psychophysiological nonsense," to borrow Kittler's description of Schreber's writing, adequate to the molecular biopolitics of control societies. Each of Shulgin's two volumes is divided in half, with the first half an autobiography coauthored with Shulgin's wife Anne, a psychologist, and the second half a list of compounds Shulgin created and assayed-179 phenethylamines in PiHKAL and 55 tryptamines in TiHKAL, including protocols for the synthesis of these compounds and descriptions of their effects at various dosage levels. As discussed above, phenylalanine and tryptophan are precursors to two important neurotransmitters. Extending this logic, PiHKAL is concerned with exploits around the decarboxylated form of phenylalanine, that is, phenethylamine, and TiHKAL is concerned with the decarboxylated form of tryptophan, that is, tryptamine. As with any other formal system of inscription, the logic in this case can only be opened on its own terms, which is, in this case, the relevant skeletal notation. Here, it is evident that tryptamine and phenethylamine are the bases of serotonin and dopamine, of which

49. Giorgio Agamben, Homo Sacer: Sovereign Power and Bare Life, trans. Daniel Heller-Roazen (Stanford, CA: Stanford University Press, 1998), 104. 
serotonin and dopamine are, respectively, substitutions. Both molecular pharmacology in general and Shulgin in particular operate by extending this logic: for example, attaching various functional groups (e.g, adding a methoxy group at the 2 and 3 positions) to these two molecules, or "transmitter" precursors.
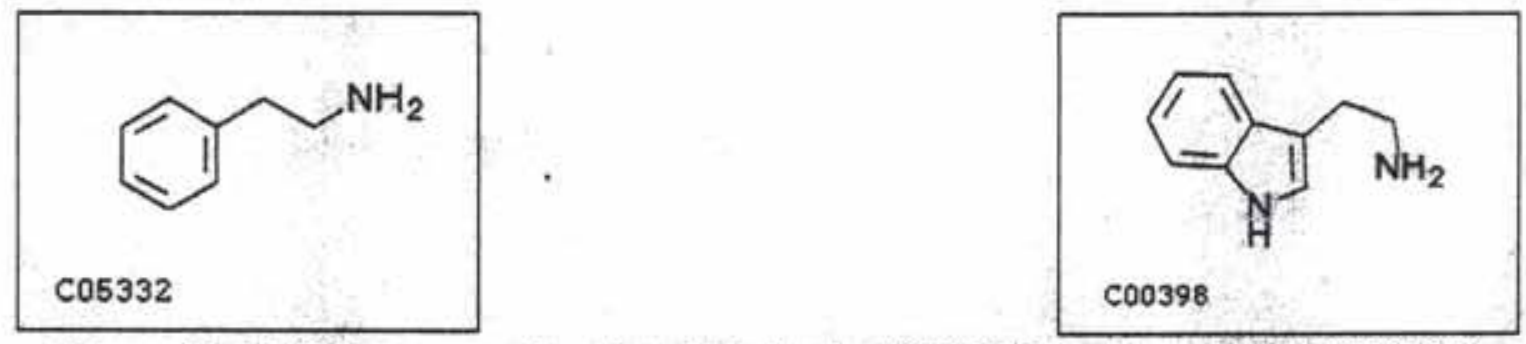

Figure 16. KEGG compounds: phenylethylamine (C05332) and tryptamine (C00398).
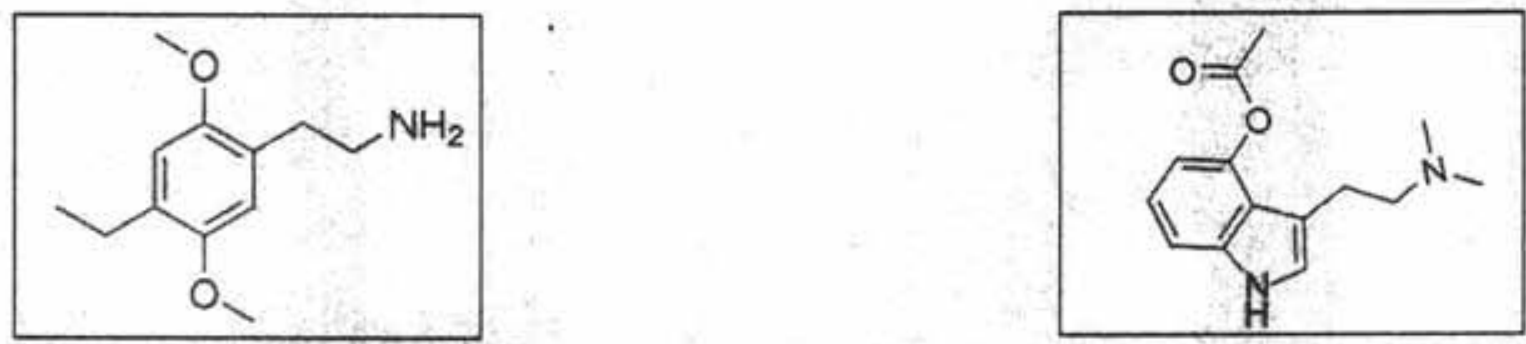

Figure 17. PiHKAL and TiHKAL: e.g., 2,5-dimethoxy-4-ethyl-phenylethylamine and 4AcO-dimethyl-tryptamine.

Shulgin was introduced to chemistry during World War II. He was stationed on a destroyer escort, the USS Pope, with nothing to read but an English translation of Nobel laureate Paul Karrer's Lehrbuch der OrganischenChemie. After the war, Shulgin entered the University of California at Berkeley, where, with an "uninspired research project" and a "dull thesis," ${ }^{30}$ he eventually completed a Ph.D. in biochemistry. Shulgin then took a position as a research chemist for Dole Chemical Company. "Within the first couple of

50. Alexander T. Shulgin and Ann Shulgin, PiHKAL: A Chemical Love Story (San Francisco: Transform Press, 1995), 18. 
years," explains Shulgin, "I made the powers that be very happy by predicting the structure of, and synthesizing, an insecticide that actually went into commercial production." ${ }^{51}$ In return for his successes, Dole allowed Shulgin to pursue his own research interests, namely, centrally active compounds. The two most common animal models for experimentally testing such compounds at the time, Shulgin explains, "were Siamese fighting fish and spiders. The spiders were reported to weave dose-dependent construction errors in their webs as a measure of $[\ldots]$ intoxication $[\ldots]$. And the fish $[\ldots]$ would do something strange [...]; swim backwards or upside down, or something equally strange." ${ }^{52}$ With his Dole laboratory quickly becoming an aquarium, and this aquarium quickly filling with algae, Shulgin and his colleagues "watched and watched [but] never saw anything occur that was even slightly suggestive of a drug effect." 53 "Thus," explains Shulgin, "all discovery must use the human animal and I was, by default, that animal. Quite simply, as I developed new structures that might show some interesting action in the realms of thought or perception, I used myself as the experimental test subject to determine these actions." 54

Shulgin left Dole in 1966. "This was, after all," explains Shulgin, "the era of our Vietnam adventure, and immense pressures were being brought to bear on big industries everywhere throughout the country, to direct all their energies to the government's need." 55 Shulgin then headed to the San Carlos Aerospace Laboratory. He could not abide

51. Ibid.

52. Ibid., 19.

53. Ibid.

54. Ibid.

55. Ibid., 41. 
the security clearance mandates, however, and so he was also ejected from that research group. "In any case," explains Shulgin, "I was out of the San Carlos Aerospace Laboratories, and I was out of the academic world as well. By good fortune, I had continued to build my own private laboratory during the time I was at Sunnyvale, so my die was cast; I was now officially a scientific consultant. ${ }^{, 56}$ For twenty years Shulgin did contract work for the U.S. Drug Enforcement Agency (DEA), identifying and analyzing different compounds for them. Meanwhile, he had established a volunteer research group of other academics and scientists from the Bay Area, in order to test the growing number of compounds he was synthesizing at home. "The question of informed consent is completely different in the context of this kind of research group," explains Shulgin, "[...] the idea of malpractice or legal redress is without meaning [...]. Everyone of us understands that any form of damage, either physical or psychological, $[\ldots]$ would be responded to by all other members of the group in any way required [...]. In other words, we are all close friends. ${ }^{57}$ Shulgin and his research group continued their experiments until just after Shulgin published PiHKAL. At that point, however, the DEA suspended his license and shut down his laboratory. PiHKAL, as it turned out, had become the bible for clandestine chemists across the US.

The second halves of both PiHKAL and THHKAL contain the protocols for synthesizing the various compounds in addition to reports from the research group on the compounds' effects at different dosage levels. In the PiHKAL entry for 2,5-dimethoxy-4ethylthioamphetamine (ALELPH-2), for example, Shulgin reports that at $7 \mathrm{mg}$ there was

56. Ibid., 46.

57. Ibid., xxvi. 
"an amazing unification of visual hallucination seen only in the very fine detail of something $[\ldots]$ a small curve or bump can become whatever you wish. For a moment. And then it chooses again, but differently. Is all of our perceived world as subjective as this?"58 Shulgin reports that at $8 \mathrm{mg}$ there was "extreme intoxication, but almost no visual phenomena. Even well into the evening, I know I absolutely could not drive. Why? [...] It's that I don't trust that the reality I see is the same reality that the other driver might see." $\$ 9$

Shulgin's autoexperiments provide a productive contrast with the sanctioned pharmaceutical prescriptions of psychiatrists. The intent and outcome of psychiatric prescription is, of course, predicated exactly upon the desire to make one see "the same reality" that "normal" people see. If the child cannot focus, the compound will help the child focus, along with everyone else. If the insurance salesperson cannot find the motivation or sense in doing his or her job, the compound will provide the salesperson with this motivation. If the CEO is overcome with anxiety in his or her dealings, the compound will help the CEO relax. Consider, now, these passages from PiHKAL. With $10 \mathrm{mg}$ of 2,5-dimethoxy-4-methylthioamphetamine (ALEPH), "there was a rapid shift of frame of reference that made simple tasks such as reading and tuning the radio quite alien [...] I am able to interact with people on the telephone quite well but mechanical things, such as arranging flowers or alphabetizing names, are beyond me." ${ }^{60}$ Shulgin reports stripping naked during an attack of panic, which lasted about twenty minutes, while on 12

58. Ibid., 466.

59. Ibid.

60. Ibid., 463 . 
$\mathrm{mg}$ of 2,5-dimethoxy-4-(i)-propylthioamphetamine: "I was weighed down by everything - physical, psychic,'emotional. My clothes had to come off, my hair had to be released, my shoes went, I needed to move away from where I was, to somewhere else, to some new place, with the hope that my other old place wouldn't follow me. Pretty soon I found I was myself, I could breathe again, and I was okay. Rather sheepishly, I dressed and rejoined the group." ${ }^{\circ} 1^{\circ}$ And finally, of a $64 \mathrm{mg}$ dose of 2-bromo-4,5dimethoxyphenethylamine (2C-B), a compound that has become a controlled substance in the US, one member of Shulgin's research group reports: "Everything that was alive was completely fearsome. I could look at a picture of a bush, and it was just that, a picture, and it posed no threat to me. Then my gaze moved to the right, and caught a bush growing outside the window, and I was petrified. A life-form I could not understand, and thus could not control. And I felt that my own life-form was not a bit more controllable." ${ }^{62}$

The experiences molecularly created and sought in the experimental life of Shulgin and his research group serve no "useful" purpose whatsoever. Importantly, this includes the purpose of relief in the soporific or merely recreational sense: Many of the experiences produced were either anxiety-producing or absolutely dysphonic, and there could be no assurance either way in advance. ${ }^{63}$ After a $60-\mathrm{mg}$ intramuscular injection of dimethyltryptamine, Shulgin writes: "I don't like this feeling-I am not myself. I saw such strange dreams a while ago. Strange creatures, dwarfs or something; they were black and moved about. Now I feel as if I am not alive. My left hand is numb. As if my heart
61. Ibid., 469.
62. Ibid.
63. See Notes 3.2.1. 
would not beat, as if I had no body, no nothing. All I feel are my left hand and stomach. I don't like to be without thoughts." ${ }^{64}$

In the U.S. and elsewhere, a whole host of legislation to restrict "designer drugs," many of which Shulgin was the first to synthesize, has appeared over the last three decades. News stories of the overblown variety, which include all of these disparate compounds under the blanket name "bath salts," ensure cries for prohibition. The state has so taken upon itself the duty to police (or facilitate, depending on the molecule in question) the "mobility" of various molecules across blood-brain barriers, much in the way that it regulates the movement of people and goods across borders. In the US, for example, Minnesota Senator Amy Klobuchar introduced legislation outlawing "harmful synthetic substances" such as Shulgin's creations (Figure 17), 2,5-dimethoxy-4-ethylphenethylamine (2C-E) and 4-Acetoxy-dimethyl-tryptamine (4-AcO-DMT), within a larger bill called the "Food and Drug Administration Safety' and Innovation Act." 2C-E, for example, is active at the milligram level; this means that without a special microscale for dosage, the likelihood of an overdose is great. The legislation, however, involves no measures to better educate would-be users; rather, it only provides "law enforcement with the tools they need to crack down on synthetic drugs," that is, to prevent such use altogether. ${ }^{65}$

However bound to the discursive conditions of possibility one's sense of reality might finally be, this sense clearly finds a material limit point in both the nutritional

64. Alexander T. Shulgin and Ann Shulgin, THKAL: The Contimuation (San Francisco: Transform Press, 1995), 476.

65. "Klobuchar's Bipartisan Provision Banning Dangerous Synthetic Substances," news release, Senator Any Klobuchar's website, June 26, 2012, http://www.klobuchat.senate.gov/public/newsreleases?ID=0bf804f5-a0b5-4825-90c9-41d964d30502. 
supplements sanctioned by Senator Hatch and the designer drugs "cracked down" upon by Senator Klobuchar. In these controls and experiments, materiality is mobilized on a level that gives the lie to any analysis that would otherwise preclude recourse to such materiality's effectiveness. Regardless of one's own locus of enunciation, and all the presuppositions and exclusions comprising it, one is also always participating in some underlying materiality. Wherever a body stands, $64 \mathrm{mg}$ of 2C-B will radically alter its range and capacities. Shulgin's autoexperiments mark a free use of the proper-the "proper" here being one's own biochemical pathways-in the strictest, chemical sense.

\subsubsection{Genopolitics}

Molecular biologists are uncovering an increasing amount of information about the brain and its relationship to behavior, and this information is increasingly being used in the service of social management. Advances have been made, for example, in the ability to intervene and modulate brain function, and the use of new classes of drugs (e.g. "smart drugs," SSRIs) is increasingly widespread. Along with pharmaceuticals, a number of interventional technologies have also been developed. Innovations such as electroconvulsive therapy (ECT) are now available alongside newer techniques such as transcranial direct current stimulation (tDCS) and transcranial magnetic simulation (TMS). In the latter, electromagnetic energy is used to manipulate and control the moods and behaviors of brains. These advances are prompting new questions in the "bioethical" community and have even led to a new subfield termed "neuroethics." This field addresses novel medical dilemmas: Is fully informed consent possible when the organ that needs evaluation is the same one that must provide the consent? Where is the 
dividing line between experimentation and therapy? Does intrusion into brains involve a form of mind control, and who is responsible for the behavioral outcome of such alterations?

Many of these questions have recently arisen because examining live brains has only become possible in recent years. The emergence of noninvasive imaging technologies began with electroencephalography, followed by radioisotope scanning, and later, computerized axial tomography (first using $\mathrm{x}$-radiation, then magnetic resonance and positron emission). These methods have enabled the development of a new "molecular" gaze that can monitor brains as they function and that can answer questions about such things as love, personality, and addiction. A great deal of research has focused on aggression.

The neurobehavioral community generally agrees that "brain dysfunction"ranging from frontal lobe disturbances to altered neurochemical metabolism-leads to violent tendencies, and that understanding such dysfunction will be crucial to future progress in predicting and arresting such tendencies. The causes and consequences of "brain dysfunction" are both assorted and complex. Some research has implicated damage to the prefrontal cortex in addition to alterations in the amygdala and corpus callosum. Researchers have also targeted other biology-based sources of behavior-for example, "[a] genotype predicting violence" ${ }^{\prime 66}$ has led to the claim that men are typically more aggressive than women. Molecular biologists also point to hormones: Higher levels of testosterone increase the likelihood that a man will commit a violent act, while the opposite relationship applies to neurotransmitters such as serotonin. Policymakers and

66. Robert Blank, "The Brain, Aggression, and Public Policy," in Politics and the Life Sciences 24, no. 1/2 (March, 2005): 15. 
legal scholars have contemplated about how new information concerning the brain should be taken into account during events such as criminal sentencing. Along these same lines, legal consequences will follow from the answers to questions such as whether defendants or criminals can be coerced into various therapies before or after they stand trial.

Alison Abbott opens her article "Scanning Psychopaths" with a peculiar scene: A prisoner, patient 13 , is about to undergo a functional magnetic resonance imaging (fMRI) scan at the University of Groningen. The researcher conducting the scan, Harma Meffert, wears an alarm around her neck, and the subject is fitted with special nonmetal handcuffs and a brace that prevents him from running. Abbott reveals that patient 13 has been selected for the study after he scored the maximum rating of 40 on the Psychopathy Checklist-Revised (PCL-R) rating scale. The PCL-R is a tool used to evaluate personality and behavioral traits attributed to psychopathy, and it requires trained psychiatrists to cover hundreds of questions in a patient interview and to incorporate other information such as social workers' reports. The evaluation has four components: "'interpersonal', covering behaviour such as manipulativeness and lying; 'affective,' covering irresponsibility and lack of empathy and remorse; 'lifestyle,' tracking impulsivity and need for stimulation; and 'antisocial,' which looks for records of things such as juvenile delinquency." ${ }^{67}$ The test, which was developed by Robert Hare, is acknowledged as a predictor of recidivism. Hare also developed a similar test to be used in the general population, the PCL-SV (for "screening version"), and he has used this test to estimate that $1 \%$ of the general population may be psychopathic. Hare believes that some degree of psychopathy could benefit individuals in certain professions, including "police officers 
or others for whom unnecessary empathy could have negative consequences. ${ }^{98}$ Since 2004, many countries have implemented PCL-R testing in their parole process. For Meffert and other researchers, the hope is that further understanding will provide answers about why certain individuals "[d]o terrible things to other people." 69

In "Neuroeconomics: Making Risky Choices in the Brain," Daeyol Lee provides a neurobiological explanation of the propensity towards "risky choices," Likewise, a study by McCoy and Platt (2005) explores the brain processes and cellular mechanisms underlying risky decision-making. Their results indicate that in animals, specific neurons in the posterior cingulate cortex are responsive to the "riskiness" of a choice. This study and other neurobiological research studies have the potential to "augment current economic theories of decision-making. ${ }^{70}$ Economists use various definitions to convey the relationship between decisions, risks, and risk evaluations. For example, in situations that are considered uncertain, risk is defined as "[a] spread from the mean in the objective values of possible outcomes (variance)." ${ }^{71}$ Utility is a term that refers to "[ $\left.t\right]$ he numerical measure of an individual's preference or subjective value for an object, ${ }^{, 72}$ often applied in concepts such as utility maximization and expected utility theory. Expected utility theory can be loosely stated as the idea that when choices involve uncertain outcomes, the utility of a choice is its expected utility. More specifically, the utility of a choice can

68. Ibid.

69. Ibid.

70. Ibid.

71. Daeyeol Lee, "Neuroeconomics: Making Risky Choices in the Brain," Nature Neuroscience 8, no. 9 (2005): 1129.

72. Ibid. 
be evaluated by adding probability-weighted utilities from each possible outcome. A decision is said to be risk neutral when combining possible outcomes leads to the same mean value: "In other words, uncertainty in the outcome (risk) does not affect utility when utility of a choice is proportional to its objective value."73

To evaluate whether brain signals relate to utility as a subjective value or to reward as an objective value, McCoy and Platt conducted a study on monkeys and their selection of "risky" targets while recording neural activity in the posterior cingulate cortex. The monkeys were presented with a choice between two targets with the same mean outcome (volume of juice dispensed from a target). One option, however, had a fixed outcome and the other had a variable outcome. The results showed that monkeys systematically chose the risky target, even when researchers altered the setup so that the risky target actually provided a smaller average reward. Regarding neural firing, it appeared that more than half of the neurons were signaling both the choice and the riskiness of the monkey's choice. Given that the monkeys demonstrated risk-prone behavior, it would seem that the utility of the risky option was considered greater than the average reward utility. Indeed, McCoy and Platt found that rather than just the size of the reward, the monkeys' neurons seemed to signal the option's utility. Although McCoy and Platt initially hypothesized that recent experience was affecting the estimates of utility and reward, their neural data showed that actions in the posterior parietal cortex did not reflect reward values from the previous trial. Revamping their theory, McCoy and Platt summed the reward and risk of each trial to find the utility of options per trial, and they found that the approach appeared to provide a better model of neural activity, McCoy and Platt's study suggests that decisions about risk can be quantified neurobiologically.

73. Ibid. 
The line of force towards the molecular has also found its way into the field of political science. In their American Journal of Political Science article "Genetic Variation in Political Participation," ${ }^{74}$ for example, James Fowler, Laura Baker, and Christopher Dawes attempt to identify specific genes related to a political behavior-in this case, voter turnout. The authors base their theories on the notion that voting is a type of prosocial behavior, and they cite as evidence the fact that analogous behaviors (such as community involvement) have already been attributed to genetic factors. This evidence involves "biomarkers," the political implications of which Nikolas Rose has investigated at some length.

A biomarker, as defined by Rose and Ilina Singh, is "[a] characteristic that is objectively measured and evaluated as an indicator of normal biological processes, pathogenic processes or pharmacological responses to a therapeutic intervention." 75 Examples of biomarkers include specific genetic sequences, patterns of neural activity, and endophenotypes indicated through biochemical, physiological, or psychological characteristics. Currently in psychiatry, diagnoses are made using the signs, symptoms, and disease trajectories described in the Diagnostic and Statistical Manual of Mental Disorders IV (DSM-IV). Biomarkers have the potential to supplement or even reorganize the way disorders are classified because they are based on physiological criteria. Singh and Rose note: "In this sense, biomarkers promise to be the most powerful psychiatric tool since the discovery of antipsychotic drugs-a biological means of predicting not

74. James Fowler, Laura Baker, and Christopher Dawes, "Genetic Variation in Political Participation," The American Journal of Political Science 102, no. 2 (May 2008): 233-48.

75. Ilina Singh and Nikolas Rose, "Biomarkers in Psychiatry," Nature 460 (2009): 204. 
only the development of a disorder but also its course and outcome." ${ }^{76}$ The clinical use of biomarkers will inevitably lead to their use in other arenas. When it comes to children, the most notable of these arenas are the classroom and the courtroom. Advocates of neuroscientific research believe that the findings should be integrated into such entities as classroom structure and that early detection systems should be employed to identify learning disabilities and other developmental disorders. Some believe that neuroscientific research findings have already influenced some decisions in the courtroom. For example, studies indicate that the brain is not fully developed in teenagers, and so adolescents may not have the same degree of control over impulsive behaviors as adults. This conclusion likely prompted lawmakers to rule out the death penalty for children under eighteen. ${ }^{77}$

Biomarkers are not the causes of disorders, but rather indicators of the probability that a problem may exist. If used alone, biomarkers usually have small effect sizes, meaning they are not strong predictors of a condition. Pairing biomarkers with other social and environmental information, however, increases the strength of the prediction. At present, many psychiatric researchers are hesitant to embrace the predictive capabilities of biomarkers. Still, it is not unusual to find overgeneralization and simplification of neuroscientific discoveries outside of professional circles. Overstated claims tend to become more widespread once commercial enterprises have a financial stake, a trend that has already been seen for many over-the-counter diagnostic tests.

In their research on political participation, Fowler and Dawes look to two genes, MAOA and 5HTT, that influence the serotonin system of the brain. They offer two

76. Ibid., 202.

77. Ibid. 
hypotheses based on previously observed associations of less transcriptionally efficient MAOA and 5HTT genotypes with antisocial conduct: first, that "people with more transcriptionally efficient alleles of the MAOA and 5HTT genes are more likely to vote," and second, that "an association between each of these genes and yoting may be moderated by social activity." ${ }^{78}$ Fowler and Dawes choose MAOA and 5HTT because these play a role in the metabolism of serotonin. Stress stimulates neurons to release excess serotonin into the synaptic cleft. If left in the cleft, serotonin can be oxidized into a toxic substance that eventually kills both the pre- and postsynaptic neurons. To prevent this, the presynaptic neuron reabsorbs serotonin via the 5HTT transporter and degrades it via the monoamine oxidase A (MAOA) enzyme. Not only do enzymes endogenous to biological systems carry out the substitution reactions necessary to convert tryptamine into serotonin; there are also enzymes that carry out the reactions necessary to breaking these transmitters down. The MAOA and 5HTT genes are responsible for this breakdown, or metabolism, of neurotransmitters.

Fowler and Dawes believe these findings are relevant to voter turnout and other political behaviors because the behaviors are fundamentally social in nature. The authors reason that individuals who are sensitive to social conflict will be less likely to vote. They also propose that individuals with more resilience to stress will be more likely to vote, and that this is a potential result of possessing either the "high" MAOA or "long" 5HTT polymorphism. Overall, they hypothesize that voter turnout will show significant association with MAOA and 5HTT and that for individuals with the "high" or "long" alleles, involvement with religious group activity will further increase the likelihood of

78. James Fowler and Christopher Dawes, "Two Genes Predict Voter Turnout," The Journal of Politics 70, no. 3 (July 2008): 579. 
voting because it builds a sense of community.

Fowler and Dawes assert that the results of their study have unique import for the political science community: "The results of this analysis are clear: we have found that two extensively studied genes are significantly associated with voter tumout. Further, these are the first two genes ever directly associated with political behavior." ${ }^{79}$ They note that previous models of voter turnout neglect to account for heterogeneity related to individual genetics. In particular, they refute the notion that such behaviors are exclusively the product of environment: "Although the environment is extremely important for turnout and other political acts, perhaps even more so than genes, we can no longer act as if genes do not matter at all. ${ }^{, 80}$ They believe that genetics may be the key to explaining other well-known voting phenomena such as the facts that parental turnout is a strong predictor of turnout in young adults and that turnout is habitual. Anticipating challenges to the practical application of their findings (and to future genetic research in the field of political science), Fowler and Dawes assert: "Genes are the institutions of the human body - they constrain ịdividual behavior just as political institutions constrain the behavior of groups of people." ${ }^{, 1}$

Evan Charney and William English have responded to Fowler and Dawes in a series of articles. They believe that the integration of behavior genetics into political science was a "natural development," one prompted by various studies purporting to show genetic associations for everything from leadership to credit card debt. Many of

79. Ibid.

80. Ibid.

81. Ibid. 
these findings use twin studies to show heritability, but Charney and English challenge this model in light of recent scientific advances: "A lot has changed in our understanding of genetics since then, and recent advances in molecular genetics are necessitating a rethinking of every one of the assumptions of the classical twin study methodology." ${ }^{182}$ More importantly, they challenge the "second wave" of political science research that uses candidate gene association (CGA) studies: "The number of recent claims by social scientists to have discovered a statistically significant association between a particular common gene variant-either on its own or in conjunction with a particular environment-and complex, politically relevant behaviors warrants careful evaluation." 83

Charney and English finally turn from the debate over Fowler and Dawes to address the program of "genopolitics" as a whole:

Genopolitics relies on a conception of the human brain that complements its conception of the genome. For all the lip service paid to complexity, the "genopolitical brain" more resembles a mechanical toy whose behavior is determined by the 25,000 little wind-up toys (i.e., genes) of which it is composed than a neuronal collective whose behavior is characterized by emergent selforganized criticality to enable rapid and flexible responses to the demands of a variable environment. Given that such a mechanical brain would have broken down long ago in evolutionary history, we can be thankful that it has no more reality than its mechanical genome. ${ }^{84}$

Charney and English's critique of Fowler and Dawes strongly supports the conclusion that research into "genopolitics" is based on a flawed and simplistic paradigm of genetic causality and brain functioning. The line of force toward the molecularization of politics represented by the work of Fowler and Dawes, however, need not lead to a fully

82. Evan Charney and William English, "Genopolitics and the Science of Genetics," American Political Science Review 107, no. 2 (2013): 382-95, 382.

83. Ibid., 384.

84. Ibid. 
realizable research program in order to achieve a certain political efficacy. After all, the eugenic legislation of a century ago did not fail to have real (and deadly) political consequences, even though the scientific claims that grounded it have been thoroughly discredited.

\subsubsection{Biocolonialism}

As an instance of the political efficacy of the line of force towards the molecular, Deborah Halbert's study of biocolonialism documents the transformation of "human rights" into what she refers to. as a "bundle of rights"; today, Halbert argues, "property law $[\ldots]$ understands the human body as a "bundle of rights." ${ }^{85}$ Halbert is referring to a juridically authorized process within which the liberal Lockean idea of property as that which has been mixed with labor and also ideas of property in chattel were extended to the molecular substrates of living organisms' genetio material such as cell lines and even certain organisms. "In other words," explains Halbert, "the researcher 'tames' the 'wild' cells and thus can take 'possession' of the cells. The image of the body as wilderness filled with wild cells again reduces the human to the status of an object." ${ }^{, 86}$ Halbert provides the example of the Hagahai people of Papua New Guinea: "The Hagahai needed medical assistance and in return for medicine they donated blood samples to U.S. anthropologist Carol Jenkins," explains Halbert. "The blood turned out to have a unique property resistant to a type of leukemia. After identifying the important properties, the National Institute of Health filed a patent on the cell line from a member of the tribe." ${ }^{87}$

85. Deborah Halbert, Resisting Intellectual Property Laws (London: Taylor and Francis, 2005), 112. 86. Ibid., 127. 
The Rural Advancement Foundation International (RAFI) and other indigenous rights groups found the implicit distinction made between the Hagahai and their genetic substrate unconvincing. The fact remains, however, that various molecular substrates, when they have been isolated and replicated through the labor of a biotech company, become by right that company's property. "Once a human body has been divided into an abstract bundle of rights," concludes Halbert, "these rights can form new networks of ownership and control over the body." 88

Halbert's research suggests that the Aristotelian distinction between bios and zoê, which has enjoyed renewed interest amongst political science scholars in light of the War on Terror, does not go far enough in addressing the complexity of government and rights in control societies. In relation to this renewed interest, for example, Agamben has deployed the distinction between "qualified life," bios, and "bare life," zoê, along with Carl Schmitt's famous definition of sovereignty, so that today, the sovereign would be that which draws the lines between bios and zoê. The drawing of such lines, he argues, is evident in spaces such as Guantánamo Bay in Cuba, Belmarsh Prison in London, and the prison at Abu Ghraib, in addition to other super secret prisons holding "enemy combatants" without a charge and without their having recourse to human rights. For Agamben, these prisons are spaces where violence over zoê is juridically authorized in that these "enemy combatants" have no bios. Precisely what the approved torture methods would involve is indicated in a memo from Major General Dunlavey, dated 11 October 2002, requesting permission from General James T. Hill to approve techniques
87. Ibid., 121.
88. Ibid., 113. 
known as "Survival Evasion Resistance Escape," or SERE, drawn from U.S. survival techniques training given to American forces during the Cold War to resist the worst of communist Gulag treatment. The techniques recommended for use against detainees in the "War on Terror" included:

The use of stress positions such as the proposed standing for four hours, the use of isolation for up to thirty days, and interrogating the detainee in an environment other than the standard interrogation booth [...] the deprivation of light and sensory stimuli, the placement of a hood over the detainees head during transportation and questioning, and the use of 20 hour interrogations [...] forced grooming and the removal of clothing [...] the use of scenarios designed to convince the detainee that death or severely painful consequences were imminent for him or his family, exposure to cold weather or water [...] the use of a wet towel to induce the misperception of suffocation. ${ }^{89}$

With this example, and in light of Halbert's research, it is evident that the problematic does not necessarily involve unqualified "bare life," but rather ever more sophisticated technologies of inscribing zoê. The U.S. citizen, for example, has a constitutional right not to undergo cruel and unusual punishment. If the sovereign decrees this citizen an "enemy combatant," however, it is not as if this citizen is no longer qualified at all with respect to the citizen's rights; on the contrary, the citizen is now even more qualified. The U.S. citizen has the relatively noncomplex right banning cruel and unusual punishment, while the "enemy combatant" has a right that precludes, for example, the breaking wheel, boiling to death, flaying, disembowelment, crucifixion, impalement, crushing, stoning, execution by burning, dismemberment, sawing, scaphism, and necklacing, but not stress positions, water boarding, humiliation, solitary confinement, 20-hour interrogations,

89. Memo from the Army Deputy to the Assistant Deputy Chief of Staff for Operations and Plans (Joint Affairs) to the Joint Staff, J-51UNMA [UN and-Multilateral Affairs Division], S/S 02-06697 (November 7,2002); Memo from Department of the Army, Office of the Judge Advocate (International and Operational Law) to The Office of the Army: General Counsel, Review-Proposed Couinter-Resistance Techniques (undated). Memo for Army General Counsel. Proposed Counter-Resistance Technigues. ") 
forced removal of clothing, or the "use of scenarios designed to convince the detainee" that all the forbidden procedures enumerated above may in fact be used against him. Similarly, it is not as if the Hagahai are considered as unqualified "bare life" from the position of the NIH; rather, they are now qualified down to the level of their cell nuclei.

I began my study with the societies of classicism, where the pistol was still a recent invention and the cannon remained the heaviest tactical weapon available. By the time the societies of discipline were disintegrating, however, it was under the clouds of the sulfur mustard that was being fired in the trenches of northeastern France. The societies of control set themselves in motion with all the force of a hydrogen bomb. Robert Stone's documentary, Radio Bikini, shows several outtakes from a black and white American propaganda newsreel, Crossroads, which was filmed on Bikini Beach only days before the first hydrogen bomb tests began in the Pacific Proving Grounds. ${ }^{90}$ A navy officer sits on the beach before a group of confused Marshallese, speaking to them by way of a translator as if they were children: "Now then, James," says the navy man, "tell them please, that the United States Government now wants to turn this great destructive power into something for the benefit of mankind, and that these experiments here at Bikini are the first step in that direction." Stone's film makes a point of the emptiness that the navy man's apparent colonial benevolence would conceal, as the film presents take after take of the navy man repeating his speech for the benefit of the camera: "[A]nd now, James, will you tell them that the U.S. government wants to turn this great destructive force into something good for mankind ... ?" Crossroads, scene 25, take 15: “... something good for mankind." Crossroads scene 25, take 23: “... something good...." This continues until Kilon Buano again appears on screen: "They were taking many 90. Radio Bikini, directed by Robert Stone (Rhinebeck, NY: Robert Stone Productions, 1988), DVD. 
pictures of us," explains Buano, "at that time, I didn't know what a camera was, [or] why they had to do everything so many times."

The Rongelap Report provides a more detailed account of what the control societies provide, through their encounter with the Marshall Islands. The report details the events surrounding 67 atmospheric nuclear weapon tests over the Marshall Islands. The people of Rongelap, Rongerik, and Ailinginae, along with other Marshallese - none of whom consented to this configuration of power-served as test subjects in a series of experiments intended to record and explicate the genetic and cellular modulations or "spontaneous mutation rates" that follow from a body's exposure to the radiation produced by a nuclear explosion. "We didn't understand what the doctors were doing to us or why," explains Lijon Eknilang, "and it was embarrassing to have them touching our breasts and putting them in the machines." ${ }^{11}$ The molecular processes modulated in these experiments included red-blood cell function (e.g., anemia), organ system functioning (e.g., hyperthyroidism), embryogenesis (e.g., hydatidiform pregnancies), and more. "Often procedures were painful," summarize Barker and Johnston, the authors of the report: "[They] resulted in additional exposure to radiation, [and] had little or no connection with the health treatment needs of the individual." ${ }^{92}$ After they had been forcibly stripped naked and photographed for medical identification cards, the Rongelapese were administered radioactive iodine uptake tests, which scan for aberrant modulations on the biomolecular level. The teeth of some Rongelapese were placed in bottles and shipped to the U.S. for assessment of radiological content, an assessment also

91. Barbara Rose Johnston and Holly M. Barker, The Consequential Damages of Nuclear War: The Rongelap Report (San Francisco: Left Coast Press, 2008), 159.

92. Ibid. 
made on a molecular level, involving modulations in the cellular processes of tooth germination. In some cases, good teeth-not just decayed teeth-were removed. "It is clear," write Barker and Johnston, "that at least some U.S. government researchers were interested in the abnormal births of Rongelapese women [...]."93 Barker and Johnston refer to a letter written by a U.S. medical officer in 1960: "Catherine gave a normal birth to a baby monster $[\ldots]$. The physical examination of the new born baby revealed $[\ldots]$ the testicles and scrotum were absent [...]. Large upper part of the brain and mininges were visible due to lack of cranial vault. The child was still alive and breathing normally during my examination, but unable to cry when pinched hard with a sharp needle." ${ }^{, 4}$

The societies of sovereignty condemn the body of the regicide to be drawn and quartered as punishment for crimes against the Crown. The societies of control modulate various biomolecular subsystems in the bodies of a population of Rongelapese with nuclear explosions for the sake of experiment itself, that is, in order to discover what the biomolecular consequences of a nuclear explosion would be, "for the benefit of all mankind." All epochal claims aside, this contrast permits me to approach the particularity of social management in control societies, where every social relation seems to acquire a biotechnical dimension. The examples just discussed reveal that the reversal of the political axis of individualization is as operative in control societies as it was in the societies of discipline, and all the more so, for not only does each case qualify to some disparate degree in relation to its sanctioned capacities, but each case can itself be divided up into a "bundle," with each of its elements qualified in its own way. The distinction between bios and zoê fades from view on the molecular frontiers where juridically

93. Ibid.

94. Ibid., 147. 
sanctioned expropriations are carried out in terms of bios. The sovereign can no longer be thought of solely as that which decides the state of exception. It must also be thought of as that which invests private property through the proliferating qualifications of bios on the molecular level and is at the same time as cognizant of acausality as the nonlinear control systems operating its U.AVs.

\subsubsection{Conclusion}

I began this section with a nod to memory, only to make a point of the fact that by "1900," the art of memory had all but become the science of brains. From the Speicher of the proverbial "mind palace" to the hyperlinks of a KEGG pathway, the concept of molecularization I subsequently attempted to develop in this section was perfectly encapsulated. The hypothesis of Canguilhem and of Thacker and Galloway-that control societies accomplish a conflation of life and digital information-is nowhere more apparent than it is as demarcated by these cartographies. The molecular biology research articles I considered went to show that the informational mapping out of life represented by these cartographies is, indeed, positively effective. What is more, other researchers in molecular biology have already begun to busy themselves with the task of serving a mobilization of this effectiveness towards the end of actuating the designs of control-if not, as with Fowler and Dawes, to render visible the cause of everything from "risky decision making" to "voting behavior," then to eradicate aggression, delusion, and every other manner of undesirable behavior. Consider, for example, Henry Markham, the director of Blue Brain, a supercomputing project intended to model components of the mammalian brain in precise cellular detail. As with the KEGG pathway, and in accord 
with the hypotheses of Canguilhem and others, here we have a conflation of digital information with the biological. "Our mission," explains Markram, "is to build a detailed, realistic computer model of the human brain." ${ }^{95}$ Markram continues, explaining the line of force behind the project in three points that also summarize the strategic function of social management in control societies: "[T]he first is, it's essential for us to understand the human brain if we want to get along in society, and I think that it is a key step in evolution. The second reason is [that] we have to embody all our data and all our knowledge into a working model. [...] And the third reason is that there are two billion people on the planet that are affected by mental disorder, and the drugs that are used today are largely empirical. I think that we can come up with very concrete solutions on how to treat disorders." ${ }^{96}$ The line of force driving these research programs remains biopolitical. The rationality behind placing the biological under the sanction of government or social management is predicated upon the desire to "get along," and in any case, it is a "key step in evolution," with "evolution," of course, here understood as an objective or "natural" process. In keeping with the imperative to universals of communication, we also have to collate "all our data and all of our knowledge into a working model." The model is provided to the end of optimization, that is, in order to "treat disorder." Examples of free use, however, such as that of the Shulgins and their research group, demonstrate something of the possibilities opened by the technologies that would otherwise collapse all possibility into probable certainty: By using the arsenal of sense-making towards the end of the senseless, where to go in search of something is

95. Henry Markram, "A Brain is a Supercomputer," http://www.ted.com/talks/henry_markram_supercomputing_the_brain_s_secrets, lecture presented at TEDGlobal 2009.

96. Ibid. 
to create. Finally, Deborah Halbert's research, together with the Rongelap Report, provide some indication that the reversal of the political access of individualization has only gathered force in its disintegration. That is, the cases I have discussed here, as with the sanctioned treatment of "enemy combatants," deploy bios, more and more qualification-indeed, all the better that any concept of zoe fall from mind entirely. A bundle of clearly qualified property rights is made for strands of sugar phosphates in the cells of the Hagahai people, just as the Rongelapese become molecular models for experiments with electromagnetic radiation. Recalling the previous section on informatics should make clear some idea of how these different technologies relate to one another, in addition to the mechanisms and lines of force they have supplanted and stimulated. In these ways, I have substantiated much of what political theories of power in control societies have been arguing, in addition to correcting any theoretical oversights a lack of such substantiation may have allowed. 


\subsection{Music}

\subsubsection{Introduction}

In this section, I examine music and music theory as mechanisms exemplary of a particular regime of sense, namely, that of listening. A detailed contrast of such distributions of sense allows me to approach the unique operations of power in control societies.

Jacques Attali argues that music provides a uniquely important field of analysis for understanding the limitations and possibilities of control societies: "Today, music heralds $[\ldots]$ the establishment of a society of repetition in which nothing will happen anymore. But at the same time, it heralds the emergence of a formidable subversion, one leading to a radically new organization never yet theorized." ${ }^{1}$ For Attali, "[Music] is a mirror, because as a mode of immaterial production it relates to the structuring of theoretical paradigms, far ahead of concrete production." Attali's Noise: An Essay on The Political Economy of Music elaborates the thesis that " $[t]$ he code of music simulates the accepted rules of society." Music, as an organization of sound, silence, and time, is "a reflection of the political hierarchy." Music "has no usage in itself, but rather a social meaning expressed in a code relating to the sound matter music fashions and the systems of power it serves." ${ }^{5}$ Rather than simply reflecting political structures, the codification of

1. Jacques Attali, Noise: An Essay on the Political Economy of Music (Manchester, England: Manchester University Press, 1985), 5.

2. Ibid., 9 ,

3. Ibid., 29.

4. Ibid., 13.

5. Ibid., 24. 
sensation in music in fact anticipates and brings into being the broader political developments with which it is bound up: "The political organization of the twentieth century is rooted in the political thought of the nineteenth, and the latter is almost entirely present in embryonic form in the music of the eighteenth century."

Attali's periodization of music resonates with the trajectory I trace in this section from societies of sovereignty to control societies. However, rather than regarding music as a "mirror of power," I maintain that music in general and music theory in particular exemplify situated regimes of sensibility, and that as such, they describe the designs of power in the precise configuration of the situations they structure. In subsection 3.3.2, I explain accordingly how the music theory of Jean-Philippe Rameau exemplifies the transformations that produce the societies of classicism described by Foucault in The Order of Things. ${ }^{7}$ Rameau attempted to found music in Nature, in keeping with the "genetic analysis" indicative of classical societies. Further, through concepts such as the basse fondamentale, he inscribed music into an economy of function and equivalence, in accordance with the order and "taxinomia" sought after in all areas of classical societies. Similarly, in the practice of equal temperament, the tuning of instruments allows them to better serve the economy of functions and equivalences, we find a line of force indicative of the "mathesis" characteristic of classical societies. My analysis of Rameau provides an example of how music, as a distribution of the sensible, bears within itself details concerning the wider social configuration of which it is a part.

Moving forward, I then consider tonality (subsection 3.3.3), Beethoven, critical dialectics, and the sonata form (subsection 3.3.4). If Rameau's theories set the societies of 6. Ibid., 4 .

7. See Notes 3.3.1. 
classicism in relief, then these sections discern the essential features of the disciplines. Elucidating the transition from the first to the second of these configurations, Foucault writes:

The space of Western knowledge is now about to topple: the taxinomia, whose great, universal expanse extended in correlation with the possibility of a mathesis, and which constituted the down-beat of knowledge-at once its primary possibility and the end of its perfection - is now about to order itself in accordance with an obscure verticality: a verticality that is to define the law of resemblances, prescribe all adjacencies and discontinuities, provide the foundation for perceptible arrangements, and displace all the great horizontal deployments of the taxinomia towards the somewhat accessory region of consequences. Thus, European culture is inventing for itself a depth in which what matters is no longer identities, distinctive characters, permanent tables with all their possible paths and routes, but great hidden forces developed on the basis of their primitive and inaccessible nucleus, origin, causality, and history. ${ }^{8}$

Foucault's description of this transition corresponds strikingly to the emerging concepts of functional harmony and tonality. Gradually, the vertical "major triads" that followed one after another without any purpose other than the horizontal movement of the voices making them up began to have functions in themselves, their adjacencies being prescribed by the abstract notions of functional harmony or tonality.

In subsection 3.3.5, I argue that in the twelve-tone method of composition, the lines of force beginning with Rameau had not yet exhausted themselves. In other words, even in the musical experiments of Sehoenberg and circle, we have not quite left the purview of the disciplines. In subsection 3.3.6, I then discuss the gramophone and gramophonic music. It is at this point that we cross the threshold to mechanisms of control. Finally, in subsection 3.3.7, I discuss music in control societies. 


\subsubsection{Rameau}

The music theory of Jean-Philippe Rameau provides an exemplification of the lines of force towards mathesis, taxinomia, and genetic analysis identified by Foucault as the core organizing principles of the classical episteme. Rameau's Traité de l'harmonie reduite à ses principes naturels is essentially an exercise in demonstrating how practices of harmony can be grounded in ratio (raison) and finally in "Nature herself." Rameau's work shares essential features with the near-contemporary mathematical formulae of Euler, in addition to the economic arguments of Adam Smith and the physical models of Isaac Newton.

In 1770, the English historian of music John Hawkins explained why Rameau was so highly regarded by his countrymen: "He has shown that the whole depends upon one single and clear principle, viz., the fundamental bass; and in this respect he is by them compared to Newton, who by the single principle of gravitation was able to assign reasons for some of the most remarkable phenomena in physics; for this reason they scruple not to style Rameau the Newton of Harmony." ${ }^{9}$ The mathematician Jean la Rond d'Alembert, another of Rameau's contemporaries, expands upon the significance of the "fundamental bass" in a tribute to Rameau, the "composer-scientist" who "[s]uccessfully explains by means of [the fundamental bass] principle the different facts of which we have spoken, and which no one before him had reduced to a system as consistent and extensive $[\ldots]$. Thus, harmony, previously guided by arbitrary laws or blind experience,

9. Thomas Christensen, Rameau and Musical Thought in the Enlightenment (Cambridge, England: Cambridge University Press, 2004), 8. 
has become through the efforts of $\mathrm{M}$. Rameau a more geometric science, and one to which the principles of mathematics can be applied with a usefulness more real and sensible than had been until now." ${ }^{10}$ More to the point, composer Jean Benjamin de Laborde writes: "Rameau appeared and dispelled this chaos. He brought at once clarity and order, revealed the mysteries of the art, and reduced music to general principles. Finally, he offered a fecund system in which all the parts reciprocally clarified and fortified one another." ${ }^{11}$ For such commentators, Rameau's concept of a fundamental bass not only brought order, foreclosed mysteries, and proposed a genetic principle; it also provided a system in which part and whole reciprocally clarified one another and grounded practices of harmony in Nature.

Rameau followed Descartes in his rational theoretical method. "Enlightened by the Méthode of Descartes which I had fortunately read and had been impressed by," writes Rameau, "I placed myself as well as I could into the state of a man who had neither sung nor heard singing, promising myself even to resort to extraneous experiments whenever I suspected that habit [...] might influence me despite myself."13 In his discussion of the relationships between different harmonies, Rameau invokes Newton when he describes the "gravitational pulls" of the different harmonies, and anticipates Smith when he writes of an "invisible force" binding them together. ${ }^{14}$

Several shifts in emphasis that reshaped European musical style around the turn of

10. Ibid., 11.

11. Ibid., 7.

12. Nicholas Cook, "Epistemologies of Music Theory," in The Cambridge History of Western Music Theory, ed. Thomas Christensen (Cambridge, England: Cambridge University Press, 2008), 84.

13. Christensen, Rameau, 12.

14. Bryan Hyer, "Tonality," in Christensen, The Cambridge History of Western Music Theory, 734. 
the sixteenth century provide an essential context for understanding Rameau's contributions. The main shift, the effects of which are still operative today, involved the recognition and use of harmonic triads as the basic units of music. Composers from the previous few centuries had located the framework of music in two-pitch intervals or independent voices. Two-pitch intervals, which had been known since antiquity, were assigned different "characters," made to appear in specific places or to proceed in certain ways. In medieval music, Guidonian hand was a mnemonic device used to assist singers with memorizing these intervals. Even today, residues of the Guidonian hand persist, as it is the first known use of solfege, that is, the familiar mnemonic of using the syllables: $\mathrm{Do}^{1}, \mathrm{Re}, \mathrm{Mi}, \mathrm{Fa}, \mathrm{Sol}, \mathrm{La}, \mathrm{Ti}, \mathrm{Do}^{2}$ to represent the major scale. From $\mathrm{Do}^{1}$ to $\mathrm{Do}^{2}$ is the interval of an octave, from $\mathrm{Do}^{1}$ to Sol is the interval of a fifth, from $\mathrm{Do}^{1}$ to $\mathrm{Fa}$ is the interval of a fourth, and from $\mathrm{Do}^{1}$ to $\mathrm{Mi}$ is the interval of a third, and so on. Progressions of intervals governed the progression of whole pieces, even though intervals were enriched by the addition of one, two, three, or even more parts. From the beginning of Western polyphony to the present, octaves, fifths, and fourths have been regarded as perfect consonances, thirds and sixths have been regarded as imperfect consonances, and the remaining intervals have been regarded as dissonances. In the fourteenth century, the addition of a third voice produced a "chord" or harmony formed of a fifth and an included third, a sound neither perfectly consonant nor dissonant. After 1450, this chord appeared with increasing frequency, until by 1550 it accounted for the overwhelming majority of sounds in the average work, the only other frequent sonority being the sixth with a third. ${ }^{15}$

During the period from 1550 to 1600 , the development of harmony entered a 15. Richard L. Crocker, A History of Musical Style (Mineola, NY: Dover, 1986), 225. 
critical phase. Around 1550, the music theorist Gioseffo Zarlino gave theoretical recognition to this group of three tones-this triad-as a distinct entity, and by the seventeenth century it was treated as such by most theorists and composers. By 1600 , open fifths seemed empty and incomplete, whereas as late as 1550 , they had not seemed so. By 1600 , the younger generation came to judge counterpoint according to whether it represented effective chords and chord progressions. "Counterpoint" is the "vertical" relationship between the separate independent voices of a piece as they move across the "horizontal" axis of abstract musical time. Throughout the Middle Ages and into the Renaissance most pedagogical material concerned the proper "voice-leading" in weaving this tapestry. Johann Fux's 1725 Gradus ad Parnassum, the seminal textbook on counterpoint, was written just as counterpoint itself was being abandoned as the unifying principle of composition. Fux's volume provides some indication of the "rules" of voiceleading as they had come to be codified over the thousand years that preceded its writing. These rules may be summarized in the following three basic principles. Firstly, every work should begin and end with a perfect consonance. Secondly, contrary motion should predominate (e.g., if the highest voice is ascending from moment to moment, then the lowest voice should be descending, and vice versa). This principle has a special importance in relation to perfect consonances, as the motion between any two perfect consonances should always be contrary. Parallel octaves and fifths between any two voices must be avoided. Thirdly, the final consonance of any given work must be approached by a half step. These three principles should provide a general idea of the rules of counterpoint or voice-leading. Richard Crocker sets the stage for Rameau:

After 1600 , composers were increasingly preoccupied with appropriate groupings and successions of chords, groupings eventually called keys. Composers after 
1600 , especially conservative ones, often used the same sounds in much the same way as before. The difference was in the way the sounds were regarded. Harmonies were no longer built by adding pitches to intervals; rather harmony consisted of readymade units of triads and sixth chords. At first the new attitude manifested itself in relatively simple, external ways, the most obvious being the general acceptance of the basso continuo. This was a bass part consisting of the lowest-sounding pitches of each chord in the piece: performers of chord-playing instruments played each pitch of the bass part triad or a sixth chord according to context. After 1600 almost all kinds of pieces were provided with a part for basso continuo, from accompanied solo songs to large ensembles of voices and instruments. The basso continuo is not a bass line but a shorthand indication of the progression of chords. Figured bass and counterpoint had thus become alternate methods of teaching composition; they could supplement or supplant each other, depending upon the inclination of teacher and pupil. Of the two, figured bass now represented the core of stylistic development; counterpoint was either a

superimposed ornament or a refinement in conduct of voices. Neither figured bass nor counterpoint, however, offered a systematic explanation of musical structure; neither was a "theory," but merely a form of systematic instruction. ${ }^{16}$

Rameau sought the "genetic principle" for the horizontal movement of a musical piece across a succession of triads. To this end, he attempted to demonstrate that the triad, the conventional unit of composition since 1600 , was "natural" because its constituent tones could be found among the partials of a vibrating string. Then he went on to demonstrate that sixth chords could be regarded as inversions of triads, containing the same pitches in an "inverted" order. While the first principle ratified the status of triads, the second implied a reorganization of figured bass pedagogy. Figured bass treatises regarded triads as triads and sixth chords as having structures and functions different from triads. From the point of view of figured bass, there was nothing to be gained by calling a sixth chord an inversion of a triad because, over any given pitch in the basso continuo, a triad and sixth chord would produce different effects. ${ }^{17}$

Rameau first explained the principle of the basse fondamentale (the fundamental

16. Ibid.

17. Ibid. 
bass) in his Traité. Published in 1722, fourteen years before Euler's Mechanica, the Traité argues that all music is foundationally harmonic and that, in turn, each harmony in music emerges rationally from a single fundamental. It would be difficult to overstate the influence of Rameau's theories of harmony on subsequent Western musical and musictheoretical practices.

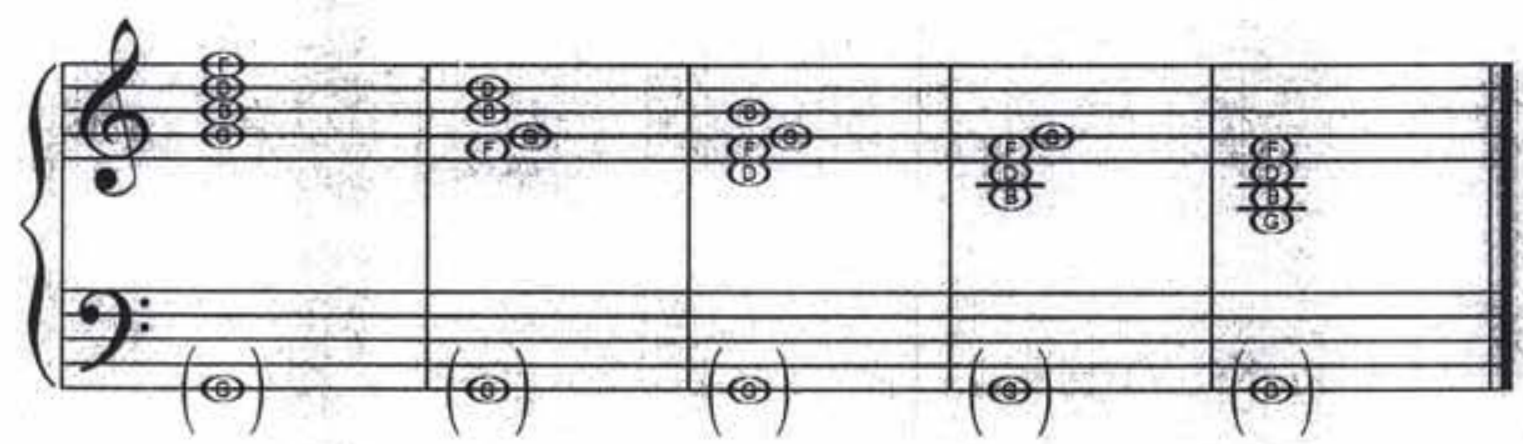

Figure 18. Fundamental Bass. A simple, and not entirely accurate, representation of harmonic inversion and the basse fondamentale. Suppose the harmony in the treble clef is the only harmony actually played. The basse fondamentale, which is parenthesized in the bass clef, remains the same in any case, whereas in earlier theories, some of the harmonies in the treble clef would have been considered disparate "sixth" chords and so would have had disparate fundamentals.

Rameau's theory suggests, roughly, that regardless of which pitch sounds lowest, the fundamental bass, parenthesized in the bass clef in Figure 18, always remains the same. Each subsequent harmony in the treble clef is the same harmony in some different inversion. This theory had important consequences for the development of functional harmony. The practice of functional harmony assigns each harmony a function relative to all the others. Rameau's system provides a function for each pitch within any collection of pitches sounding simultaneously - that is, any vertical harmony along the horizontal axis of abstract musical time. Similar to the workers in Adam Smith's pin factory, each pitch within Rameau's system is guided by an invisible force.

Shortly after publication of the Traité, relates Joel Lester, Rameau learned of 
Joseph Sauveur's acoustical experiments. Sauveur's work had proven that the ratios arising from the division of a vibrating string were audible. ${ }^{18}$ In his 1722 review of Rameau's Traité, Father Bernard Castel writes: "Nature gives us the same system that M. Rameau discovered in numbers."19 Rameau's discovery of an arithmetical-and, subsequently, an empirical-system created the necessity for a redefinition of basic harmonic theory. It was this that Rameau proceeded to accomplish; essentially, in Joel Lester's words, Rameau "chang[ed] it from a Cartesian deductive system to a Newtonian empirical system. ${ }^{, 20}$ Lester reminds us that the preface of the Traité contained properly Cartesian statements such as the following: "Music is a science which should have definite rules; these rules should be drawn from an evident principle; and this principle cannot really be known to us without the aid of mathematics."21 Fifteen years later, in the Génération harmonique, Rameau issued far more definitive proclamations: "Music is a physico-mathematical science; sound is its physical object, and the ratios found between different sounds constitute its mathematical object." ${ }^{22}$ The Génération harmonique was filled with proofs of the corps sonore that had Newtonian optics as their model. ${ }^{23}$

Figure 19 reveals how Rameau set out to ground Western harmonic practices in "Nature herself." The figure represents the harmonic or "overtone" series, which Rameau creates in the Traité by arithmetically dividing the string of a monochord, a physical

18. Joel Lester, "Rameau and the Eighteenth-Century Harmonic Theory," in Christensen, The Cambridge History of Western Music Theory, 769.

19. Ibid.

20. Ibid.

21. Ibid., 770 .

22. Ibid.

23. Ibid. 
vibrating body or corps sonore. The idea is this: Suppose we pluck the string of a monochord and the pitch $\mathrm{C} 1$ is heard; if we then divide that string in half, and pluck one of those halves, the pitch $\mathrm{C} 2$ will be heard, that is, the pitch $\mathrm{C}$ will sound an octave higher. If we then divide that half into three, the pitch G2 will sound, and so on.

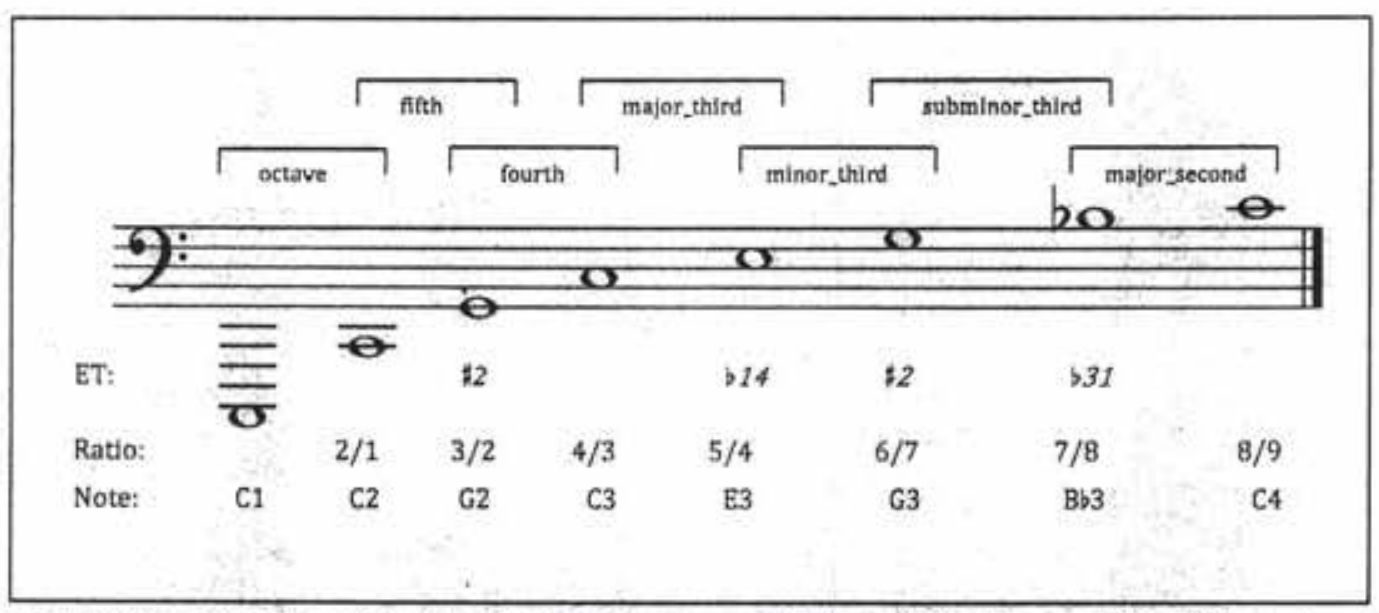

Figure 19. The Overtone Series: A simple representation of the harmonic or "overtone" series. The lowest row, "Note," provides the name of the pitch and its octave number. The row above that, "Ratio," provides the ratio that yields the pitch in question from the first of the series. The row "ET" provides the difference between the justly intoned pitches and those same pitches as they would be tuned on an equal tempered instrument. Notice, for example, that the seventh partial is flattened 31 cents. This means that on an equal tempered piano, the seventh partial is raised by more than a quarter tone. Finally, the name of the musical interval (e.g., octave, fifth, or fourth) between any two successive pitches appears above the staff:

By the time he wrote the Génération harmonique, Rameau had discovered that these same principles can be discerned in any vibrating body or corps sonore. That is, he discovered that any time a body vibrates at $\mathrm{Cl}$, we can decompose that $\mathrm{Cl}$ into its constituent harmonic series-the fundamental bass $\mathrm{Cl}$ is physically just each of these partials (C2, G2, C3, E3, and so on) sounded together at various different volumes. Indeed, it was eventually discovered that the relative volume of each of these partials is what provides any pitch its distinct sound or timbre. The only difference between $\mathrm{C} 1$ 
played on a piano and $\mathrm{C} 1$ played on a bassoon is the relative volume of each partial in this harmonic series as it resonates in either instrument. On a clarinet, for example, the odd-numbered partials are the loudest, while on a flute, the first three partials are the loudest and then the series falls off exponentially. These are all basic ideas in music theory and acoustics. What is important here, however, is how such phenomena were mobilized by Rameau and his followers.

Between the first nine partials, we have nearly all the pitches we need in order to construct the most ubiquitous harmonies of Western music: the major triad (e.g., C-E-G), the dominant seventh (e.g., C-E-G-Bb), and so on. "By manipulating the various ratios and proportions of his monochord," explains Thomas Christensen, "Rameau was able with more or less success to account for all of the harmonies commonly employed in French Baroque practice. Moreover, by reducing most chord-root motion to a simple cadential paradigm of a dissonant seventh chord resolving to a consonant triad, he was able to show how the succession of chord fundamentals imitated these same ratios and proportions. From this mechanistic basis, all other musical parameters-melody, counterpoint, mode, and even rhythm — could be seen as derivative."24

Another convention that bears mentioning here involves the tuning of instruments. Throughout the Middle Ages and into the Renaissance, standard practice was to tune instruments using "just intonation" or "pure intonation." This is a method of tuning in which each pitch on an instrument is tuned according to Pythagorean perfect ratios. The ratio of a perfect fifth, for example, is three perfect periods over two perfect periods, $3 / 2$. This was the tuning system used by the Greeks and explained by Ptolemy, and it was the

24. Christensen, Rameau, 5 
cosmic ideal of Renaissance theorists. It was easy enough to specify the ratio of thirds: $5 / 4$ for major ones and $6 / 5$ for minor ones. The problem, however, was how to combine these perfect thirds into a tuning system with perfect fifths that could be used for the tuning of actual instruments. A complete tuning system containing both types of "just" intervals cannot be applied to a practical instrument. Various multi-manual keyboard instruments were built during the sixteenth century to allow more perfect tunings. Such instruments furnish evidence of the intensity with which musicians of this century searched for the ideal perfect harmony. ${ }^{25}$

At some point, the "primeval error" 26 embodied in this striving after just tuning was abandoned for the sake of economy. In addition to the problem of the commensuration of thirds and fifths, when instruments were tuned using just intonation, the seventh partial, $7 / 8$ or "Bb3" in Figure 18, was out of tune relative to the new functional harmony being developed. Tuning instruments in this way, the seventh partial sounded "wrong." For these reasons, around the time of Rameau, alternatives to just intonation were starting to be explored. One such alternative, the alternative that would become the norm, was equal temperament (ET). ET is a musical temperament, or a system of tuning, in which every pair of adjacent pitches has an identical frequency ratio. As opposed to tuning each interval playable by the instrument according to perfect arithmetical ratios, each subsequent pitch is simply separated by an identical frequency of 100 "cents" (a logarithmic unit of measure). The octave is divided into a series of equal steps, with equal steps in frequency between successive pitches. The result approximates

25. Crocker, A History of Musical Style, 225.

26. See Notes 3.3.3. 
just intonation in the sense that, for example, the fifth between $C$ and $G$ is still close to three over two. It is only approximate, however, because by tuning each subsequent pitch in this way, perfect arithmetical ratios are not followed. The difference between ET and just intonation is indicated in Figure 18 in the ET row. On an equal tempered instrument, the third partial would be sharpened by two cents, the fifth partial would be flattened by fourteen cents, the sixth partial would be sharpened by two cents, and the seventh partial would be flattened by thirty-one cents.

During the sixteenth and seventeenth centuries, equal temperament was well known among theorists; however, its practical application had remained limited. Although informal descriptions had already been given by Zarlino, Salinas, and Vincenzo Galilei, it was not until the eighteenth century that equal temperament started to become the standard. What this meant, among other things, was that the above-mentioned seventh partial was "enlightened," sharpened away from its "natural" state by thirty-one cents so that it might better serve its new role in the developing functional harmony. This poor partial, so seemingly evident in the natural ratios of sound itself, that is, in the resonance of spaces and vibrating bodies, was beaten into shape by equal temperament and functional harmony and hidden from view alongside the newly confined mad and criminal. The barbarity of torture gives way to the civility of confinement, and, similar to the worker in a pin factory, the seventh partial is led by the administration of the invisible hand to take its place, resolving again and again towards the third of the tonic. A system of tuning that had held sway over Western imagination for more than a thousand years, grounded in notions of the perfection of the cosmos, gave way to a more functional 
method of tuning. Practices and aspirations that had been at the center of music theory since Pythagoras disappeared in this economy of functional relationships.

In his study of Adam Smith, Michael Shapiro suggests that Smith "recast the divine will as a set of dynamic mechanisms regulating the process of production. The Creator was banished from the world and was replaced by a view of nature that construed it as a series of mechanisms in the world regulating the play of interest and exchange value. This marks the beginning of theorizing the state as a complex governing entity that has to conceive of itself as managing the economy, where 'economy' had begun to emerge from its ancient connotation associated with families or households into its modern sense of a field of calculation applied to the new collective identity known as the population."27 Shapiro's descriptions of Smith's project apply equally to the musicaltheoretical activity around Smith's time. The Creator and his cosmos are banished and replaced by an economy of functional relations, grounded in the invisible forces of Nature. Not only is the holy name starting to be omitted from the cadences, but the perfect ratios that so fascinated music theorists for nearly a millennium and a half are also being subordinated to a new economy of functional relations. Rameau's music theory, similar to Smith's economics, corresponds to the classical episteme as it was described by Foucault:

The problem that now presents itself [...] is to determine what form of relation may be legitimately described between these different series; what vertical system they are capable of forming; what interplay of correlation and dominance exists between them; what may be the effect of shifts, different temporalities, and various rehandlings; in what distinct totalities certain elements may figure simultaneously; in short, not only what series; but also what 'series of series' - or, . in other words, what 'tables' it is possible to draw up. ${ }^{28}$

27. Michael Shapiro, Discourse, Culture, Violence, eds. Terrell Carver and Samuel Chambers (London: Taylor and Francis, 2012), 63.

28. Foucault, Archaeology of Knowledge, 11. 
With Rameau, the "vertical system they are capable of forming" is the triad and its inversions. From one of these vertical systems to the next, an interplay of dominance is described in the sense of "gravity," a point that I elaborate at greater length in my discussion of tonality.

\subsubsection{Tonality}

"Tonality implicitly serves no other social function than to help anchor the status quo of an unjust society," writes Adorno, "by aestheticizing and naturalizing its fundamental ideological principles. ${ }^{29}$ In this section, I elaborate upon the social function performed by tonality. By the time the conventions of the classical societies were giving way to the enclosures of discipline, the vigorous repetitions of the old style had already established sanctioned relationships between chords. The process whereby these relationships were clarified was the process that made harmony functional. The function of each chord, its implied relationship to key, became its most expressive aspect.

François-Joseph Fétis is usually credited with having popularized the notion of tonalité, another term for "functional harmony," as the "collection of necessary relations, both successive and simultaneous, between the pitches of the scale." ${ }^{30}$ A revelationwhich, Fétis claimed, came'serendipitously while sitting under a tree, in proper Newtonian style, one afternoon in 1831 -led Fétis to imagine harmonic relations as forces of "attraction" and "repose" such that, for example, the dissonance between scale degrees four and seven of the major scale formed an "appellative consonance"; this was a

29. Theodor W. Adorno, Essays on Music, ed. Richard Leppert, trans, Susan H. Gillespie (Berkeley: University of California Press, 2002), 86.

30. Hyer, "Tonality," 729. 
call on the part of both pitches that "summoned" their respective resolutions. ${ }^{31}$ The term "tonality," however, in fact came from Alexander Choron, who used it in his 1810 Sommaire de l'histoire de la musique "to describe the constellation of tonic, dominant, and subdominant harmonies familiar to musicians since Rameau., ${ }^{32}$ For Fétis, the "mysterious" powers of attraction between pitches in the scale could only be explained as "purement métaphysique." F33 Fétis, who had read Hegel, situated this "purely metaphysical" quality of tonality in relation to a far broader notion of human consciousness: For him, the subject impressed "a certain cognitive organization-a certain set of dynamic tendencies—on the musical material. ${ }^{34}$

Rameau used the metaphor of gravity to elucidate the attraction of the dominant to the tonic in addition to the general concept of the progression of harmonies toward a cadence. Intention has also been ascribed to the attraction that one chord holds for another: To describe the seventh scale degree as sensible, for instance, as is commonly done in French systems, is to imply that the pitches themselves have emotions. ${ }^{35}$ Rameau even went so far as to call the tonic the object of musical desire "to whom all our wishes tend" ${ }^{\prime 36}$ : The dominant, desirous of the tonic, dominates the tonic by assigning it a passive role. ${ }^{37}$ This reductive approach contrasts with Fétis's invocation of the attractive forces of

31. Ibid.

32. Ibid., 730 .

33. Ibid. "Purement métaphysique" was yet another of Fétis's borrowed expressions, Hyer points out, this one from Momigny.

34. Ibid., 747.

35. Ibid., 730-31.

36. Rameau, Génération harmonique, 108-9, quoted in Hyer, "Tonality," 731.

37. Hyer, "Tonality," 731. 
harmony as metaphysical and mysterious. Fétis's inability to classify tonal phenomena in a static, causal manner places him among those who exemplified the movement inwards, in stark opposition to the classical lines of force in Rameau. ${ }^{38}$

Social metaphors are common in tonal music theory. As Hyer points out, while Rameau thought of the relationship between tonic and dominant as one between individuals with differing social influence, Schoenberg went so far as to fashion the tonic a ruling monarch. A century earlier, Momigny had also endowed the tonic with royal qualities; the tonic for him was "the purpose of all purposes, the end of all ends," for "it is to her that the scepter of the musical empire is entrusted." ${ }^{39}$ Even earlier, Riepel's Grundregeln zur Tonordnung insgemein (1755) compared the diatonic harmonies within $\mathrm{C}$ major to the respective positions of workers on a farm: "C major was the bailiff or master (Meyer), G major the overseer (Oberknecht), A minor the head maid (Obermagd), F major the day laborer (Taglöhner), E minor the chamber maid (Untermagd), and D minor the errand girl (Unterlaufferin). ${ }^{400}$ Riepel conceived of the six $\mathrm{C}$ major diatonic harmonies as forming two "hierarchical orders, one masculine and agricultural (major harmonies), the other feminine and domestic (minor harmonies), both operating under the watchful supervision of the master."41 Hyer suggests that later comparisons between musical structures and social laws (rather than natural ones) provided by theorists such as Momigny (with his description of the seven pitches of the scale as a hiérarchie naturelle under the tonic's authorité) and Fétis (for whom tonalité was "le principe régulateur des

38. Ibid., 730 .

39. Momigny, Cours complet d'harmpnie et de composition, vol. 1, p. 47, quoted in Hyer, "Tonality," 731.

40. Riepel, Grundregeln zur Tonordnung insgemein, 65, quoted in Hyer, "Tonality," 731.

41. Hyer, "Tonality," 731. 
rapports") make clear the "strong correlation between tonal theories and conservative political ideologies." ${ }^{42}$

Joseph Vogler, in his Tonwissenschaft of 1776, was the first to use Roman numerals to designate the function of any harmony, a practice that continues today. The music theorist Gottfried Weber expanded upon Vogler's ideas. Unlike the earlier dependence on a separate bass pitch written in staff notation, each of Weber's numerals indicates not only the structural root of the pitches under which it resides, but also interprets the chord within a tonal framework. In Weber's formulation, the quality of the chord is acknowledged by the relative size of the numeral itself: Capital numerals refer to major harmonies, while those in small capitals refer to minor harmonies.

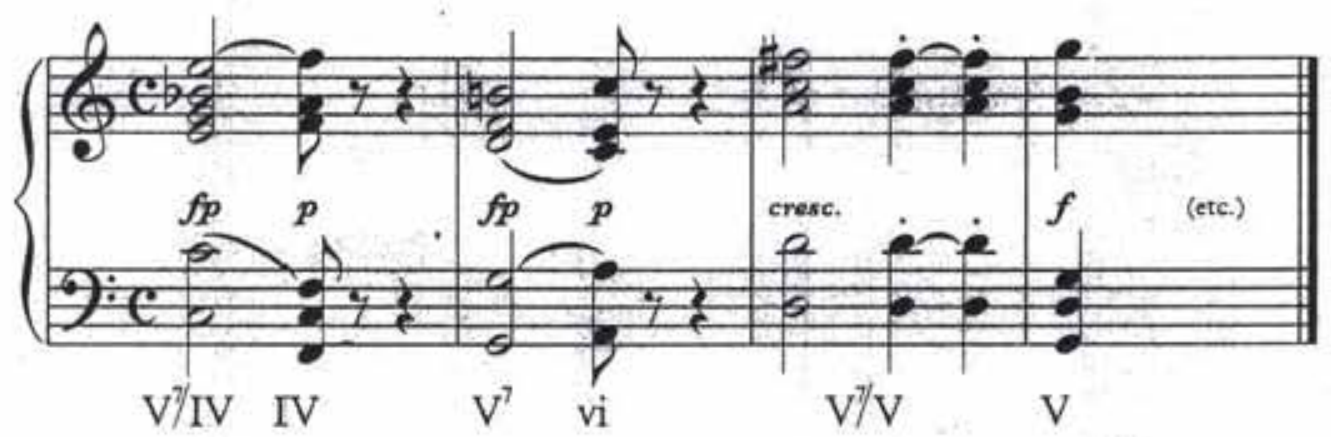

Figure 20. Beethoven, Symphony No. 1 in C major, Op. 21 (1801).

Figure 19, the first few bars 'of Beethoven's first symphony, provides an example of functional harmony (or tonality). Note that there are, in addition to functions, "secondary functions." The first harmony, for example, functions as the $V^{7}$ (i.e., the "dominant [seventh]") of IV (i.e., "the subdominant"). The first symphony is in the key of C major; however, it opens with the $\mathrm{C}$ major chord operating in this "secondary" capacity-that is, the chord does not function as I (i.e., the "tonic"), as would be expected; rather, it 42. Ibid., 732. 
functions as the V of IV. Similarly, in the next bar, we have an example of the "deceptive cadence." The dominant $\mathrm{V}^{7}$ appears again; however, it "deceives" the listener by resolving to vi (i.e., the "submediant"). In this way, functional harmony possesses a kind of narrative authority.

Music theory codifies a society's manners in relation to listening. By contextualizing sound in this manner, the theorists of tonality reveal something about the way people listened within these situations. The societies of control retain some residues of this functional system; however, the manner of listening has returned to something resembling the pretonal (i.e., "modal") musics of the societies of sovereignty. The type of narrative authority we see in Figure 19 is impossible in control societies. Even if the Fugs had a song entitled "I Hate the White Man in C Major," none of its listeners would be surprised if the opening chord was $\mathrm{C}$ major seven functioning as the dominant of $\mathrm{F}$ major, and none would follow a narrative of tension and release wrought by the colors of resolving dissonances all progressing towards a final goal.

Choron, examining music theory from a historicist perspective of progress and decline, saw tonality as an "entirely modern" concept. ${ }^{43}$ For Choron, tonality represented the culmination of a "teleological process," a sociohistorical era passing through stages"formation, development, progress toward perfection, permanence, and decline"-in which the decline of one age met with the formation of the subsequent historical age. ${ }^{44}$ Hyer goes on to say that "Choron believed that the guiding spirit of each age (and here Hegelian language is appropriate) manifests itself in the objective tendencies of the

43. Ibid., 747.

44. Ibid. 
musical material, hence the epochal division between tonalité antique and moderne."45 Choron saw his musical epoch as the stage of "permanence" of tonalité moderne, which had attained perfection. Hyer' recounts Choron's anticipation of later music and "its inevitable historical descent." ${ }^{, 6}$ Successive musical "styles" enact a dialectic of progress.

Fétis, holding to what he considered tonality's metaphysical properties, felt that while tonality was flexible and dynamic, it was also universal and applicable to all people in all times. ${ }^{47}$ Fétis did, however, postulate "the undeniable historical progress of Western music as a series of discrete advances toward completion, the ever more perfect realization of a musical absolute." ${ }^{48}$ Fétis referred to these advances using Hegelian nomenclature-"historical transformations"-to demonstrate his view of the development of Western music theory, which he (like Choron) considered to be at its peak in his own time. ${ }^{49}$ Fétis divided Western music into four categories or ordres: unittonique, transitonique, pluritonique, and omnitonique, each of which correspond to a particular stage of historical development. His first stage, the ordre unitonique, encompassed plainchant. Fétis found its tonalité ancienne to be calm and without conflict; these characteristics, along with early liturgical music's simplicity and lack of appellative tendencies, differed from modern tonality in that it did not contain modulations (or key changes) as such. ${ }^{50}$ Fétis placed the moment of the second stage, the

45. Ibid.

46. Ibid.

47. Ibid.

48. Ibid.

49. Ibid., 748.

50. Ibid. 
ordre transitonique, at 1600 with Monteverdi's invention of the dominant seventh; the strong pull and intervallic constitution of this dynamic chord made modulations easier to achieve, corresponding to the birth of tonalité moderne. Transitonic music introduced increased intensity and motion into composition and corresponded, appropriately, with the beginnings of opera. ${ }^{51}$ The ordre pluritonique, finally, was epitomized in the music of Mozart and Rossini and represented a finer distinction than that between earlier pairs of stages. Involving previously unheard-of levels of chromaticism, Fétis saw gallant-style music as the culmination and perfection of tonalité moderne. The frequent use of diminished seventh chords and augmented sixth chords - and, according to Fétis, both of these harmonies sternmed directly from dominant seventh chords-led to far more appellative tendencies in composition, also permitting more drastic and distant modulations, which Fétis saw as reflective of the passions of the historical moment. ${ }^{52}$ Fétis envisaged music in the future as follows: "[T] he chromaticism of the ordre pluritonique would dissolve into the ambiguous enharmonism of an ordre omnitonique." ${ }^{53}$ For Fétis, the omnitonic music of his own time represented a decline not dissimilar to that of a debauched society.

Nineteenth-century theories of tonality echoed not only "cultural anxieties [and] worries about the future of music, but also about race." 54 Fétis argued that "different human societies were attracted to different pitch repertoires because of their different

51. Ibid.

52. Ibid.

53. Ibid.

54. Ibid. 
mental capacities." $35 \mathrm{He}$ asserted that the more advanced minds of Europeans were better suited to "realize, over historical time, the full musical potential of tonalite",;, 3 nonWesterners, with their relatively poor mental capacity, were limited to an understanding of simpler scales. Embracing biological determinism in addition to racism, Fétis's studies of non-Western music "conceal[ed] emotive assertions within the neutral language of factual description." ${ }^{57}$ Hyer identifies fear as a primary motive behind these racist conclusions. Europeans feared that the attitudes and behaviors of the African and Eastern countries they had colonized could force thoughtful Europeans to reconsider their own identities, causing social upheaval; from a European point of view, as Hyer puts it, nonWestern societies constituted "a primitive or even animalistic realm of sexual desire, religious violence, and racial terror." ${ }^{58}$ In essence, Europeans writing at this time created "cross-cultural comparisons that served to denigrate non-Western others and thus associated the Oriental with marginalized elements in their own societies-the ignorant, backward, degenerate, insane, and the feminine." ${ }^{59}$ As far as Fétis was concerned, pentatonic East Asian music, because of its lack of appellative half steps, sounded "grave and monotonous," ${ }^{10} \mathrm{He}$ found Arab, Persian, and Indian music "langoureuse et sensuelle," befitting "the manners and mores (moeurs) of the nations that conceived it," and he also believed that "the dangerous excess of microtonal inflections in the pitch

55. Ibid.

56. Ibid.

57. Ibid., 749.

58. Ibid.

59. Ibid.

60. Ibid. (trans., orig. from Fétis, Traité complet de la théorie et de la pratique de l'harmonie, p. xxi.). 
repertoires of the Levant" reflected the decadent content of their "amorous songs and lascivious dances." ${ }^{61}$

Determinations such as Fétis's, the equation of pitch preferences and racial characteristics, obviously have no part in contemporary Western music scholarship; however, the remnants of this so-called research-in the guise of self-congratulatory confidence in the superiority of the Western tradition-are difficult to excise. What remains of interest in this context, though, as Hyer points out, is that tonality as a concept assumed ideological proportions in the nineteenth century, providing personal and subjective records of aesthetic conceptions as mirrors of European social anxieties of the time. Hyer concludes: "The notion of a tonal evolution or progress, in particular, has been appropriated for both conservative and radical aesthetic agendas: decisions about what constitute historical continuities or discontinuities are never empirical. Conservative ideologies, drawn to the hierarchical organization of harmonies in tonal music, have often advanced the concept of tonality (as Fétis did) as a method of regulating compositional practice or to naturalize Western music as a form of cultural expression."

\subsubsection{Beethoven and Critical Philosophy}

Along with tonality, new musical forms were emerging in the eighteenth century. Unquestionably, the most popular form by " 1800 " was the sonata-allegro form. ${ }^{63}$ Adolph Bernhard Marx, in the 1845 third volume of his landmark treatise Die Lehre von der

61. Ibid.

62. Ibid.

63. See Notes 3.3.4. 
musikalischen Komposition, praktisch-theoretisch, was the first to codify the notion of the sonata form (the term was also his) as tripartite. The sonata form is modeled on the dramatic interaction of two themes, which Marx called "masculine" and "feminine." The form consists of an exposition section, where the two themes are each heard; a development section, where the two themes are heard over and over again, shifting through different keys and different variations; and finally, a recapitulation, where the two themes are sounded separately once again. Marx suggested that, in order to create a cohesive whole, the sections of the sonata form must constitute an "inwardly unified whole." ${ }^{, 64}$

"If [Beethoven] is the musical prototype of the revolutionary bourgeoisie," writes Adorno, "he is at the same time the prototype of a music that has escaped from its social tutelage and is aesthetically fully autonomous, a servant no longer. His work explodes the schema of a complaisant adequacy of music and society. In it, for all its idealism in tone and posture, the essence of society, for which he speaks as the vicar of the total subject, becomes the essence of music itself." ${ }^{65}$ Understanding Adorno's insight here provides a greater appreciation of the ways in which the transition from classical to disciplinary societies came about. It allows me to approach the thought of disciplinary society's relation to control societies, in addition to exploring the analogy between the thought (i.e., philosophy) and music of a particular situation. Adorno-who was both a critical theorist and a composer-identified himself with a class of "intellectuals, who are at one

64. Marx, Musical Form in the Age of Beethoven, 102.

65. Theodor W. Adorno, Beethoven: The Philosophy of Music, ed. Rolf Tiederman, trans. Edmund Jephcot (Minneapolis: University of Minnesota Press, 2002), 43. 
and the same time the last enemies of the bourgeois and the last bourgeois." ${ }^{.66}$ In this respect, Adorno asks, "How many of us are there now who can still 'recognize' the 'fundamental experiences of the bourgeois era,' can still understand the passage [from Wagner's opera Tristan und Isolde] where the horn 'catches the chorus of the shepherd's melancholy song?' We are fast shrinking in number and already find ourselves surrounded by masses who can no longer 'recognize' anything. May heaven grant us something of that productive energy which can wrest fresh moments from every moment of decay! ${ }^{167}$ In order to elaborate exactly what it was that authorized Adorno-as heir to the inextricable traditions of German critical philosophy and Austro-German music-to write statements such as the following -

It is in fitting together under their own law, as becoming, negating, confirming themselves and the whole without looking outward, that [Beethoven's] movements come to resemble the world whose forces move them; they do not do it by imitating that world. In this respect Beethoven's attitude on social objectivity is more that of philosophy - the Kantian, in some points, and the Hegelian in the decisive ones-than it is the ominous mirroring posture: in Beethoven's music society is conceptlessly known, not photographed. ${ }^{68}$

-I situate his critical project within its historical conditions. In this passage, in addition to others taken from his unfinished monograph on Beethoven, Adorno provides an exemplary way forward. "The following definition of the nature of philosophy given in the Preface to the Phenomenology of Spirit," writes Adorno, "looks like a direct description of the Beethovenian sonata":

For the real subject matter is not exhausted in its purpose but in working the matter out; nor is the mere result attained in the concrete whole itself, but the

66. Detlev Claussen, Theodor W. Adórno: One Last Genius, trans. Rodney Livingstone (Cambridge, MA: Belknap Press, 2008); 137.

67. Ibid., 93.

68. Adorno, Beethoven, 43. 
result along with its Becoming. The purpose by itself is a lifeless universal, just as the general drift is a mere activity in a certain direction, which is still without its concrete realization; and the naked result is the corpse of a system which has left its guiding tendency behind it." ${ }^{69}$

The fragments comprising Adorno's unfinished Beethoven monograph include attempted parallels between the critical Hegelian dialectic and the motivic-thematic integrity of Beethoven's music. It is precisely because Adorno's own discourse is so intertwined with the apparatuses under investigation here (i.e., " 1800 ") that his work provides such a privileged site from which to approach the significance of Beethoven.

"A prominent and fundamental motif of the work must be that Beethoven-his language, his substance and tonality in general, that is, the whole system of bourgeois music-is irrecoverably lost to us, and is perceived only as something vanishing from sight. As Eurydice was seen. Everything must be understood from that viewpoint." "Beethoven's attitude on social objectivity is more that of philosophy $[\ldots]$ than it is the ominous mirroring posture." ${ }^{71}$ In these statements of Adorno we find a perfect "musical" vertex from which to gauge the transition from the "classical/mimetic" to the "critical/romantic" Aufschreibesysteme of "1800" outlined by Kittler. The vocative "Oh!," which Kittler suggests is the "minimal signified" of "1800," should already be all too apparent. The composer is no longer a scribe of the neo-classical order implicit in nature, but rather the tragic poet who sings of mystical Nature. For Adorno, Beethoven stands at the crossroads of the mimetic and romantic; however, Beethoven's music is not entirely reducible to either. Beethoven is reducible only to that transition itself. Adorno

69. Georg W. F. Hegel, The Phenomenology of Mind: Two Volumes in One, trans. J. B. Baillie (New York: Cosimo Classics, 2011), 63. quoted in Adorno, Beethoven, 43.

70. Adorno, Beethoven, 6.

71. Ibid., 43 . 
presents Beethoven in the passages given below as the consummate image of his (Adorno's) own Hegelian Aesthetic Theory: In Beethoven, the simple motive is unfolded into a whole symphonic movement much as the "thesis" and its "antithesis" are sublated in the "synthesis" in the familiar caricature of Hegelian dialectics and philosophy.

Adorno sees Beethoven as an exemplar of the Hegelian dialectic and vice versa: "Beethoven, showing an elective affinity for the spirit of the mature bourgeois spirit of the natural sciences, faced the antinomy of the universal and the particular by qualitatively neutralizing the particular." ${ }^{72}$ For Adorno, this was to do more than continue and advance tradition; it was to safeguard the art form against what he considered to be unreasonable levels of abstraction. In Beethoven's music, he argued, the particular "is and is not an impulse toward the whole," something that becomes itself only in its entirety; however, the particular in general, for Adorno, is predisposed to become tonally indeterminate and formally amorphous. He suggests that upon careful listening, Beethoven's "extremely articulated" music "resembles a continuum of nothing." Beethoven's works achieve a Hegelian form: "[T]he totality of nothing determines itself as a totality of being." ${ }^{74}$ Indeed, Adorno suggests, Beethoven was "more Hegelian than Hegel:",75 within Beethoven's music the tiny motive, or the "individual," becomes the Whole through development (which Adorno understands as the theme's negation of itself). Beethoven's thematic developments consist of "the mutual abrasion of the

72. Theodor Adorno, Aesthetic Theory, eds. Gretel Adorno and Rolf Tiedeman, trans. Robert Hullot-Kentor (London: Continuum, 1997), 185:

73. Adorno, Beethoven, 43.

74. Adorno, Aesthetic Theory, 185.

75. Adorno, Beethoven, 160. 
antithesis, the individual interests. The totality that governs the chemism of his work is not a cover concept schematically subsuming the various moments" ${ }^{\text {;6 }}$; rather, that totality governs both the elemental theme and the complete work. Rather than authenticating the "natural material" with which a piece is constructed, Beethoven succeeds in invalidating it. Beethoven's motives (which have already been reduced from the Classical ideal of a melodic construction to tiny, individual bits of sound), are for Adorno both discrete and universal. No longer following tonal principles and creating additional examples of music according to such principles, Beethoven reduced his motives to the point that they were no longer single entities standing alone; they had, rather, become integral parts of a totality. Further, "the developing variation, an image of social labor, is definite negation: from what has once been posited it ceaselessly brings forth the new and enhanced by destroying it in its immediacy, its quasi-natural form." ${ }^{17}$ For Adorno, Beethoven stood midway between Mozart, who, radical though he was, remained bound to convention, and Wagner, who would abandon convention entirely. Beethoven is, rather, the perfect exemplar of Adorno's definition of genius to the extent that Beethoven is able to "subjectively achieve the objective., ${ }^{78}$ Adorno suggests that Beethoven was able to accomplish what he did to the extent that he mobilized objective conventions (tonality, sonata form, etc.) beyond their limits through precisely following that which was objectively implicit to these conventions themselves.

On the subject of Mozart's disobedience of convention as compared to Beethoven's disregard for it, Adorno writes: "[Mozart's] music is a sustained attempt to

76. Ibid.

77. Ibid., 44.

78. Adorno, Aesthetic Theory, 234. . 
outwit convention. In piano pieces such as the B minor Adagio, the Minuet in D major; in the 'Dissonance Quartet;' in passages of Don Giovanni and heaven knows where else,' traces of the dissonance he intended can be discerned. His harmony is not so much an expression of his nature as an effort of 'tact.' Only Beethoven dared to compose as he wanted: that, too, is a part of his uniqueness." ${ }^{, 79}$ Mozart's uniqueness, suggests Adorno, was his ability to unify a musically "absolutist" character with the nature of the bourgeois. "By contrast, in Beethoven the traditional forms are reconstructed of freedom." ${ }^{80}$ Adorno goes on to evaluate the "misfortune" of the Romanticism that developed in the wake of Beethoven's reinvention of tradition: "[Romanticism] no longer faced the tension between the permitted and the intended: this is a position of weakness. Now, they could dream only what was allowed. Wagner." ${ }^{81}$ This state of affairs might finally explain why the subjectivist Beethoven left the sonata pattern as such intact. But the reconciliation of these demands, in showing up a contradiction objectively contained within the form, finally abolishes the prescribed order. The subject-object relationship in music, therefore, is a dialectic. in the strictest sense; it is not a tugging at each end of a rope by the subject and object, but rather an objective dialectic disconnected from the logic of form as such. It is the actual movement of the concept within the subject matter, which needs the subject only as an agent who complies with the necessity of freedom (but only the free subject who can perform this function). And that is, at the same time, the supreme confirmation of conception of the musical process as directed towards the

79. Ibid., 26 .

80. Ibid., 61 .

81. Ibid., 26. 
object. $^{82}$

Considering Beethoven's late period, Adorno comes to an overarching conclusion about the reconstruction of not only form, but also harmony-and in a social sense in addition to a musical one; he refers to Beethoven's polyphony as "in the most literal sense an expression of the waning belief in harmony. It presents the totality of the alienated world. Much music by the late Beethoven sounds as if someone, alone, were gesticulating and mumbling to himself. The episode with oxen." ${ }^{83}$ The episode to which Adorno refers is elaborated by Thayer: ${ }^{84}$

Two old peasants told the owner of Wasserhof 1862 stories which confirm Krenn's account of Beethoven's unusual behavior in the fields. Because of his unaccountable actions they at first took him for a madman and kept out of his way. When they had become accustomed to his singularities and learned that he was a brother of the landlord they used to greet him politely; but he, always lost in thought, seldom if ever returned their greetings. One of these peasants, a young man at the time, had an adventure with Beethoven of a most comical nature. He was driving a pair of young oxen, scarcely broken to the yoke, from the tile-kiln toward the manor-house when he met Beethoven shouting and waving his arms about in wild gesticulations. The peasant called to him: $A$ bissel stada! ("A little quieter") but he paid no attention to the request. The oxen took fright, ran down a steep hill and the peasant had great difficulty in bringing them to a stand, turning them and getting them back on the road. Again Beethoven came towards them, still shouting and gesticulating. The yokel called to him a second time, but in vain; and now the oxen rushed towards the house, where they were stopped by one of the men employed there. When the driver came up and asked who the fool was who had scared his oxen the man told him it was the proprietor's brother. "A pretty brother, that he is!" was the answering comment. ${ }^{83}$

What is emphasized in this recounting already shows " 1800 " as an accomplished fact: the mad genius, the prototype of the bourgeois individual. As Hegel would have the concept

82. Ibid., 62 .

83. Ibid., 157 ,

84. See Notes 3.3.3.

85. Alexander W. Thayer, Life of Beethoven, vol. 3 (Cambridge, MA: Harvard University Press, 1921), 243. 
of spirit historically unfold Kant's pure reason, so too does Beethoven explode the Viennese niceties of Haydn and Mozart.

\subsubsection{The Twelve-Tone Method}

In the autoexperiments I discussed in the previous chapter, the psychophysicist Ebbinghaus had called his groups of meaningless syllables "series," the same term Arnold Schoenberg would sometimes use to designate the twelve-tone rows he used in his influential technique of composition. The parallels do not end there: As Kittler points out, Ebbinghaus would set aside each syllable he had already memorized until the other 2,299 had been used, just as Schoenberg used each pitch once and only once in each twelve-tone row. Moreover, adds Kittler, "[I]n order to refute the doctrine of free association taught in 1800, Ebbinghaus produced a complicated demonstration showing that the interconnection of members of a row facilitates memorization; for example, if an already memorized series dosch pam feur lot..., is reordered into the series lot pam feur dosch... Accordingly, 'not only are the original terms associated with their immediate sequents,' that is, those following in either direction, but also 'connections are also established between each term and those which follow it beyond several intervening members. ${ }^{\prime 86}$ Schoenberg's technique, again, entailed similar permutations.

Kittler discerns in Ebbinghaus's experimental protocols certain correspondences to the four "axioms" of the twelve-tone technique. Firstly, the basis of this technique is a twelve-tone series, that is, a twelve-tone row, a uniquely ordered arrangement of the twelve pitches of the chromatic scale (the twelve equal tempered pitch classes). Secondly,

86. Kittler, Discourse Nerworks 1800/1900, 210. 
and implicitly, none of these pitches are repeated within the series. Thirdly, within any given twelve-tone work, the series can occur as such or as any of its linear transformations: retrograde, inversion, or retrograde-inversion. When the series occurs as such, it is called the "prime basis." The retrograde permutation is the prime basis in reverse. The inversion permutation, however, is not so easily carried over to Ebbinghaus's nonsense syllables, because the inversion permutation is the prime basis upside down, that is, in place of "dosch pam feur lot...," we would have something like:

\section{possy dpur fani $101 \cdots$}

Finally, the retrograde-inversion permutation is the prime basis in reverse and upside down. "Permutations of permutations eliminate any natural relation," asserts Kittler. ${ }^{87}$ "Nonsense syllables or chromatic tones of equal value constitute media in the modern sense: material produced by random generation, selected and grouped into individual complexes. The fact that these materials always join discrete elements and do not develop in continuous genesis from an unarticulated nature distinguishes them from minimal signifieds." ${ }^{88}$ For Ebbinghaus, the primal "oh!" would have had no more meaning than any other combination of letters or sounds-which is to say, it would have had no meaning at all.

As we have seen, the Austro-German musical tradition, of which Schoenberg was a part, finds its conceptual parallel in critical dialectics, certainly more so than in psychophysics. The Second Viennese School no less than Beethoven achieved what it

87. Ibid.

88. Ibid., 211 . 
achieved by following conventions through unto their undoing. As Adorno notes, "Schoenberg's compositional techniques: thematic construction, exposition, transitions, continuation, fields of tension and release, etc., are all scarcely distinguishable from traditional, especially Brahmsian, techniques, even in his most daring works." ${ }^{89}$ The harmonic language of Schoenberg's totally chromatic works tends to avoid the most obvious tonal references (sevenths and ninths replace octaves, fourths and tritones are as common as thirds, triads are augmented to span a diminished sixth, and anything approaching a perfect cadence is virtually unknown); however, it continues to exploit the effects of tension and release that give harmony its expressive force and sense of movement, although the tension is fiercer and the release more equivocal. This is essentially an extension, not a negation, of the Western ear's previous musical experience. And behind the ear lies the heart's ability to sense the expressive reality composed into the music and the brain's resourcefulness in perceiving, with patience and application, the infinite variety of relationships which, on the largest scale, make up each work's "tonal" integrity. Schoenberg was no less explicit on this point than was Adorno, as we see in the following passage, taken from a letter of Schoenberg's:

You have rightly worked out the series of my string quartet [No. 3]. You must have gone to a great deal of trouble, and I don't think I'd have had the patience to do it. But do you think one's any better off for knowing it? [...] This isn't where the aesthetic qualities reveal themselves, or, if 'so, only incidentally. I can't utter too many warnings against overrating these analyses, since after all they only lead to what I have been dead against: seeing how it is done; whereas I have always helped people to see: what it is! I have repeatedly tried to make Wiesengrund [Adorno] understand this, and also Berg and Webern. But they won't believe me. I can't say it often enough: my works are twelve-note compositions, not twelve-note compositions. [...] You may wonder at my talking about this at such length. But although I'm not ashamed of a composition's having a healthy constructive basis even when it is a spontaneous result, produced unconsciously, I still don't care to be regarded as a constructor on account of the bit of juggling I can do with series,

89. Adorno, Essays on Music, 186 . . 
because that would be doing too little to deserve it. I think more has to be done to deserve such a title, and actually, I think I am capable of fulfilling the considerable demands made on me by those entitled to do so. ${ }^{90}$

The Second Viennese School, including even Webern's last works, remains at the limits of a tradition that began with Haydn. In essence, twelve-tone, or dodecaphonic, music requires one and only one use of each of the twelve pitches of the Western chromatic scale —each, in this context, called a "pitch class" or "pc"-before any of them can be used a second time. John Covach chooses the work of composer Josef Matthias Hauer (1883-1959) to illustrate this method, as Hauer may have been the first to write on the organization of this new theory. Hauer, who began to publish on Zwölftongesetz in 1920 , considered the rotation and equality of the twelve pitches to be a "technical solution to a number of music-aesthetic problems" with which he had been struggling. ${ }^{91}$ Therefore, we can approach the technical aspects of twelve-tone theory only by way of its broader context.

Among the many principles that Hauer set forth was the principle that music properly fashioned and received is a spiritual (geistig) creation. Music in its pure form, for Hauer, must be distinguished from the music that "occurs in the physical world around us, which constitutes its material form." ${ }^{92}$ Hauer advocates raising music to the highest possible spiritual plane by means of the elimination of material, worldly influences. The musical gesture originates with the composer (or, perhaps, with the improviser or performer), but it must be passed through the physical world in order to be

90. Arnold Schoenberg to Rudolf Kolisch, 27 July 1932, quoted in Arnold Schoenberg, Letters, ed. Erwin Stein, trans. Eithne Wilkins and Ernst Kaiser (Berkeley: University of California Press, 1987), 164-65.

91. John Covach, "Twelve-Tone Theory," in Christensen, The Cambridge History of Western Music Theory, 604.

92. Ibid. 
communicated to someone else. However, the idea is always harmed during its transmission by means of "instrumental noise, poor intonation, and/or other purely physical impediments." ${ }^{\prime 93}$ As Covach interprets Hauer, the listener has the responsibility for understanding the original, ideal gesture and restoring its spirit in spite of its environmental corruption. The music that actually sounds is inferior, but the ear of the listener should be capable of reestablishing the composer's true intention.

Because of Hauer's wish to cast off the fetters of the physical transmission of music, he rejects "Schoenberg's notion of Klangfarbenmelodie, a technique in which different instruments or instrumental groups of some performing ensemble are juxtaposed in musical succession forming a kind of melody of instrumental timbres. For Hauer, this focuses the musical attention in precisely the wrong way; by relishing the physical timbres and their differences, the listener gets stuck in the physical transmission line itself, and is unable to hear through to the spiritual content of the music." ${ }^{94}$ Hauer considers tone color to be a question of the "internally perceived interval," not a characteristic that resides in the physical, external, imperfect mode of representing music. Hauer is consistent, too, in his dismissal of virtuosity in performance; he asserts that one can readily lose one's focus on the music's spiritual properties when distracted by admiration of the performer's technical ability. The physical, material aspect of music must, according to Hauer, always be shunned to the greatest degree possible. ${ }^{95}$

Covach goes into greater detail with respect to Hauer's program:

93. Ibid.

94. Ibid., 605.

95. Ibid. 
First, Hauer argues for a tempered twelve-note tuning. He begins his discussion by surveying the ways in which one can generate all twelve pitch classes acoustically. Starting from C, Hauer generates the remaining eleven pitches in three ways: up from $\mathrm{C}$ in acoustically perfect fifths (2:3); up from $\mathrm{C}$ in acoustically perfect fourths ( $3: 4)$; and up from $\mathrm{C}$ in overtones. He then reduces everything down to within an octave and compares the results. The collections of eleven pitches generated from the same starting pitch are in each case different, generating various representatives for each of the other eleven pitch classes. The tempered pitch classes, which are not to be found in nature, offer yet another [sic] of twelve pitch classes. Hauer thus asserts that the physical realm is imperfect because it produces no usable chromatic scale. ${ }^{96}$

Because tempered tuning, by contrast, does indeed provide a chromatic scale and because it is a system not found in the physical, material world, "the tempered scale constitutes a kind of spiritualization of musical materials." ${ }^{, 97}$ The mind can move successfully away form the physical and toward the spiritual, the essential. Hauer cites Goethe's Farbenlehre, which notes that the complete spectrum of colors cannot be seen in nature. Similar to his tempered set of twelve tones, Hauer sees the color circle-likewise designed by the human mind-as a supplement to and extension of the natural.

In his justification of the twelve-tone system of composition, Hauer postulates a spectrum with pure rhythm on one end and pure melody on the other. Purely rhythmic music, clearly, has no pitch; for this reason, Hauer sees it as "entirely material," while purely melodic music, music without rhythm, is "entirely spiritual." ${ }^{98}$ All music contains elements of both rhythm and pitch and therefore falls at some distance from the two ends of the spectrum. Because tonality entails the eminence of one pitch above others, it is for Hauer more akin to the rhythmic realm than is atonality, whose "constant circulation" of

96. Ibid.

97. Josef Matthias Hauer, Vom Wesen des Musikalischen, page 35, translated and quoted in Covach, "Twelve-Tone Theory," 605.

98. Covach, "Twelve-Tone Theory," 606. 
each of the twelve pitches of the chromatic scale "suppresses this rhythmic component," resulting in a more purely spiritual music. ${ }^{99}$ As a result, Hauer sees tonality as inferior to the twelve-tone system. At this point, we can see his preference in the context of Hauer's overall aesthetic formulation:

In atonal music, which arises out of the "totality," only the intervals matter. They express musical character, no longer through major or minor or through characteristic instruments (thus through one color), but rather directly through the totality of intervals, which are best and most purely rendered on an equaltempered instrument. In atonal music there are no more tonics, dominants, subdominants, scale degrees, resolutions, consonances or dissonances, but rather only the twelve intervals of equal temperament; their "scale" arises out of the twelve, tempered half steps. In atonal music, both the purely physical, material, and the trivial, sentimental, are, as much as possible, shut out and their "law," their "nomos," is that, within a given tone-series, no tone may be permitted to be repeated or left out. ${ }^{100}$

His correspondence shows that in 1924, Hauer was still struggling to find an "underlying objective principle" in his own atonal music in addition to that of Schoenberg and Webern-music that was, at the time, sharply criticized by the Viennese. The "objective and eternal law of music" appeared to Hauer during the composition of his piece Nomos, Op. 19: "the notion of constantly circulating the aggregate." ${ }^{101}$ Covach asserts, though, that the piece is "not entirely dodecaphonic," due to the smaller collections of pitch classes (smaller than twelve, that is) used in some areas of the work. Hauer's compositions would soon be completely twelve-tone.

Hauer's early theory of dodecaphony exhibits the hallmarks of what Kittler terms "1800." Equal temperament, atonality, and the principles that follow from them are

99. Ibid.

100. Hauer, Vom Wesen des Musikalischen, page 35, quoted in Covach, "Twelve-Tone Theory," 606.

101. Covach, "Twelve-Tone Theory," 606. 
understood in the context of progressive purification of "materiality" towards its "spiritual" truth. In spite of this, however, we do see the beginnings of a movement from a rhetoric of tonics, dominants, and so on, to a rhetoric of aggregates, combinatoriality, and the like. Herbert Eimert, a younger contemporary of Hauer, claimed to have put together a system of atonal composition using the discoveries and developments of others, naming Hauer and Jefim Golyscheff as musical influences. Giving 46 musical examples in only 36 pages, Eimert provides an explanation of atonality from both the theoretical/compositional and the historico-aesthetic viewpoints, and Covach points out that he makes obvious and liberal use of Hauer's previous work throughout earlier sections, while the third chapter ("The Atonal Principle of Melody") "emphasizes the almost infinite number of melodies that can arise when the nearly 500 million possible orderings of the twelve pcs are combined with an unlimited freedom in rhythmic configuration." ${ }^{102}$ Recommending an avoidance of tonal associations in the creation of atonal melodies, Eimert makes his own twelve-tone rows "melodic aggregates" more than melodies. Eimert avowed that the important technique was the circulation of the twelve tones, or pitch classes-not their strict ordering. In this, Eimert differed from what would soon become standard practice for Schoenberg and his followers. Covach argues that, for Eimert, "so long as the music progresses according to melodic aggregates, the harmonic dimension of the music is free from restrictions (except, one might expect, from creating tonal associations)."

Chapter 4 of Eimert's pamphlet discusses the "complex," the harmonic principle

102. Ibid., 608.

103. Ibid. 
of dodecaphonic music. "The complex can be thought of," Covach asserts, "as a 'harmonic aggregate' in which the defining feature is that all voices in a texture, when taken together, complete the twelve-pc aggregate. In a four-voice texture, for instance, all four voices taken together unfold a harmonic aggregate even though each voice alone does not unfold a melodic aggregate." 104 Covach goes on to explain Eimert's thinking: "[I]n two voices there are eleven possible partition patterns: these would be $1+11$ (one pitch in one voice, eleven in the other), $2+10$, and so on, ending with $11+1$. In three voices there are 55 possible partitionings and in four voices there are $165, " 105$ Depending on the number of pcs contained in a single voice, the possible reorderings of the tones vary exponentially. As Covach puts it, "[A]s the number of voices in a partition increases, the number of possible melodic permutations decreases; and as the number of melodic permutations increase, the number of voices in a partition decrease [sic].,106

Eimert approached twelve-tone music from a practical point of view and not from a spiritual one such as Hauer's. He considered the systematization of the use of the twelve pitch classes to be a natural outgrowth of tonality. Given this idea of atonality as a natural development, it is difficult to uncover some kind of radical "event" that suddenly erupted and completely transformed the musical-theoretical inscription systems for music. Visions of musical progress, organic unity, and expressivity still reign supreme. If notions of "dominant" and "tonic," "masculine" and "feminine," are replaced with notions of "series," "aggregation," and "permutation," these still have an expressive end in view. Neither entirely Dada in their avant-garde ambitions nor entirely Wagnerian in

104. Ibid.

105. Ibid.

106. Ibid., 608-9. 
the traces of Romanticism they retain, the first twelve-tone compositions and the theories that surrounded them occupy a position similar to the position of Beethoven: They stand at the crossroads of a transition. Unlike Ebbinghaus, whose arbitrary sequences of syllables were deliberately devoid of sense, Eimert and Hauer were both grappling with some way to wrest sense from the music being made in the Vienna of their day.

Rather than Hauer's and Eimert's systems, it was Schoenberg's twelve-tone system that was to become the standard; its ordered series and row forms based on transposition, inversion, retrograde, and retrograde-inversion are still studied today. Schoenberg's theory, though, was the last of the three to be published and the only one to be explained not by the theorist himself but by a student of his, Erwin Stein. The article in question is "Neue Formprinzipien," which appeared in the September 1924 issue of Musikblätter des Anbruch celebrating Schoenberg's fiftieth birthday. Stein's exposition of Schoenberg's theory contextualized the new method as a response to the "crisis" of composition that had resulted from the downfall of tonality along with its importance as a formal, architectural support. It presented atonality as historically inevitable, arising naturally from tonality via the advanced chromaticism of composers from Wagner to Scriabin. Covach also notes the deep historical resonance of Stein's argument "that modern music is turning away from harmony as its principal structural determinant and toward counterpoint, reversing the stylistic change that occurred from Bach to Mozart by returning again to polyphonic thinking."107

Stein explains inversion, retrograde, and retrograde-inversion, writes Covach, "not as operations on twelve-pc rows - an idea that would figure prominently in integral 107. Ibid., 610. 
serialist composer Milton Babbitt's writing-but rather more generally as melodic transformations of motives." ${ }^{108}$ Stein posited that these procedures would provide a balance of melodic variety and motivic unity. The Grundgestalt (basic shape), "which, appearing early in a work, is the source of all subsequent musical material," ${ }^{109}$ is introduced by Stein through excerpts and analyses of Schoenberg's Opp. 23-25. Notably, not all of these musical examples were dodecaphonic; the Grundgestalt and the twelvetone row are not to be equated. As Covach notes, "Stein presents the twelve-tone method not as the only way, but rather as one approach among many. It thus seems that even within his own circle it was not clear that Schoenberg would turn to exclusively twelvetone composition after his first extended dodecaphonic work." 110 Nor was it certain that Schoenberg's followers "ever understood the row as more than a melodic resource; the idea that a row could function as a background context in Schoenberg's music, establishing structural hierarchy and row disposition within a given piece, would have to wait for the later theoretical work of Schoenberg's American exegetes led by Milton Babbitt."111

For Hauer, with his idealistic preoccupation with the spiritual realm, the structure of a musical work "was only ever part of a much greater structure that could never be projected in any single piece but was nevertheless already and always present."112 Schoenberg considered dodecaphony to be "a means for projecting the musikalischer

108. Ibid.

109. Ibid.

110. Ibid.

111. Ibid.

112. Ibid. 
Gedanke [musical notion or concept] of a work."113 Although it was not discussed explicitly by Stein, the concept of communicating the Gedanke had a spiritual component for Schoenberg. ${ }^{114}$ Schoenberg would later go so far as to compare artistic creation with divine creation. Eimert, in contrast, was apparently uninterested in any spiritual aspect of his musical system, and concerned himself primarily with the creation of a practical handbook of the technical possibilities afforded by dodecaphony. Therefore, Covach asserts, early twelve-tone theory proves to have been subject to "a wide variety of approaches; the dodecaphony of Hauer, Schoenberg, and Eimert are at once contrasting and related, often hitting on similar technical solutions as responses to very different sorts of questions." 115

Even in its prescriptive guises, the primary concern of dodecaphony is to address the age-old dialectic between the harmonic and the melodic. Twelve-tone theory and composition will not find themselves entirely reducible to the discourse network of "1900" until after the Second World War, and even here, we are already at the beginning of something other than " 1900 ": that is, "2000," or whatever we would call the epoch within which we presently stand. It is not until we reach figures such as Stockhausen and Varèse that we find the logic and dialectic of intervals abandoned to a physics of frequency. Physiological acoustics, in turn, are the musical-theoretical activities that are part and parcel with the writing-down systems of "1900."

113. Ibid.

114. Ibid.

115. Ibid., 611. 


\subsubsection{The Gramophone}

The grooves of the gramophone needle bring about a shift from a focus on the signifieds, or the meanings, of texts to the materiality of its signifiers themselves. Media such as film and the gramophone, Kittler states, "store acoustical and optical data serially with superhuman precision." 116 These two media, developed by the same engineers at the same time, immediately posed a challenge to the monopoly that the book had held on data storage since universal alphabetization. "Data-storage machines are much too accurate to make the classical distinctions between intention and citation, independent thought and the mere repetition of something already said. They register discursive events without regard for so-called persons."117

Kittler places the phonograph, or gramophone, at the center of the transformations from " 1800 " to " 1900 ." The gramophone was the first invention capable of recording the real movement of things for more than an instant. After listening to a demonstration, the writer Edward Bellamy published a short story, "With Eyes Shut," in Harper's Monthly. ${ }^{118}$ Bellamy's hero, traveling west from Boston by train and unable to read because of motion sickness, is rescued from boredom by a vendor renting gadgets uncannily similar to the modern digital audio file player, complete with earphones. The traveler listens to a book (in these early days, most imagined that the future of the gramophone would largely involve recordings of speeches and books as opposed to music) as he watches the passing scene and then discovers, after arriving in remote

116. Kittler, Discourse Networks 1800/1900, 245.

117. Ibid., 300 .

118. Edward Bellamy, "With Eyes Shut," Harper's New Monthly Magazine 79 (1889): 736-45. 
Colorado, that everyone in Denver is walking around with these gadgets in their ears. In the short time since they had become "listeners," these westerners had forgotten to read and write. Bellamy suggests that hearing would be the sense of the future, coming none too soon to rescue eyesight, which "was indeed terribly overburdened previous to the introduction of the phonograph, and now that the sense of hearing is beginning to assume its proper share of work, it would be strange if an improvement in the condition of people's eyes were not noticeable."119

Adorno suggests that the gramophone is still infused with aura:

The dog on records listening to his master's voice off of records through the gramophone horn is the right emblem for the primordial affect which the gramophone stimulated and which perhaps even gave rise to the gramophone in the first place. What the gramophone listener actually wants to hear is himself, and the artist merely offers him a substitute for the sounding image of his own person, which he would like to safeguard as a possession. The only reason that he accords the record such value is because he himself could also be just as well preserved. Most of the time records are virtual photographs of their owners, flattering photographs-ideologies. ${ }^{120}$

For Adorno, "the gramophone belongs to the pregnant stillness of individuals."121 Adorno's remarks imply a disagreement with Walter Benjamin, who, in his famous essay "The Work of Art in the Age of Mechanical Reproduction," argues that to the extent that there are so many mechanical reproductions of artwork, there is no longer a single auratic artwork. ${ }^{122}$ However, Adorno does allow-and here he concurs with Kittler-that were the gramophone itself to become the body that speaks, that is, were it give up any

119. Bellamy, "With Eyes Shut," 745

120. Adorno, Essays on Music, 274.

121. Ibid., 272 ,

122. Walter Benjamin, The Work of Art in the Age of Mechanical Reproduction (New York: Prism Key Press), 2010. 
suggestion of an "outside," of being a voice's supposed carrier, it could gain a different kind of legitimacy: "Only where the body itself resonates, where the self to which the gramophone refers is identical with its sound, only there does the gramophone have its legitimate realm of validity."123

Pursuing this logic, Adorno, lamenting that "there has never been any gramophone-specific music," called for the rise of a music that would be performed directly from the grooves of a record, a music in which those grooves would be the primary material rather than a weak method of secondary capture. ${ }^{124}$ American experimental composer Henry, Cowell, who along with Charles Ives paved the way for the later experiments of John Cage and his circle, imagines something similar: $\mathrm{He}$ is aware that "there are possibilities in the phonograph record which would be hard to duplicate. It produces new tone qualities which might be used in composition. A record of a violin tone is not exactly the same as the real violin; a new and beautiful tone-quality results. Many variations in tone can be artificially produced by different placements of the microphone in recording. $" \sqrt{25}$

By 1930, the phonograph and the optical track for film had been invented and developed to the point of practical use. Several composers and filmmakers experimented with these recording media. In 1928, Walther Ruttman composed a sound track montage for a film without visuals; during 1929 and 1930, Paul Hindemith and Ernst Toch produced several short phonograph studies; and between 1933 and 1937, Arthur

123. Adorno, Essays on Music, 274.

124. Ibid., 277.

125. Henry Cowell, "Music of and for the Records," Modern Music 8 (1931): 33. 
Honegger and other composers manipulated sound tracks for their film music. In 1948, Pierre Schaeffer conceived the idea of a "concert of locomotives"; the resources of Radio-Diffusion-Télévision Français (RTF), where Schaefer was an engineer, provided him with phonograph turntables, phonograph disc recording devices, mixers allowing him to combine two or more signals into one, and a library of records with sound effects. Schaeffer spent several months experimenting with the technology available to him. He discovered he could record sound material on locked-groove discs instead of spiralinginward-groove disos (as with normal phonograph records). These locked-groove discs allowed him to make loops of sound that created repetitive rhythmic patterns. Using these techniques and recordings of train sound effects, Schaeffer composed Étude aux chemins de fer in 1948. This three-minute work contains various sounds: wheels clacking along the track, steam escaping from the boiler and cylinders, whistles calling out various signals. Schaffer decided to call this music musique concrète because of the ways it differed from traditional "abstract" music:

The qualification of "abstract" is used to describe ordinary music because it is first conceived of in the mind, then notated on paper, and finally realized only by instrumental performance. Musique concrète, on the other hand, begins with preexisting sound elements which may be music or noise. These elements are then experimentally manipulated and a montage is created. The final composition is a result of these experiments and the ideas contained in the sketches for the work. ${ }^{126}$

For Schaeffer, "traditional" music begins with abstract ideas that become concrete only in performance, while the new music begins with concrete material that is made abstract through experimentation. It is appropriate that the raw sonic matter Schaeffer would manipulate in his study involved the thermodynamics of the steam engine and the locomotive. After all, according to both Wiener and Deleuze, it was precisely

126. Pierre Schaeffer, A la reserche d'une musique concrete (Paris: Seuil, 1952), 35. 
technologies such as these that would be overcome by control societies. Here we have a perfect indication of what is at stake with the gramophone. Schaeffer does not pretend to infuse "voice" or "soul" into language, but rather manipulates materiality itself as a new kind of language.

Kittler draws out the potential of these "indelible traces" through a discussion of Rainer Maria Rilke's famous 1919 essay, "Primal Sound."127 Kittler recounts that as a schoolboy, Rilke had made a rudimentary phonograph in class using candle wax, hairbrush bristles, and cardboard, and the experience had a lasting influence. Some fifteen years later, while attending anatomy lectures at the École des Beaux-Arts in Paris, Rilke was "enchanted" by the "special housing closed against all worldly space"128 that was the human skull. He acquired a skull and studied it constantly. Rilke discovered that the clearly delineated cranial suture reminded him of "those unforgotten lines that were once scratched onto a little wax roll by the point of a bristle!" 129 He found himself inspired to "read" the sutures of a human skull with a gramophone needle, expecting the result to be a primal ur-sound. Kittler writes of Rilke's fantasy: "What the coronal suture yields upon replay is a primal sound without a name, a music without notation, a sound even more strange than any incantation for the dead for which the skull could have been used. Deprived of its shellac, the duped needle produces sounds that "are not the result of a graphic transposition of a note but are an absolute transfer, that is, a metaphor." ${ }^{130}$ The

127. Rainer Maria Rilke, "Primal Sound," in Primal Sound and Other Prose Pieces, trans. Carl Niemeyer (Madison: University of Wisconsin Press, 1943), 8.

128. Kittler, Discourse Networks $1800 / 1900,315$.

129. Ibid.

130. Ibid., 44-45. 
skull, or the "corpse," speaks. The signal is no longer a "voice" from the sender through the transmitter to the receiver; it is, rather, the noise in this circuit itself. The coronal suture, Kittler speculates, "effects the shift from reproduction to inscription, from reading to writing in the technological age." 131

Kittler further asserts that "the suture that divides the two cranial hemispheres like a sagittal incision designates the status of all script for a writer of 1900 . Only a scratch or cut into the flesh of forgetfulness itself can be unforgettable." 132 Rilke had learned from anatomy "what Nietzsche learned investigating the genealogy of morals, what Kafka's explorer learned in the penal colony. If ever an initiation did justice to the material, then this was it." ${ }^{133}$ The cranial suture functions as the leftover trace of a writing energy or art that, instead of "making variations or imitating," "had its joy in the dance of existences," in a "dictatorial art that presents dispositions of energy." ${ }^{\text {134 }} \mathrm{A}$ "consciousness of an ethical nature" of the kind evoked in the titles of Nietzsche and Kafka can add nothing to this. Technology and physiology are responsible for material inscription-or rather, Kittler specifies, "a system composed of technology and physiology is responsible."135

Kittler contrasts the common poetic response to seeing a skull- "throw[ing] their heroes into the traditional melancholy associations"136 - with that of Rilke, the clearheaded experimenter, and celebrates Rilke's ability to propose "more radically than

131. Ibid., 45.

132. Ibid., 316 .

133. Ibid.

134. Ibid.

135. Ibid.

136. Ibid. 
technicians and physiologists-and in a language that maintains a wonderful balance between precision and caution-a phonographic test of human body parts." ${ }^{\text {137 }}$ Kittler's conclusion is a radical one: through information science, we discover that "recording and playback devices are essentially convertible" and that we can "[decode] [...] a track that no one had ever encoded."138 Rather than leaving the mysteries of the physical world unexamined, we can "track traces without a subject,"139 as Simmel and Freud do in their attempts at objective analysis, and as Rilke does with his imagination of the primal sound of the skull read by the gramophone needle. A writing without the writer records the the basis of all media: noise, primal sound. ${ }^{140}$

Writers and "analysts of the mental apparatus" in " 1900 " saw themselves in a real situation of direct competition. Rilke imagined a bold, precise, and resolute artistic practice that would contribute even more than could scientific research "to an extension of the several sense fields." 141 Though he "fled psychoanalytic vivisectors," he saw "the transposition of coronal sutures" as the primary charge of the writer. ${ }^{142}$ "Even his enigmatic "inner-world space," Kittler alleges, "was only another name for the engram stored in the brain and transcribed by writers." ${ }^{143}$ For Kittler, Rilke's reference to the skull as a "special housing closed against all worldly space" bore a close association to

137. Ibid., 316.

138. Ibid.

139. Tbid.

140. Ibid.

141. Ibid., 317.

142. Ibid.

143. Ibid. 
"the physiologist's insight that, for such a housing, 'our own body is the external world." 144 Those insisting or continuing to interpret the "inner-world space" from a philosophical stance-despite the fact that the world behind the closed housing is a "technological and physiological system"-are engaged in a useless attempt and "thus remain $[\ldots]$ far behind the state of the art." ${ }^{145}$ Once again, Kittler couches in different terms his assertion that, "circa 1900, the ersatz sensuality of Poetry could be replaced, not by Nature, but by technologies. The gramophone empties out words by bypassing their imaginary aspect (signifieds) for their material aspects (the physiology of the voice)."146 Kittler uses Rilke's fantasy about putting a gramophone needle to the skull to illustrate what writing in "1900" means. Being a "corpse" should not be understood morbidly or melancholically; rather, it is the positive possibility, the proper, the body, materiality. Schaeffer's etude parallels Rilke's imagined experiment in its use of loops, cuts, splices, speed changes, and direction changes to materialize a music of primal noise.

In 1822 , while studying the flow of heat, the mathematician J. B. J. Fourier developed the theorem that any complex periodic vibration may be resolved into a number of simple harmonic vibrations. In 1843, the physicist Georg Ohm hypothesized that musical sounds are characterized by the distribution of energies among the harmonics in accordance with Fourier analysis and that the distribution pattern is the source of timbre perception. Ohm's law motivated German scientist Herman Helmholtz to demonstrate experimentally that, in effect, the ear itself performs a Fourier analysis on

144. Ibid.

145. Ibid., 316-17.

146. Ibid., $245-46$. 
a complex sound wave, discerning each partial tone in the frequency spectrum. This model depended on physiologist Johannes Muller's law of specific nerve energies. ${ }^{147}$ The decomposition of a given pitched tone into a multiplicity of different pitched tones, each at different levels of intensity, points the way to a physics of sound wholly different from the metaphysics or logic of sound that had previously held sway.

Green and Butler suggest that while "resonance theories of hearing based on sympathetic vibration between the sound stimulus and receptors in the ear were not new to the mid-nineteenth century, ${ }^{\mathbf{p} 48}$ it was only then that-owing to the improvements in the compound microscope that took place in the 1830 s-the anatomy of the ear could be examined in great detail. The scientist Hermann von Helmholtz, who explored both the physiological and the music-theoretical aspects of sound perception, believed psychology to be founded in the physical, and he aimed "to apply the methods of physics to at least the physiological aspects of perception., ${ }^{149}$ Helmholtz began to move from a physics of sound towards a physics of listening; within this emerging knowledge, there are only vibrating bodies, intensities, sympathies. There is no longer any mystery, any "outside"; there is only a system: The energy of a vibrating body energizes the air, nerve fibers on the basilar membrane are agitated by these energies, and they vibrate in sympathy. The significance of this paradigm shift cannot be overstated. Music, which for centuries had been seen as a kind of magic or mathematics, was now beginning to be understood in terms of physiological and physical-acoustic systems.

147. Burdette Green and David Butler, "From Acoustics to Tonpsychologie," in Christensen, The Cambridge History of Western Music Theory, 256.

148. Ibid.

149. Ibid., 256-57. 
Following his precocious and astonishing invention of the ophthalmoscope (a device to examine the interior of the eye), the young Helmholtz came to the realization that our sensations are far from direct perceptions of external phenomena. According to Green and Butler, "[H]is work on neural impulses and responses (the theory of specific fiber energies) suggested to him that 'inductive inference' (unconscious mental activity that interprets the input) based on experience and conditioning accounts for the sensory 'signs' that represent external objects. In other words, sensory mechanisms add supplemental data not found in the stimulus, and these additions accrue to perception through the experience and learning of the individual." ${ }^{150}$ Helmholtz's groundbreaking work in optics influenced his thinking as he turned to aural studies; in an 1857 lecture, he "isolate[d] the role of the ear [and] delineated a new point of view, 'physiological acoustics." ${ }^{151}$ Having separated the physical from the physiological dimensions of acoustics, Helmholtz went on to examine "the sensation of tone, the operation of resonance in the ear, compound waveforms, the harmonic series, acoustic beats, dissonance, combination tones, and organ stop mixtures," demonstrating the concepts he discovered using such items as "sirens, tuning forks, resonators, and plucked and bowed strings." ${ }^{152}$ In his later work Die Lehre von den Tonempfindungen (The Principles of Aural Sensation), Helmholtz would provide a formal explanation of human sensation of sound that went far beyond the physical and physiological realms to include such seemingly disparate fields as aesthetics and music theory.

150. Ibid., 258.

151. Ibid., 259.

152. Ibid. 
Helmholtz was convinced of the feasibility of creating a theory of harmony based purely on scientific fact, without recourse to consideration of metaphysical principles. He considered consonance and dissonance to be intrinsic physical properties of tone and believed himself to have succeeded (to a greater degree than had mathematicians such as Euler) in elucidating the bases of Pythagorean notions of consonance. As for dissonance, Helmholtz remained convinced that it is something native to bodies. His view is both material and systematic: The intensity of a physical body crosses the threshold of a physiological body, and at this threshold, "sensory mechanisms add supplemental data not found in the stimulus." 153 Everything is entirely reducible to bodies at different thresholds of intensification. Predicates other than degrees of intensity and relative velocity lose meaning; thought finds itself confined to the immanence of material bodies and their intensities.

In the practices of the integral serialists who followed upon Schoenberg and his school, electronic music enters into the development of Western compositional techniques. The integral serialists took one of Schoenberg's pupils, Anton Webern, as their patron saint. Webern had already adopted Schoenberg's twelve-tone technique in his 1925 Drei Volkstexte, Op. 17. The tone rows Webern uses, following a line of force towards thematic integrity, often possess a magical symmetry. In his 1934 Konzert fir neun Instrumente, Op. 24, for example, the twelve-tone row that Webern uses can be divided into four collections of three pitches each, where each collection, although comprised of different pitches, has an invariant intervallic relationship. In Figure 21, below, the number pairs in each set represent, in the first number, the interval between the first and second pitch of a collection and, in the second number, the interval between

153. Ibid. 
the second and third pitch of a collection. The arrow next to each interval represents the direction that the interval moves from the first pitch to the second pitch, and the letters below each set represent the transformation group, that is, the prime basis, the retrogradeinversion, the retrograde, and the inversion:

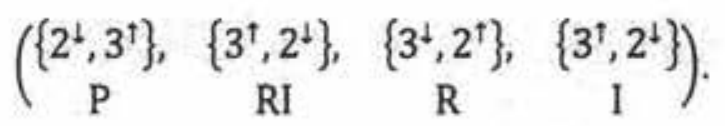

Figure 21. Intervallic Symmetry of Webern's Op. 24.

Once again, the retrograde permutation is the prime basis in reverse. In place of moving down two and then up three, we move up three and then down two. The inversion permutation is the prime basis upside down. Finally, the retrograde-inversion permutation is the prime basis in reverse and upside down. Here, Webern is using the same permutations normally reserved for an entire twelve-tone row within that row itself. Figure 21, though it contains each permutation within itself, would itself and in its entirety appear in each of these permutations.

By the time of his 1936 Variationen für Klavier, Op. 27, Webern takes this even further, so that, for example, not only pitches, but also duration, dynamics, and articulations seem to be determined in advance (e.g., every time G sharp occurs in the work, its duration is that of an eighth note, its dynamic is forte, and its articulation is legato). While it is doubtful that Webern was intent on absolutely "mathematizing" music, it was precisely this absolute mathematizing of music that the generation of composers following Webern attempted to accomplish, claiming that they were following Webern himself and the great dialectic of Western musical progress. One such composer, Karlheinz Stockhausen, provides an example of the integral serialist program. 
Stockhausen's 1954 Study II typifies the techniques and procedures of classical studio electronic music, in addition to the compositional thinking of the integral serialism. The source material for Study II consists entirely of sine waves. This was considered to be the purest sound source for electronic music composition, because it is the most elemental and allows composers to construct their own timbres. According to Stockhausen himself, "Such sinus tones were the first elements with which we composed (literally put together) various spectra according to the structural demands of a particular composition. [...] The composer determines [their] various characteristics, also called parameters." ${ }^{154}$ Stockhausen based Study II on the number 5, and so, in relation to pitch or frequency, he used a series of pitches separated by a constant interval of $\sqrt[25]{5}$. Beginning from a frequency of $100 \mathrm{~Hz}$, the remaining 81 frequencies were each successive multiples of $\sqrt[25]{5}$ :

$$
\begin{gathered}
100 \mathrm{~Hz} \cdot \sqrt[25]{5}=107 \mathrm{~Hz}, \\
107 \mathrm{~Hz} \cdot \sqrt[25]{5}=114 \mathrm{~Hz}, \\
114 \mathrm{~Hz} \cdot \sqrt[25]{5}=121 \mathrm{~Hz}, \\
\text { etc. }
\end{gathered}
$$

Having generated this pitch material, and using similar procedures based on the number 5, Stockhausen determined the dynamics, the articulations, and so on, that each of these pitches would have. To complete this scheme of fives, Stockhausen then divided the piece itself into five sections. This brief gloss on Study $I /$ and its explicit compositional thought provides insight into just how this music would approach a physics of sound.

The missed opportunity in the integral serialist works of this type was all too obvious to Adorno. "The vain hope of art," he wrote, "that in the disenchanted world it

154. Karlheniz Stockhausen, "Electronic and Instrumental Music," DIE REIGE 5 (1959): 61. 
might save itself through pseudomorphosis into science, becomes art's nemesis. Its gesture corresponds to what is psychologically termed identification with the aggressor."155 Jacques Attali levels a similar critique at integral serialism, calling it "an elite, bureaucratic music."156 Attali quotes both Stockhausen and another serialist composer, Iannis Xenakis, in order to make the point:

Take Xenakis: "Musicians could have, for the benefit of nineteenth-century physics, created the abstract structure of the kinetic theory of gases, exclusively by and for music." "Musical thought lagged far behind thinking in physics and mathematics, an avant-garde cut off from philosophy, thus chastised. We have decided that it is necessary for it to catch up with them to lead once more, as at the time of its Pythagorean birth." Or Stockhausen: "Without question, I want to integrate everything." This is the power vocabulary of the managers of industrial society. Of men of learning persuaded of the existence of an all-encompassing truth, of a society that desires to make its simple management the matrix of its meaning. A frenzied search for universal abstraction by men whose labor has lost its meaning and who are incapable of finding a more exalting one for it than the statistical organization of repetition. ${ }^{157}$

Adorno, in addition, asserts that "electronic music has failed to fulfill its own idea; even though it theoretically disposes over the continuum of all imaginable sound colors." ${ }^{158}$ In actual practice, adds Adorno, "it sounds as though Webern were being played on a Wurlitzer organ." 159 Adorno would continue to insist, as would Attali following him, that the idea of total determination as such merely confirmed a development that Max Weber, in the Sociology of Music, identified as the overall tendency of more recent musical history: the progressive rationalization of music. Adorno

155. Adorno, Essays, 193.

156. Attali, Noise, 113.

157. Ibid.

158. Adorno, Essays, 194.

159. Ibid. 
insisted that this "elite bureaucratic music" had entirely misunderstood Webern: "The idea informing Webern's music is his absolute lyricism [my emphasis], the attempt to resolve all musical materiality, all the objective elements of musical form, into the pure sonority of the subject, withoùt an alien remainder that refuses to be assimilated. As a composer, Webern never departed from this idea, whether consciously or not." ${ }^{, 160}$ Adorno understands lyricism as the expression of affect in a beautiful or a sublime, which is to say, from Adorno's position, a subjective manner. Webern's music was the first to realize a pure lyricism precisely because it had cast off the architectonic spell that later enchanted the integral serialists. Webern's music presents a contrast to the work that would later be carried out in its name.

If integral serialist music only approaches the pure physics of sound from the position of the integral and scientistic, the music of Edgard Varèse, the "stratospheric colossus of sound," ${ }^{161}$ provides a more thorough working out of the new thought. Indeed, Varèse claimed that Helmholtz's On the Sensations of Tone gave him the idea of incorporating the crank siren into his music as a method of creating "curved shapes" of sound. Varèse also claimed the philosopher Józef Maria Hoene-Wroński as another important influence on his music. "When I was about twenty," explains Varèse, "I came across a definition of music that seemed suddenly to throw light on my gropings toward music I sensed could exist. Hoene-Wroński, physicist, chemist, musicologist and philosopher of the first half of the nineteenth century, defined music as 'the corporealization of the intelligence that is in sounds.' It was a new and exciting

160. Adorno, Sound Figures, 93. See Notes 3.3.5.

161. Mary Kersey Harvey, "Edgard Varèse: 'Stratopheric Collosus of Sound,'” The Diplomat, May 1959, 40. 
conception and to me, the first that started me thinking of music as spatial-as moving bodies of sound in space, a conception I gradually made my own."162

Varèse's concept of music as "organized sound" fits into Hoene-Wroński's vision of "sound as living matter" and of "musical space as open rather than bounded." $163 \mathrm{He}$ conceived the elements of his music in terms of "sound-masses," likening their organization to the natural phenomenon of crystallization. ${ }^{164}$ In a text that functions as a manifesto, Varèse also claimed a music that "refuse[d] to admit any limitation, either of volition or of action," a music that "disapprove[d] of all 'isms;' denie[d] the existence of schools; recognize[d] only the individual." ${ }^{165}$ Adorno was sympathetic to Varèse, writing:

The work of Edgard Varèse bears witness to the possibility of musically mastering the experience of a technologized world without resort to arts and crafts or to a blind faith in the scientization of art. Varèse, an engineer who in fact really knows something about technology, has imported technological elements into his compositions, not in order to make them some kind of childish science, but to make room for the expression of just those kinds of tension that the aged New Music forfeits. He uses technology for effects of panic that go far beyond run-ofthe-mill musical resourçes. ${ }^{166}$

Indeed, one critic likened the 1933 premiere of Varèse's Ionization to "receiving a sock in the jaw." 167 With thirteen players and forty instruments, almost all of which are percussion instruments, Ionization converged upon timbre, texture, and density over any

162. Edgard Varèse, quoted in Robert Erickson, Sound Structure in Music (Oakland: University of California Press, 1975), 142.

163. Ibid.

164. Ibid.

165. Ibid.

166. Adorno, Essays, 194.

167. Chris Woodstra, "Edgard Varèse," in All Music Guide to Classical Music: The Definitive Guide to Classical Music, eds. Chris Woodstra, Gerald Brennan, and Allen Schrott (New York: Hal Leonard, 2005), 1427. 
logic of harmony or melody. Varèse explained the thought behind the composition of Ionization with words that anticipate Deleuze and Guattari's definition of an assemblage: "I have long felt the need and anticipated the effect of having [unrelated sound masses] move simultaneously at different speeds.,"168

In the first bars of Ionization, we hear the low grumbling of bass drums along with a piercing "metallic" fog of cymbals, tam-tams, and a gong. Two crank sirens, one high and one low, swell from "quieter than very quiet" (i.e., $p p p$ ) to "moderately quiet" (i.e., $m p$ ). A string-drum—a type of friction drum also known as a "lion's roar" because the length of gut pulled through its membrane produces a sound like a deep bellowingthen joins the cacophony, beginning toward an overwhelming crescendo with the "metallic" fog and now the high-pitched ringings of a triangle. This crescendo then ends abruptly, giving way to another sound mass entirely: precise strokes upon a military drum countered by metrically unrelated popping bongos. A variation of these two disparate sound masses, in the first instance, a cacophony of air raid sirens, rumbling, and hissing metal, and in the second instance, precise strokes upon a military drum countered by popping bongos, is then repeated, only to be interrupted suddenly by the prickling of Chinese blocks and a piccolo drum, that is, another sound mass with another temporality. The piece proceeds along these jagged diverging and converging lines for the six minutes of its duration, but in terms of the piece, it is misleading to refer to any absolute notion of duration at all. There is amongst all of this percussion, of drums, anvils, cymbals, church bells, glockenspiels, and so on, rather only "comparative rates of flow on these lines 
[that] produce phenomena of relative slowness and viscosity, or, on the contrary, of acceleration and rupture."169

Varèse's later Poème Électronique provides another example of a musical assemblage. The piece was commissioned by Philips for its pavilion at the 1958 Brussels World Fair. This pavilion was designed by the noted architect Le Corbusier with assistance from Xenakis. The inside of the three-peaked circus-tent structure was made up of hundreds of parabolic and hyperparabolic surfaces along which were arranged some four hundred loudspeakers. The final version of Poème Électronique was recorded on a three-channel tape. Each channel of each of the many sections of the work was individually routed to a particular number and arrangement of speakers. This routing was accomplished by a fifteen-channel control tape, a tape containing information not meant to be heard but used to control certain aspects of the actual composition. In the case of Poème Électronique, the control tracks determined the routing of the sound material in addition to certain visual and lighting effects that were used to accompany the music. Each of the work's sections is 'clearly differentiated from adjacent sections by the nature and treatment of the sound elements and, again, various sound masses comprised of bells, percussion instruments, voices, sirens, jet planes, and other sources.

In this section, I traced the explosion of Western musical practices from constellations of harmony and motivic integrity into a physics of sound. After approximately 1600 years of modal counterpoint, voice-leading, the cosmos of musica instrumentalis would give way to the musics of discipline: organism, harmony, integrity. But by the time of " 1900 " not even the work of the integral serialists would be able to sustain these conceits, and music shifted from organism into an assemblage of unrelated 
sound blocks moving at different speeds.

\subsubsection{Punk Music}

Consider "White Freckles," a punk track by Ariel Pink. To begin with, the track has all the familiar tape recording effects: the characteristic harmonic distortion, dynamic range compression, "wow and flutter," and so on. Already, then, in relation to its medial dimension, the track follows something else than the "industry standard" of music in control societies (i.e., a purely digital standard that would render the medium of magnetic tape obsolete). Most likely, this something else involves the intensive capacities of magnetic tape itself, that is, the expressive mobilization of the tape effects I mention above. Typical of punk music, the lyrics (e.g., "Freckles! Freckles! Where d'you get those freckles?! White freckles! Etc.) are nothing more than a phonetic assault on meaning. The pulse of the track, its tempo or beats per minute $(\sim 185)$, sounds perfectly regular; but in fact, it is gradually accelerating beneath the listener's perception. To complicate matters, this acceleration is itself perfectly regular; suggesting that, at some point, the track was loaded into a computer and quantized; each beat of the pulse separated and made to conform to a grid such that computer, rather than performer, is keeping the steadily accelerating pulse of the track. In addition to medial instruments such as the tape recorder, a familiar ensemble-drums, synthesizer, bass guitar, and two guitars - carries

the track forward across the three sections of its form (i.e., A, B, C), which is parabolic (e.g., $\left.\|: A:\| B\|C\| B\left\|: A^{\prime}:\right\|\right)$. The guitars are all electric, and their resonance is such that it does not sound as if they were ever recorded "live" (e.g., in a room as played through an amplifier and recorded by a microphone), but rather, recorded directly and exclusively by 
way of electronic signal processors. The sound of these instruments, in other words, will not have "lived" in any real space until or unless the track is played back in such a space; having only been passed from one electronic component to another, without ever having been played out loud. Some of these signal processors, such as "distortion pedals," do not pass the original signal forward with any added fidelity or noise reduction, but rather, by way of "memoryless nonlinearities" (e.g., clipping in amplifier circuits), they pass the original signal forward with an added noise, with additional frequencies. The synthesizer in the ensemble is digital; probably a mass-produced bit of consumer technology, such as the Casio CTK-630. Casio is a multinational corporation best known for supplying the world's first compact electronic calculator, and the CTK-630 operates in the much the same way as an electronic calculator. The CTK-630, as with any digital computer, operates on the basis of an integrated CPU chip. A CPU chip being, in this instance, a precise combination of semiconducting material such that the voltage being passed through it at any given instant, and as clocked against the steady frequency of an oscillator component (i.e., the clock), immediately carries out "instructions" in much the same way we saw "decisions" immediately handed down by the access control model I described in section 3.1. On the basis of simple operators (e.g., AND, OR, XOR, etc.), and at each increment of the clock, the CPU executes a simultaneous fetching (from memory) and decoding of a 16-bit sample. The 16-bit samples are then converted and output as analog waveforms under the command of the CPU. The essential correspondence between digital signals in relation to controls and dividuals in relation to the control societies is again made obvious: both are sampled, encoded, processed, and converted; this modulation is effected from an elsewhere, and on a molecular scale. 


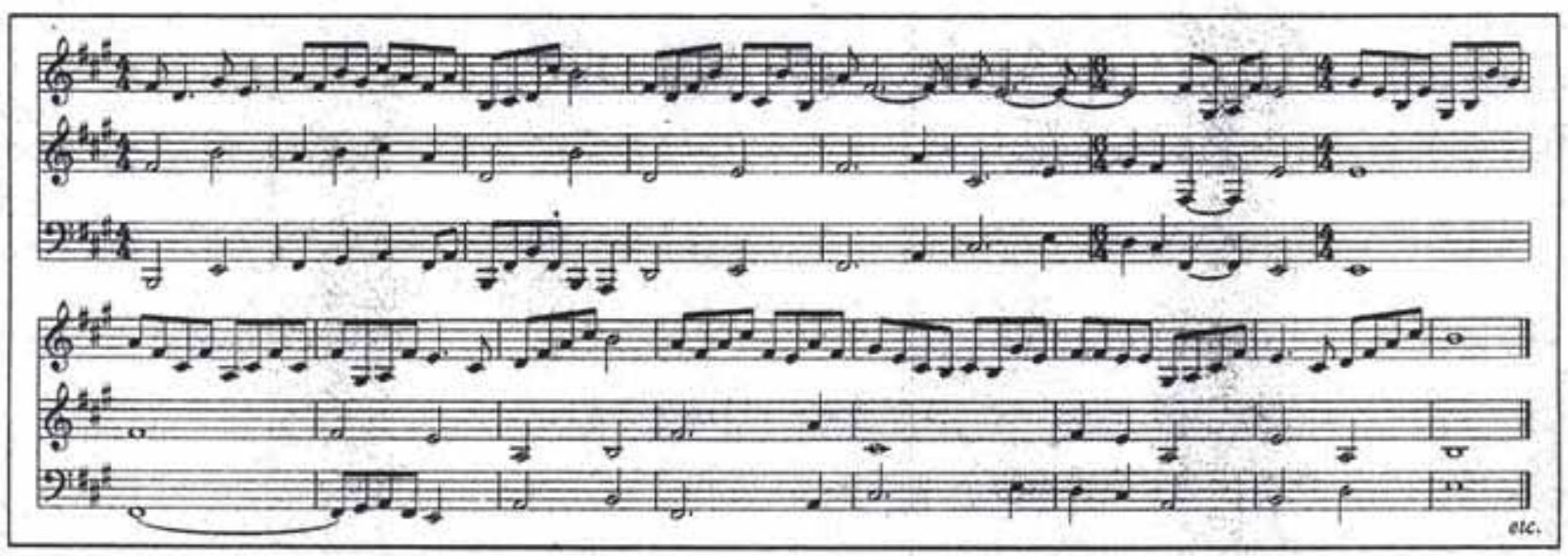

Figure 12. Ariel Pink, "White Freckles."

In punk music, functional harmonic progressions grounded in chromatic tension and resolution would be hallowed out around naked modes of sound. This quality of being unbound, in other words, partly follows from a renewed and single-minded fixation upon the horizontal movement of voice to the neglect of its vertical correspondences. The individual playing of the guitar line, keyboard line, bass line, and vocal melody in most punk music, each bound only to its own anarchic version of Gradus ad Parnassum, effects the harmonic dimension of most punk music, and in much the same way the rules of voice-leading did for the music of other situations. As I explained in Section 3.3.2., from the Middle Ages until the early Baroque, composers approached their task primarily by way of voice-leading rules. These rules assigned much importance to the clarity, independence, and horizontal movement of each voice, and they assigned little importance to the chords or harmonies, that is, the vertical correspondences between such voices. A similar impulse returns in punk music, each member of the "band" or "rock group" plays a voice (i.e., melody) with little or no regard for the chords each of these voices together make up, and even less regard for any functional relationships between 
such chords. This disregard effects a vertical or harmonic dimension much closer to that of Medieval and early Renaissance musics. In relation to the horizontal movement of its voices, however, what sets punk music apart from these earlier modal musics is exemplified by Figure 22 . The track does not begin with a perfect consonance; contrary motion does not predominate; there are parallel octaves and fifths as well as dissonances on down beats, unresolved dissonances, ambiguous harmonies, and the rest. In other words, in addition to disregard for functional harmony, there is also disregard for the niceties of voice-leading.

The dimension of timbre-perhaps because it can be manipulated on the scale of the electron-could well be approached as whole new axis of abstract musical time in punk music. In addition to the $x$ axis of horizontal motion and the $y$ axis of vertical correspondence, there is also a $z$ axis of timbre: for example, low frequency oscillations of a filter's resonance, the "wow and flutter" of magnetic tape mentioned above, phase shifting, wave folding, frequency modulation, and the rest. To the neglect the other two axes, in more recent punk music, an increasing amount of attention has been given to this $z$ axis. For example, some tracks consist of little more than a simple melodic figure being repeated to a beat, in harmony with nothing, undergoing spontaneous frequency modulations or otherwise changing in timbre.

Admittedly, punk music often bears the residues of functional tonality and its prescribed harmonic relations. Indeed, when the "Electric Blues" first emerged following WWII, such was mostly bound to a caricature of tonal relationships (e.g., I-IV-I-V-IV-I, Ivi-IV-V, etc.), and some suggestion of this fact can be discerned even in "White Freckles." However, these residues are not what is unique to such music, and so they are 
relatively insignificant in relation to the task of approaching this music's singular implications. This is not to suggest that approaching such harmonic relations precisely as residues does not approach this music's singularity; rather, it is only to suggest that, in the final analysis, such relations are foreign to this music's singularity. In any case, however, modal harmony affords greater accommodation to sound as it is supposed to be in its immediacy, that is, sound as it is manifest in the acoustic resonance of things (e.g., as with the justly intoned seventh partial). The polyphony of music in societies of sovereignty as well as the punk music in societies of control sets forth sound in its supposed immediacy and so with more of its naked mystery intact. In this sense, before "1700" and after "1900" musical practices in the West have had a greater respect for the "natural" physics of acoustic resonance: They accomplish the natural tendencies of acoustic physics rather than deliberately modifying this physics in the interest of some functional economy.

For another example, consider the example of the Puro Instinct track, "Can't Take You Anywhere." As with some medieval and Renaissance music, close inspection reveals that the "chords" (I-IV-v-I) are never aware of themselves as such. They are instead an accident of the interaction of the different modal melodies (guitar, bass, vocal, keyboards, etc.), the vertical counterpoints to their horizontal motion. There is never a moment where one can look at the pitches in this music, as they might be transcribed directly, and identify I, IV, and $\mathrm{v}$, because there are (from the perspective of common practice in functional harmony) too many nonchord tones and unresolved dissonances involved, all resulting from the independent voices as they move melodically (i.e., horizontally) through time, never mind the fact that the presence of the tonally ambiguous $\mathrm{v}$ in place of 
the functional $\mathrm{V}^{7}$ is itself only one example of the many modal harmonic relationships in the track. I am not suggesting that one could not easily argue, "There's a I, there's a IV, there's a v." Rather, I am suggesting that in doing so one would miss something more significant: The compositional thought here clearly has more concern for the independent voices moving along their horizontal axes than it does for the vertical sonorities one might wrest from them. Further, this compositional thought is decidedly modal.

We can suggest that these modal harmonies, however unintentional, already have a precedent in Jazz or in the so-called "Impressionist" music of nineteenth-century France. The compositional thinking in both of these other musics, however, has a deeper conscious relationship with functional harmony, in addition to a more defined notion of "chords" than is found in most punk music. Performers and composers of punk music can and do learn such chords and functional relationships. The tablature in any popular music guitar book, for example, is articulated entirely by way of such notions. My argument is that all of this is finally about something other than what is unique to punk music.

The concept of a musical "cadence" has different meanings in different contexts. Rameau's Traité, for example, has entire sections on the different species and proper voice-leading of musical cadences. In music theory, the term "cadence" is used to denote the close of a musical phrase or section. In polyphonic medieval music, we can already hear this phenomenon as it arose in conventions of liturgical chants, that is, conventions concerning the "final" or closing of a phrase or work, which, similar to the intervals of thirds and sixths, were only then beginning to emerge. Throughout the thirteenth century, for example, composers had tended toward a two-part cadence formula of a fifth moving outward to the octave in contrary motion. This fifth-to-octave progression was usually 
mediated by a sixth, and during the fourteenth century, this major-sixth-to-octave progression in which both voices moved stepwise in contrary motion became so standardized as to seem inevitable to contemporary observers. This progression existed in two forms, in one of which the half step (as Ti to $\mathrm{Do}^{2}$ ) occurred in the upper part and the other of which it occurred (as, Fa to Mi) in the lower part; and in each case, the other voice moved by a whole step (e.g., Re to $\mathrm{Do}^{1}$ in the first instance and Re to Mi in the second). The distance from $\mathrm{Mi}$ to $\mathrm{Fa}$ and from $\mathrm{Ti}$ to $\mathrm{Do}^{2}$ is a half step, and the principle indicated above suggested that the final consonance of a work must be approached by a half step. ${ }^{170}$

During the fourteenth century, composers regularly used the progression with the half step at the top for final cadences. As chords and standard cadence formulas became common, they necessitated more frequent application of musica ficta, or the insertion of flats and sharps (which, except for $B$ b, were not part of the now traditional Guidonian system). Musica ficta, known since the middle of the thirteenth century, had two basic purposes. It was used to eliminate tritones, or augmented or diminished octaves, from consonant chords when occurring in juxatoposed positions, and also to turn normally minor sixths into major ones, the better to move outward to an octave. ${ }^{171}$ In some senses, then, the adventure of Western harmony is inextricably linked to or anchored upon these conventions of cadence. The functional relationships mentioned above, for example, largely develop around the voice-leading conventions of the cadence. Protocols of cadence are transhistorically what Western musical works come to be consummated on. With this consummation in mind, consider the plagal cadence, the subdominant (i.e., Fa)

170. Crocker, A History of Musical Style, 225.

171. Tbid. 
coming to rest upon the tonic (i.e., $\mathrm{Do}^{1}$ ). When music students today learn the plagal cadence, the mnemonic used is "a-men" (i.e., Fa-Do ${ }^{1}$ ). Throughout the Renaissance, when a phrase or work came to its final cadence, it did so upon the name of God (e.g., Jesu Christie, Rex benigne, Alkeluia). Even when the holy name is eventually omitted, as it is in all instrumental music, and as it was beginning around or just before Rameau's lifetime, it remains present unconsciously in that the works still come to their finality using the same ritual. ${ }^{172}$

In the music characteristic of control societies, the work most often ends without any cadential rituals; in this way, as Heidegger put it, the "default of God is no longer discerned as a default." ${ }^{173}$ The work sometimes ends by fading off, as if it were going somewhere else, and will remain there until visited again. Sometimes the work comes apart in shambled madness, or at its climax. Perhaps most often, the work ends arbitrarily, without any apparent point or purpose. None of these remarks are meant to suggest there are not examples where the work remains more indebted to traditional folk song conventions. Music in control societies is unique to the extent that it dispenses almost entirely with protocols of cadence.

The example of the track for a 1986 television commercial for a children's bicycle, "Street Machine," can help make all of this clear. Heard together, its electronically synthesized noises, modal harmonies, melodic fragments, and explosive (however finally regular) percussion underscore much of what is unique to punk music compared to the music of other situations. In terms of form, for example, the track is not a song (i.e., comprised of verses and a chorus) and, with perhaps the exception of the last

172. Ibid.

173. Heidegger, "What are Poets For?," 101. 
six pitches, it is not an advertising jingle either. The four-pitch cantus-firmus-like bass voice is repeated twice. The rhythmic values of the bass voice are halved during the second of these two repetition's and so accomplish an emphatic and restless quickening effect. The melodic figures-irregular bursts-secure the harmonic space firmly in G Aeolian (the affected word "Aeolian" is preferable to the word "minor" here, as it indicates the absence of the $\mathrm{F} \#$ leading tone and its correlate functional implications). The irregularity of these melodic fragments finds an equally irregular counterpoint in the percussive fills and explosions of electronically generated sound effects. These irregularities themselves finally refer back to a steady and uniform pulse, although only as an afterthought or a silent organizing principle. "Street Machine" foregrounds the important elements of the new music: electronic instruments, modal harmonies, fragmented "childish" melodies, and flat-footed, simple, constant rhythms.

Tangerine Dream's track "Street Hawk," the opening theme for a television program of the same name, als $\rho$ exemplifies these dimensions. Electronically synthesized noises, modal harmonies, and irregular percussive fills pervade and structure the "Street Hawk" theme. After an introductory exposition of the theme, the harmonies move by way of rising thirds. This type of harmonic motion, mostly excluded by the regime of functional harmony, occurs so often in punk music that it is as if it had replaced the tonic/dominant relationships most important to tonal music. The transition from the first section of "Street Hawk" to its second section involves an entirely dysfunctional change of key. This change is "dysfunctional" because it is without a pivot or other vindication in terms of functional harmony. At times, the second section seems to display residues of subdominant/dominant/tonic relationships; however, they are connected by way of thirds, 
and the transition from this second into a third section frustrates any implication of a functional root by another dysfunctional change in key. In the third and final section of the track, it is not even clear what mode (i.e., key) we are in, as the section lacks any tonic gravity whatsoever, any suggestion of definitive root or a "final"; both melody and harmony are (for want of a better way of putting it) only ever supposed to be going where they end up going. In this track, and in punk music generally, the narrative authority implicit to the functional harmonic relationships one finds in tonal music is most often absent, except as residue or barely recognizable caricature; nor does any thematic integrity offset this absence as it does in the music of the Second Viennese School and the integral serialists.

Some critical theorists condemn punk music for precisely these reasons. Absent both function and thematic integrity, the theorists suggest, each detail of the punk track (e.g., any one of the three sections comprising the "Street Hawk" theme) might just as well be substituted for another, The theorists draw a parallel between this fungibility and the universal equivalence of capital. Were we to follow the critical theorists' suggestion and replace, for example, the third section of the "Street Hawk" theme with the second section and vice versa, we would find that they were correct. Because this music lacks any functional or thematic integrity, the one section might as well, be heard in place of the other with no great consequence in relation to the track as whole. Similar critiques have been leveled against the music's steady pulse: "This is the way in which their response to music immediately expresses their desire to obey. [T] he standardized meter of dance music $[\ldots]$ suggests the coordinated battalions of a mechanical collectivity."174 Again this is true; the uncanny precision of some punk performers, for example, Motown's The 
Funk Brothers, has something of the assembly line about it, just as the founder of Motown Records, Berry Gordy, consciously modeled his "hit factory" after the Ford plant where he had worked. But all of this changes nothing. The absence of an inward integrity outwardly proving the whole as untrue merely draws attention elsewhere, for example, towards the surface and its adornment, as with cosmetics, which equally escapes subsumption into a whole. And this has been the case with pop from the beginning. The fascination for the cosmetic in Warhol (e.g., Marilyn's makeup) draws attention towards whatever the remainder over-and-above the surface is always suggesting anyway (e.g., a hope): the hope to be seen, to be admired, to be loved. Warhol's fascination for the cosmetic; indeed, for the icon, presents this as truth: the cosmetic is never simply a handing over of the surface to power, a mere subordination of part in relation to untrue whole; even where the surface is intermingled with power, here it is already tragic (or cynical) in such a way so as to reveal something else than power, precisely, what had hoped to be seen, something else than power coming to both its ruin and true expression in this intermingling. The only condition is that it not be exhausted in its own ennui, as with an idol; it must be cynical enough, at least, to exclaim "NO FUTURE!" Or, when shown the digital clock, to remark that it is a "useful thing to save a person from being late for dinner." Warhol's "perspective" calls attention towards what hopes to appear (or more generally, a potentiality): it draws-forth this hope cosmetically, upon the surface, exactly upon the surface, as all of its singular elements, and in this way it is already closer to the non-identical, and closer even still to the non-identical as it would be "a thing's own identity against its identification"175 This is what it means to be a "superstar." This is

175. Theodor Adorno, Negative Dialectics, trans. E.B. Ashton, (New York: Continuum, 2005), 61. 
what is meant by Warhol's question: "so what?" Punk music has no integrity, neither in relation to its thematic material or its harmony. It often consists of nothing more than unrelated, undeveloped, and banal melodic fragments sounded through mass-produced household appliances and structured in a form that corresponds exactly to the empty repetition of work and spectacle. Punk music is often sung by singers who "can't sing" and performed by performers who would consider the execution of the arpeggios in Figure 22 a feat of virtuosity, but to suggest that for all these reasons it is incapable of attaining to what the theorists once understood "high" and "low" to critically signify is too neglect its monstrosity, the zebra stripe of its stupidity, that which would donate nothing of its potential to the design of its control. "Rock 'n' roll has nothing to say," explains Griel Marcus, "only a divine noise to make."176

Most of my remarks about both "Street Machine" and the "Street Hawk" theme apply equally to Hirokazu "Hip" Tanaka's "Kraid," a track that was included on the sound track for the video game Metroid (for the Nintendo Entertainment System [NES]). What sets "Kraid" apart from these tracks, however, are first, the context in which it is presented (i.e., the sound track for a video game), and second, the technology through which it is generated (i.e., a microchip running an 8-Bit instruction set). As part of the sound track for a video game, the track is intended to be repeated indefinitely, without any prearranged ending. For the seventy million people who owned the NES, it is likely - whether because they were stuck at a certain "level" or "stage" within the video game or because they played the video game often-that they heard such tracks, such loops, more often than even the most ubiquitous popular music or advertising jingles of

176. Griel Marcus, Lipstick Traces: A Secret History of the Twentieth Century, (Cambridge, MA: Harvard Univeristy Press, 1989), 88. 
the time. In this way, such music was and is especially effective. In relation to the technology through which the track is generated, the track is bound to the limitations of an integrated circuit, the Ricoh $2 \mathrm{~A} 03$. The $2 \mathrm{~A} 03$ included a very basic programmable sound generator (PSG) with five channels, each of which was capable of sounding only a single voice at any given time: two square wave oscillators, one triangle wave oscillator, a noise channel, and a PCM channel. The square oscillators enabled pulse modulation of the volume, frequency (pitch), and widths of the peaks. Most often, this channel was used for the melody and harmony lines. The triangle wave had less dynamic range, and so was usually used for the bass line. The noise channel was only capable of outputting bursts of white noise, and so was often used for drum hits and other sound effects. The PCM (pulse code modulation) channel was able to output recorded samples, although these were all of low (8-bit) quality. Interestingly, the possibilities and limitations of this PSG were rarely explored in their own right; most often, they were used to emulate a traditional four-piece rock band (with, as indicated, triangle wave as the bass, two square waves as two guitars, and a noise channel as drums). Programmers would often go out of their way to compose complex and rapid sequences of notes, and pitch bends and delay effeets were brought to bear in an effort to overcome the restrictions of the medium to make, for example, an 8bit square wave sound similar to a rock guitar. "Kraid" manages to wrest a surprising versatility from the limitation of five channels. The track is divided into five sections, with each of these five sections containing a subsection that is repeated twice. As with "Street Hawk" and "Street Machine," the abstract form of the track does not abide by any familiar conventions. In relation to harmony, the second section involves the back-andforth between two major triads that are a major second apart from one another. It is worth 
noting that before the $1980 \mathrm{~s}$, the harmonic space so opened was rarely explored in itself. When and if there was a passage through this space, it would function as a tensionbuilding device (the lower of the two chords would function as the subdominant, the chord a major second higher would function as the dominant, and, inevitably, repose would be achieved through resolution to the tonic).

The Sensation Fix's "Fragments of Light" (Figure 23) reveals something of melody in the music of control societies. When the melody of this track is placed in juxtaposition with melodies from disparate musical situations, for example, the first theme from the first movement of Mahler's Symphony No. 10 (Figure 24), much of what is unique about music in control societies is revealed.

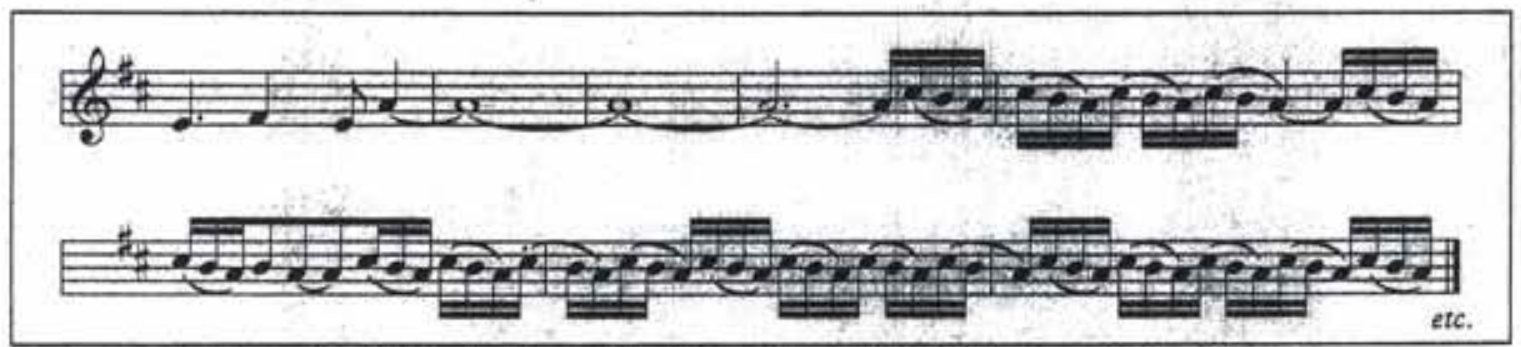

Figure 23. Melody from The Sensations Fix's "Fragments of Light."

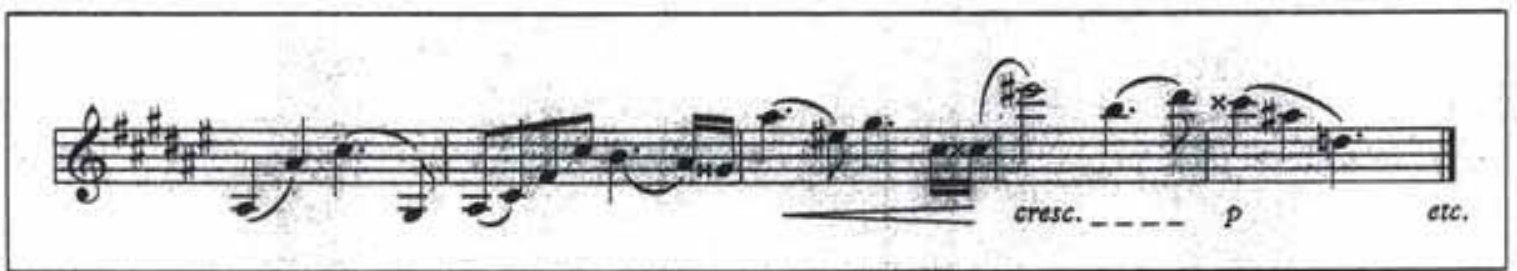

Figure 24. The first theme of the first movement of Mahler's Symphony No. 10 (1910).

The theme from Mahler's tenth symphony is filled with chromatic "longing" tones. Each of these tones has a functional tendency of some kind, and the functional harmonic underpinnings of the theme could just as easily be approximated using Roman 
numerals. The theme comprises enormous "aching" leaps (octaves, elevenths, ninths, etc.), devices of tension and release, and so on. By contrast, the melody from "Fragments of Light" consists primarily of a three-note figure repeated again and again, the largest interval is that of a fourth, and any functional implications are primarily residual. What is more, the notation provided in. Figure 23 is somewhat misleading, as the performance of the melody is by no means that precise. The melody has no chromatic "leading tones," and its harmonic underpinnings are decidedly modal. The "key signature," were this a tonal piece of music, would indicate the key of D major or B minor. The track, however, actually sounds as if it were in the mode of F\# Phrygian. The Mahler theme is marked to be performed by the violin section of a symphony orchestra reading a score, while the Sensations Fix melody is performed by a musical synthesizer magnetically recorded onto tape.

It should come as no surprise that the consequences of these facts are only beginning to be explored. For example, despite the fact that its operation can be emulated using computer software, some punk musicians still insist upon using the Ricoh $2 \mathrm{~A} 03$ to make music. Indeed, the Ricoh $2 \mathrm{~A} 03$, like the SID 6581 , the SN 76477 , and others, is only one of many sought after programmable sound chips. Presumably, this is because each of these chips, like magnetic tape recorders and analog synthesizers, have their very own material or intensive qualities. Deleuze explains, "[d]igital synthesizers $[\ldots]$ are 'integral': their operation passes through a codification, through a homogenization and binarization of the data, which is produced on a separate plane, infinite in principle, and whose sound will be produced as the result of a conversion-translation. [...] Digital filters proceed by an additive synthesis of elementary codified formants, whereas the analogical 
filter usually acts through the subtraction of frequencies ('high pass, 'low pass' ...). What is added from one filter to the next are intensive subtractions, and it is thus an addition of subtractions that constitutes modulation and sensible movement [...]." ${ }^{n 17}$ This is not to suggest any opposition between analog and digital, but rather to emphasize the singular intensivity of any given media technology. Indeed, one could reasonably assume that right now there are punk musicians tearing the smoothing filters from a CTK-630 precisely in order to exploit the singularity of the digitally "stepped" uninterpolated samples in its read only memory chip.

In the end, it is fair to say that music in control societies is as unprecedented in relation to the music of other situations as its mathematics and chemistry and equally as illuminating in this regard. Behind the classical physics of acoustic energy, the vibrating string and the resonant cavity, there was always an inaccessible electrodynamics. The possibilities are endless in relation to connections and interruptions where the whole array of WWII surplus equipments, multiple apparatuses of control, are used in the right way. Speaking musically, it is a direct action as with the industrial sabotage once advocated by "old moles" like the IWW. This is not a challenging-forth of the proper as a standing reserve, but rather a setting-forth or a letting-be of the proper onto the level of its electrodynamics. Who needs a development section or Mahler when there are distortion pedals and "White Freckles"?

\subsubsection{Conclusion}

The trajectory I outlined in this section was that of sensation or the sensible-in

177. Gilles Deleuze, Francis Bacon: The Logic of Sensation, trans. Daniel W. Smith, (Minneapolis: University of Minnesota Press, 2005), 95. 
general, that of listening, and in particular, that of music. Nowhere so much as in this section has the disparity between the societies of control, discipline, and classicism been made more apparent in relation to how the sensible or sensation, precisely, listening, was distributed; how it was instructed, and to what end it was supposed to operate. The material physics was, in each case, consistent. Nevertheless, how this physics was organized, the designs it actuated, and the possibilities discerned in it could not have been any more disparate. The operation of thought and the operation of music in any situation would seem always to stand in some analogy to each another. So, for example, we saw in the example of Adorno on Beethoven an inescapably manifest resemblance-even if only as stated outright by Adorno himself-between the development section of a sonata and the critical science, from the niceties of neo-classicism, of Kant and Haydn, and through the heroic integrity of Hegel and Beethoven, until the advent of the negative dialectics of Adorno and Schoenberg. In the city on the edge of forever, however, this is no longer the story, no longer the conceit. Precisely what Kittler had emphasized through the gramophone in relation to writing could be said of the gramophone in relation to music, namely, that up until this point writing had still been conceived in the sense that Aristotle conceived it in his De Anima, the sound of that which has soul in it. Linguistics in "1800" had, notes Kittler, "empirically confirm[ed]" the philosophical claim that the character of the literary Word consisted of "pure poetic flash that disappears without a trace, leaving behind it but a vibration suspended in the air for one brief moment., ${ }^{178}$ Hegel had notably referred to tone as "the fulfillment of the expressiveness by which inwardness makes itself known" because it is "determinate being within time," and Bernhardi insisted in his

178. Kittler, Discourse Networks 1800/1900, 53. 
On Language that "the whole of nature sounded in minimal signifieds." 179 In short, language in "1800" and up until "1900" remained "full of living sounds." 180 The concept of philology in " 1800 " focused entirely on the elements of language that had clear significative meaning: "choice of words" and (perhaps surprisingly) syllables. The field did not extend to words themselves, let alone to phonemes or letters. As a building block, the syllable provides incontrovertible evidence of the "unification of sound and meaning" as central: "Nature and Spirit" imbue the study of words down to the minimal element, which is, simultaneously, the "summit of language:"181 Kittler asserts that "at the end of a sequence of iterated decompositions the minimal signified equaled Poetry." 182

Continuing, Kittler suggests that the mediator between voice and script in " 1800 " is handwriting, which seems to enact the seamless continuity of mind, hand, and word. It is no different in the case of music. Until the gramophone, music no less than language was inscribed by hand, with pen and paper. The aesthetic of " 1800 " hinged on the "fine and accurate connection" of handwriting as signifier of the flowing of thoughts (like the flowing of sounds) as seen in cursive writing. This visible continuity was sought in the promotion of connecting capital letters with lowercase letters (naturally more important in German, where uppercase letters are used to begin all nouns, than in English) so as not to disrupt the flow of the written-down thoughts. Such a connection served a purpose similar to that of vowels in speech or song, preventing consonant clusters from

179. Ibid., 43 .

180. Johann Gottfried Herder, Treatise on the Origin of Language (1772), 17, quoted in Kittler, Discourse Networks 1800/1900, 43.

181. Kittler, Discourse Networks 1800/1900, 43.

182. Ibid., 42 . 
interrupting continuity. ${ }^{183}$ The typewriter, with its equalizing "nature," as it were, "tears writing from the essential realm of the hand" by its setting into action "mechanical forces." ${ }^{184}$ The typewriter, in changing the written word to the typed one, reduces the sovereignty and agency of the human hand just as it relegates the word to the degraded level of a mere "means of communication." 185 The typewriter, the gramophone, and "1900" in general exorcise soul from corpse, and so what remains is the body, newly opened for both control and free use down to the level of its molecules. From a cosmos of ratios through the early taxonomies of Rameau through integral unity and developmentthe "organisms" of Beethoven and Schoenberg-the physics of sound had no more opened itself to manipulation than had the molecules of the body. The societies of control are molecular. What this means, however, only comes by way of contrast with transmitters, channels, and receivers that operate on another scale or order. In contrast with earlier channels, music today is not so much written as it is made, often with electricity, and often with instruments (such as scramblers and voltage controls) created for WWII. Indeed, here it is no longer even a question of the typewriter, but rather of the "smart tablet," that is, an online Remington capable of autocompleting one's sentences. Examining music in societies of control, we can discern exactly the manner in which the residues of discipline and sovereignty swarm within it, with the automatic, that is, unacknowledged, nods to cadence, functional tonality, and the rest. But even here, something novel emerges, a polyphony of fragmented, relatively "childish," endlessly

183. Ibid., 83.

184. Martin Heidegger, Parmenides, trans. André Schuwer and Richard Rojcewicz (Bloomington: University of Indiana Press, 1998), 81, quoted in Timothy Campbell, Improper Life: Technology and Biopolitics from Heidegger to Agamben, Minneapolis: University of Minnesota Press, 2011), 81. 185. Campbell, Improper Life, 4. 
repetitive voices, which in their "vertical" correspondences with one another sometimes mark out the movement of abstract harmonic time, however-and unlike functional tonality, this is a movement towards no end, no home, and without any possibility of consummation. The substance of the sounds comprising this polyphony, as with the situation of which they are a part, is fashioned down to the level of the electron. That is, rather than a breath through a resonant cavity, or a bow across a string, we have voltage through a circuit and the sympathetic inductance of piezoelectric sensors. Everything that is distinct about control societies, that is, in their substance and in their operation, can be articulated upon such bases as these. 


\section{Conclusion}

\subsection{Introduction}

"The miraculous is everywhere," states the narrator of a television commercial for cell phones. A series of images appears underneath the word "unlimited": blood vessels, leaves, an electrified Earth seen from high orbit. The narrator continues, "In our homes. In our minds." Footage of a child running into the arms of his mother appears; at each step, another frame freezes in place, as with a series of still photographs, one on top of the other, duplicating mother and child in their joyous approach. When they finally embrace, the camera zooms in to the mother's eye, which explodes into a swarm of pixels. The narrator remarks, "A billion roaming photojournalists uploading the human experience." Another series of images flashes by in rapid succession: a child clumsily taking photographs with the cell phone, a dreamy teenage girl taking photographs out the window of a car at sunset, with the wind blowing through her hair. "And it is spectacular," concludes the narrator, over footage of an infant laughing. The narrator then asks, "So why would you cap that?" The narrator explains that the cell phone he would have us buy "can see every point of view" (on screen, the eye of a human being becomes the camera lens on the back of the phone), "every panorama, the entire gallery of humanity." The succession of generic images continues: more upper-middle-class people, the beach, a dog playing, and so on. "I need to upload all of me," declares the narrator, as a group of smartly dressed teenage boys play on the street; "I need, no, I have the right to be unlimited." Again, the word "unlimited" appears on the screen, only to be joined a moment later by the phrase, "I am ... [unlimited]."

Throughout/this dissertation, I have attempted to substantiate the claim that the 
"right to be unlimited" celebrated by the cell phone commercial, if not the marketing apparatus of the entire spectacle, is nothing other than the right to donate potentiality to the design of actuating probable certainty: a billion roaming photo journalists, "phone numbers," uploading the human experience, smashing watermelons, for fun and for free, for the "elsewhere" of communication and control.

In control societies, power does not operate by way of coercion or even alienation. The "free labor" analyzed by Terranova and others, the "cell phone apparatus" discussed by Agamben, these rely upon the full knowledge and willful-even joyfulconsent of those involved. The dividual is no more obliged by sovereign fiat than it is confined in an enclosure of discipline: it is continuously in orbit, a vector, governed by the proliferation of its own desires-above all, by the desire to communicate.

"1984," a U.S. television commercial for the Apple corporation directed by Ridley Scott, offers an allegory of the emergence of the freely assenting subject of control out of the demise of the disciplinary enclosure. The commercial presents a conventional dystopian scene: Colorless, uniform rows of human beings march like prisoners through underground tunnels. The drones then come to sit lifelessly before an enormous screen. Their Master, projected on the screen, gives them commands. Suddenly, a blonde woman, dressed as a track athlete and carrying a hammer, runs through this hive of drones and throws her hammer through the screen just as the ominous figure projected on it is declaring, "We shall prevail!" The advertisement concludes with a voiceover accompanied by scrolling text: "On January 24th, Apple Computer will introduce Macintosh. And you'll see why 1984 won't be like '1984." If the drones and the regimented world they inhabit represent the disciplinary factory, then the female runner 
heralds the appearance of the new subject of marketing, consonant with the eager cell phone users of the "Unlimited" commercial, as exemplary of control as it is of an uncoerced donation of potentiality. The Fordist drones who march in lockstep in the opening sequence and occupy circumscribed, enclosed spaces stand as the last representatives of the increasingly obsolete mechanisms of discipline, and the runner is prophetic of the dividual of the society of control for whom assent to the design of control is a joyous act of freedom. The injunction is no longer handed down by the ominous face of a ruler, but rather, without any contention, in the self-assured complicity of figures like Henry Markram: communicate, enjoy, participate-because, in any case, we all want to "get along" with each other, to participate in the next "key step in our evolution."

Multinationals like the Apple corporation "saved" prosperous. Western liberal democracies from "big brother" Fordism. However, if today these prosperous citizens find themselves working on the campuses of the information service economy rather than in factories, then it is only because elsewhere, "capitalism has retained as a constant the extreme poverty of three-quarters of humanity, too poor for debt, too numerous for confinement." Such figures, for example, the hundreds of thousands of workers in any Foxconn "city" busily manufacturing gadgets for Apple, were absent from my study. Whether it is a worker in one of Foxconn's cities or someone waiting in line outside of a store in order to buy the new apparatus, it is in any case the same design the dividual is working to actuate, save the unproductive, or those who would refuse work and so donate

1. Deleuze, "Postscript," 7. 
only nothing. "It feels kinda like a playground, a big playground,"2 explains first-week intern Matt Malone regarding his impressions of the Google campus. Here, then, and again, the point is not that Maione is mistaken, that he has been duped or is alienated, but rather, that he is entirely correct. "There is no need to publicize what is private," explains Deleuze; "just make sure that what is already public is being admitted publicly."

In control societies, everything is either actually or potentially digital information. I attempted to substantiate this point in Section 3.1 of Chapter 3. In my analysis of stylometry, I considered algorithms that would abstract affects and emotions from individuals, assess what threats, if any, they pose in any situation, identify their perspectives, "boil them down" into synopses, and above all, identify and classify them, in order to predict and potentially determine what they will do next. "Preemption does not prevent, it effects," writes Massumi; "Rather than acting in the present to avoid an occurrence in the future, preemption brings the future into the present. ${ }^{14}$

In addition to stressing information over meaning and process over identity, control societies would inspire external relations (i.e., "behavior") over interiority and causality. There is less of a need to discipline the interior when, by way of its purely external relations, the exterior can be controlled. Whether apparatus or person, identity as such is of less consequence than behavior within a network of external relations. This behavior is also more important than causality: "Who knows why people do what they

2. Google, Youtube video, 5:50, 6/4/2013, "Google Interns' First Week," https: //www.youtube.com/watch?v=9No-FiEInLA.

3. Félix Guattari, Chaosophy: Texts and Interviews 1972-1977, ed. Sylvère Lotringer (Boston: MIT Press, 2008), 268.

4. Brian Massumi, "The Euture Birth of the Affective Fact," proceedings of the "Genealogies of Biopolitics" conference, online, available at: http://radicalempiricism.org (accessed 6/28/2009). 
do? The point is they do it, and we can track and measure it with unprecedented fidelity." 5

Section 3.2 of Chapter 3, on molecular biology, showed how far the conflation of digital information with materiality extends in control societies. There are already, for example, several widely available algorithms that, using little more than the information provided through the cameras' on most cellular phones, can measure skin temperature, blood pressure, heart rate, respiration rate, eye movement, fasciculation, and similar phenomena. Such observables would be compiled into continuously updatable feature sets: eigenvectors, ever more distinct and predictable "banks," and dividuals. Databases of biomarkers and enzyme pathways, the biological dimension of these same dividuals, would be mapped out, hyperlinked, and endlessly appended, so that finally nothing would remain beyond the domain of control, save nothing itself, that is, the unproductive.

But not even nothing remains beyond control. Section 3.1.5 of Chapter 3, on control theory, revealed that a "community of singularities" is precisely what a control system is designed to stabilize. That such perturbations remain "uncounted" and "invisible," as the "void of a situation," is understood in advance from the position of a model grounded in terms of detectability, reachability, observability, and the like. More than any observable, these noises, even if only by way of the faintest traces, will be made to actuate system stability. At each point in time after $t_{0}$, possibility increasingly becomes probable certainty, and probable certainty in turn reinforces system stability.

Throughout my study, I have attempted to substantiate control by way of contrast with disparate configurations of power and by way of exploring its historical resonance.

5. Chris Anderson, "The End of Theory: The Data Deluge Makes the Scientific Method Obsolete," Wired 16 , no. 7 (2008): 24. 
In Section 3.3, on music, I provided an instance of how such disparity extends even to the level of sensation, to the extent that sensation is in each case instructed and bound to operate in accord with a particular end. From the elegant taxinomia of Rameau through critical dialectics and the integral thematic relations of twelve-tone music, I approached a situation where such had all but been forgotten, its residues persisting only in the voltagecontrolled oscillations of the Ricoh $2 \mathrm{~A} 03$. In all of this, however, there remains a free use or a positive feedback.

In this concluding chapter, I offer some speculations in relation to politics. In Section 4.2 , I consider a politics of non-communication. In Section 4.3 , I explore the possibilities of the countertemporalities. In Section 4.4, I offer a note on method. Finally, in Section 4.5, I explore the taking up of a sinthome.

\subsection{Non-communication}

Deleuze and others have argued that opening "vacuoles of non-communication" is one of the most radical activities possible in control societies. In his essay "Mediators," Deleuze makes the point as follows: "The problem is no longer getting people to express themselves, but providing little gaps of solitude and silence in which they might eventually find something to say. Repressive forces don't stop people from expressing themselves, but rather force them to express themselves. What a relief to have nothing to say, the right to say nothing, because only then is there a chance of framing the rare, or even rarer, the thing that might be worth saying." ${ }^{\prime 6}$ For a number of theorists advocating resistance against the obligation to communicate, Herman Melville's Bartleby has become an emblematic figure for the "right to say nothing."

6. Gilles Deleuze, Negotiarions (New York: Columbia University Press, 1997), 229. 
To Agamben, Bartleby "represents a potentiality that, instead of passing into actuality, remains pure potentiality."” According to this account, "Bartleby's gesture is that of a potential that does not proceed, but follow[s] its act, [and thus] has left it behind forever." Bartleby comes not to save the world, "but to save what was not." Deleuze reads Bartleby in a different way. According to Deleuze, "I prefer not to,' murmured in a soft, flat, and patient voice, [...] attains to the irremissible, by forming an inarticulate block, a single breath. In all these respects, it has the same force, the same role as an agrammatical formula." ${ }^{10}$ For Deleuze, "[T] here is a stupor surrounding Bartleby, as if one had heard the Unspeakable or the Unstoppable [...] as if he had said everything and exhausted language at the same time [...] being as being, and nothing more, [Bartleby expresses] a negativism beyond all negation." In any case, for both of these thinkers, Bartleby resists the imperatives of enjoyment and communication and so resists the consequent production of a value instrumental only to social management.

Michael Hardt and Antonio Negri, on the other hand, point to the limitations of Bartleby's gesture alone as an act of resistance:

[Bartleby's] refusal certainly is the beginning of a liberatory politics, but it is only a beginning. The refusal in itself is empty. [...] In political terms, too, refusal in itself (of work, authority, and voluntary servitude) leads only to a kind of social suicide. As Spinoza says, if we simply cut the tyrannical head off the social body, we will be left with the deformed corpse of society. What we need is to create a new social body, which is a project that goes beyond refusal. Our lines of flight,

7. Giorgio Agamben, Potentialities: Collected Essays in Philosophy, trans. Daniel Heller-Roazen (Stanford, CA: Stanford University Press, 1999), 240.

8. Ibid.

9. Ibid.

10. Gille Deleuze, Essays Critical and Clinical, trans. Daniel W. Smith (New York: Verso, 1998), 68.

11. Ibid., 71. 
our exodus must be constituent and create a real alternative. Beyond the simple refusal, or as part of that refusal, we need also to construct a new mode of life and above all a new community. ${ }^{12}$

The 1989 television show Quantum Leap provides another parable of escape from the mechanisms of control. In the show, protagonist and time traveler Sam Beckett finds himself lost in an achronological series of places, as different people with different lives. In the title sequence to the program, the narrator explains:

Theorizing that one could time travel within his own lifetime, Dr. Sam Beckett stepped into the quantum leap accelerator and vanished. He woke to find himself trapped in the past, facing mirror images that were not his own and driven by an unknown force to change history for the better. His only guide on this journey is $\mathrm{Al}$, an observer from his own time, who appears in the form of a hologram that only Sam can see and hear. And so, Dr. Beckett finds himself leaping from life to life, striving to put right what once went wrong, and hoping each time that his next leap will be the leap home. ${ }^{13}$

In each episode, Sam leaps into the bodies and lives of other people. In one episode, for example, Sam might be a young woman facing sexist discrimination in an early 1960 s U.S. workplace, while in another episode, he might be an elderly black man in the racially segregated southern U.S. Sam Beckett is lost in a series of episodes, each in a different time and within which he does not appear to others, or even in the mirror, as himself, but rather as a "woman" or a "child" or a "criminal" or a "lunatic" or a "soldier." The show is obviously shot through with liberal progressivism: now Sam is fighting for women's rights, now Sam is fighting for the disabled; at one point, Sam even becomes a test subject chimpanzee, in order to fight against animal cruelty. The real emphasis of the show, however, is always on Sam's becomings: that he is a pregnant woman, that he has no legs, that he has Down's syndrome, and that, in the element of his becoming in these

12. Michael Hardt and Antonio: Negri, Empire (Boston: Harvard University Press, 2000), 204.

13. Donald P. Bellisario, Quantum Lẹap (1989; Los Angeles: Universal Studios, 2004), DVD. 
ways, he transforms history. This is not a matter of sympathy, nor even of empathy; it is a matter of becomings in the strictest Deleuzian sense: "Becoming isn't part of history," explains Deleuze; "history amounts only to the set of preconditions, however recent, that one leaves behind in order to 'become,' that is, to create something new. This is precisely what Nietzsche calls the Untimely."14 According to this definition, becomings are a matter of going back into the event, taking one's place in it, growing both young and old in it at once, and so going through all of its components or singularities. To this extent, the television show approaches the dividualism of control societies and offers a form of politics adequate to these societies.

Sam is never a part of any history, as he was never "there" to begin with. Rather, he is the creation of something new in history, that is, precisely this novelty and nothing else. In contrast to Bartleby's celebrated "I would prefer not to," Sam's catch phrase is "Oh boy...," as in, "Oh boy, look where I am now." Each episode concludes with Sam leaping into another place and person, and always into some highly dramatic context: he is about to be executed in an electric chair ("Oh boy!"), he is about to give birth ("Oh boy!"), he is locked up in an asylum ("Oh boy?"), and so on. If Bartleby "represents a pure potentiality," a potentiality to "not-write," Dr. Beckett also prefers not to, and no one will ever know he did anyway, except for a hologram only he can see and hear. It is as if he was never there at all, save the amendment that he makes in each case to history from outside history. With Sam Beckett it is not a question of holding a potentiality in reserve, but rather, of somehow, impossibly, donating more potentiality to potentiality than was there to begin to with. Sam would bring about a new social body, not through refusal, but

14. Deleuze and Negri, Control and Becoming, 4. 
by effecting events that refuse any causal temporality: Past, present, and future have no meaning and are by no means ever understood as accomplished facts. Bartleby withers in starvation, but the narrator of Bartleby the Scrivener remembers Bartleby to the ages. There is no narrator to remember Sam, and indeed, in the series finale, in order to benefit someone, Sam annihilates the future from which his only companion, the hologram, was being projected, and so we are told that he "never returns home" and remains bound to bouncing through the circuits of time.

Radical passivity, then, most assuredly presents a way of doing politics in control societies. This passivity, however, must be more radical than Bartleby's, and it is here that the character of Sam Beckett presents a valuable alternative. In place of the passivity demonstrated in preferring not to, as with Bartleby, Quantum Leap puts forward an image of passivity that is not even passive in the sense that it will never have even been, or will never have been positively observed. In place of refusing to participate in the manufacture of the living- or un- dead, Sam would create or become as if from the standpoint of the unborn. In situations where control can effect the present from the future by way of prediction, the only standpoint that remains available to politics is one altogether outside of temporality. This would be a passivity that everywhere effects, "putting right what once went wrong" by becoming in a way bound neither by linear time and causality nor by any generic temporality whatever. Such a conclusion suggests that the attempt to wrest images of political subjectivity from literary characters, such as in the case of Bartleby and radical passivity, stands to benefit from an engagement with the complex characters that appear in the commercial culture of control societies. 


\subsection{Creative Temporalities}

"For Bergson," remarks Deleuze, "the past is perpetually available and alterable because of the way it can surface, changing its significance as it insinuates itself within the present $[\ldots]$ one sees the past in the present specifically but is encouraged to appreciate, in general, how the past always 'is' rather than 'was."'15 This Bergsonian notion of time, as evidenced by Quantum Leap, is an idea familiar to commercial culture in control societies. Kittler observes something similar to this as a possibility of media, primarily in relation to auditory persistence. The idea is this: An acoustic event effects a sound wave, but the particles through which that wave then propagates do not themselves go anywhere. "The [inscription] system of 1900 effects this elementary decomposition," explains Stephen Connor, "moving in close to every discourse as one might move in closer and closer to a newspaper or video screen, until all one sees is the clustering of the dots which compose it. This cures or destroys the ongoingness of time; it makes time reversible at the cost of pulverising all meaning," ${ }^{16}$ This principle is exemplified in a number of fantasies and romances Kittler considers, one of which is Florence McLandburgh's 'The Automaton Ear' (1877):

As a particle of the atmosphere is never lost, so sound is never lost. A strain of music or a simple tone will vibrate in the air forever and ever, decreasing according to a fixed ratio. The diffusion of the agitation extends in all directions, like the waves in a pool, but the ear is unable to detect it beyond a certain point. It

15. Gilles Deleuze, Cinema II: The Time-Image, trans. Hugh Thomlinson and Robert Galeta (Minneapolis: University of Minnesota Press, 1989), 15.

16. Steven Connor, "Scilicet: Kittler,-Media and Madness" (lecture presented to the symposium "Media Matters: Friedrich Kittler and Technoculture," Tate Modern, London, June 28, 2008), http://stevenconnor.com/scilicet.html. 
is well known that some individuals can distinguish sounds which to others under precisely similar circumstances are wholly lost. Thus the fault is not in the sound itself, but in our organ of hearing, and a tone once in existence is always in existence. $^{17}$

"The vanishing of words and sounds," explains Connor, "is therefore henceforth to be understood simply as a diminishment of volume. In order to retrieve the lost voices of the past it is no longer necessary to traverse time: one must simply reach down into matter, and, through a conjoined process of amplification and of attunement, restore the lost sounds of the past. We need, not a time-machine, but a hearing aid, like the ear-trumpet that the inventor in Mclandburgh's 'The Automaton Ear' purchases and modifies."18 Kittler concurs: "[B]ecause the frequency spectrum and transmission speed of sound are so low," he writes, "they are easy to measure (to posthumously film Goethe would require technologies capable of recording in the terahertz range)."19 Stochastic signal analyses such as linear prediction or autonomous measurement, suggests Kittler, may enable a technologically enhanced future to assign a time axis even to past events, provided that signal processors have been programmed with certain parameters.

This is precisely what Kittler means when he suggests that the gramophone marks an inscription in the Real. It inscribes sound and so it inscribes time; by extension, then, it can also be said to materialize sound and so to materialize time. "Thus," states Connors, "late nineteenth-century Recording Angel on the old gramophone loge anticipates Walter Benjamin's Angel of History, who, with his back towards the future, experiences the

17. Florence McLandburgh, "The Automaton Ear," in The Automaton Ear and Other Sketches (Chicago: Jansen, McClurg and Co., 1876), 8.

18. Connor, "Scilicet."

19. Kittler, Gramophone, Film, Typewriter, 72. 
passage of the centuries only, as the steady accumulation of the pile of rubble at his feet." 20

Benjamin's Angel of History is not a figure of salvation or redemption. Rather, he is a messenger who announces the true concept of history. In earlier essays, Benjamin had introduced this angel as one announcing a new humanism, a "humanism that proves itself by destruction." 21 This idea underwent modification in a work of Benjamin's on Baudelaire: "That things are 'status quo' is the catastrophe. Hence [catastrophe] is not something that may happen at any time, but what in each case is given." ${ }^{22}$ Thesis 12 of Benjamin's "Theses on History" explains the Angel:

His face is turned toward the past. Where we perceive a chain of events, he sees one single catastrophe which keeps piling wreckage upon wreckage and hurls it in front of his feet. The angel would like to stay, awaken the dead, and make whole what has been smashed. But a storm is blowing from Paradise; it has got caught in his wings with such violence that the angel can no longer close them. This storm irresistibly propels him into the future to which his back is turned, while the pile of debris before him grows skyward. This storm is what we call progress. ${ }^{23}$

It is somehow the same, then, with Bill and Ted in Stephen Herek's 1989 film Bill \& Ted's Excellent Adventure. ${ }^{24}$ For Bill and Ted, however, unlike Benjamin's Angel of History, history does not appear as a disaster so much as it does as both immediate and the mutable, however admittedly caricaturesque "Let's reach out and touch someone."

20. Connor, "Scilicet."

21. Walter Benjamin, "Karl Krauss," in Selected Writings, vol. 2: 1927-1934, eds. Marcus Paul Bullock, Michael William Jennings, and Howard Eiland, trans. Howard Eiland (Cambridge, MA: Harvard University Press, 1999), 476.

22. Walter Benjamin, "Central Park," in Selected Writings, vol, 4: 1938-1940, eds. Marcus Paul Bullock, Michael William Jennings, and Howard Eiland, trans. Howard Eiland (Cambridge, MA: Harvard University Press, 1999), 184.

23. Walter Benjamin, "Theses on the Philosophy of History," in Illuminations, ed. Hannah Arendt (London: Harcourt, 1999), 249.

24. Bill \& Ted's Excellent Adventure, directed by Stephen Herek (Hollywood, CA: MGM, 1989), DVD. 
Stephen Herek's film tells the story of two imbecilic suburban white teenagers from southern California who are trying to start a punk music band as they struggle with their grades in high school. A time traveler from the future, Rufus (George Carlin), visits them in a time machine disguised as a telephone booth and conveys to Bill (Alex Winter) and Ted (Keanu Reeves) that history itself depends upon their getting a passing grade in the final presentation for their high school history course. If they fail in this task, Rufus explains, Ted's father (Hal Landon Jr.), a policeman, will send Ted to Col. Oat's Military Academy and ruin the course of history. "That's why I was sent to make sure you passed your history report," explains Rufus; "If you guys were separated, it would have been disastrous for life as we know it. You see, eventually, your music will help put an end to war and poverty. It will align the planets and bring them into universal harmony, allowing meaningful contact with all forms of life from extraterrestrial beings to common household pets, and [...] it's excellent for dancing." In order to help Bill and Ted with their task, Rufus lends them the time machine. And so, in place of studying or learning by rote, Bill and Ted will pass their final presentation by physically traveling into the past, abducting various historical figures-Freud, Napoleon, Socrates, and Beethoven amongst them-and bringing these figures back to give the presentations about themselves themselves, but not until after they have taken the figures to the shopping mall.

"This is the San Dimas mall," Bill explains to Freud ("I'frudl"), as they both step off an escalator, "this is where the people of today's world hang out. Beethoven ("I' $b \bar{a}-, \underline{\text { th }}$ -vən|"), make sure you don't get sucked under. Socrates ("I'sō-, krâtsl), watch out for your robe, dude." Here, Freud-for all the tomes he has inspired across the academic disciplines since the Interpretation of Dreams-is laughed off by the teenage girls he 
attempts to psychoanalyze because of their giggling ("You seem to be suffering a mild form of hysteria"). Meanwhile; elsewhere in San Dimas, the world-spirit on horseback no longer "reaches out over the world and masters it" as he had for Hegel. Indeed, it is absolutely possible not to admire him, as he is "ditched" by a group of teenagers for being a "dick" while they were bowling.

The Sam Dimas mall was, in actuality, the Metrocenter shopping mall in Phoenix, Arizona. Most of the several available newspaper articles emphasize that the mall was the first to sport five anchor stores and that it remained, for a time, one of the largest shopping malls in the United States. The mall was surrounded by a "Golf N' Stuff" and contained an ice-skating rink. Suspended above the ice-skating rink was a bar inside of an empty 747 fuselage. It is within this arcade, then, that Freud, Socrates, Beethoven, and others suddenly materialize: “today's world."

The figure of the police and the father are conflated into a single person in the film. It is interesting that in the film, presumably aimed at a preteen audience, Ted's father is played straight. That is, to the extent that one could ever claim as much about a Hollywood genre film, Ted's father isn't played comedically or caricaturesque, but rather seriously; at one point, for example, he violently confronts Ted for his poor performance in school: "What am I gonna do with you, huh? You lose my keys. You fail History. You spend all your time with your loser friend planning a band that'll never happen. When I get back from the station I want you packed and ready to go. Got it?" Ted's father, the figure of the police, means business. But finally, the discipline of police and father finds itself inadequate to arresting the countertemporalities open to "young people." (For a more concrete example of what this might mean, consider the example of Julian Assange 
who, in 1987, at the age of 16 and using little more than consumer technology, penetrated the United States Air Force 7th Command Group in the Pentagon and other "sensitive" networks). At the shopping mall, meanwhile, the historical figures that Bill and Ted have abducted from the past have begun running amok. Ghengis Kahn is smashing the heads and limbs off of the mannequins in a sporting goods store, Beethoven has made the musical instrument store into his own orchestra, and no sooner have the police swooped into the mall, in disbelief, when Bill and Ted outwit them by actualizing countertemporalities. At one point, for example, as they are cornered by the police, it occurs to Bill and Ted that sometime in the future, after all is said and done, they can take their time machine into the past, long before the present in which they are being cornered by the police, and prepare all that is necessary for escaping from the situation. Trash cans suddenly fall from the ceiling to trap their antagonists, tape recorders suddenly begin playing diversions for their escape, and so on. The film is filled with every manner of countertemporality against temporality, so that, for example, it is not Rufus who convinces Bill and Ted to go on their adventure through time-rather, it is "future" Bill and Ted themselves. Near the beginning of the film, "future" Bill and Ted appear to "present" Bill and Ted:

"Future" Bill: Dudes! You guys are gonna go back in time!

"Future" Ted: Yeahl You are gonna have a most excellent adventure through history.

Bill: Who are you guys?

"Future" Ted: We're you, dude!

Ted: No way....

"Future" Ted: Yes way, Ted!

"Future" Bill; Look, we know how you feel. We didn't believe it either when we were you and we-us said what we-us are saying right now. 
Later in the film, this scene is repeated, only now "future" Bill and Ted have become present Bill and Ted.

To assume that an audience of children would have no trouble following the achronological series of events presented here (e.g., that we might escape our past or present circumstances by taking the necessary steps in the future) only speaks to the avenues and weapons available to them. The point here is that the generation of Marx and Coca-Cola comprehends, follows, and accepts this logic as a matter of course, as something that might be mobilized to fight the police. It is always their time, because every other time is always and immediately available to them through the time machine.

\subsection{A Note on Method}

It would be easy to dismiss the example of the film Bill \& Ted's Excellent Adventure as nothing more than the bad faith or wish fulfillment of an alienated culture, rather than trying to affirm something about the way it imagines temporality and its creative uses against police. When Rufus, for example, explains the world of the future, it is a utopia firmly couched in capitalist ideology and leisure: "The air is clean, the water is clean, even the dirt ... is clean! Bowling averages are way up. Mini-golf scores are way down. And we have more excellent waterslides than any other planet. we communicate with. I'm telling you, this place is great!" To point to the ideological bad faith in the film, however, would be to perpetuate the cycle of "critical science" identified by Rancière. Consider Rancière's remark that "[F]orty years ago, critical science made us laugh at the imbeciles who took images for realities and let themselves be seduced by their hidden 
messages." ${ }^{25}$ Rancière continues, explaining that since then, the "imbeciles" had been educated in the art of recognizing the ideology concealed in these images. "Naturally enough," Rancière adds, "recycled critical science makes us smile at the imbeciles who still think such things as concealed messages in images and a reality distinct from appearances exist. The machine can work in this way until the end of time, capitalizing on the impotence of the critique that unveils the impotence of the imbeciles." ${ }^{26}$ For his own part, Rancière would avoid another turn of the screw: "To escape the circle," he suggests, "is to start from different presuppositions, assumptions that are certainly unreasonable from the perspective of our oligarchic societies and the so-called critical logic that is its double [my emphasis]. ${ }^{, 27}$

In his article "Wild Things," Thomas Dunn makes an important point in relation to this unreasonableness, however ad hominem it would seem. Dunn recounts an academic conference from the spring of 1989 , "Baudrillard in the Mountains," at the University of Montana in Missoula. One of Rancière's "recycled" critical scientists, Jean Baudrillard, had earlier delivered a lecture at the conference with his name and was now in attendance, with other students and faculty, at a coffee house where various poets and musicians also invited to the conference would give their presentations. Dunn continues,

Then, suddenly, a familiar melody emerged from the speakers, simple, primitive, inevitable, based on the most common three-chord progression in rock and roll. [...] As if with one voice the audience began to sing: "Wild Thing, you make my heart sing, you make everything groovy, Wild Thing." At this moment of audience participatory bliss, a loọk of uncomprehending panic crossed Baudrilliard's face. The theorist (in)famous for his implacable stoicism in the face of the collapse of realty, the person who only two nights before had been urging an audience of

25. Rancière, Emancipated Spectator, 25.

26. Ibid.

27. Ibid. 
Montana ranchers, hippie farmers, black-garbed graduate students, and avantgarde literary theorists to "drive (slowly) to a delirious point of view" in response to what he claimed to believe to be the fact of a world driving us to a delirious state of things, appeared to be resisting the trip to delirium. ${ }^{28}$

Dunn remarks that "[T]his look of incomprehension betrayed Baudrillard's studied indifference $[\ldots]$ the event somehow overcame his faith in a stoicism that he had imagined could match the depthless nihilism he had prophesied. In observing the enthusiastic response of these (alleged) postmodern intellectuals, by an audience composed primarily of assembled admirers, Baudrillard could not discern an answer-a really good answer-to questions he himself had been posing for years.concerning the paths that mutual recognition and attempted acknowledgement of others might take in an era when signals have come to be as important as, if not more important than, signs."29

Here, then, it is neither a question of mindless participation nor the willful holding of one's potentiality in reserve. Dunn mentions signals and, in terms of control theory, signals tend to reinforce themselves and grow larger. It is a question, then, of adding system output to system input such that the sum is itself input into and so "explodes" the apparatus-that is, noise from the system is added back to the input, and that in turn produces more noise. Critical science can analyze the object of the personal watercraft in terms of leisure and vacation, that is, as part of some economy of alienation, but this reveals nothing about the intensities and capacities personal watercraft open for any body. Dunn, like Bill \& Ted's Excellent Adventure, invites us to imagine Adorno on a personal watercraft no less than to explore the ways in which Heidegger's project might have benefitted from a section on Dasein's various attunements as they would be onticly or

28. Thomas L. Dunn, "Wild Things, in Cultural Studies and Political Theory, ed. Jodi Dean (Ithaca, NY: Cornell University Press, 2000), 259.

29. Ibid. 
facticly situated in such a context. Perhaps this is what it means to "start from different presuppositions, assumptions that are certainly unreasonable from the perspective of our oligarchic societies and the so-called critical logic that is its double."

\subsection{The Sinthome}

"At the heart of the psychoses there is a dead end," states Lacan, "a perplexity concerning the signifier. Everything takes place as if the subject were reacting to this by an attempt at restitution, at compensation. Fundamentally the crisis is undoubtedly unleashed by some question or other. What is it...? I've got no idea. I suppose that the subject reacts to the signifier's absence by all the more emphatically affirming another one that as such is essentially enigmatic." ${ }^{30}$ By way of the "essentially enigmatic signifier" Lacan deseribes here, we can approach his concept of psychosis and, eventually, his concept of the sinthome. Firstly, then, psychosis, according to Lacan, involves the "signifier's absence." Lacan also refers to this absence as the "foreclosure" of the "Name-of-the-Father," ${ }^{, 1}$ that is, the sudden absence of the Master signifier that anchors or quilts all the other floating signifiers of the Symbolic Order to the Imaginary Order, or their correlate signifieds. This is what Lacan means by a perplexity concerning the absence of the signifier. In Lacan's psychoanalysis, the Name-of-the-Father is precisely what gives the Real some Imaginary sense from the standpoint of an Oedipal or "phallic" project of desire. Put simply, the notion here is that without some phallic project of desire, a project placed upon the subject through his psychosexual individuation, the

30. Jacques Lacan, The Psychoses, trans. Russell Grigg (London: Norton, 1993), 194.

31. Jacques Lacan, Ecrits: A Selection, trans. Bruce Fink (London: Norton, 1997), 200. 
subject becomes a pervert, a hysteric, a psychotic, or whatever. But even here, in the absence of this phallic project, that is, in the absence of the Name-of-the-Father, there is always some other project, that is, some substitution for the Name-of-the-Father. ${ }^{32}$

Given that the foreclosure of the Name-of-the-Father entails the corresponding absence of any Imaginary "phallic" meaning, psychosis and its own supplement to this absence is integrally linked to a subject's sexual identity. Lacan speaks of a "push towards woman," for example, in order to describe the transformation of sexuality in Schreber's delusions. "How beautiful it would be to be a woman undergoing sexual intercourse," muses Schreber, although his "manly honor" would resist the temptations of this beauty, in addition to resisting God's attempts to "unman" him by transforming him into a woman. ${ }^{33}$ Eventually, however, Schreber ceases in his resistance, and decides to embrace the transformation:

I must now discuss the nature of the frequently mentioned inner voices which since then have spoken to me incessantly, and also of what in my opinion is the tendency innate in the Order of the World, according to which a human being ("a seer of spirits") must under certain circumstances be "unmanned" (transformed into a woman) once he has entered into indissoluble contact with divine nerves (rays). ${ }^{34}$

It is entirely consistent with Lacanian psychoanalytic theory that Schreber believes this "unmanning" is necessary in order for him to enter into an indissolubility with the divine. According to Lacan, after the subject assumes his sex through the Oedipal psychosexual individuation process, he is henceforth bound to a phallic project of desire. This means that his enjoyment or jouissance is always only a phallic jouissance, the jouissance of the

32. Russell Grigg, Lacan, Language, and Philosophy (Albany, NY: SUNY Press, 2009), 13.

33. Ibid.

34. Schreber, Memoirs, 220. 
signifier. Those who assume or are made to assume the sex of woman, on the other hand, already betray the possibility of a jouissance beyond the signifier or beyond the phallus. Lacan variously equates this kind of enjoyment with the ecstasy of the mystics, or the ecstasy of the divine. In other words, within Lacan's psychoanalytic theory it is necessary to be unmanned, to substitute or put something else in place of the Name-of-the-Father, in order to experience the ecstasies of bodies and materiality in place of Imaginary phallic enjoyment.

In Discourse Networks 1800/1900, Kittler suggests that this unmanning, or what he calls the "queen's sacrifice," goes hand in hand with media in "1900." He suggests that Lacan's dictum, "La femme n'éxiste pas," is meant to suggest that the realm of sense, that is, the Imaginary consistency of reality as such, is always male to the extent that it centers upon phallic desire. However, abandoned to the mechanisms of new media, "Women in the discourse network of 1900 are enumerable singulars, irreducible to the One Woman or Nature. All the media and sciences that support the network compete in a queen's sacrifice. ${ }^{35}$ In place of the One Woman, the Queen, the object of the poet-man's desire as configured from the standpoint of a libidinal economy centered upon the Nameof-the-Father, Kittler suggests that media such as the gramophone allow women, or queers, to emerge as innumerable singulars.

Kittler then turns to the example of Gertrude Stein, whose early experiments in automatic writing began while she was studying at the Harvard Psychological Laboratory. Although Stein was referred to in her lab reports as a "he," Kittler makes a point of emphasizing the fact that, while German universities "still trembled at the thought of the

35. Kittler, Discourse Networks 1800/1900, 355. 
chaos woman students would provoke, ${ }^{36}$ Harvard University had, to some extent at least, been desexualized; and Stein, like any man, could study psychophysics. The consequence of this, according to Kittler, was that "real women, as they exist in plurality, had attained access to writing as practiced in university discourse. Their hysteria, rather than remaining out of the way as some idiosyncrasy like Brentano's sister, was experimentally simulated in order to make it a completely normal motoric automatism. ${ }^{37}$ In Stein's experiments, one test subject would read to another who, while listening to the first, would automatically write on a page something other than what was being read to them. It was in this way, Kittler suggests, that the "hysteria," which had in disciplinary societies only formed the poet-man's Other, was beginning to speak itself-that is, such as in Stein's practices of automatic writing. What Kittler is suggesting is simply that the hysterical voice of "Woman," which once only formed an object of desire, had suddenly begun to explode the discourses of men, the university, and phallic desire altogether.

Kittler proceeds to draw another example, in this instance from the new figure of the office secretary or the typist:

Machines do away with polar sexual difference and its symbols. An apparatus that can replace 'Man or the symbol of masculine production is also accessible to women. Apart from Freud, it was Remington who 'granted the female sex access to the office.' A writing apparatus that does not represent an erotic union of script and voice, $[. .$.$] is made to order for coeducational purposes. The typewriter$ brought about (Foucault's [The] Order of Things overlooks such trivialities) 'a completely new order of things. ${ }^{38}$

I hasten to point out that Jennifer Fleissner has objected to Kittler's argument: "Rather

36. Ibid., 200.

37. Ibid., 351-52.

38. Ibid., 295. 
than leading necessarily to disembodiment, then, technology $[\ldots]$ in discourses of women's clerical labor can be seen to reembody the woman worker as a particular kind of body, one that makes this labor historically and narratively imaginable, ${ }^{39}$ and her point is well taken. For my purposes, however, the relationship between the materiality of the signifier (i.e., a jouissance beyond the signifier)—as evident in the gramophone-and "unmanning" is what is of interest.

In his seminar on James Joyce given some twenty years after his seminar on Schreber, Lacan again raises the question of the "signifier's absence" in psychosis, and elucidates what is meant by the emphatic affirmation of another, "essentially enigmatic," signifier. In this seminar, Lacan refers to this affirmation as a "suppletion": the supplement the subject affirms. in the absence of the Name-of-the-Father in order to give the Symbolic Order some kind of consistency, however perverse or psychotic it may be from the standpoint of those who remain bound to the Name-of-the-Father. By way of topology, Lacan revises his earlier thesis that the Symbolic, the Imaginary, and the Real are linked like the rings of a Borromean knot-in such a way, that is, that severing any one link will untie the other two. It is not the case, Lacan suggests, that the separation of the three rings is the result of some defect, because the three are already separate. Where they are joined, they are connected by a fourth link, the sinthome. The Name-of-theFather, then, is but one possible sinthome: "The Oedipus complex is, as such, a sinthome. It is insofar as the Name-of-the-Father is also the Father of the Name that hangs

39. Jennifer L. Fleissner, "Secretary to the Stars: Mediums and the Agency of Authorship," in Literary Secretaries/Secretarial Culture, eds. Leah Price and Pamela Thurschwell (Farnham, England: Ashgate Pub, 2005), 69. 
everything together, which does not make the sinthome any the less necessary. ${ }^{, 40}$ Lacan's idea here is that whether it is the Name-of-the-Father as such or some other "essentially enigmatic" Master signifier the subject is beholden to, in either case it is always a sinthome "hanging everything together." Lacan turns to the example of James Joyce. Lacan's thesis is that although Joyce was psychotic like Schreber, that is, although Joyce was not bound to the Name-of-the-Father, he succeeded in avoiding the onset of any "symptomatic" psychosis by supplementing that signifier's absence with his own sinthome: writing, or more specifically, the materiality of the letter.

Once again, then, in order to make the point perfectly clear: The Name-of-theFather is foreclosed for the psychotic, and so she is unmanned in the sense that the Symbolic Order is no longer anchored upon phallic desire. Here, according to Lacan, the psychotic must quilt everything upon some other Master signifier: and this is the subject's sinthome. In his seminar on Joyce, Lacan suggests that writing was Joyce's sinthome, that is, his stand-in for the absent or foreclosed Name-of-the-Father. Russell Grigg explains:

Indeed, Lacan says, through his writing Joyce went as far as one can in analysis. Joyce's achievement in preventing his own psychosis means that in him the psychotic phenomena appear in a different form both from neurosis and from a declared psychosis. Lacan claims that this process, in which the absence of meaning of the epiphany is transformed into its opposite, the certainty of an ineffable revelation, is comparable to the enigmatic experience and its conversion into psychotic conviction in Schreber. Joyce of course differs from Schreber, and differs in that he cultivates the phenomenon and transforms it into a creative work. In Finnegan's Wake, Joyce transforms linguistic meaning into "non-sense" and vice versa, so that what corresponds to the enigmatic experience of a Schreber is raised to the level of an artistic process. Joyce's writing transforms the enjoyment that literature normally conveys into jouissance of the letter, into an enjoyment that lies outside of phallic meaning. ${ }^{41}$

40. Grigg, Lacan, Language, and Philosophy, 21.

41. Ibid., 23. 
By way of Grigg's discussion of Lacan, then, the equation of Schreber and Joyce is explained. Both of these figures are "unmanned" in the sense that their enjoyment is no longer captured in a libidinal economy bound to an Oedipal desire. Besides this, both approach the whole reason for discussing Lacan here at all, namely, the materiality of the letter as that which would exceed the letter's signified. The Real, then, which Kittler suggests can be recorded for the first time by media in control societies, can also form a possible site of jouissance in this element of its positivity-that is, if the Real itself can be inscribed and for the first time by way of technological media, then the experimental subject is capable of taking the materiality of letter, the Mother-of-the-Name, as a sinthome.

Neither Joyce nor Schreber made any distinction between Schiller and bawdy verse, and every aspect of mass culture and media technology makes an appearance across the spectrum of Joyce's writing, from newspapers, magazines, gramophones, silent films, newsreels, telephones, telegraphy, and photo studios in the earlier works to radio and even an intimation of television in Finnegan's Wake. Consider the following passages from Joyce's Finnegan's Wake:

bababadalgharaghtakamminarronnkonnbronntonnerronntuonnthunntrovarrhouna wnskawntoohoohoordenenthur- nuk! $!^{42}$

And again:

Lipoleums is nice hung bushel- lors. This is hiena hinnessy laughing alout at the Willing- done. This is lipsyg dooley krieging the funk from the hinnessy. This is the hinndoo Shimar Shin between the dooley boy and the hinnessy. Tip. This is the wixy old Willingdone picket up the half of the threefoiled hat of lipoleums fromoud of the bluddle filth. This is the hinndoo waxing ranjymad for a bombshoob. This is the Willingdone hanking the half of the hat of lipoleums up the tail on the buckside of his big white harse. Tip. That was the last joke of

42. James Joyce, Finnegan's Wake (Oxford: Oxford University Press, 2012), 1. 
Willingdone. Hit, hit, hit! This is the same white harse of the Willingdone, Culpenhelp, waggling his tailoscrupp with the half of a hat of lipoleums to insoult on the hinndoo see- boy. Hney, hney, hney! (Builsrag! Foul!) This is the seeboy, madrashattaras, upjump and pumpim, cry to the Willingdone: Ap Pukkaru! Pukka Yurap! ${ }^{43}$

In all of this, the brains within an apparatus are approached. And so Joyce, for example, insists upon taking the materiality of the letter, the Mother-of-the-Name, as his sinthome in place of the transcendental signified, the Name-of-the-Father. In this way, Joyce is unmanned, and his brains emerge through the positive feedback of everything that would otherwise only capture such potentialities. ${ }^{44}$

\subsection{Conclusion}

In this concluding chapter, I explored a politics that would begin from "assumptions that are certainly unreasonable." Beginning with radical passivity, I explored the unique ways in which temporality opens in control societies, and suggested that in place of holding one's potentiality in reserve through a refusal to participate, the figure who would impossibly donate more potentiality to potentiality as such, a figure so without place, unborn, it would forever be undetectable, presents a more workable alternative. I further explored just what such a figure might look like through the countertemporalities of Bill and Ted, and raised a defense of my explorations by way of Dunn. Finally, I anchored all of this on the notion of the sinthome. None of this should be surprising in relation to my dissertation as a whole. Throughout, I have argued that the principle of positive feedback, beginning from where the danger comes, the free use of

43. Ibid., 10.

44. See Notes 4.1. 
the proper, marks the best wager for politics in control societies. Lacan's emphasis that such involves the materiality of the signifier "unmanning" any potentiality from the Name-of-the-Father only serves to underscore this point. By anchoring the signifier on the jouissance that is its material remainder (i.e., the Mother-of-the-Name) rather than anchoring it on the signified that is its meaning, something ungovernable will always emerge.

This concludes my sociotechnological study of the mechanisms of control. I have substantiated some of the political theories that have been carried out towards this same end, and I also have provided some indication of what it might entail to approach a politics adequate to the societies of control. 


\section{Appendix I: Notation}

$€$ - This symbol means "is a member of" or "belongs to." The formula $u \in X$ is read as " $u$ is a member of $X$ " or " $u$ belongs to $X$."

C - This symbol means "is a subclass of" or "is included in." The formula $C \subset D$ is read as " $C$ is a subclass of $D$ " or " $C$ is included in $D$."

$\forall-$ The universal quantifier means "for all," or "for every" or "for each." The expression $\forall u$ is read as "for every $u$."

$\exists-$ The existential quantifier means "there exists." The expression $\forall u \exists c$ is read as "for every $u$ there exists a $c . "$

:- The colon means "such that." The formula $\forall u \exists c: c \in X$ is read as "for every $u$ there exists a $c$ such that $c$ is a member of $X . "$

$\wedge$ - This symbol means "and." The formula $u \wedge c$ is read as " $u$ and $c . "$

$V$ - This symbol means "or." The formula $u \vee c$ is read as " $u$ or $c . "$

$\rightarrow-$ This symbol denotes logical implication. The formula $u \rightarrow c$ is read as " $u$ implies c." 


\section{Appendix II: Additional Results}

This appendix includes some additional results from the informal experiment I describe in section 3.1.6 However informal, the experiment was computationally intensive, requiring, for example, approximately 144 hours of processing time @3.47 $\mathrm{GHz}$ with $24 \mathrm{~GB}$ of RAM merely in order to compute the corpus' centroid. Further, document $\mathrm{OCR}$ and preparation for annotation in GATE was very labor intensive. There is no perfectly consistent standard book layout and writing code to recognize and separate page numbers, chapter headers and footers, section titles, in-text citations, and the restwould have been too difficult. Consequently, I ended up doing most of this work manually, and so much of this "noise" ended up skewing the final results of (e.g., the DS for Comments on the Society of the Spectacle was "Amiat (1782);" Means Without End, "nediation;" etc.). In the figures below, "N/A" appears in place of such aberrant results. In other cases, the results were intelligible enough, but nevertheless skewed by the presence of this same noise (e.g., the CS for Empire includes "refer-ring;" Madness and Civilization includes "mad-ness;" the DS for The History of Western Music Theory includes "conÂ-stant;" Lacan and Science includes "(Lacan, 1977a);" State of Exception includes "[Schmitt 1928,109;" etc.). In most cases, the logic behind the results was obvious. I discuss this logic in 3.1.6, but here I would offer some additional discussion. Lengthy sentences seemed to have been privileged, and this only makes sense because longer sentences have more chance of containing multiple heavily weighted terms. As noted in 3.1.6, proper names were also heavily weighted, and this fact in itself caused some interesting problems. For example, the DS for the History of Western Music Theory includes a reference to "Marx." This Marx, however, was A.B. Marx, the music theorist, 
not Karl Marx.

One of the most striking facts about NLP platforms and applications is that almost all of them are designed for classification and identification, while there is very little designed for NLG. Further, the applications available for NLG remain surprisingly unsophisticated. My annotation of 65 documents using GATE included not only token and sentence weights and similarities, but also POS, hypernyms, hyponyms, eponyms, metonyms, synonyms, antonyms, and sentence morphology and structure (subject, object, etc.). Even so, there is as of yet no NLG software available that can use this information to generate anything resembling an intelligible original text. Most of the NLG software available follows a fill-in-the-blanks or template logic. While some such software is able to find the appropriate verb tense as it fills-in-the-blanks, at this point in time it can do little else.

I include the extended results here not because this experiment was of any special importance in relation to my study, but rather, because I expect that some of the results could be of interest and/or even surprising to those already familiar with the material (e.g., CS: Birth of the Clinic, Dialectic of Enlightenment, Foucault, Intensive Science Virtual Philosophy; DS: Difference and Repetition, Écrits, Madness and Civilization, etc.). As described 3:1.6., the DS is the sentence "most similar" to the entire document in which it is contained, and the CS is the sentence "most similar" to the entire corpus of 65 documents. 
Foucault, M.

For now, I want to follow the thread of this French evolution you are almost retracing: a thread of references (both very dogmatic and inspired by a will to antidogmatism) to Marx, Freud, and

CS structuralism, in the hope of discovering in people like Jacques Lacan a figure who would put an end to synoretism and would manage to unify all these strands?

DS I said earlier that I wondered why I had read Nietzsche. ${ }^{2}$

Giorgio Agamben: A Critical Introduction

Durantaye: $\mathrm{L}$.

At the other end of the critical spectrum, Heller-Roazen (1999) notes that "whether the subject is

CS Aristotle or Spinoza, Heidegger or Benjamin, what is at issue [in Agamben's writing] is always a messianic moment of thinking in which the practice of the 'historian' and the practice of the 'philologist,' the experience of tradition and the experience of language, cannot be told apart.".3

DS For Agamben, it is this and more."

\begin{tabular}{|c|l|c|}
\hline \multicolumn{1}{|c|}{ Anchaeology of Knowledge } & \multicolumn{1}{|c|}{ Foucault, M. } \\
\hline CS & $\begin{array}{l}\text { But the historians had long ago deserted the old fortress and gone to work elsewhere; it was realized } \\
\text { that neither Marx nor Nietzsche were carrying out the guard duties that had been entrusted to them. }\end{array}$ \\
\hline DS & $\begin{array}{l}\text { The never completed, never wholly achieved uncovering of the archive forms the general horizon to } \\
\text { which the description of discursive formations, the analysis of positivities, the mapping of the } \\
\text { enunciative field belong. }\end{array}$ \\
\hline
\end{tabular}

$$
\text { Bach's Dialog With' Modernity }
$$

Butt, John.

It is therefore tempting to divide it into three historical phases, the first dating from the sixteenth

CS century to the end of the eighteenth; the second, from the time of the French Revolution to the late nineteenth century; and the final phase characterized by modernism (these latter two coincide with the German Moderne)?

DS $\quad$ N/A

$$
\begin{array}{l|l}
\text { Being and Event } & \text { Badiou, A. }
\end{array}
$$

What authorizes the poet to interpret Germany in such a way, in accordance not with its disposition

CS but with its event-that is, to think the Rhine, this 'slow yoyage / Across the German lands', according to its imploring, angry source-is a faithful diagonal traced from another event: the Greek event. ${ }^{8}$

DS We attain the following result: if an ordinal $B$ is an element of an ordinal $a$, and if an ordinal $y$ is an element of the ordinal $B$, then $y$ is also an element of $a:[(B, a)(y \in \beta)]-\infty)(y e a)$.

1. Michel Foucault, Aesthetics, Method, and Epistemology, trans. Robert Hurley, ed. James D. Faubion, (New York: The New Press, 1998), 435.

2. Ibid., 439.

3. Leland de la Durantaye, Giorgio Agamben: A Critical Introduction, (Stanford: Stanford University Press, 2009), 366.

4. Tbid., 331 .

5. Michel Foucault, Archaeology of Knowledge, trans. A. M. Sheridan Smith, (London: Routledge, 2002 ), 16.

6. Ibid., 148.

7. John Butt, Bach's Dialogue with Modernity: Perspectives on the Passions, (Cambridge; England: Cambridge University Press, 2010), 5.

8. Alain Badiou, Being and Event, trans. Oliver Feltham. (New York: Continuum, 2005), 257.

9. Ibid., 134. 


\begin{tabular}{|c|l|c|}
\hline \multicolumn{2}{|c|}{ Being Singular Plural } & \multicolumn{1}{|c|}{ Nancy, J-L. } \\
\hline CS & $\begin{array}{l}\text { If one wants to give a full account of "capital"-starting from the very first moments of history that } \\
\text { began in the merohant cities - then it is necessary to remove it, far more radically than Marx could } \\
\text { have, from its own representation in linear and cumulative history, as well as from the representation } \\
\text { of a teleological history of its over-coming or rejection. }\end{array}$ \\
\hline DS & End, like Principle, is a form of the Other.
\end{tabular}

\begin{tabular}{|c|l|c|}
\hline \multicolumn{2}{|c|}{ Bergsonisim } & \multicolumn{1}{|c|}{ Deleuze, G. } \\
\hline CS & $\begin{array}{l}\text { Only the hypothesis of a single Time can, according to Bergson, account for the nature of virtual } \\
\text { multiplicities. }\end{array}$ \\
\hline DS & Bergson evolved, in a certain sense, from the beginning to the end of his work. ${ }^{13}$ \\
\hline
\end{tabular}

\begin{tabular}{|l|l|c|}
\hline \multicolumn{2}{|c|}{ The Birth of Biopolitics } & \multicolumn{1}{|c|}{ Foucault, M. } \\
\hline CS & $\begin{array}{l}\text { But if they took the trouble to argue with Marx I think it is quite easy to see what they could say } \\
\text { [about] his analysis. }{ }^{14}\end{array}$ \\
\hline DS & Today I would like to continue with what I began to say about German neo-liberalism. ${ }^{\text {IS }}$ \\
\hline
\end{tabular}

The Birth of the Clinic

Foucanit, $M$.

\begin{tabular}{|c|l|l|}
\hline \multicolumn{2}{|c|}{ The Birth of the Clinic } & \multicolumn{1}{c|}{ Foucanil, M- } \\
\hline CS & $\begin{array}{l}\text { Consequently, the complexity of individual cases could no longer be attributed to those uncontrollable } \\
\text { modifications that disturb essential truths, and force us to decipher them only in an act of recognition } \\
\text { that neglects and abstracts; it may be grasped and recognized in itself, in a complete fidelity to } \\
\text { everything it presents, if one analyses it according to the principles of a combination, that is, if one } \\
\text { defines all the elements that compose it and the form of that composition. }\end{array}$ \\
\hline DS
\end{tabular}

10. Jean-Luc Nancy, Being Singular Plural, trans. Robert D. Richardson and Anne E. O'Byrne, (Stanford, CA: Stanford University Press, 1996), 22.

11. Ibid., 13.

12. Gilles Deleuze, Bergsonism, trans. Hugh Tomlinson and Barbara Habberjam, (New York: Zone Books, 1988), 85.

13. Ibid., 34.

14. Michel Foucault, Birth of Biopolitics: Lectures at the Collège de France, 1978-79, trans. Graham Burchell, ed. Arnold L. Davidson, (London, Palgrave Macmillan, 2008), 221.

15. Ibid., 129.

16. Michel Foucault, Birth of the Clinic, trans. Alan Sheridan, (London: Routledge, 1989), 121.

17. Ibid., 131. 
Care of the Self

Foucault, M.

CS But it is a trait manifested by all Greek and Roman medicine to accord much more space to the dietetics of alimentation than to that of sex. ${ }^{18}$

Now, in Musonius, Seneca, Plutarch, or Hierocles, although utility has its part to play, although dis-trust of the transports of pleasure is very strong, the link between marriage and the aphrodisia is

DS not really established by positing the primacy of the social and political objectives of marriage, or by postulating an original evil intrinsic to pleasure, but by affirming a natural, rational, and essential relationship between them. ${ }^{19}$

\begin{tabular}{|c|l|c|}
\hline \multicolumn{1}{|c|}{ Cinema I } & \multicolumn{1}{|c|}{ Deleuze, G. } \\
\hline CS & $\begin{array}{l}\text { According to Bergson the whole is neither given nor giveable (and the error of modern science, like } \\
\text { that of ancient science, lay in taking the whole as given, in two different ways). }\end{array}$ \\
\hline DS & $\begin{array}{l}\text { Hence, it is inevitable that causes are rejected from another perspective, and only appear in the form } \\
\text { of individual duels which sometimes oppose a representative of the poor and a representative of the } \\
\text { rich, sometimes a decadent and a man of the future, sometimes a just man and a traitor, etc. }\end{array}$ \\
$\begin{array}{l}\text { Eisenstein's strength thus lies in showing that the principal technical aspects of American montage } \\
\text { since Griffith - the alternate parallel montage which makes up the situation, and the alternate } \\
\text { concurrent montage which leads to the duel - relate back to this social and bourgeois historical } \\
\text { conception. }\end{array}$
\end{tabular}
Cinema II
Deleuze, G.

\begin{tabular}{|c|l|}
\hline CS & $\begin{array}{l}\text { Bergson is much closer to Kant than he himself thinks: Kant defined time as the form of interiority, in } \\
\text { the sense that we are internal to.time (but Bergson conceives this form quite differently from Kant). }{ }^{22}\end{array}$ \\
\hline DS & There is no longer an alternative between montage and shot (in Welles, Resnais, or. Godard). ${ }^{23}$ \\
\hline
\end{tabular}

Coming Community

Agamben, G.

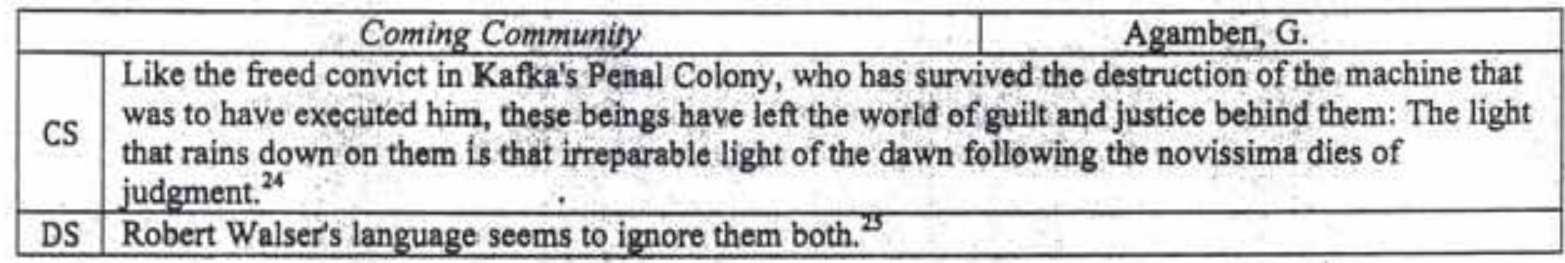

18. Michel Foucault, The History of Sexuality, Vol. 3: The Care of the Self, trans. Robert Hurley, (New York: Vintage, 1998), 141.

19. Ibid., 183.

20. Gilles Deleuze, Cinema I: The Movement-Image, trans. Hugh Tomlinson and Barbara Habberjam, (London Continuum, 2005), 9.

21. Ibid., 149-150.

22. Gilles Deleuze, Cinema II: The Time-Image, trans. Hugh Tomlinson and Robert Galeta. (Minneapolis: University of Minnesota Press, 1989), 80.

23. Ibid., 42.

24. Giorgio Agamben, The Coming Community, trans. Michael Hardt, (Minneapolis: University of Minnesota Press, 1993), 6.

25. Ibid., 58. 


\begin{tabular}{|c|c|c|}
\hline \multicolumn{2}{|r|}{ Comments on the Society of the Spectacle } & Debord, G. \\
\hline CS & $\begin{array}{l}\text { But Marx unfortunately remains all too up to } \\
\text { government, which "rather than deciding by } \\
\text { night. }\end{array}$ & $\begin{array}{l}\text { ok he describes this } \\
\text { decides by day and strikes by }\end{array}$ \\
\hline DS & N/A & \\
\hline
\end{tabular}

\begin{tabular}{|c|c|}
\hline \multicolumn{2}{|r|}{ Deleuzian Encounter } \\
\hline CS & $\begin{array}{l}\text { Deleuze and Guattari give the name non-historical becoming to this other account of the future, and } \\
\text { link it to Nietzsche's untimely, Foucault's actual, and Kant's idea of revolutionary enthusiasm. }{ }^{27}\end{array}$ \\
\hline DS & However, this is not my claim about Deleuze. ${ }^{28}$ \\
\hline & \\
\hline & Deleuze History and Science \\
\hline CS & $\begin{array}{l}\text { For Deleuze and Foucault, the visible and the articulable define an "disciplinary age" that is, a } \\
\text { historical period defining a whole "society".29 }\end{array}$ \\
\hline DS & $\begin{array}{l}\text { To apply assemblage theory to these entities Deleuze and Guattari introduced the concepts of major } \\
\text { and minor languages. }\end{array}$ \\
\hline
\end{tabular}

\begin{tabular}{|c|l|c|}
\hline \multicolumn{2}{|c|}{ Deleuze and the Limits of Mathematical Time } & \multicolumn{1}{c|}{ Olkowski, D. } \\
\hline CS & $\begin{array}{l}\text { However, according to Deleuze, when Bergson puts forward his three theses on movement and } \\
\text { accuses cinema of producing false movement, movement distinct from the space covered by that } \\
\text { movement (which Deleuze refers to as the 'cinematographic illusion'), Bergson is mistaken and must } \\
\text { be corrected. }\end{array}$ \\
\hline DS & $\begin{array}{l}\text { Moreover, Deleuze's argument might well rest on his assertion - an assertion that seems to have been } \\
\text { anticipated by'Bergson - that the theory of relativity alters Bergson's fundamental critique of } \\
\text { cinematographic knowledge. }\end{array}$ \\
\hline
\end{tabular}

$$
\text { Delenze Marx and Politics } \quad \text { Thoburn, } \mathrm{N} \text {. }
$$

CS It also considers Marx's mode of ereation in terms of the minor author function, Guattari's analysis of groups, and Deleuze's critique of Roucault's model of 'resistance.'.

The chapter then focuses on Marx's 'Fragment on Machines', a text which is of great importance to

DS Negri and to contemporary understandings of work, and also has a place in Deleuze and Guattari's understanding of capital. ${ }^{34}$

26. Guy Debord, Comments on the Society of the Spectacle, trans. Malcolm Emrie, (London: Verso, 1998), 23.

27. Jonathan Roffe, "The Revolutionary Dividual" in Gilles Deleuze and Four Movements in Social Thought, eds. Anna Hickey-Moody, Peta Malins, (London: Palgrave Macmillan, 2007), 40-50: 47.

28. Todd May, "Deleuze and the Tale of Two Intifiadas," in Ibid. 212-223: 218.

29. Manuel DeLanda, Deleuze History and Science, (New York: Atropos Press, 2010), 168.

30. Tbid., 100 .

31. Dorthea Olkowski, "Deleuze and the Limits of Mathematical Time," in Deleuze Studies 2, no. 1, 1-17: 2

32. Ibid., 3.

33. Nicholas Thoburn, Deleuze, Marx, and Politics, (London: Routledge, 2003), 13.

34, Tbid., 71. 
CS In this, Nietzsche renews Kant's endeavor to transform the divine law into an autonomous principle, to rescue European civilization from giving up the ghost in English skepticism. ${ }^{35}$

DS Odysseus is represented in the sphere of work. ${ }^{36}$

\begin{tabular}{|l|l|c|}
\hline \multicolumn{2}{|c|}{ Difference and Repetition } & Deleuze, $G$. \\
\hline CS & No doubt Bergson's example is not the same as Hume's ${ }^{31}$ \\
\hline DS & $\begin{array}{l}\text { Individuation is the act by which intensity determines differential relations to become actualised, } \\
\text { along the lines of differenciation and within the qualities and extensities it creates. }\end{array}$ \\
\hline
\end{tabular}

\begin{tabular}{|l|l|l|}
\hline \multicolumn{2}{|c|}{ Discipline and Punish } & \multicolumn{1}{|c|}{ Foucault, M. } \\
\hline CS & N/A & $\begin{array}{l}\text { One should not see in delinquency the most intense, most harmful form of illegality, the form that the } \\
\text { penal apparatus must try to eliminate through imprisonment because of the danger it represents; it is } \\
\text { rather an effect of penality (and of the penality of detention) that makes it possible to differentiate, } \\
\text { accommodate and supervise illegalities. }\end{array}$ \\
\hline
\end{tabular}

Discourse Networks 1800-1900

Kittler, F.

CS Kafka's "K." and "Joseph K." allow only the kind of game that Freud played with his anonymous personnel of Emmy $v$. $^{4}$

DS Writers like Faust or Anselmus were allowed to trust their inmost feeling only because it was supported by reading, which in turn was supported by a human language or voice. ${ }^{41}$

\begin{tabular}{|c|l|c|}
\hline \multicolumn{1}{|c|}{ Ecrits } & \multicolumn{1}{c|}{ Lacan, J. } \\
\hline CS & $\begin{array}{l}\text { In any case, my two-pronged reference to Hegel's absolute subject and to science's abolished subject } \\
\text { sheds the light necessary to accurately formulate Freud's dramatism: the return of truth to the field of } \\
\text { science at the same time as it comes to the fore in the field of its praxis-repressed, it reappears there. }{ }^{42}\end{array}$ \\
\hline DS & In other words, Freud never really knew what he was doing.
\end{tabular}

35. Theodor Adorno and Max Horkheimer, Dialectic of Enlightenment, trans. Edmund Jephcott (Stanford University Press, 2002), 90.

36. Ibid., 27

37. Gilles Deleuze, Difference and Repetition, trans. Paul Patton (New York: Columbia University Press, 1994), 72.

38. Ibid., 246.

39. Michel Foucault, Discipline and Punish: The Birth of the Prison, trans. Alan Sheridan, (New York: Vintage Books, 1995), 277.

40. Friedrich Kittler, Discourse Networks 1800/1900, trans. Michael Metteer and Chris Cullens, (Stanford, CA: Stanford University Press, 1990), Xi.

41. Ibid., 183.

42. Jacques Lacan, Écrits: The First Complete Edition in English, trans, Bruce Fink, (London: Norton, 2006), 799. 43,Ibid., 427. 


\begin{tabular}{|c|l|c|}
\hline \multicolumn{1}{|c|}{ Empire } & \multicolumn{1}{c|}{ Hardt, M; Negri, A. } \\
\hline CS & $\begin{array}{l}\text { The passage we are refer-ring to, however, is fundamentally different in that instead of focusing on } \\
\text { the unidimensionality of the process described by Marx and reformulated and extended by the } \\
\text { Frankfurt School, the Foucauldian passage deals fundamentally with the paradox of plurality and } \\
\text { multiplicity -and Deleuze and Guattari develop this perspective even more clearly. }\end{array}$ \\
\hline DS & $\begin{array}{l}\text { The European debates about Empire and decline interest us for two primary reasons: first, because the } \\
\text { crisis of the ideal of imperial Europe is at the center of these debates, and second, because this crisis } \\
\text { strikes precisely in that secret place of the definition of Empire where the concept of democracy } \\
\text { resides. }\end{array}$ \\
\hline
\end{tabular}

\begin{tabular}{|l|l|l|}
\hline \multicolumn{2}{|c|}{ Empiricism and Subjectivity } & Deleuze, G. \\
\hline CS & Writers as different as Bergson and Freud converge on this point. \\
\hline DS & $\begin{array}{l}\text { What Hume means is this: principles of human nature produce in the mind relations of ideas as they } \\
\text { act "on their own" on ideas, }\end{array}$ \\
\hline
\end{tabular}

\begin{tabular}{|l|l|l|}
\hline \multicolumn{2}{|c|}{ Essays Critical and Clinical } & Deleuze; $G_{\text {: }}$ \\
\hline CS & It is a machine for manufacturing giants, what Bergson called a fabulatory function. \\
\hline DS & Why does Dionysus need Ariadne, or to be loved? \\
\hline
\end{tabular}

\begin{tabular}{|l|l|c|}
\hline \multicolumn{2}{|c|}{ The Foucault Reader } & \multicolumn{1}{|c|}{ Foucault, M. } \\
\hline CS & N/A & \\
\hline DS & $\begin{array}{l}\text { I wondered what the technology of the self before Christianity was, or where the Christian technology } \\
\text { of the self came from, and what kind of sexual ethics was characteristic of the ancient culture. }\end{array}$ \\
\hline
\end{tabular}

\begin{tabular}{|c|l|c|}
\hline \multicolumn{2}{|c|}{ The Fold } & \multicolumn{1}{|c|}{ Deleuze, G; Guattari, F. } \\
\hline CS & $\begin{array}{l}\text { According to Deseartes, the initial criterion of substance is the simple, simple notion: that from which } \\
\text { elements can be distinguished only by abstraction or distinction of reason (thus extension and the } \\
\text { body, thought and the mind). }\end{array}$ \\
\hline DS & $\begin{array}{l}\text { Leibniz begins to use the word "to read" at once as the inner act in the privileged region of the monad, } \\
\text { and as the act of God in all of the monad itself. }\end{array}$ \\
\hline
\end{tabular}

44. Michael Hardt and Antonio Negri, Empire, (Cambridge, MA: Harvard University Press, 2009), 25.

45. Ibid., 374

46. Gilles Deleuze, Empiricism and Subjectivity: An Essay on Hume's Theory of Human Nature, trans. Constantin V. Boundas, (New York: Columbia Uniysitry Press, 1991), 102.

47. Ibid., 66

48. Gilles Deleuze, Essays Critical and Clinical, trans.Daniel W. Smith and Michael A. Greco, (London: Verso, 1998), 118.

49. Ibid., 100.

50. Michel Foucault, "On the Genealogy of Ethics: An Overview of Work in Progress" in The Foucault Reader, ed. Paul Rabinow, (New York: Pantheon Books, 1984), 340-373: 341.

51. Gilles Deleuze, The Fold: Leibniz and the Baroque, trans. Tom Conley, (Minneapolis: University of Minnesota Press, 1992), 62.

52. Ibid., 35. 


\begin{tabular}{|l|l|c|}
\hline \multicolumn{2}{|c|}{ Foucault } & \multicolumn{1}{c|}{ Deleuze, G. } \\
\hline CS & It is as if, finally, something new were emerging in the wake of Marx. $^{33}$ \\
\hline DS & And perhaps these are Foucault's most moving statements. & ${ }^{34}$ \\
\hline
\end{tabular}

\begin{tabular}{|c|l|c|}
\hline \multicolumn{2}{|c|}{ Governmentality } & \multicolumn{1}{|c|}{ Misc. } \\
\hline CS & $\begin{array}{l}\text { According to Agamben, the main difference within the realm of the political is not that between friend } \\
\text { and enemy (pace Schmitt) but that between "bare life" (zoe) and political existence (bios), natural } \\
\text { being and a human being's legal existence. }\end{array}$ \\
\hline DS & $\begin{array}{l}\text { It is probably fair to say that the theme of frontiers is largely absent from the two courses that are } \\
\text { today read together as Foucault's lectures on "governmentality" (Foucault 1991;2007;2008). }\end{array}$ \\
\hline
\end{tabular}

\begin{tabular}{|c|l|c|}
\hline \multicolumn{2}{|c|}{ Gnamophone Film Typewriter } & \multicolumn{1}{|c|}{ Kittler, E. } \\
\hline CS & $\begin{array}{l}\text { Kafka's call For the Establishment and Support of a Military and Civilian Hospital forthe Treatment } \\
\text { of Nervous Diseases in German Bohemia stated: This great war which encompasses the sum total of } \\
\text { human misery is also a war on the nervous system, more a war on the nervous system than any } \\
\text { previous war. }^{\text {s7 }}\end{array}$ \\
\hline DS & $\begin{array}{l}\text { Cinema and the phonograph, Edison's two great achievements that ushered in the present, are } \\
\text { complemented by the typewriter. }\end{array}$ \\
\hline
\end{tabular}

Madness and Civilization

Foucault, M.

\begin{tabular}{|l|l|c|}
\hline \multicolumn{2}{|c|}{ Madness and Civilization } & \multicolumn{1}{c|}{ Foucault, M. } \\
\hline CS & $\begin{array}{l}\text { But we must not think of this continuity in terms of a system, of a thematics, or even of an existence: } \\
\text { Nietzsche's mad-ness - that is, the dissolution of his thought-is that by which his thought opens out } \\
\text { onto the modem world. }\end{array}$ \\
\hline DS & Madness no longer exists except as seen. \\
\hline
\end{tabular}

53. Gilles Deleuze, Foucault, trans. Sean Hand, (Minneapolis: University of Minnesota Press, 1988), 27.

54. Ibid., 8

55. Thomas Lemke, "Beyond Foucault: From Biopolitics to the Government of Life" in Governmentality: Current Issues and Future Challenges, eds. Ulrich Brockling, Susanne Krasmann and Thomas Lemke, (London: ROutledge 2011), 165-185: 167

56. William Walters, "Foucault and Frontiers: Notes on the Birth of the Humanitarian Border," in Ibid.,138-164: 140

57. Friedrich Kittler, Gramophone, Film, Typewriter, trans. Geoffrey Winthrop-Young and Michael Wutz, (Stanford, CA: Stanford University Press, 1999), 223.

58. Ibid., 13.

59. Michel Foucault, Madness and Civilization: A History of Insanity in the Age of Reason, (New York: Vintage, 1988), 288.

60. Ibid., 250. 
At the moment when Freud was uncovering the nature of Dora's desire and allowing it to be put into words, preparations were being made to undo those reprehensible proximities in other social sectors; on the one hand, the father was elevated into an object of compulsory love, but on the other hand, if he was a loved one, he was at the same time a fallen one in the eyes of the law. ${ }^{61}$

DS So we must not refer a history of sexuality to the agency of sex; but rather show how "sex" is historically subordinate to sexuality. ${ }^{62}$

\begin{tabular}{|c|c|}
\hline & History of Western Music Theory \\
\hline CS & $\begin{array}{l}\text { Marx insists repeatedly that the nature and type of the opening theme determine the way it is } \\
\text { continued, and ultimately the type of overall form. }\end{array}$ \\
\hline DS & $\begin{array}{l}\text { Despite his conA-stant reformulation of the acoustical underpinnings of his theory in light of } \\
\text { scientific developments, the principal problems which Rameau faced were familiar to a line of } \\
\text { theorists from Zarlino to Scheriker. }\end{array}$ \\
\hline
\end{tabular}

\begin{tabular}{|c|l|c|}
\hline \multicolumn{1}{|c|}{ Homo Sacer } & \multicolumn{1}{c|}{ Agamben, G. } \\
\hline CS & $\begin{array}{l}\text { One of the peculiar characteristics of Kafka's allegories is that at their very end they offer the } \\
\text { possibility of an about-face that completely upsets their meaning. }\end{array}$ \\
\hline DS & $\begin{array}{l}\text { Insofar as it is sovereign, the nomos is necessarily connected with both the state of nature and the } \\
\text { state of exception. }\end{array}$ \\
\hline
\end{tabular}

\begin{tabular}{|c|l|c|}
\hline \multicolumn{2}{|c|}{ The Infinite Conversation } & \multicolumn{1}{c|}{ Blanchot, M. } \\
\hline CS & $\begin{array}{l}\text { At the same time and slightly later, the work of numerous French Germanists (that of Albert Béguin, } \\
\text { the publications of the Cahiers du Sud, research on the young Hegel and the young Marx, then the } \\
\text { reflections of Henri Lefebvre, which constantly seek to free within Marxism its romantic source) } \\
\text { contributes not only to a knowledge of this movement but, through this knowledge, to a new feeling } \\
\text { about art and literature that paves the way for other changes, all oriented toward challenging the } \\
\text { traditional forms of political organization. }\end{array}$ \\
\hline DS & $\begin{array}{l}\text { The fact that Nietzsche takes his leave from the thought of the One God, that is to say, from the god } \\
\text { of Unity, must be taken seriously. }\end{array}$ \\
\hline
\end{tabular}

61. Michel Foucault, The History of Sexuality: An Introduction, trans. Robert Hurley, (New York: Random House, 2012), 130.

62. Ibid., 157.

63. Scott Burnham, "Form" in The Cambridge History of Western Music Theory, ed. Thomas Christensen, (Cambridge, England: Cambridge University Press, 2008), 880-906: 889.

64. Nicholas Cook, "Epistemologies of Music Theory," in Ibid., 78-108: 86.

65. Giorgio Agamben, Homo Sacer: Sovereign Power and Bare Life, trans. Daniel Heller-Roazen, (Stanford, CA: Stanford University Press, 1998), 38.

66. Ibid., 27.

67. Maurice Blanchot, Infinite Conversation, trans. Susan Hanson (Minneapolis: University of Minnesota Press, 1993), 351.

68. Ibid., 154. 


\begin{tabular}{|l|l|c|}
\hline \multicolumn{2}{|c|}{ Information Bomb } & \multicolumn{1}{|c|}{ Paul Virilio } \\
\hline CS & $\begin{array}{l}\text { They think they are advancing, but they are simply rumning on the spot and falling into the void, that } \\
\text { is all,' observed Kafka, }\end{array}$ \\
\hline DS & The American people would be satisfied. & \\
\hline
\end{tabular}

\section{\begin{tabular}{l|l}
\hline Inoperative Community & Nancy, J-L.
\end{tabular}}

\begin{tabular}{|l|l|c|}
\hline \multicolumn{1}{|c|}{ Inoperative Community } & \multicolumn{1}{|c|}{ Nancy, J-L. } \\
\hline & $\begin{array}{l}\text { This character functions as does, for Marx, the "social" character of labors in primitive "communes": } \\
\text { CS }\end{array}$ & $\begin{array}{l}\text { Under the rural patriarchal system of production, when spinner and weaver lived under the same roof- } \\
\text { the women of the family spinning and the men weaving, say for the requirements of the family-yarn } \\
\text { and linen were social products, and spinning and weaving social labour within the framework of the } \\
\text { family. }^{71}\end{array}$ \\
\hline DS & If there are no more gods, there is no more community.
\end{tabular}

\begin{tabular}{|c|l|c|}
\hline \multicolumn{2}{|c|}{ Intensive Science Virtual Philosophy } & \multicolumn{1}{c|}{ Delanda, M. } \\
\hline CS & $\begin{array}{l}\text { Deleuze, as I said, does not view the differential relations defining a model as expressing a law } \\
\text { governing the generation of the series of states that make up a trajectory, but as defining a vector field } \\
\text { which captures the overall tendencies of the system as a distribution of singularities. }\end{array}$ \\
\hline DS & In short, I will not be concerned with Deleuze's words only with Deleuze's world. \\
\hline
\end{tabular}

\begin{tabular}{|l|l|c|}
\hline \multicolumn{2}{|c|}{ Kafka: Toward a Minor Literature } & Deleuze, G, \\
\hline CS & $\begin{array}{l}\text { German plays precisely the double role of ve-hicular and cultural language, with Goethe always on } \\
\text { the horizon (Kafka also knows French, Italian, and probably a bit of English). }\end{array}$ \\
\hline DS & N/A \\
\hline
\end{tabular}

\begin{tabular}{|l|l|l|}
\hline \multicolumn{2}{|c|}{ Lacan and Science } & \multicolumn{1}{|c|}{ Misc. } \\
\hline CS & The separation between Bossuet and.Marx has not been completely achieved. \\
\hline DS & $\begin{array}{l}\text { This gives a rationale to the title of one of Lacan's Ecrits, "The agency of the letter in the unconscious } \\
\text { or reason since Freud" (Lacan, 1977a). }\end{array}$ \\
\hline
\end{tabular}

69. Paul Virilio, The Information Bomb, trans. Chris Turner, (London: Verso, 2005), 38.

70. Tbid., 23.

71. Jean-Luc Nancy, The Inoperative Community, trans. Peter Connor, (Minneapolis: University of Minnesota Press, 1990), 74.

72. Ibid. 143

73. Manuel DeLanda, Intensive Science and Virtual Philosophy, (London: Continuum, 2002), 174.

74. Ibid., xiii

75. Gilles Deleuze, Kafka: Towards a Minor Literature, trans. Dana Polan, (Minneapolis: Univerity of Minnesota Press, 1986), 25.

76. Jacques-Alain Miller, "Elements of Epistomology" in Lacan and Science, ed. Jason Glynos and Yannis Stavrakakis, (London: Karnac, 2002), 147-166: 156.

77. Jason Glynos, "Psychoanalysis Operates Upon the Subject of Science: Lacan between Science and Ethics" in Ibid., 51-88: 60 . 
The Limits to Capital

Harvey, D.

An inspection of those brief sections where Marx does explicitly consider the shape and form of crises yields a check-list of matters invoked that have yet to be considered:

(1) the peculiar mode of production, circulation and realization of fixed capital and the difficulties that arise from differential turnover times;

(2) the process of organizational and structural change which affects the degree of centralizationdecentralization of capital;

(3) the role of the credit system, interest-bearing and money capital (all of which require that the

CS monetary aspects of circulation of capital be analysed);

(4) the interventions of the state in the circulation of capital;

(5) the physical aspects of circulation of commodities (the movement of commodities in space)

together with foreign trade, the formation of the 'world market' and the whole geographical structure of capitalism;

(6) the complex configurations of class relations both within and between social formations (for example, factional distinctions within the capitalist class and distinctions within the proletariat based on different national values of labour power). ${ }^{76}$

DS But what, exactly, does Marx mean by the value of labour power? ${ }^{79}$

The Logic of Sense

Deleuze, $G$

2 In this manner Nietzsche reopened the whole problem of the orientation of thought: is it not rather

CS in line with other dimensions that the act of thinking is engendered in thought and the thinker engendered in life? ? $^{\text {BO }}$

DS It is that of rendering our substance incapable of being assumed by a nature either interior or superior to our own. ${ }^{\text {s1 }}$

\begin{tabular}{|l|l|c|}
\hline \multicolumn{2}{|c|}{ Memoirs of my Nervous Illness } & \multicolumn{1}{c|}{ Schreber, D.P. } \\
\hline CS & $\begin{array}{l}\text { The Christian teaching that Jesus Christ was the Son of God can be meant only in a mystical sense } \\
\text { which but approximates the human sense of these words, because no-body would maintain that God, } \\
\text { as a Being endowed with hu-man sexual organs, had intercourse with the woman from whose womb } \\
\text { Jesus Christ came forth. }\end{array}$ \\
\hline DS & $\begin{array}{l}\text { In each case when first I entered the Asylum I had not the faintest idea of an antagonism existing } \\
\text { between the Schreber and Flechsig families, nor of the supernatural matters of which I have treated } \\
\text { in the preceding chapters. }\end{array}$ \\
\hline
\end{tabular}

78. David Harvery, The Limits to Capital, (London: Verso, 1999), 191.

79 Ibid., 46.

80. Gilles Deleuze, Logic of Sense, trans. Constantin V. Boundas, (London: Continuum, 2004), 128.

81. Ibid., 292.

82. Daniel Paul Schreber, Memoirs of My Nervous Illness, trans. Ida Macalpine and Richard A. Hunter, (New York: New York Review of Books, 2000), 17.

83.Ibid., 45 . 
The so-called law of nature, which nevertheless would only be one of capitalist society, is therefore termed mystification by Marx: "The law of capitalist accumulation, mystified into a law of nature,

CS expresses therefore in fact only that its nature excludes every such decrease in the degree of exploitation of labor or every such increase of the price of labor, which could seriously endanger the continual reproduction of the relationships of capital and its reproduction on a constantly expanded level. ${ }^{\text {h }}$

DS $\quad$ Since Kant, idealism could not escape this, not even Hegel's. ${ }^{33}$

\begin{tabular}{|c|l|c|}
\hline \multicolumn{2}{|c|}{ Network Culture } & Terranova, T. \\
\hline CS & $\begin{array}{l}\text { This improbability that can only be predicted with the benefit of hindsight can be made to } \\
\text { correspond to the category of the virtual - as it is formulated in the work of Henri Bergson, Gilles } \\
\text { Deleuze and more recently Brian Massumi and Pierre Levy. }\end{array}$ \\
\hline DS & $\begin{array}{l}\text { On the contrary, they are related to the overall informational dimension that cuts across the global } \\
\text { matrix of communication of which the Internet is part. }\end{array}$ \\
\hline
\end{tabular}

\begin{tabular}{|c|l|c|}
\hline \multicolumn{2}{|c|}{ Noise } & Attali, J. \\
\hline CS & Marx wisely set the problem aside. & \\
\hline DS & Music accounts for them. & \\
\hline
\end{tabular}

The Ontology of Social Being

Lukács, G.

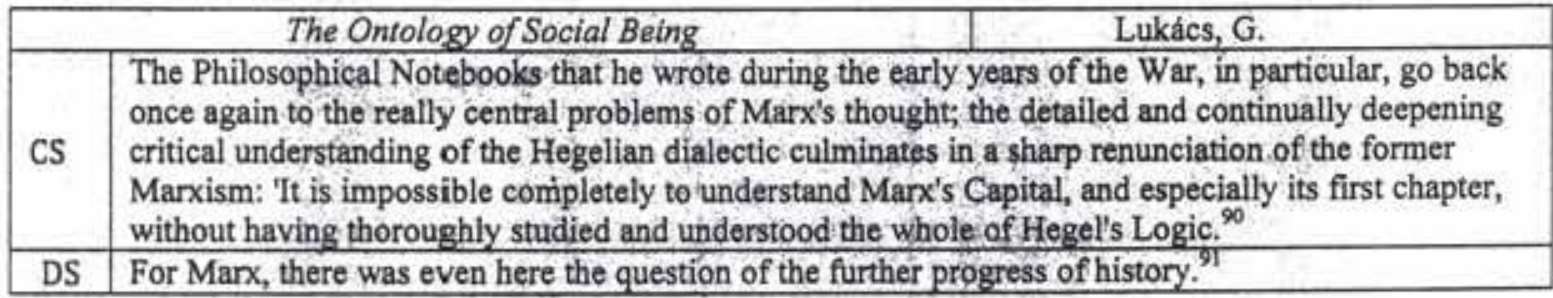

84. Theodor Adorno, Negative Dialectics, trans. E. B. Ashton, (New York: Continuum, 2005), 347.

85. Ibid., 100.

86. Tiziana Terranova, Network Culture: Politics for the Information Age, (Ann Arbor: University of Michigan Press, 2004), 26.

87. Ibid., 70.

88. Jacques Attali, Noise: An Essay on the Political Economy of Music, trans. Brian Massumi, (Manchester, UK: Manchester University Press, 1985), 42.

89. Ibid., 20.

90. György Lukács, Ontology of Social Being, trans. David Fernbach, (London: Merlin Press, 1978), 22.

91. Ibid., 163. 
The Order of Things

Foucault, M.

CS Sade, Nietzsche, Artaud, and Bataille have understood this on behalf of all those who tried to ignore it; but it is also certain that Hegel, Marx, and Freud knew it. ${ }^{2 / 2}$

The commentary resembles endlessly that which it is commenting upon and which it can never

DS express; just as the knowledge of nature constantly finds new signs for resemblance because resemblance cannot be known in itself, even though the signs can never be anything but similitudes. ${ }^{93}$

\section{Politics of Aesthetics $\quad$ Rancière, J.}

What it cast aside - which was reappropriated by film and photography - was the logic revealed by the

CS tradition of the novel (from Balzac to Proust and Surrealism) and the reflection on the true that Marx, Freud, Benjamin, and the tradition of 'critical thought' inherited: the ordinary becomes beautiful as a trace of the true. 94

DS The aesthetic regime of the arts does not contrast the old with the new. ${ }^{95}$

\section{\begin{tabular}{l|l} 
A Very Popular Exile & Nandy, A.
\end{tabular}}

\begin{tabular}{|l|l|l|}
\hline CS & $\begin{array}{l}\text { Marx wrote about the processes of declassing oneself and about breaking the barriers of one's false } \\
\text { consciousness; Freud, about the possibility of working through one's personal history or, rather, the } \\
\text { defenses against such history. }\end{array}$ \\
\hline DS & N/A. \\
\hline
\end{tabular}

\begin{tabular}{|c|l|c|}
\hline \multicolumn{2}{|c|}{ Power } & \multicolumn{1}{|c|}{ Foucault, M, } \\
\hline CS & One had to be on fa-miliar terms with Marx and not let one's dreams stray too far from Freud., \\
\hline DS & $\begin{array}{l}\text { And Oedipus is the one who says repeatedly: "I asked questions, and since no one was able to inform } \\
\text { me, I opened my eyes and ears, and I saw. }\end{array}$ \\
\hline
\end{tabular}

\section{\begin{tabular}{l|l}
\hline Rhythmanalysis & Lefebvre, $\mathrm{H}$. \\
\hline
\end{tabular}}

Followed by Marx, Hegel laicised this sacred number; that is, dialectical analysis observes or

CS constitutes the relations between three terms, which change according to circumstance: going from conflict to alliance and back again."

DS In and through rhythm? ${ }^{\text {Io }}$

92. Michel Foucault, The Order of Things, (New York: Pantheon Books, 1971), 328.

93. Ibid., 41.

94. Jacques Rancière, The Politics of Aesthetics, trans. Gabriel Rockhill (London: Continuum, 2004), 30.

95. Ibid., 20.

96. Ashis Nandy, A Very Popular Exile: An Omnibus, (Oxford: Oxford University Press, 2010), 22.

97. Michel Foucault, Power: Volume 3 of Essential Works of Foucault, 1954-1984, ed. James D. Faubion, New York: New Press, 2000), 106.

98. Ibid., 29.

99. Henri Lefebvre, Rythmanalysis: Space, Time and Everyday Life, trans. Stuart Elden and Gerald Moore, (New York: Continuum, 2004), 11.

100. Ibid., 60 


\begin{tabular}{|c|l|c|}
\hline \multicolumn{2}{|c|}{ Security Territory Population } & \multicolumn{1}{c|}{ Foucault, M. } \\
\hline CS & $\begin{array}{l}\text { It is crystallized, of course, with the treaty of Westphalia,33 the first com-plete, conscious, explicit } \\
\text { expression of a politics of European balance, the main function of which, as you know, is to } \\
\text { reorganize the Empire, to define its status and its rights in relation to the German principalities, and } \\
\text { the zones of influence of Austria, Sweden, and France on German territory, all according to the laws } \\
\text { of equilibrium, which actually explains why Germany could become, and actually became, the center } \\
\text { for the elaboration of the European republic. }\end{array}$ \\
\hline DS & $\begin{array}{l}\text { This is the form in which you find some apologists for Machiavelli, obviously not among the } \\
\text { adversaries of raison d'Etat, but m some, and only some, of those who are m favor of raison d'Etat. }\end{array}$ \\
\hline
\end{tabular}

\begin{tabular}{|c|l|c|}
\hline \multicolumn{2}{|c|}{ Society Must Be Defended } & \multicolumn{1}{|c|}{ Foucault, M. } \\
\hline CS & $\begin{array}{l}\text { We then see it reappear in France at the end of the seventeenth century, at the end of the reign of } \\
\text { Louis XIV, and in other political struggles-let us say, the rearguard struggle waged by the French } \\
\text { aristocracy against the establishment of the great absolute administrative monarchy. }\end{array}$ \\
\hline DS & According to Bonlainvilliers, the Franks and the Gauls lived happily side by side.
\end{tabular}

\section{\begin{tabular}{l|l} 
The Society of the Spectacle & Debord, G.
\end{tabular}}

\begin{tabular}{|c|l|c|}
\hline \multicolumn{2}{|c|}{ The Society of the Spectacle } & \multicolumn{1}{c|}{ Debord, G. } \\
\hline CS & $\begin{array}{l}\text { It is in this regard that the relationship between Marx and Hegel has generally been ignored or } \\
\text { misunderstood, or even denounced as the weak point of what became fallaciously transformed into a } \\
\text { doctrine: "Marxism. }\end{array}$ \\
\hline DS & $\begin{array}{l}\text { It is obvious that ideas alone cannot lead beyond the existing spectacle; at most, they can only lead } \\
\text { beyond existing ideas about the spectacle. }\end{array}$ \\
\hline
\end{tabular}

\section{The Space of Literature}

Blanchot, $\mathrm{M}$.

\begin{tabular}{|l|l|}
\hline CS & $\begin{array}{l}\text { We come back here to what Kafka, at least-in the sentences we ascribed to him, seemed to seek to } \\
\text { express: I write to die, to give death its essential possibility, through which it is essentially death, } \\
\text { source of invisibility; but at the same time, I cannot write unless death writes in me, makes of me the } \\
\text { void where the impersonal is affirmed. }\end{array}$ \\
\hline DS & Kafka feels deeply here that art is a relation with death. \\
\hline
\end{tabular}

101. Michel Foucault, Security, Territory, Population: Lectures at the Collège de France 1977-1978, trans. Graham Burchell, ed. François Ewald, Alessandro Fontana and Arnold I. Davidson, (New York: Picador, 2009), 304.

102. Ibid. 322 .

103. Michel Foucault, Society Must Be Defended: Lectures at the College de France 1975-1976, trans. David Macey, ed. François Ewald, Alessandro Fontana and Arnold I. Davidson, (New York: Macmillan, 2009), 304.

104. Ibid., 151.

105. Guy Debord, Society of the Spectacle, trans. Ken Knabb, (Berkeley: Bureau Of Public Secrets, 2013 ), 79.

106. Tbid., 203.

107. Maurice Blanchot, The Space of Literature, trans. Ann Smock, (Lincoln, NE: University of Nebraska Press, 1989), 149.

108. Ibid., 90 . 


\begin{tabular}{|c|l|c|}
\hline \multicolumn{2}{|c|}{ Speed and Politics } & Virilio, P. \\
\hline CS & $\begin{array}{l}\text { In the final account, it is not so surprising that a trafficker and buccaneer like Laffitte financed the } \\
\text { publication of Marx's manifesto. }\end{array}$ \\
\hline DS & For Virilio, this also signals the production of logistical space as a Modern administrative horizon. ${ }^{\text {"10 }}$ \\
\hline
\end{tabular}

\begin{tabular}{|l|r} 
State of Exception & Agambren \\
\hline
\end{tabular}

\begin{tabular}{|c|l|c|}
\hline \multicolumn{2}{|c|}{ State of Exception } & \multicolumn{1}{|c|}{ Agambren } \\
\hline CS & $\begin{array}{l}\text { While these terms have close correspendences in French (droit, lot), Spanish (derecho, ley), and } \\
\text { German (Recht Gesetz), some of their sense is inevitably. lost in the passage to Eng lish." }\end{array}$ \\
\hline DS & $\begin{array}{l}\text { Already in his 1928 treatise on constitutional law, though without defining the op-position, Schmitt } \\
\text { evoked its "great importance in the general theory of the state," and referred back to Roman law to } \\
\text { describe it ("the Senate had auctoritas; on the contrary, potestas and imperium derive from the } \\
\text { people" [Schmitt 1928,109]). }\end{array}$ \\
\hline
\end{tabular}

\begin{tabular}{|c|l|c|}
\hline \multicolumn{2}{|c|}{ The Unavowable Community } & Blanchot, ML \\
\hline CS & $\begin{array}{l}\text { Nietzsohe had theiardent desire to be heard, hut also at times the proud certainty of carrying within } \\
\text { himself a truthitoo dangerous or too superior to be welcomed }\end{array}$ \\
\hline DS & $\begin{array}{l}\text { When Georges Bataille evokes a principle of insufficiency, we believe we understand without } \\
\text { difficulty what he is saying. }\end{array}$ \\
\hline
\end{tabular}

\begin{tabular}{l|l} 
The Use of Pleasure & Foucault, $\mathrm{M}$.
\end{tabular}

CS From this angle, Plato's answer seems only more complex and more elaborate than those that might have been put forward in the various "debates" on love; or by "Socrates" in the texts of Xenophon. "15

It is doubtless correct to say that there is no noun in the Greek yocabulary that would consolidate, into a common notion; whatever might be specific to male sexuality and female sexuality, but it should be remarked that in the practice of sexual pleasures two roles and two poles can be clearly distinguished, just as they can be distinguished in the reproductive function; these consisted of two positional values: that of the subject and that of the object, that of the agent and that of the "patient", as Aristotle says,

DS "the female, as female, is passive, and the male, as male, is active," Whereas the experience of the "flesh" would be considered as an experience common to men and women, even if it did not take the same form in both, and while "sexuality" would be marked by the great caesura between male and female sexuality, the aphrodisia were thought of as an activity involving two actors, each having its role and function-the one who performs the activ-ity and the one on whom it is performed. ${ }^{116}$

109. Paul VIrilio, Speed and Politics, trans. by Mark Polizzotti, ((Cambridge, MA: MIT Press, 2006), 66.

110. Ibid., 12.

111. Giorgio Agamben, State of Exception, trans. Kevin Attell, (Chicago: University of Chicago Press, 2005), 27.

112. Ibid. 75 .

113. Maurice Blanchot, The Unavowable Community, trans. Pierre Joris. Barrytown, (New York: Station Hill Press, 1988), 22.

114 Ibid., 8.

115. Michel Foucault, The History of Sexuality, Vol. 2: The Use of Pleasure, trans. Robert Hurley, (New York: Vintage Books, 1990), 242.

116. Ibid., 46. 


\begin{tabular}{|l|l|c|}
\hline \multicolumn{2}{|c|}{ The Vision Machine } & Virilio, P. \\
\hline CS & Aaagh! ${ }^{\text {M }}$ & \\
\hline DS & $\begin{array}{l}\text { When Bergson asserts that mind is a thing that endures, one might add that it is our duration that } \\
\text { thinks, feels, sees. }\end{array}$ \\
\hline
\end{tabular}

War in the Age of Intelligent Machines

Delanda: $M$.

\begin{tabular}{|c|c|}
\hline & War in the Age of Intelligent Machines \\
\hline CS & $\begin{array}{l}\text { Computer technology is also at the frontier between two other worlds: the world of abstract } \\
\text { machines of the machinic phylum and that of concrete assemblages and human practices. }{ }^{119}\end{array}$ \\
\hline DS & $\begin{array}{l}\text { Swiss pike troops, German landsknecht, Irish and English adventurers, displaced French } \\
\text { gen-darmes, tough Castilian foot soldiers - they would come from every corner of the continent } \\
\text { to join the fighting... Geopolitically, Europe at this point was far from complete. }\end{array}$ \\
\hline
\end{tabular}

:

What is Philosophy

Deleuze, G; Guattari, F.

CS According to Bergson the Figure is like fabulation: it has a religious origin. ${ }^{12}$

Conceptual personae constitute points of view according to which planes of immanence are

DS distinguished from one another or brought together, but they also constitute the conditions under which each plane finds itself filled with concepts of the same group. ${ }^{122}$

\begin{tabular}{|l|l|c|}
\hline \multicolumn{2}{|c|}{ The Writing of Disaster } & Blanchot, M; \\
\hline CS & N/A & \\
\hline DS & Kafka's trial can be interpreted as a tangle of three different realms (the Law, laws, rules). ${ }^{12}$ \\
\hline
\end{tabular}

117. Paul Virilio, The Vision Machine, trans. Julie Rose, (Bloomington: Indiana University Press, 1994), 11.

118. Ibid., 3.

119. Manuel DeLanda, War in the Age of Intelligent Machines, (New York:Zone Books, 1991), 229.

120. Ibid., 21.

121. Gilles Deleuze and Félix Guattari, What is Philosophy?, trans. Hugh Thomlinson and Graham Burchell (New York, Columbia University Press, 1996), 193.

122. Ibid., 75.

123. Maurice Blanchot, The Writing of the Disaster, trans. Ann Smock (Lincoln, NE: Univeristy of Nebraska Press, 1995), 144. 


\section{Appendix III: Notes}

2.1. Positivitat alludes to the "self-incurred tutelage" that German Idealism saw it as an imperative for the "fully autonomous" subject to overcome.

2.2. For an extended discussion on Western providential "guilt" history, specifically, a critique of Christianity as the religion of guilt economy and capitalism as a system of a deterministic debt religion, see Werner Hamacher, "Guilt History: Benjamin's Sketch 'Capitalism as Religion,"' in Diacritics 32, no.3-4 (Fall-Winter 2002): 81-106.

2.3. Although he invokes the oikos, significantly, Agamben's etymology of the term "apparatus" does not contrast the oikos with the polis; rather, it contrasts the oikos with its own oikonomia. Hannah Arendt had already suggested that a loss of any distinction between the oikos and the polis was a characteristic of modern government. The term Arendt used to describe this phenomenon was "society": "Society is the form in which the fact of mutual dependence for the sake of life and nothing else assumes public significance," writes Arendt, "and where the activities connected with sheer survival are permitted to appear in public." Hannah Arendt, "The Public and Private Realm," in The Portable Hannah Arendt, ed. Peter Baelir (London: Penguin, 2003), 197. The rise of "society," which for Arendt corresponded with the rise of societies of discipline, already involved the conflation of the polis, the sphere of the social, with the oikos, the sphere of the home and family. The concept of an apparatus, however, resituates this contrast. In terms of its etymological residues, it is not an appropriation of the oikos by the polis; rather, it is the foreclosure of both spheres by way of their appropriation into an oikonomia, which is significant because, unlike the oikos and the polis, an oikonomia is finally without any foundation in being.

2.4. In "Postseript on the Societies of Control," Deleuze writes, "The individual never ceases passing from one closed environment to another, each having its own laws: first, the family; then the school ('you are no longer in your family'); then the barracks ('you are no longer at school'); then the factory [...]" (3). These transitions, from son/daughter to student, from student to soldier, from soldier to worker, etc., exemplify the processes of subjectification discussed here (i.e., the disappearance of an "old" self and the emergence of a "new" self).

2.5. In recent years, several studies have explored the concept of the "living dead," more specifically, the cultural significance of this "capitalist monster," the zombie, already so familiar in the sensational entertainment of control societies. The classic example here, in any case, is George Romero's Dawn of the Dead (1978), which is set almost entirely inside of a shopping mall. When one character asks another why the zombies are so attracted to the shopping mall, her interlocutor can only speculate, "Some kind of instinct. Memory of what they used to do. This was an important place in their lives." Dawn of the Dead, in other words, figures the zombie as a not so thinly veiled caricature of the brainless consumer blindly following the rituals and imperatives of consumerism; and no less as complemented by elevator music, indoor fountains, and other recognizable fixtures of the shopping mall. Significantly, then, these zombies are not figures of some alien other intent upon sabotaging the community from without; rather, "they resonate with, and refigure, the very processes that produce and enforce social order." Steven Shaviro, The Cinematic Body, (Minneapolis: University of Minnesota Press, 1993), 87. In other words, "they do not mirror or represent social forces; [rather] they are directly animated and possessed, even in their allegorical distance from beyond the grave, by such forces." Ibid. In relation to this last point, it bears mentioning that by the time of Zack Snyder's 2004 remake of Dawn of the Dead, the figure of the zombie had been entirely transformed. As with the social forces they are supposed to represent, zombies had been transformed from the clumsy, sluggish, almost comical figures first presented by Romero in Night of the Living Dead (1968), into ferocious machines able sprint indefinitely, with full force and at high speed towards their would be victims. In Danny Boyle's 28 Hours Later (2002), not only are the zombies able to sprint, they also have the ability to "virally infect" their would be victims with by spraying them from afar with projectile blood-vomit.

Steven Shaviro provides another example of an attempt to explore the cultural significance of this figure. Shaviro suggests that the prevalence of zombies in popular entertainment is a consequence, inasmuch as zombies would represent, the "tendential fall of the rate of profit" first explained by Marx. Shaviro writes, "Businesses expand by continually accumulating capital. More and more living labor is transformed into dead labor, through the extraction and realization of surplus-value, and the zombification of the work force. Productivity inereases, and prices are driven down, because the same amount of living labor is progressively able to produce more commodities, by setting more dead labor into motion. [...] At the tendential limit, nearly every last person in the world will have become a zombie. 'All you really need 
[...] is enough of an uninfected elite at the executive level to rake off the profits' everybody else can just founder in eternal indeadtedness [sic]." Steven Shaviro, Connected: Or What It Means to Ltve in a Network Society, (Minneapolis: University of Minnesota Press, 2003), 166. For Shaviro, then, zombies represent something like the impotence wrought upon workers by capitalist relations of production. Shaviro's observations also relate to Marx's analysis of automatic systems of machinery.

2.6. Concerning Stiblitz's remark, Galison observes that Freud, in his 1919 essay The Uncanny, protested too much when he argued no less than four times that it is not the conflation of the living with the dead that lies behind the experience of the uncanny in E. T. A. Hoffmann's "The Sandman" "The Ontology of the Enemy," 243). But ultimately, whether the uncanny results from "the idea of being robbed of one's eyes," as Freud argues, or the animation of a mechanical doll, as Freud's interlocutor Jentsch argues, is a moot question because in control societies, the uncanny will always come to the same thing in either case. The labor animating the automatic system of machinery cannot be traced back to the worker, and so this system appears to the worker as the living-dead, similar to Hoffmann's mechanical doll, Olympia. To the extent that this automaton would both appropriate the value living labor produces into svalue existing foritself' and further separate living labor from the processes of production, it appears-similar to the figure of the Sandman - to rob living labor of its eyes.

2,7. The terminology here could be confusing. The term "subjectification," as Deleuze uses it here, should not be confused with the term as it was used by Agamben earlier in section 2.2. Agamben's definition of subjectification (i.e., the disappearance of an "old" self and the emergence of a "new" self) corresponds to Foucault's concept of "individualization," not the "lines of subjectification" described here by Deleuze.

2.8. For an extended discussion on stupidity see Michel Foucault, "Theatrum Philosophicum," in Aesthetics, Method, and Epistomology, trans. Robert Hurley, ed. James D. Faubion, (New York: The New Press, 1998), 343-369, esp. 361-363.

2.9. This a thread is worth following, even if only because it suggests that the events and processes of subjectification already so familiar to political theory "are more or less the same thing" as brains. In his 1985 book, Cinema II. The Image Movement, Deleuze briefly traces this concept of brains, In a language as remote from that of neurology as any imaginable, Deleuze suggests that time travel films, such as Alain Resnais' 1968 time travel film, Je t'aime, Je t'aime, abandon the disciplinary "cerebral" model of brain for a new "cinema of the brain," the latter corresponding to the term brains as Deleuze uses it in his conversation with Negri. The former cerebral model of the brain, according to Deleuze, corresponds to the montage, a cinematic technique in which a series of images are edited into a sequence in order to condense time, space, or narrative. The suggestion here is that in a montage, as with the disciplinary brain, each image or sensation remains subject to an integral whole, that is, some horizontal organization of associations. Deleuze, Cinema 11,203. In the cinema of the brain, however, "we no longer believe in an association of images - -ven crossing voids; we believe in breaks which take on an absolute value and subordinate all association [...]. Internal sheets of memory and the external layers of reality will be mixed up, extended, short-circuited and form a whole moving life, which is at once that of the cosmos and of the brain, which sends flashes from one people to the other. Hence zombies sing a song, but it is that of life." Ibid., 209. The cinema of the brain, in other words, refigures brains as the "creativity of the:world," that through which the world and its colors are "aroused by new space-times," an infinite series of unrelated breaks and fractures. With the disciplinary brain, images and sensations remain bound to axes of association. With the cinema of the brain, however, these associations are abandoned or subordinated to the materiality of the images and sensations themselves. The inexplicable and irreducible passages between these disparate images and sensations, as they remain unbound from any axis of association, forms Deleuze's concept of brains as deployed in his conversation with Negri, that is, as something more or less the same as lines of subjectification and events. Brains, then, are the "two-way movement" between absolute inside and absolute outside, from one singulay sensation or image to another singular sensation or image. "Between the two," concludes Deleuze, "in the in-between, it is as if zombies peopled the brain*world for a moment." Ibid., 208. For an extended discussion of brains, see the final chapter "From Chaos to the Brain" in What is Philosophy?

This remark also relates to Appendix III, 2.5., that is, in relation to brains, the zombie becomes an even more appropriate analogy for the apparatuses of capitalism, because zombies eat brains. The film that best underlines this relationship between zombies and brains, then, is Dan O'Bannon's 1985 Return of the Living Dead. In one scene, for example, the protagonists, Ernie Kaitteribrunner (Don Calfa) among them, manage to tie down the naked torso of an elderly woman zombie and begin interrogating her: 
Ernie Kaltenbrunner: You can hear me?

1/2 Woman Corpse: Yes.

Ernie Kaltenbrumner: Why do you eat people?

1/2 Woman Corpse: Not people, Brains!

Ernie Kaltenbrunner: Brains only?

1/2 Woman Corpse: Yes.

Ernie Kaltenbrunner: Why?

1/2 Woman Corpse: The painl

Emie Kaltenbrunner: What about the pain?

1/2 Woman Corpse: The pain of being dead.

Ernie Kaltenbranner: (In disbelief, to his friends) It hurts... to be dead.

1/2 Woman Corpse: I can feel myself rot.

Ernie Kaltenbrunner: Eating brains, how does that make you feel?

1/2 Woman Corpse: It makes the pain go away!

Return of the Living Dead, directed by Dan O'Bannon, (Hollywood, CA: MGM, 1985), DVD.

I provide this comical scene simply in order to pull the following analogy from it: zombies, here an analogy for whatever apparatus, do not eat people, they eat brains, and they do so in order to make the pain go away. An apparatus, in other words, as imagined in the figure of the zombie, is shown to have an instinctive and a reflexive tendency towards eating brains.

2,10. Kittler's English translators used the phrase "discourse network" in order to translate Aufschriebesystem, a more literal rendering would be "writing-down-system."

2.11. This tertiary scheme (i.e., sovereignty, discipline, control) has already been discussed extensively, see Gailoway and Thacker, The Exploit, 35-36; Galloway, Protocol: How Control Exists After Decentralization, (Cambridge, MA: MIT Press, 2004), 3-5; Rose, Powers of Freedom, 233-235.

2.12. Nikolas Rose identifies an important starting point for my analyses when he suggests skepticism in relation to approaches that would frame this contrast between disciplinary and control societies in terms that are too excessively "epochal." In place of suggestions that a historically specific mechanics of power has been "erased or consigned to history," Rose suggests an approach that would examine changes in these mechanics by way of the new as it "emerges and operates alongside the old." Nikolas Rose, Powers of Freedom: Reframing Political Thought (Cambridge, England: Cambridge University Press, 1999), 173.

2.13. "Dividual" is the neologism Deleuze puts forward in "Postscript on the Societies of Control" to emphasize these unique mechanisms of inscribing of the body. The prefix in-, meaning "not" or "opposite of," is detached from its root dividual, so that this root is returned to its original meaning, from the Latin divider, "to distribute, to sejparate, to force apart." The citizens of control societies are dividuals: they are continuously in orbit and inscribed in a manner that is increasingly distributed, digitized, and easily optimized.

2.14. Nikolas Rose and Peter Miller suggest that government must be recognized as "not so much a matter of imposing constraints upon citizens as of 'making up' citizens capable of bearing a kind of regulated freedom." In the element of its historical positivity, in other words, personal autonomy is not the antithesis of government but "a key term in its exercise, [because] most individuals are not merely the subjects of power but play a part in its operations." Nikolas Rose and Peter Miller, "Political Power beyond the State," The British Journal of Sociology 43, no. 2 (1992): 174.

2.15. Deleuze, "Postscript" on the Societies of Control," 6. Deleuze defines "higher-order production" as follows: "It no longer buys raw materials and no longer sells the finished products: it buys finished products or assembles parts. What it wants to sell is services and what it wants to buy is stocks. This is no longer a capitalism for production but for the product, which is to say, for being sold or marketed. Thus it is essentially dispersive, and the factory has given way to the corporation" (6).

2.16. The statement appears in the draft material for Celan's 1960 Meridian speech, in the section titled "Grundlosigkeit und Abgrund." Paul Celan, Der Meridian: Endfassung, Vorstufen, Materialien: Tubinger Ausgabe, eds. Bernhard Boschenstein and Heino Schmull (Frankfurt: Suhrkamp, 1999), translated and quoted by Salminen in "Falling Upwards," 224. Salminen does not give a page number for the source.

2.17. Celan, "Wer auf dem Kopf geht, meine Damen und Herren, - wer auf dem Kopf geht, der hat den Himmel als Abgrund unter sich," in Selections, 161, translated and quoted in Saliminen, "Falling Upwards," 225.

2.18. I provide Figure 2 not only to help summarize/clarify the concepts I carry forward into the 
subsequent chapters; as such (and as with Figure 1), the figure also provides some indication as to how, in accord with the principle of free use or the method of positive feedback, this carrying-forward can be accomplished. Here, as with my excessive citations in this chapter, explanandum would become its own explanans, that is, an attempt is made to use the site in need of explanation freely, that is, as the explanation for itself from itself andin itself.

3.1.1. For example, this passage from the Phenomenology reads like a description of the concept behind Fourier analysis: "But the ceaseless activity of their own inherent nature makes them at the same time moments of an organic unity, where they not merely do not contradict one another but where one is as necessary as the other; and this equal necessity of all moments constitutes alone and thereby the life of the whole." Georg W. F. Hegel, The Phenomenology of Mind: Two Volumes in One, trans. J. B. Baillie (New York: Cosimo Classics, 2011), 2.

3.1.2. In response to a crisis of foundations in the field of mathematics that coincided with the major developments of Kittler's " 1900 ," Gottlob Frege, Bertrand Russell, and others attempted to deduce the principles of mathematics from axioms and inference, rules. To this end, Ernst Zermelo and Abraham Fraenkel began developing Cantor's algebra of sets into (what is today known as) ZFC set theory.

Initially, three opposing philosophies emerged in response to the crisis of foundations in mathematics: the logicism of Frege and Russell, the intuitionism or constructivism of L. E. J Brouwer, and the formalism of David Hilbert. Brouwer's intuitionism attempted to found mathematics in critical philosophy. From the standpoint of this foundational philosophy, mathematical propositions are understood as synthetic a priori propositions, and by extension, as founded in the subject. The formalism of Hilbert understood the propositions of mathematics as so many language games. When "carried out according to certain definite rules," Hilbert explains, "this formula game enables us to express the entire thought-content of the science of mathematics in a uniform manner and develop it in such a way that, at the same time, the interconnections between the individual propositions and facts become clear." David Hilbert, "The Foundations of Mathematics" (1927), in The Emergence of Logical Empiricism: From 1900 to the Vienna Circle, ed. Sahotra Sarkar (London: Taylor and Francis, 1996), 475. As disparate as these three opposing philosophies are, none of them, with a few exceptions concerning details, would find anything objectionable about the axioms of ZIFC. Whether they found mathematics on logic, synthetic a priori judgments, or a game of formulas, these three schools are all in agreement on the necessity of some suppositions regarding identity, quantity, and transitivity.

The collectivist philosophy of Saul Kripke extends Hilbert's notion of "formula games" outward onto the social collectives within which such games are played. Kripke begins from Wittgenstein's remarks about language games in Philosophical Investigations: "This was our paradox," states Wittgenstein, "no course of action could be determined by a rule, because every course of action can be made out to accord with the rule. The answer was: if everything can be made out to accord with the rule, then it can also be made out to conflict with it. And there would be neither accord nor confliet here." Ludwig Wittgenstein, Philosophical Investigations, eds. P. M. S. Hacker and Joachim Schulte (New York: Wiley, 2010), cxcvii. The example Kripke provides in order to explain this paradox is instructive. "Let me suppose," writes Kripke, "that ' $68+57$ ' is a computation I have never performed before [...]. I continue the computation [...] obtaining, of course, the answer 125." Saul A. Kripke, Wittgenstein on Rules and Private Language (Cambridge, MA: Harvard University Press, 1982), 8.

In his hypothetical example, Kripke next encounters a "bizarre skeptic" who suggests that in keeping with the way Kripke had used the term "plus" in the past, that is, before performing the present computation " $68+57$," Kripke should have obtained the solution 5 instead of the solution -125 . "Who is to say that this is not the function I had previously meant by '+'?" asks Kripke, "[and that] now, under the influence of some insane frenzy, or a bout of LSD, I have come to misinterpret my own previous usage [...]. If I use language at all, I cannot doubt 'plus,' as I now use it, denotes plus! Perhaps I cannot [...] doubt this about my present usage. But I can doubt that my past usage of 'plus' denoted plus? The previous remarks - about frenzy and LSD-should make this quite clear." Ibid., 13. Kripke's example demonstrates that the formal quality of any formula can be understood in terms of the collective norms implicit to the social relations within which that formula is presented.

David Bloor, similar to Kripke, understands formal languages in terms of social relations. "Certain conditions have to be obtained," writes Bloor, "before a computation has any meaning. These conditions are social in the sense that they reside in the collectively heldisystem of classifications and meanings of a culture." David Bloor, Knowledge and Social Imagery (Chicago: University of Chicago Press, 1991), 124. 
One example Bloor provides involves the disparate understandings of algebra articulated in the nineteenth century, in the first case, by William Rowan Hamilton, and in the second case, by George Peacock and other mathematicians at Cambridge University. As with Brouwer a century later, Hamilton was inspired by German idealism: "He adopted the Kantian view that mathematics is synthetic a prioni knowledge," Bloor explains, "[where] mathematics derives from those features of the mind which are mnate and which determine a priori the general form that our experience must take. Thus geometry unfolds for us the pure form of our intuition of space [and] algebra the science of pure time." David Bloor, "Hamilton and Peacock on the Essence of Algebra," in History of Nineteenth Century Mathematics, eds. H. Mehrtens and H. Schneider,(Ann Arbor: University of Michigan, 1981) 217.

The "practical import" of Hamilton's idealism, according to Bloor, "was to place mathematics as a profession in a relation of general subordination [...]. Algebra, as Hamilton viewed it, would always be a reminder of, and a support for, a particular conception of the social order. It was symbolic or an 'organic' social order of the kind which found its expression of Coleridge's work." Ibid. The Cambridge group, on the other hand, was a group of protoformalists who "suggested that mathematical symbols and the systems in which they were embedded were sufficient unto themselves, in need of no extra-mathematical foundations and subject to whatever interpretation proved appropriate to specific uses." Tbid.

Bloor suggests that the members of the Cambridge school were "reformers and radicals." Ibid., 222. By rebelling against tradition and authority and imposing independence onto their symbols, they were freeing themselves from authority and control. Bloor summarizes:

Stated in its broadest terms, to be a formalist was to say: "we can take charge of our selves." To reject formalism was to reject this message. These doctrines were, therefore, ways of rejecting or endorsing the:established institutions of social control and spiritual guidance, and the established hierarchy of learned professions and intellectual callings. Attitudes towards symbols were themselves symbolic, and the messages they carried were about the autonomy and dependence of the groups which adopted them. Ibid., 228.

These opposing philosophies of algebra, according to Bloor, served to support opposing social programs and values. "[n]n our social life," writes Bloor, "we are always putting pressure on our fellows and seeking to evade that pressure ourselves [...]. In order to do these things:we try to make reality our ally, showing how the nature of things supports the'status quo, or how the established social order is at odds with what is natural." Ibid., 231. Similar to Kripke, Bloor postulates a social dimension of formal languages. Bloor, however, approaches this dimension sociologically, viewing formal languages as instruments used by selfinterested social agents in order to make reality their ally.

3.1.3. For example,

The AXIOM OF THE POWER SET. For any $X$ there exists a set

A set $U$ is a subset of $X, U \subset X$, if

$$
Y=\mathbb{P}(X): \forall X \exists Y \forall u(u \in Y \leftrightarrow u \subset X) \text {. }
$$

$\forall z(z \in U \rightarrow z \in X)$.

The set of all subsets of $X, P(X)=\{u: u \subset X\}$, is called the power set of $X$.

The axiom of the power set reminds us that a set does not necessarily include all of its subsets. For example, consider the set $X=\{a, b, c\}$. The power set of $X, \mathbb{P}(X)=\{\emptyset,\{a\},\{b\}$, $\{c\},\{a, b\},\{a, c\},\{b, c\},\{a, b, c\}\}$ includes all the subsets of $X$, while $X$ itself does not.

AXIOM OF FOUNDATION. Every nonempty set has an $\in$-minimal element: $\forall S(S \neq \emptyset \rightarrow(\exists x \in S) S \cap x=\emptyset)$.

Also called the axiom of regularity, this axiom implies that certain sets do pot exist. More specifically, any set without a "limit" in relation to its potential decomposition into subsets. Jech emphasizes this restriction on the universe of sets, in addition the axiom's irrelevance for ordinary mathematics. "However," writes Jech, "[the axiom] is extremely useful in the meta-mathematics of set theory, and in the construction of models. In particulap, all sets can be assigned ranks and can be arranged in a cumulative hierarchy." Jech, Set Theory, 63. For'Badiou, as well, this irrelevance bears emphasis, Badiou, Being and Event, 187. In relation to the axiom of foundation, we see that if $S$ is not equali to $\emptyset$, then the intersection of $S$ with at least one of its elements is precisely $\emptyset$. For Badion, this implies that given any nonempty set, at least one of its subsets "stands at the edge of the void," that is, at a point of excess . Moreover, the subsets of any set can be endlessly re-presented or decomposed (i.e,, separated-and classified), and the limit of such re-presentations and decompositions, in any case, would be the empty set. 'Applied to a situation-in which 'to belong' means: to be [...] presented," writes Badiou, "the theorem of the point of excess simply states: there are 
always sub-multiples which, despite being included in a situation as compositions of multiplicities, cannot be counted in that situation as terms, and which therefore do not exist." Ibid., 97.

3.1.4, We might consider the example of undocumented residents in terms of "mathematical" concepts in the work of Deleuze. In what he describes as an attempt to "formulate a materialist theory of race," Arun Saldanha "[builds his] conceptual apparatus with ample aid from Deleuze, who, unlike most theorists of race and colonialism, doesn't ground his thought in negativity and representation." Arun Saldanha, Pyschedelic White: Goa Trance and the Viscosity of Race, (Minneapolis: University of Minnesota Press, 2007), 9. As a supplement to Badiou's set theory, then, within which the undocumented resident is figured on the basis of re-presentation, Saldanha provides a differential topology of such figures as "[emerging] when bodies with certain characteristics become viscous through the ways they connect to their physical and social environment." Ibid. Psychedelic White is an ethnography, and Saldanha's field work, in this instance, involved visiting a large open-air party for tourists in Anjuna, a Goan village, in order to catalog the "practices of white tourists in Anjuna and their exoticist relationship to India." Ibid., 47. "Observing again and again that certain spaces and times tended to attract hippies and ravers," writes Saldanha, "which then made these spaces and times relatively impenetrable for Indians, I needed a concept to account for both the attractive forces between white tourists and the surface tension that enveloped them, without losing sight of the possibility that the boundaries could be (and were regularly) transgressed. [...] Viscosity is a decidedly materialist way into the virtual topology, the abstract machine of social space." Ibid., 49. In terms of Saldanha's "Deleuzian" conceptualization, then, undocumented residents could be conceptualized through viscosity, where it is no longer a question of re-presentation or inclusion, but rather a question of speeds and slownesses: "viscosity explains why music, ways of dancing, clothing, architecture, the beach, stereotypes, the psychohistories of colonialism, the distribution of light and money power together make white bodies stick and exclude others. Viscosity is about how aggregate bodies hold together, how relatively fast or slow they are, and how they collectively shape the aggregate." Ibid., 50 . The field notes Saldanha provides substantiate the productiveness of this conceptualization: the whites, Indians, Israelis, and others observed by Saldanha, emerge as so many aggregate flows of relatively different speeds and densities. Saldanha observes the audience at this open air party and documents the assemblage of whites, the assemblage of Israelis, and the assemblage of locals. Each of these assemblages, observes Saldanha, seem to abide their own rates of flow, their own density, and their own degree of surface tension in the sense that the locals were much more likely to escape their aggregation and flow about according to their own rule, in these that the Israelis were the least likely to escape such flows, and so on. As with a chromatograph, then, a chemistry apparatus that separates mixtures into their constituent elements on the basis of their relative speeds through an eluent, a "people" here emerges through the relative speeds and slownesses of its movements. Approached in these terms, the undocumented resident would not be conceptualized as the singularity who belongs but is not included, but rather as the singularity around which an assemblage of bodies, or a "people," precipitates in its relative density, speed

3.1.5. c.f., the struggles in France surrounding the sans papiers (undocumented residents), concerning which Badiou and his political group, L'Organisation Politique, declare: "if you live here, then you're from here!"

3,1.6. A more specific and elaborate account of exactly how Badiou discerns an image of police and politics in ZFC remains beyond the scope of my dissertation. Put simply, and somewhat inexactly, Badiou equates presentation (i.e., the count) with the infinite set $\omega$; and re-presentation (i.e., the count of the count) with the power set that infinite set $\mathbb{P}(\omega)$. A famous proof of Cantor demonstrates that the powerset of an infinite set is, counter-intuitively, "larger" than the original set. In ZIFC, in other words, there are an infinity of infinites, "Cantor's Paradise," and each infinity is infinitely greater or lesser than the other:

$$
\forall|x|:|x|=\infty,|x|<|\mathbb{P}(x)| .
$$

Cantor used the Hebrew $k$ to represent this transfinite series: $k_{0}<k_{1}<\cdots<k_{n}$. This, then, is Cantor's theorem, and following from it, Cantor's Contimum Hypothesis (CH):

$$
x_{n+1}=\mathbb{P}\left(\kappa_{n}\right) \text {. }
$$

The $\mathrm{CH}$ is the hypothesis that there is no infinite cardinal set between the initial infinite set $\omega$ or $\mathrm{x}_{0}$ and the power set of that set $\mathbb{P}(\omega)$ or $\mathrm{x}_{1}$. "The set of [the subsets] of a set is 'more numerous' than the set itself," writes Badiou, "but by how much? What is this excess worth, apd how can it be measured? In the finite, the problem is simple: if a set possesses $n$ elements, the set of its [subsets] possesses $2 n$ elements [...]. But what happens if the set in question is infinite?" Badiou continues: 
That it is necessary, in the end, to decide upon this power introduces randomness into the heart of what can be said of being. Action receives a warning from ontology: that it endeavours in vain when it attempts to precisely calculate the state of the situation in which its resources are disposed. Action must make a wager in this matter, rather than a calculation; and of this wager it is knownwhat is called knowledge-that all it can do is oscillate between overestimation and underestimation. The state is solely commensurable to the situation by chance. Badiou, Being and Event, 278.

The question, in other words, is thisi if we equate a situation, a presentation, with $\mathrm{x}_{0}$ and the state, or representation with $\mathbb{P}\left(\kappa_{0}\right)$ or $\kappa_{1}$, then what is the measure of the excrescence $x_{1}$ holds over $\kappa_{0}$ ? According to the $\mathrm{CH}$, the measure is exactly this: $\mathrm{K}_{1}=\mathbb{P}\left(\mathrm{K}_{0}\right)$. Badiou's answer to this question, that the measure of this excrescence is a wager or a choice, can only be explained in terms of the axiom of choice.

AXIOM OF CHOICE. Every family of nonempty sets has a choice function. If $S$ is a family of sets and $\emptyset \notin \mathrm{S}$, then a choice function for $S$ is a function $f$ on $S$ such that:

for every $X \in S$.

$$
f(X) \in X
$$

The axiom of choice postulates that for every $S$ such that $\emptyset \notin S$ there exists a function $f$ on $S$ that satisfies the expression above. Jech points out that the axiom of choice differs from other axioms of ZFC because it postulates the existence of a set (i.e., a choice funetion) without defining that set. This too, is exactly what Badiou draws attention towards. "For in the other axioms," writes Badiou "the type of connection between the first multiple and the second is explicit." Badiou, Being and Event, 226. Meaning, for example, that the axiom of the power set indicates that we can construct of a set $\mathbb{P}(A)$ upon the basis of $A$, while the axiom of separation indicates that we can construct some subset $a$ of A. With the axiom of choice, however, the choice function that is posited is not in any way defined. Badiou suggests this axiom is axiomatic to notions of "intervention" into any situation. "All that it can specify is a from-multiple," Badiou writes, "that of a function, whose existence, despite being proclaimed, is generally not realized in any existent. The axiom of choice tells us: 'there are some interventions.' The existential marking-that contained in the 'there are'cannot surpass itself towards a being, because an intervention draws its singularity from that excess-of-onethe event-whose non-being is declared by ontology." Tbid., 230.

To understand more fully what is meant here, we need consider one more idea of set theory, that of forcing. The main idea of forcing is that the ground modef M of ZIFC set theory can be extended by adjoining a new generic set $G$ in order to obtain a larger model, or generic extension, of set theory MIG]. This generic set is approached by forcing conditions in the ground model by way of the axiom of choice. Paul Cohen first introduced forcing in his proof of independence of the $\mathrm{CH}$ and of the axiom of choice from ZFC. Cohen began with a countable transitive model M of ZFC (and a set of forcing conditions in M), and, from this, he proved the existence of generic set M[G], on the basis of which the $\mathrm{CH}$ fails. Because the $\mathrm{CH}$ fails once the forcing of conditions in ZFC is admitted, Badiou suggests that forcing conditions is the generic image of doing polities, the space where the excrescence $k_{1}$ holds over $k_{0}$ is re-determined or decided.

3.1.7. The doxa that such consideration (i.e., the consideration of a worm by a human being) would be nothing eise than utter disregard could aiso be compared with St. Francis of Assisi: "He removed from the road little worms, lest they be crushed underfoot." Thomas of Celano, St. Francis of Assisi, (Chicago: Franciscan Herald Press, 1988): 124.

3.2.1. In addition to any soporific utility, Shulgin's auto-experiments also precluded any hocuspocus around something "more truthful than the real." Here, I have in mind a passage from Foucault's article "Theatrum Philosophicum." This article, among other things, contains Foucault's famous remark to the effect that "perhaps one day this"century will be known as Deleuzian," and so Arun Saldahna has drawn attention to Deleuze's own notes on the article, specifically, pext to the passage given below, Deleuze wrote: "what will people think of us?"

We can easily see how LSD inverts the relationships of ill humon stupidity, and thought: it no sooner eliminates the supremacy of eategories than it tears away the ground of its indifference and disintegrates the gloomy dumbshow of stupidity; and itpresents this univocal and acategorical mass not only as variegated, mobile, asymmetrical, decentered, spiraloid, and reverberating but causes it to rise; at each instant, as a swarming of phantasm-events. As it slides on this surface at once regular and intensely vibratory, as it is freed from its catatonic chrysalis, thought invariably 
contemplates this indefinite equivalence transformed into an acute event and a sumptuous, appareled repetition. [...] Drugs-if we can speak of them generally have nothing at all to do with truth and falsity; only to fortune-tellers do they reveal a world "more truthful than the real." In fact, they displace the relative positions of stupidity and thought by eliminating the old necessity of a theater of immobility. But perhaps, if it is given to thought to confront stupidity, drugs, which mobilize it, which color, agitate, furrow, and dissipate it, which populate it with differences and substitute for the rare flash a continuous phosphorescence, are the source of a partial thought, perhaps. Michel Foucault, "Theatrum Philosophicum," Aesthetics, Method, and Epistomology, trans. Robert Hurley, ed. James D. Faubion, (New York: The New Press, 1998), 363.

3.3.1. "Postscript on the Societies of Control" does not mention the classical societies Foucault describes in The Order of Things. Classical societies, according to. Foucault, could be said to form the pivot between societies of sovereignty and disciplinary: a transformation corresponding to the Enlightenment. It was during this period that elegant new taxonomies appeared (i.e., toxconiomia, e.g., of the Linnaean variety), in addition to a new rhetoric upon the order (i.e., mathesis) and natural genesis (i.e., the genetic analysis) of things. In his monograph on Adam Smith, Michael Shapiro observes the correspondence between this transformation and an exchange impulse, which answered to the newly emerging market economies. "To put it abstractly and comprehensively," writes Shapiro;

The sovereignty impulse tends toward drawing firm boundaries around the self in order unambiguously to specify individual and collective identities, to privilege and rationalize aspects of a homogenous subjectivity that is eligible for memberships and recognition and to constitute forms of non-identical and ineligible otherness, and to specify and bound both spaces in which subjects achieve eligibility and the space in which the collective as a whole has dominion. In contrast, the exchange impulse encourages flows and thus (often) the relaxation of specifications of eligible subjectivities and territorial boundaries. The opposition between flows of exchange and the inhibitions of sovereignty is oriented around issues of selfhood and location, and consequently involves an emphasis either on ownership and the maintenance of authority and control or on reciprocity, substitutability, and the relaxation of control in order to produce expanded domains in which things circulate. Shapiro, Reading Adam Smith, 2.

In contrast to the blood lineage of the guild structures, in other words, the exchange impulse necessitated the relaxation of specifications, substitutability, and expanded domain within which things might circulate. The identity of the subject could no longer be grounded in the fixed estates of the societies of sovereignty, observes Shapiro, because "exchange orientations operate as if the value produced is independent of the symbolically ordered identity structures and domains within [...] exchanges occur." Ibid., 28.

According to Foucault, along with mathesis, taxinomia, and genetic analysis; classical societies were also characterized by a mimetic duality as between Nature and rhetoric. "Rhetoric did not enunciate the laws or forms of a language," explains Foucault, "it established the relationship between two forms of speech: the first, mute, indecipherable, fully present to itself, and absolute; the other, garrulous, had only to voice this first speech according to forms, operations, and conjunctions whose space measured its distance from the first and inaudible text." Foucault, Aesthetics, Method and Epistemology, 100. In Discourse Networks 1800/1900, Kittler refers to classical societies as the "Republio of Scholars," and he elucidates the rhetoric implicit to these societies in terms of Protestant philology. "Humanism proceeded as philological activity," writes Kittler, "and philology means love of the Word. Luther's belief in and translation of the Bible were obedient to the rule of sola scriptura and meant in a quite practical sense that students in the catechumenical schools that arose along with the Reformation had to be able to learn sacred texts by heart and 'recount' them 'word for word." Kittler, Discourse Networks 1800/I900, 10. The rhetoric Foucault suggested as characteristic of classical societies is thus situated by Kittler partly in the reading practices fostered by the Reformation.

3.3.2. Kittler describes the transition from classical to disciplinary societies as the transition from the "Republic of Scholars" to the "Scholar's Tragedy. Here, representation had to find a new way of relating to itself. The liniking of the signified with a word, for instance, requires the comprehension and use of linguistic grammar, which grammar is part of a meticulous system quite separate from any word's ability to represent a signified or the language as a whole to serve as a set of referential signs. Before this transition to a new age, "languages had a grammar because they had the power to represent; now they represent on the basis of that grammar, which is for them a sort of historical reverse side, an interior and 
necessary volume whose representative values are no more than the glittering, visible exterior." Foucault, The Order of Things, 257. The characterization of a living being, likewise-the reconciliation of "a partial structure" with confrontation of the fact of that living being as a whole-now must be achieved by resorting to "purely biological laws,", which, again, "apart from all descriptive signs and as it were set back from them, organize the relations between functions and organs." Ibid., 258.

Describability no longer represents and defines living beings and their familial relationships or similarities with other beings. Rather than appearances on the surface, an outwardly invisible, mysterious physical structure characterizes what being are. Language indeed has access, to this new way of representation, to this "dark, concave, inner side of [the] visibility [of living beings]: it is on the clear and discursive surface of this secret but sovereign mass that characters emerge, a sort of storehouse exterior to the periphery of organisms now bound in upon themselves." Ibid., 258. With regard to value determination of a commereial object, Foucault demonstrates that the pattern is, once again, the same: form and quantity are essential in assigning worth to a work. Rather than basing itself on supply and demand:and the trading of other needed objects (all of which can be cleanly measured and the results of these measurements entered neatly into tables and graphs), the hierarchy of valuation is now determined by an inner characteristic, labor, which has "silently lodged itself within [an object]."Ibid. The time required in "manufacture, extraction, or transportation" determines the worth, marketability, and "internal law" of a thing, in other words, its "real price." Ibid., 258.

The classical political economists, for example, had already begun to imagine that value, labor, and even population, could be abstracted from concrete social relations. The classical taxinomia, once drawn up as so many images of a mute Nature, began to present questions in themselves in correspondence with this exchange impulse or the increasingly complex relations of exchange. Man, as the societies of classicism took him for granted, was now in need of explanation. This is the difference, then, between the English madrigal of sovereignty in Hobbes' 1651 Leviathan and the elegant taxonomy of the categories in Kant's 1781 Critique of Pure Reason. The former book inscribes Man as something self-evident. The latter book, however, inscribes the subject as something only deducible through the critical science.

Ian Biddle's 1995 study (Ian D. Biddle, "Autonomy, Ontology and the Ideal: Music Theory and Philosophical Aesthetics in Early Nineteenth-Century German Thought" [doctoral dissertation, University of Newcastle-upon-Tyne, 1995]) offers a clear discussion of the classical episteme as it was manifest in Rameau and his German contemporaries, the aesthetic theorists Bateaux and Gottsched. Biddle's work, which explicitly follows Foucault's-method, analyzes the texts these scholars produced; in so doing, Biddle not only reveals the discernible presence of mathesis, taxinomia, and genetic analysis in these works, but also demonstrates how it was that the classical societies contained the seeds of their own undoing into the societies of discipline.

Biddle begins his inquiry into the nature of the relationship between music theory and "the epistemological framework of the commodity equivalence paradigm" by wondering to what extent twentieth-century understandings of the "aesthetie landscape of the period" are influenced by the fact that the texts available for examination are "introspective discourses of the literate classes." Ibid., 79. Despite the quest for an authentic sense of universality in post- 1750 theoretical literature, Biddle maintains, the attempt to determine a comprehensive prescription as to music's internal structure- the "drive for a kind of musical ontology" -inescapably considered written-down, upper-class European music almost exclusively, with insufficient (if any) attention paid to musics conveyed by traditional oral methods. Ibid., 79-80. However, although the bourgeois experience is given undue weight in aesthetic theoretical texts of the time-which fact is reflective of the "ontological impulses of an, as yet, still isolated Gelehrtenstand" Ibid., 80 . and not of the "overriding authenticity" for which their authors were striving - the theoretical works examined here, while inherently elitist, are useful in helping modern readers to develop an idea of the internal (and, again, self-conscious and privileged) discourses presumed to reflect the whole of eighteenthcentury politico-aesthetic experience, Ibid., 80.

The neatly defined Cartesian tradition upon which French aesthetic thought of the time was based had little to do with the still "qualsi-feudal infrastructure of the German-speaking lands." Ibid., 80 . According to Biddle, Fernand Braudel's description of the common man as still "an unconscious prisoner of the frontier marking the inflexible boundaries between the possible and the impossible" Ibid., 80, Braudel, Capitalism and Material Life, New York, 1973, xiv, was applicable to the ordinary German citizen through the greater part of the eighteenth century. The obstifiate monarchical tradition, in other words, persisted in the German collective consciousness until at least the beginning of the revolutionary period, providing the mimetic notions of the Cartesian thinkers little purchase in its world of immobile social order. 
Ibid., 80. "The [classical] mimesis paradigm in Germany," explains Biddle "represented much more a part of this intransigent order insofar as it was imbued with a profound sense of the impenetrable materiality of social order." fbid., 81 .

Indeed, Biddle goes on to draw a distinction between French rationalist attitudes toward music-that is, as a "mirror of nature" and an opportunity for the expression of mimetic, naturalist human emotions-and German readings of mimesis theory, which were grounded in a certain hopelessness regarding German experiences of social fixity as opposed to the "broader [French] drive for the clarification and radical reordering of the external world." Ibid., 81. The French rationalism that generated such works as Rameau's 1722 Traite, the attempt to apply deductive-reductive-Cartesian methods to the systemization of musical harmony, in fact, led inevitably to the breakdown of the system itself. Ibid., 81 . A microcosmic representation of the concurrent demise of the cohesive classical societies into a fragmented societies of discipline and their concomitant exchange impulse.

We can see how the transformation into disciplinary societies would soon come about, following Biddle suggestions, through Rameau, In trying to provide a system of ordering harmony based on Cartesian notions of clarity and intelligibility, Rameau had, to some extent, undermined quite fundamentally the basic tenets of classical mimetic theory. With Rameau's Traité, music begins to turn inwards on itself away from external reality and representation. And so one can see how the Cartesian world vision destroyed itself from within: the will to encompass everything within the domain of the intelligible took mankind into the center of the object and there lost all sense of the visible. In Rameau, following from Mersenne's mathesis of the Harmonie universelle (1636) the turn inwards came from the burning curiosity of Cartesian science. Rameau's system-a profoundly reductive and yet ontological methodology-instigated in part this loss of the "visible" in music theory. It was now legitimate to attempt to find out how the "system" of music not only represented nature as understood by the baroque Cartesian elite, but also to question how its "internal" physical properties related to those of nature. The notion of semiological fixity and separateness in this question began to necessitate ever greater levels of ontological analysis before the nature of the relationship could become clear.

3.3.3. The composer Arnold Schoenberg regarded "medieval modes as a primeval error of the human spirit." Quoted in Glenn Gould, "Portrait of a Cantankerous Composer," The Globe and Mail, March 18, 1978.

3.3.4. In 1987, feminist musicologist Susan McClary famously stirred controversy by approaching these forms in relation to their constructions of "Woman." McClary suggests that the sonata form can be interpreted as patriarchal and that "tonality itself-with its process of instilling expectations and subsequently withholding promised fulfillment until climax-is the principal musical means during the period from 1600 to 1900 for arousing and channeling desire." Susan McClary, Feminine Endings (Minneapolis: University of Minnesota Press, 1991), 12. She interprets the sonata form in terms of its constructions of gender and sexual identity. The primary, "masculine" theme represents the male self, while the secondary, "feminine" key represents the other, a territory to be explored and conquered, assimilated into the self and stated in the tonic home key. In relation to the first movement of Beethoven's Symphony No. 9 in D minor, Op. 125, McClary notes: "The point of recapitulation in the first movement of the Ninth is one of the most horrifying moments in music, as the carefully prepared cadence is frustrated, damming up energy which finally explodes in the throttling murderous rage of a rapist incapable of attaining release." McClary, Feminine Endings, 8.

The crescendo (i.e., bars 240-283) of the development section of the first movement (Allegro con brio) of Symphony No. 3 in E-flat major, Op. 55, seems to fit MoClary's description (e.g., frustrated, a damming up energy [exploding] in throttling murderous rage) much better than does the point of recapitulation of the first movement of Symphony. No.9. Of course, already by his third symphony, Beethoven had abandoned the convention of using only two themes, but even so, from the position of the discourse McClary is considering here, the "new theme" that appears in bars 288-303 would have almost certainly been described as "feminine," especially as it is placed in juxtaposition with the "masculine" proper first theme of the movement. In any case, this new "feminine" theme would only seem to calm the "masculine" theme (bars 304-333) after his "throttling murderous rage," even to the point of reassurance, providing the "masculine" theme new strength and joy after the breakdown at the crescendo. This backand-forth between "feminine" (bars 334-341) and "masculine" (342-399) is repeated twice, until the recapitulation (400) where the heroic "masculine" theme returns in all of his glory, fully confident once again.

In relation to " 1800 " constructions of "Woman," in other words, the implicit violence described by 
Kittler (e.g., the repositioning of the Mother, the Mother's mouth, etc.) would seem more apropos in relation to Beethoven than the explicit violence (i.e., rape) described by McClary. "Woman" in Beethoven's Third (i.e,, the tender, bittersweet "feminine" theme [288-303]) only caims the "mad hero," as his muse, his affectionate Mother, his "Other," which he does not so much rape as he does sing for/to (although, perhaps still without acknowledging as agent in her own right). In his letters, as much as in his music, Beethoven speaks to "Woman" in "1800": "Music should strike fire from the heart of man, and bring tears from the eyes of woman." Perhaps it is too easy, or hardly worth pointing out, that in Beethoven's sentiments we find both of the elements crucial to the "Scholar's Tragedy" as Kittler outlines them: "fire in the heart of man" and "tears from the eyes of woman." The project of "1800," according to Kittler, was to replace rote learning with "understanding." And in this, he insists, mothers assumed strategic positions. The " 1800 " system of equivalents "Woman $=$ Nature $=$ Mother" came about, Kittle maintains, largely through pedagogical media such as ABC books and their concomitant processes of acculturation in which the "Mother" was figured as an absolute origin (i.e., by teaching the child how to pronounce syllables, it was from the Mother's mouth that speech, for the child, and thus entry into language as such, began).

A culture established on this basis speaks differently about language," claims Kittler, "writes differently about writing. Briefly put, it has Poetry. For only when phonetics and the alphabet shortcircuit the official route from a natural source to those on the receiving end can a kind of speech arise that can be thought of as an ideal of Nature. This placing of mothers at the origin of discourse was the condition of production for Classical poetry, and the Mother was the first Other to be understood by poetical hermeneutics [...]. What is important are not biographical mothers with their coinedies and tragedies, but the mothers and midwives of a completely new $\mathrm{ABC}$ book; not the transformation of dreams or desires, but a new technique of transcription that determines writing. "'In the beginning' was, not the Act, but the ABC book." Kittler, Discourse Networks $1800 / 1900,29$.

Where better can we find the "Republic of Scholars" undone in its tragedy than in Beethoven? The "minimal signified" of Woman and Nature were, according to Beethoven, the "school of [his] heart." Beethoven, personal diary, 1818, copied from Christoph Christian Sturm, Betrachtungen über die Werke Gottes in der Natur. "It is well; I shall be a scholar in this school and bring an eager heart to her instruction. Here I shall learn wisdom, the only wisdom that is free from disgust; here I shall learn to know God and find a foretaste of heaven in His knowledge. Among these occupations my earthly days shall flow peacefully along until I am accepted, into that world where I shall no longer be a student, but a knower of wisdom." Ibid.

Kittler refers to the rise in the Aufschreibesysteme of maternal instruction as "the input component of elementary acculturation techniques." Kittler, Discourse Networks, 27. These books, which appeared beginning around 1800 , intended to instruct mothers as to how to educate their children from birth through the age of early literacy. Kittler provides a long list of authors and titles which, indeed, require no further explanation. Among them are: Samuel Hahnemann, Handbook for Mothers, or Rules for the Early Education of Children (after the Principles of J.J. Rousseau) (1796); Christoph Wilhelm Hufeland, Good Advice for Mothers on the Mast Important Points of Physical Education in the First Years (1799); and Johann Heinrich Pestalozzi, How Gertrude Teaches Her Children, an Attempt to Provide Guidance for Mothers in the Self-Instruction of Their Children (1801). Such books "emphasize that it is only by conferring elementary acculturation techniques on mothers that the Self of this identity has been found." Ibid., 28. Kittler asserts that "by addressing themselves to mothers the pedagogical tracts and primers shortcircuited [sic] existing official channels." In "1800," everything from social mores to learning the alphabet would now be taught and learned by individuals in a natural setting, something to be celebrated, given that there was no "central locus of acculturation that could claim legitimacy in Nature;" the 1800 synonymization of Woman and Nature drastically changed the nature of discourse by bypassing "the official route:" to do so, according to Kittler, endows a culture with Poetry. If the mother, a natural source, teaches her ehild, then the speech that that child learns "can be thought of as an ideal of Nature." Ibid., 28.

The goal of the mother's primer, Kittler suggests, was "to replace rote learning with "understanding'" and to do the same to letters that Faust had done to words. Ibid., 28. Crucial here to Kittler are not the mothers themselves, but their relationship to a "completely new $\mathrm{ABC}$ book;" the point is "a new technique of transcription that determines writing." "In the beginning" was, not the Act, but the ABC book." Ibid., 29.

In American musical pedagogical texts contemporaneous with these German maternal primers, the tendency Kittler describes above encouraged can be found as well. In the Manual of the Boston Academy of 
Music: for instruction in the Elements of Vocal Music (1839) by Lowell Mason, not only do we find emphasis upon the use of music towards an explicitly disciplinary end- "The course of instruction pursued in the Manual, is INTELLECTUAL and DISCIPLINARY. The mind is exercised and disciplined by it, as by the study of arithmetic; and the voice by training and speaking. It tends to produce habits of order, both physical and mental" Lowell Mason, Manual of the Boston Academy of Music: far instruction in the Elements of Vocal Music (Boston: Wilkins and Carter, 1839), 23.-we can also see the new position of the Mother in Mason's appeal that she teach her child "the simplest, and, at the same time, the richest truths, by means of sacred song." When the young person reaches a crossroads, "the little hymn chanted by a fond mother" can help ensure that he stays on the proper path to righteousness. Ibid.

3.3.5. In other words, Webern's music was, above all, contrary to work that would then be carried out in its name. Adorno provides examples from Webern's-work; and even Webern's extra-musical writings and letters to the end of defending his contentions here. What is more interesting from the standpoint of my analyses, however, is the manner in which Adorno then ties all of this back into correspondences with critical philosophy. Adorno draws our attention, for example, to a "disconcerting phrase" from Hegel's Phenomenology, the "firy of disappearance." Adorno then claims that Webern's work "converted this fury into his angel." In order to elucidate this remark, in addition to returning to a theme that has been running through my analyses from the section on Beethoven, Adorno compares Webern's work with the writings of Walter Benjamin, both of whom, according to Adomo, shared a "penchant for the micrological and the confidence that the concrete concentration of a fulfilled moment is worth more than any amount of development that is merely ordained from the outside. The signatures of the two men, the philosopher and the musician who was fanatically tied to his material, two men who did now know each other or even much about each other, were nevertheless similar. Both were like letters received from a kingdom of dwarves in miniature format, which always looked as if they had been reduced from something of vast dimensions." Theodor Adorno, Sound Figures, trans. Rodney Livingstone, (Stanford: Stanford University Press, 1999), 94. Here, then, I present an aphorism from One Way Street, a collection of Benjamin's writings, which could easily serve as the programmatic description of many of Webern's work:

Noises. High in the empty streets of the barbour district they are as densely and loosely clustered as butterflies on a hot flower bed. Every step stirs a song, a quarrel, a flapping of wet linen, a rattling of boards, a baby's bawling, a clatter of buckets. Only you have to have strayed up here alone, if you are to pursue them with a net as they flutter away unsteadily into the stillness. For in these deserted corners all sounds and things still have their own silences, just as, at midday in the mountains, there is a silence of hens, of the axe of the cicadas. But the chase is dangerous, and the net is finally torn when, like a gigantic hornet, a grindstone impales it from behind with its whizzing sting.

Walter Benjamin, "One Way Street" in Reflections: Essays, Aphorisms, Autobiographical Writings, trans. Peter Demetz, (New York: Schocken Books, 1986), 132.

4.1. A new "school" of philosophy, post-structuralism, emerges in correspondence with the inscription systems of "1900," It should be noted that this label tends to fump together thinkers as entirely different from one another as Derride, Deleuze, and Lacan. Even so, in the philosophy of Deleuze we find what is perhaps the most rigorous attempt to engage materiality and the body without any recourse to the transcendental signified of " $1800^{\prime}$ " (1.e., a post-structualism). That is, to create a conceptual system or open a thought of that which would emerge from the intensities immanent to these bodies themselves. The main question in Deleuze's. The Logic of Sense, for example, is to invest, above and beyond the opposition of the ground and the surface, the propositional articulation of sense and language in the actions and passions of bodies. In Deleuze's philosophy the transcendental is replaced by the "Virtual" or the potentials immanent to whatever material and the singularities around which this material is distributed.

We seek to determine an impersonal and pre-individual transcendental field, which does not resemble the corresponding empirical fields, and which nevertheless is not confused with an undifferentiated depth. [...] What is neither individual nor personal are, on the contrary, emissions of singularities insofar as they occur on an unconscious surface and possess a mobile, immanent principle of auto-unification through a nomadic distribution, radically distinct from fixed and sedentary distributions as conditions of the syntheses of consciousness. Singularities are the true transcendental events [...] Only when the world, teaming with anonymous and nomadic, impersonal and pre-individual singularities, opens up, do we tread at last on the field of the transcendental. Gilles Deleuze, The Logic of Sense, 102-103 
The above passage elucidates the steps Deleuze would take beyond both Heidegger's ontology as well as the critical soience towards an endlessly creative materiality. Fundamental ontology and critical theory, would, according to The Logic of Sense, "hold onto the establishment of [a sensible] surface language," rather than plunging into the "depth" or the materiality of language itself. This is the conicept of the "body without organs" which Deleuze takes from Artaud. This "schizophrenic" language does not hover above the surface, rather it is mixed up with the teeth of being, the "depth" of the surface as the surface's pure involution; the materiality of the surface. It is on this Spinozist field that Deleuze will use Artaud's concept of a body without organs as an attack on transcendental organization. The Kantian transcendental field of critical philosophy of "1800" and its implicit "subject" or "voice" thus becomes an intensive Spinozist Egg - that is, an embryonic or endlessly creative surface-a body without organs.

The breasts on [...] judge [Schreber's] naked torso are neither delirious nor hallitinatory phenomena: they designate, first of all, a band of intensity, a zone of intensity on his body without organs. The body without organs is an egg, it is crisscrossed with axes and thresholds, with latitudes and longitudes and geodesic lines, traversed by gradients marking the transitions and the becomings, the destinations of the subject developing along these particular vectors. Nothing here is representative; rather, it is all life and lived experience: the actual, lived emotion of having breasts does not resemble breasts, it does not represent them, any more than a predestined zone in the egg resembles the organ that it is going to be stimulated to produce within itself.

Gilles Deleuzerand Felix Guattari, Anti-Oedipus, 19.

The passage above indicates what is at stake in Schreber's unmanning, the breasts on his naked torso, are no less real than the modulations of the COMT gene. They are, rather, an affect or a band of intensity arising from this same body without organs. In the passages above, we see that the post-structural "materialist" philosophy of Gilles Deleuze can be understood within the writing-down-systems of " 1900 " in the same way that Kittler reads Schreber. Just as soon as systems of inscription had abandoned the transcendental signified of " 1800 " over to the corpse of " 1900 ," did the question of this corpse in the element of its creativity arise for philosophers. In societies of control, moreover, it is precisely this body without organs that opens as an objeot of social management. For such social management, in is no longer a question of disciplining the transcendental implicit to the voice of the individual, rather, it is a question of the free floating modulation of the body without organs itself at the level of the molecule. Some political theorists have suggested that the only manner of politics adequate to the mechanisms of a social management that would operate in this way, would need begin from the standpoint of the voice it would exorcise. In her book Democracy and Other Neoliberal Fantasies, for example, Jodi Dean suggests, firstly, that "symbolic identities," as they were constituted by prohibitions and the inner-disciplines of "1800" are increasingly coming apart under the pressures of advanced capitalism. "Not only do the multiplicity and variability of such identities prevent them from serving as loci of political action," writes Dean, "but their inseparability from the injunctions of consumerism reinforces capitalism's grip." Dean continues, "Communicative capitalism captures our political interventions, formatting them as contributions to its circuits of affect and entertainment-we feel political, involved, like contributors who really matter." Dean is suspicious of this, as she suspects "imaginary identities" (e.g., social success, fitness, etc.), which are marketable and thus easily controllable, have come to take their place. There may be truth in Dean's analysis, however, given the tripartite nature of RSI, what I am interested here is a movement in the other direction: something like the shattering of both "imaginary" and "symbolic" identities, as with the ummaning implicit to making the Mother-of-the-Name one's sinthome. 


\section{Bibliography}

Abbasi, Ahmed, and Hsinchun Chen. "Affect Intensity Analysis of Dark Web Forums." Intelligence and Security Informatics, 2007 IEEE, (New Brunswick) 282-88. 2007.

- "Writeprints: A Stylometric Approach to Identity-level Identification and Similarity Detection in Cyberspace." ACM Transactions on Information Systems 26, no. 2 (2008): $71-72$.

Abbott, Alison. "Abnormal Neuroscience: Scanning Psychopaths." Nature 450 (2007): $942-44$.

Adorno, Theodor W. Aesthetic Theory. Edited by Gretel Adorno and Rolf Tiedeman. Translated by Robert Hullot-Kentor. London: Continuum, 1997.

- Beethoven: The Philosophy of Music. Edited by Rolf Tiederman. Translated by Edmund Jephcot. Minneapolis: University of Minnesota Press, 2002.

- Essays on Music. Edited by Richard Leppert. Translated by Susan H. Gillespie. Berkeley: University of California Press, 2002.

- Sound Figures. Translated by Rodeny Livingstone. Stanford: Stanford University Press, 1999.

Agamben, Giorgio. The Coming Community. Translated by Michael Hardt. Minneapolis: University of Minnesota Press, 1993.

Homo Sacer: Sovereign Power and Bare Life. Translated by Daniel HellerRoazen. Stanford, CA: Stanford University Press, 1998.

- Infancy and History: Essays on The Destruction of Experience. Translated by Liz Heron. London: Verso, 1993.

- Means without Ends: Notes on Politics. Transiated by Vincenzo Binetti and Cesare Casarino. Minneapolis: University of Minnesota Press, 2000.

Potentialities: Collected Essays in Philosophy. Translated by Daniel HellerRoazen. Stanford, CA: Stanford University Press, 1999.

- "What is an Apparatus?" What is an Apparatus? And Other Essays. Translated by David Kishik and Stefan Pedatella. Stanford, CA: Stanford University Press, 2009.

Almela, Angela, Pascual Cantos, and Rafael Yalencia-Garcia. "Seeing Through Deception: A Computational Approach to Deceit Detection in Written Communication." In Workshop on Computational Approaches to Deception 
Detection, 15-22. Stroudsburg, PA: Association for Computational Linguistics, 2012.

Anderson, Chris. "The End of Theory: The Data Deluge Makes the Scientific Method Obsolete." Wired 16, no. 7 (2008): 15-24.

Anderson, James P. Computer Security Technology Planning Study. Air Force Electronic Systems Division, Hanscom Air Force Base, Bedford, MA, October, 1972. Available at http://csrc.nist.gov/publications/history/ande72.pdf.

Andrejevic, Mark, "Surveillance and Alienation in the Online Economy." Surveillance and Society 8, no. 3 (2011): 278-87.

- "The Work That Affective Economics Does." Cultural Studies 25, no. 4-5 (2011): 604-20.

Arendt, Hannah. "The Public and Private Realm." In The Portable Hannah Arendt, edited by Peter Baehr, 182-231. London: Penguin, 2003.

Armitage, John, and Friedrich A. Kittler. "From Discourse Networks to Cultural Mathematics: An Interview with Friedrich A. Kittler." Theory, Culture \& Society 23 (2006): 17-38.

Atluri, Qin and Li Vijayalakshmi. "Concept-Level Access Control for the Semantic Web." In ACM Workshop on XML Security, 94-103. New York: ACM, 2003.

Attali, Jacques. Noise: An Essay on the Political Economy of Music. Translated by Brian Massumi. Manchester, UK: Manchester University Press, 1985.

Austrian, Geoffrey D. Herman Hollerith: Forgotten Giant of Information Processing. New York: Columbia University Press, 1982.

Ayers, Ian. Super Crunchers. New York: Bantam Books, 2007.

Barbieri, Mario. The Codes of Life: The Rules of Macroevolution. New York: Springer, 2007.

Bachrach, Peter, and Morton S. Baratz. "Two Faces of Power." American Political Science Review 56, no. 4 (1962): 947-52.

Badiou, Alain. Being and Event. Translated by Oliver Feltham. New York: Continuum, 2005 .

Bates, Jason. "The Role of Emotion in Believable Agents." Communications of the ACM 37 , no. 7 (1994): 122-25.

Bell, David E. OH 411. Oral History Interview by Jeffrey R. Yost, 24 September 2012, 
Reston, VA. Charles Babbage Institute, University of Minnesota, Minneapolis, http://purl.umn.edu/144024.

Bell, David E., and Leonard LaPadula. Secure Computer Systems: Mathematical Foundations and Model, Technical Report M74-244. Bedford, MA: MITRE Corp., 1973.

Bellamy, Edward. "With Eyes Shut." Harper's New Monthly Magazine 79 (1889): 73645.

Benjamin, Walter "Central Park." In Selected Writings, vol. 4: 1938-1940, edited by Marcus Paul Bullock, Michael William Jennings, and Howard Eiland, translated by Howard Eiland, 161-200. Cambridge, MA: Harvard University Press, 1999.

—. "Karl Krauss." In Selected Writings, vol. 2: 1927-1934, edited by Marcus Paul Bullock, Michael William Jennings, and Howard Eiland, translated by Howard Eiland, 450-80. Cambridge, MA: Harvard University Press, 1999.

- "Theses on the Philosophy of History." In Illuminations, edited by Hannah Arendt, 253-64. London: Harcourt, 1999.

- The Work of Art in the Age of Mechanical Reproduction. New York: Prism Key Press, 2010.

Biddle, Ian D. "Autonomy, Ontology and the Ideal: Music Theory and Philosophical Aesthetics in Early Nineteenth-Century German Thought." Doctoral dissertation, University of Newcastle-upon-Tyne, 1995.

Bird, N. D., O. Masoud, N. P. Papanikolopoulos, and A. Isaacs. "Detection of Loitering Individuals in Public Transportation Area." IEEE Transactions on Intelligent Transportation Systems' 6, no. 2 (June, 2005): 167-77.

Blanchot, Maurice. The Unavowable Community. Translated by Pierre Joris. Barrytown, NY: Station Hill Press, 1988.

Blank, Robert. "The Brain, Aggression, and Public Policy." Politics and the Life Sciences 24, no. 1-2 (March, 2005): 12-21.

Bloor, David. "Hamilton and Peacock on the Essence of Algebra." In History of Nineteenth Century Mathematics, edited by H. Mehrtens and H. Schneider, 20232. Ann Arbor: University of Michigan, 1981.

—. Knowledge and Social Imagery. Chicago: University of Chicago Press, 1991.

Bolzano, Bernard. A Translation of Bolzano's Paper on the Intermediate Value Theorem. Translated by S. B. Ruiss. San Diego: Academic Press, 1980. 
Bonsu, Samuel K., Aron Darmody, and Detlev Zwick. "Putting Consumers to Work: 'CoCreation' and New Marketing Governmentality." Journal of Consumer Culture 8, no. 163 (2008): 163-96.

Bontcheva, Kalina, Hamish Cunningham, Diana Maynard, and Valentin Tablan. "GATE: A Framework and Graphical Development Environment for Robust NLP Tools and Applications." In 40th Annual Meeting of the ACL, np. Philadelphia, PA: np, 2002.

Brighenti, Andrea. "The Wall and the Mobile Phones." In Urban Plots, Organizing Cities, edited by Claudio Coletta, Franceseo Gabbi, and Giovanni Sonda, 24-35. New York: Ashgate, 2012.

Brown, Wendy. "Power After Foucault." In The Oxford Handbook of Political Theory, edited by John S. Dryzek, Bonnie Honig, and Anne Phillips, 65-84. Oxford: Oxford University Press, 2008.

Cajal, Ramón y Santiago. Recollections of My Life. Cambridge, MA: MIT Press, 1989.

Campbell, Timothy. Improper. Life: Technology and Biopolitics from Heidegger to Agamben. Minneapolis: University of Minnesota Press, 2011.

Canguilhem, George. A Vital Rationalist: Selected Writings from George Canguilhem. Edited by Francois Delaporte. New York: Zone Books, 1994.

Canguilhem, Georges. On the Normal and the Pathological. Translated by Carolyn R. Fawcett. Cambridge, MA: Zone Books, 1989.

Cantor, George. Über eine Eigenschaft des Inbegriffes aller reellen algebraischen Zahlen." Journal filr die reine und angewandte Mathematik,77 (1874): 258-62.

Carruthers, Mary. The Book of Memory: A Study of Memory in Medieval Culture. Cambridge, England: Cambridge University Press, 2008.

Castells, Manuel. The Information Age: Society, and Culture. Vol. 5, The Rise of Network Society. Oxford: Blackwell, 1996.

Celan, Paul. Collected Prose. Translated by Rosmarie Waldro. New York: Routledge, 2003.

- Der Meridian: Endfassung, Vorstufen, Materialien. Tübinger Ausgabe. Edited by Bernhard Boschenstein and Heino Schmull. Frankfurt: Suhrkamp, 1999.

- Selections. Edited by Pierre Joris and Jerome Rothenberg. Translated by Pierre Joris. Berkeley: University of California Press, 2005. 
Charney, Evan, and William English. "Genopolitics and the Science of Genetics." American Political Science Review 107, no. 2 (2013): 382-95.

Christensen, Thomas. Rameau and Musical Thought in the Enlightenment. Cambridge, England: Cambridge University Press, 2004.

Claussen, Detlev. Theodor W. Adorno: One Last Genius. Translated by Rodney Livingstone. Cambridge, MA: Belknap Press, 2008.

Cline-Cohen, Patricia. A Calculating People: The Spread of Numeracy in Early America. Chicago: University of Chicago Press, 1982.

Connor, Steven. "Scilicet: Kittler, Media and Madness." Lecture presented to the symposium "Media Matters: Friedrich Kittler and Technoculture," Tate Modern, London, June 28, 2008, http://stevenconnor.com/scilicet.html.

Cook, Nicholas. "Epistemologies of Music Theory." In The Cambridge History of Western Music Theory, edited by Thomas Christensen, 78-106. Cambridge, England: Cambridge University Press, 2008.

Cooke, Kristina, and John Shiffman. "U.S. directs Agents to Cover Up Program Used to Investigate Americans." Reuters, August 5, 2013.

Covach, John. "Twelve-Tone Theory." In The Cambridge History of Western Music Theory, edited by Thomas Christensen, 603-27. Cambridge, England: Cambridge University Press, 2008.

Cowell, Henry. "Music of and for the Records." Modern Music 8 (1931): 32-34.

Crocker, Richard L. A History of Musical Style. Mineola, NY: Dover, 1986.

Curtis, Bruce. "Foucault on Governmentality and Population: The Impossible Discovery." Canadian Journal of Sociology 27 (2002): 505-33.

Cutler, Brian, Devlin Daley, Kevin Tew, and Phillip J. Windley. "Using Reputation to Augment Explicit Authorization." In ACM Workshop on Digital Identity Management, 72-81. New York: ACM, 2007.

Daston, Lorraine, and Elizabeth Lunbeck. Histories of Scientific Observation. Chicago: University of Chicago Press, 2010.

Davenport, Thomas H., and Jeanne G. Harris. Competing on Analytics: The New Science of Winning. Cambridge, MA: Harvard Business Press, 2013.

Debord, Guy. Comments on the Society of the Spectacle. Translated by Malcolm Emrie. London: Verso, 1998. 
- The Society of the Spectacle. Translated by Ken Knabb. Berkeley: Bureau Of Public Secrets, 2013.

De Lauretis, Teresa, Queer Theory: Lesbian and Gay Sexualities. Bloomington: Indiana University Press, 1991.

Deleuze, Gilles. Cinema II: The Time-Image. Translated by Hugh Tomlinson and Robert Galeta. Minneapolis: University of Minnesota Press, 1989.

_. Essays Critical and Clinical. Translated by Daniel W. Smith. New York: Verso, 1998.

—. Negotiations. New York: Columbia University Press, 1997.

—. "Postscript on the Societies of Control." October 59 (1992): 3-7.

—. "What is a Dispositif Michel Foucault, Philosapher. Translated by Timothy J. Armstrong. New York: Harvester, 1992.

Deleuze, Gilles, and Félix Guattari. Anti-Oedipus. Translated by Robert Hurley. Minneapolis: University of Minnesota Press, 2004.

- A Thousand Plateaus. Translated by Brian Massumi. Minneapolis: University of Minnesota Press, 1987.

Deleuze, Gilles, and Toni Negri. "Control and Becoming." Negotiations 1972-1990, translated by Martin Joughin, 169-76. New York: Columbia University Press, 1990.

Duhigg, Charles. "How Companies Learn Your Secrets." New York Times Magazine, February 16, 2012, http://www.nytimes.com/2012/02/19/magazine/shoppinghabits.html.

Dunn, Thomas. "Wild Things." In Cultural Studies and Political Theory, edited by Jodi Dean, 258-269. Ithaca, NY: Cornell University Press, 2000.

Durantaye, Leland. Giorgio Agamben: A Critical Introduction. Stanford, CA: Stanford University Press, 2009.

Eckhard, Petra. "A Queer Reading of Moby Dick." Landscapes of Postmodernity: Concepts and Paradigms of Critical Theory, edited by Petra Eckhard, Michael Fuchs, and Walter W. Hobling, 179-94. Berlin: Verlag, 2010.

Edleman, Lee. Homographesis: Essays in Gay Literary and Cultural Theory. Hoboken, NJ: Taylor and Francis, 2013.

Epstein, Robert. "From Russią, with Love." Scientific American Mind, October 2007, 
http://www.nature.com/scientificamericanmind/journal/v18/n5/full/scientificameri canmind1007-16.html.

Erickson, Robert. Sound Structure in Music. Oakland: University of California Press, 1975.

Fernstrom, J. D. "Can Nutrient Supplements Modify Brain Function?" American Journal of Clinical Nutrition 71, no. 6 (2000): 1669-75.

Fleissner, Jennifer L. "Secretary to the Stars: Mediums and the Agency of Authorship." In Literary Secretaries/Secretarial Culture, edited by Leah Price and Pamela Thurschwell, 632-73. Farnham, UK: Ashgate Pub, 2005.

Foucault, Michel. Archaeology of Knowledge. Translated by A. M. Sheridan Smith. London: Routledge, 2002.

—. "The Confession of the Flesh" (a conversation with Alain Grosrichard, Gerard Wajeman, Jacques-Alain Miller, Guy Le Gaufry, Dominique Celas, Gerard Miller, Catherine Millot, Dominique Celas, Gerard Miller, Catherine Millot, Jocelyne Livi, and Judith Miller). In Power/Knowledge: Selected Interviews and Other Writings, translated by Colin Gordon, 194-229. New York: Pantheon, 1980.

- Discipline and Punish: The Birth of the Prison. Translated by Alan Sheridan. New York: Vintage Books, 1995.

- The History of Sexuality: An Introduction. Translated by Robert Hurley. New York: Random House, 2012.

- Order of Things. New York: Pantheon Books, 1971.

- Society Must Be Defended: Lectures at the Collège de France, 1975-76. Translated by David Macey. New York: Macmillan, 2003.

Fowler, James, Laura Baker, and Christopher Dawes. "Genetic Variation in Political

Participation." The American Journal of Political Science 102, no. 2 (May 2008): $233-48$.

Fowler, James, and Christopher Dawes. "Two Genes Predict Voter Turnout." The Journal of Politics 70, no. 3 (July 2008): 579-94.

Fynsk, Christopher. Heidegger: Thought and Historicity. Ithaca, NY: Cornell University, 1993.

- Language and Relation: That There is Language. Stanford, CA: Stanford University Press, 1996.

Galison, Peter. "The Ontology of the Enemy: Norbert Weiner and the Cybernetic Vision." 
Critical Inquiry 21, no. 1 (Autumn, 1994): 228-66.

Galloway, Alexander, and Eugene Thacker. The Exploit: A Theory of Networks. Minneapolis: University of Minnesota Press, 2007.

Gianvecchio, Steven, Xie Mengjun, Wu Zhenyu, and Wang Haining. "Measurement and Classification of Humans and Bots in Internet Chat." In 17th Conference on Security Symposium, 155-69. Berkeley: USENIX Association, 2008.

Gillespie, Sam. The Mathematics of Novelty: Badiou's Minimalist Metaphysics. Prahran: re.press, 2008.

Good, Irving John. "Speculations Concerning the First UltraIntelligent Machine." In Advances in Computers, edited by Franz L. Alt and Morris Rubinoff, 31-89. Waltham, MA: Academic Press, 1966.

Goodell, Geoffrey L. Perspective Access Networks. Cambridge, MA: Harvard University Press, 2006.

Gould, Glenn. "Portrait of a Cantankerous Composer." The Globe and Mail, March 18, 1978.

Gray, Andrew R., and Stephen G. Macdonell. "Software Forensics: Extending Authorship Analysis Techniques to Computer Programs." Information Science Discussion Papers Series No. 97/14, 1-7. Dunedin: University of Otago, 1997.

Green, Burdette, and David Butler. "From Acoustics to Tonpsychologie." In The Cambridge History of Western Music Theory, edited by Thomas Christensen, 246-71. Cambridge, England: Cambridge University Press, 2008.

Grigg, Russell. Lacan, Language, and Philosophy. Albany, NY: SUNY Press, 2009.

Gruber, Thomas R, "A Translation Approach to Portable Ontology Specifications." Knowledge Acquisition 5, no. 2 (1993):199-220.

Guarino, Noicola, and Pierdaniele Giaretta. "Ontologies and Knowledge Bases Towards a Terminological Clarification." In Towards Very Large Knowledge Bases: Knowledge Building \& Knowledge Sharing, edited by N. J. I. Mars, 25-32. Amsterdam: IOS Press, 1995.

Guattari, Félix. Chaosophy: Texts and Interviews 1972-1977. Edited by Sylvère Lotringer, Boston: MTT Press, 2008.

Hacking, Ian. "How Should we Do a History of Statistics?" In The Foucault Effect: Studies in Governmentality, edited by Graham Burchell, Colin Gordon, and Peter Miller, 181-95. Chicago: University of Chicago Press, 1991. 
- Rewriting the Soul: Multiple Personality and the Sciences of Memory. Princeton, NJ: Princeton University Press, 1995.

T The Taming of Chance. Cambridge, England: Cambridge University Press, 1990.

Halbert, Deborah. Resisting Intellectual Property Laws. London: Taylor and Francis, 2005.

Halberstam, Judith. "The Politics of Negativity in Recent Queer Theory." PMLA 121, no. 3 (2006): 823-25.

- "Queer Temporality and Postmodern Geographies." In In a Queer Time and Place: Transgender Bodies, Subcultural Lives, 1-21. New York: New York University Press, 2005.

Hallward, Peter. Badiou: A Subject to Truth. Minneapolis: University of Minnesota Press, 2003.

Hardt, Michael, and-Antonio Negri. Empire. Boston: Harvard University Press, 2000.

Harris, Stefanie. Mediating Modernity: German Literature and the "New" Media, 18951930. University Park: Pennsylvania State University Press, 2009.

Harvey, Mary Kersey. "Edgard Varèse: 'Stratopheric Collosus of Sound.'” The Diplomat, May 1959.

Heflin, Jeff. "OWL Web Ontology Language, Use Cases and Requirements." Last modified November 12, 2009. http://www.w3.org/TR/webont-req/.

Hegel, Georg W. F. The Phenomenology of Mind: Two Volumes in One. Translated by J. B. Baillie. New York: Gosimo Classics, 2011.

Heidegger, Martin. Being and Time. Translated by Joan Stambaugh. Albany: State University of New York Press, 1996.

- Parmenides. Translated by André Schuwer and Richard Rojcewicz. Bloomington: University of Indiana Press, 1998.

- Poetry, Language, Thought. Translated by Alfred Hofstadter. New York: Harper and Row, 2002.

- What is Called Thinking? Translated by J. Glenn Gray. New York: Harper \& Row, 1968.

Herman, Ivan. "W3C Semantic Web Activity." Accessed 6/1/2013. http://www.w3.org/2004/sw/. 
Hilbert, David. "The Foundations of Mathematics" (1927). In The Emergence of Logical Empiricism: From 1900 to the Vienna Circle, edited by Sahotra Sarkar, 321-40. London: Taylor and Francis, 1996.

Hyer, Bryan. "Tonality." In The Cambridge History of Western Music Theory, edited by Thomas Christensen, 728-29. Cambridge, England: Cambridge University Press, 2002.

Iroju, O., A. Soriyan, I. Gambo, and R. Ikono. "State-of-the Art: A Comparative Analysis of Ontology Matching Systems." African Journal of Computing \& ICT 5, no. 4 (June 2012): 81-93.

Jech, Thomas. Set Theory. New York: Springer, 2002.

Johnston, Barbara Rose, and Holly M. Barker. The Consequential Damages of Nuclear War: The Rongelap Report. San Francisco: Left Coast Press, 2008.

Joyce, James. Finnegan's Wake. Oxford: Oxford University Press, 2012.

Kanamori, Akihiro. "Set Theory from Cantor to Cohen." In Handbook of the History of Logic, vol. 6, edited by Dov M. Gabbay, Paul Thagard, and John Woods, 395461. Amsterdam: Elsevier, 2012.

Kim, Soo-Min, and Eduard Hovy. "Crystal: Analyzing Predictive Opinions on the Web." 22nd International Conference on Computational Linguistics, 473-80. Stroudsburg: Association for Computational Linguistics, 2008.

Kittler, Friedrich A. "Code (or, How You Can Write Something Differently)." In Software Studies: A Lexicon, edited by Matthew Fuller, 40-48. Boston: MIT Press, 2008.

_. "Computer Graphics: A Semi-Technical Introduction," translated by Sara Ogger. Grey Room no. 2 (Winter, 2001): 30-45.

- Discourse Networks 1800/1900. Translated by Michael Metteer and Chris Cullens. Stanford, CA: Stanford University Press, 1990.

- Gramophone, Film, Typewriter. Translated by Geoffrey Winthrop-Young and Michael Wutz. Stanford, CA: Stanford University Press, 1999.

Kittler, Friedrich A., and John Armitage. "From Discourse Networks to Cultural Mathematics: An Interview with Friedrich A. Kittler." Theory, Culture \& Society 23 (2006): 17-38.

Kripke, Saul A. Wittgenstein on Rules and Private Language. Cambridge, MA: Harvard University Press, 1982. 
Kushal, Dave, Steve Lawrence, and David M. Pennock. "Mining the Peanut Gallery: Opinion Extraction and Semantic Classification of Product Reviews." In 12th International Conference on World Wide Web, 519-28. New York: ACM, 2003.

Lacan, Jacques. Ecrits: A Selection. Translated by Bruce Fink. London: Norton, 1997.

—. "Lituraterre." Translated by Jack W. Stone. Ornicar? 41 (April, 1987): 5-13.

- The Psychoses. Translated by Russell Grigg. London: Norton, 1993.

Lazzarato, Maurizio. "Immaterial Labor." In Radical Thought In Italy: A Potential Politics, translated by Paul Colilli and Ed Emory, 133-47. Minneapolis: University of Minnesota Press, 2006.

Lee, Daeyeol. "Neuroeconomics: Making Risky Choices in the Brain." Nature Neuroscience 8, no: 9 (2005): 1162-63.

Lester, Joel. "Rameau and the Eighteenth-Century Harmonic Theory." In The Cambridge History of Western Music Theory, edited by Thomas Christensen, 769-70. Cambridge, England: Cambridge University Press, 2000.

Lin, Wei-Hao, Theresa Wilson, Janyce Wiebe, and Alex Hauptmann. "Which Side Are You On? Identifying Perspectives at the Document and Sentence Levels." In Tenth Conference on Computational Natural Language Learning, 109-16. Stroudsburg: Association for Computational Linguistics, 2006.

Lipton, Eric. "Hatch a 'Natural' Ally of Supplements Industry." New York Times, June 20, 2011.

Liu, Yang, Huang Xiangii, An Aijun, and Yu Xiaohui. "ARSA: A Sentiment-Aware Model for Predicting Sales Performance Using Blogs." In SIGIR'07, July 23-27, 2007, $607-14$.

Loève, Michel. Probability Theory 1. 4th ed. Berlin: Springer Verlag, 1977.

Mader, Mary Beth. "Foucault and Social Measure." Journal of French Philosophy 17, no. 1 (Spring 2007): 2-25. .

- Sleights of Reason: Norm, Bisexuality, Development. Albany, NY: SUNY Press, 2012.

Mann, Thomas. Doctor Faustus. Translated by John E. Woods. New York: Vintage, 1997.

Markram, Henry. "A Brain is a Supercomputer." Lecture presented at TEDGlobal 2009.

Marx, Karl. Grundrisse: Foundations of the Critique of Political Economy. Translated by 
Martin Nicolaus. New York: Vintage Books, 1973.

Mason, Lowell. Manual of the Boston Academy of Music: for instruction in the Elements of Vocal Music. Boston: Wilkins and Carter, 1839.

Massumi, Brian. "The Future Birth of the Affective Fact." In Conference Proceedings: Genealogies of Biopolitics (2005).

McClary, Susan. Feminine Endings. Minneapolis: University of Minnesota Press, 1991.

McLandburgh, Florence. "The Automaton Ear." In The Automaton Ear and Other Sketches, 7-43. Chicago: Jansen, McClurg and Co., 1876.

Michelson, Noah. "Kirk Cameron Tells Piers Morgan Homosexuality Is 'Unnatural,' "Ultimately Destructive." The Huffington Post, February 3, 2012, http://www:huffingtonpost,com/2012/03/03/kirk-cameron-piers-morganhomosexuality-unnatural_n_1318430.html.

Mihalcea, Rada, and Carlo Strapparava. "Learning to Laugh (Automatically): Computational Models' for Humor Recognition." Computational Intelligence 22, no. 2 (2006): $126-42$.

Nancy, Jean-Luc. Being Singular Plural. Translated by Robert D. Richardson and Anne E. O'Byrne. Stanford, CA: Stanford University Press, 1996.

- The Inoperative Community. Translated by Peter Connor. Minneapolis: University of Minnesota Press, 1990.

Nass, Clifford, Jonathan Steuer, and Ellen R. Tauber. "Computers Are Social Actors." In SIGCHI Conference on Human Factors in Computing Systems, 72-78. New York: ACM, 1994.

O'Connor, Clare. "The Mystery Monk Making Billions with 5-Hour Energy." Forbes, February 27, 2012.

Palmås, Karl. "Predicting What You'll Do Tomorrow: Panspectric Surveillance and the Contemporary Corporation." Surveillance \& Society 8, no. 3 (2011): 338-54.

Pasquier, Phillipe, Roberto A. Flores, and Brahim Chaib-draa. "An Ontology of Social Control Tools." In AAMAS '06: Proceedings of the Fifth International Joint Conference on Autonomous Agents and Multiagent Systems, 1369-71. (New York: ACM), 2006.

Patil, Ramesh, Don Mckay, Tim Finin, Richard Fikes, Thomas Gruber, Peter F. PatelSchneider, and Robert Neches, "The DARPA Knowledge Sharing Effort: Progress Report." In Principles of Knowledge Presentation and Reasoning: Proceedings of 
the Third International Conference, 777-88. New York: Morgan Kaufmann, 1998.

Perlis, Vivian, and Libby Van Cleve. Composers' Voices from Ives to Ellington: An Oral History of American Music. New Haven, CT: Yale University Press, 2005.

Pierce, Charles S. Collected Papers. Cambridge, MA: Harvard University Press, 1935.

Poisson, S. D. Probabilité des jugements en matière criminelle et en matière civile, précédées des règles générales du calcul des probabilities. Paris: Bachelier, 1837.

Potter, Michael. Set Theory and its Philosophy: A Critical Introduction. Oxford: Oxford University Press, 2004.

Qin, Li, and Vijayalakshmi Atluri. "Concept-Level Access Control for the Semantic Web." In ACM Workshop on XML Security, Fairfax, VA, USA, 94-103. New York: ACM, 2003.

Ranciere, Jacques. Disagreement: Politics and Philosophy. Translated by Julie Rose. Minneapolis: University of Minnesota, 1999.

— . "Dissenting Words: A Conversation with Jacques Ranciere." Diacritics 30, no. 2 (2000): 113-24.

—. Emancipated Spectator. Translated by Gregory Elliott. London: Verso, 2009.

__. "Introducing Disagreement." Angelaki 9, no. 3 (2004): 3-9.

- The Politics of Aesthetics: The Distribution of the Sensible. Translated by Gabriel Rockhill. London: Continuum, 2004.

Resnick, Paul, Ko Kuwabara, Richard Zeckhauser, and Eric Friedman, "Reputation Systems: Facilitating Trust in Internet Interactions." Communications of the ACM 43 , no. 12 (2000): $45-58$.

Rilke, Rainer Maria. "Primal Sound" in Primal Sound and Other Prose Pieces. Translated by Carl Niemeyer. Madison: University of Wisconsin Press, 1943.

Rose, Nikolas. The Politics of Life Itself: Biomedicine, Power, and Subjectivity in the Twenty-First Century. Princeton, NJ: Princeton University Press, 2009.

- Powers of Freedom: Reframing Political Thought. Cambridge, England: Cambridge University Press, 1999.

Rose, Nikolas, and Peter Miller. "Political Power beyond the State." The British Journal of Sociology 43, no. 2 (1992): 173-205.

Rose, Nikolas, and Ilina Singh. "Biomarkers in Psychiatry." Nature 460 (2009): 202-7. 
Saggion, Horacio. "SUMMA: A Robust and Adaptable Summarization Tool." TAL 49, no. 2 (2008): 103-25.

Saldanha, Arun. Pyschedelic White: Goa Trance and the Viscosity of Race. Minneapolis: University of Minnesota Press, 2007.

Salminen, Antti. "Falling Upwaards: Paul Celan's Poetics." Partial Answers: Journal of Literature and the History of Ideas 10, no. 2 (June 2012): 223-40.

Schaeffer, Pierre. A la reserche d'une musique concrete. Paris: Seuil, 1952.

Schoenberg, Arnold. Letters. Edited by Erwin Stein. Translated by Eithne Wilkins and Ernst Kaiser. Berkeley: University of California Press, 1987.

Schreber, Daniel Paul. Memoirs of My Nervous Illness. Translated by Ida Macalpine and Richard A. Hunter. New York: New York Review of Books, 2000.

Shannon, Claude. "Communication in the Presence of Noise." Proceedings of the Institute of Radio Engineers 37, no. 1 (1947): 1-21.

Shapiro, Michael. Discourse, Culture, Violence. Edited by Terrell Carver and Samuel Chambers. London: Taylor and Francis, 2012.

Shaviro, Steven. Connected. Minneapolis: University of Minnesota Press, 2003.

—. The Cinematic Body. Minneapolis: University of Minnesota Press, 1993.

Shulgin, Alexander T., and Ann Shulgin. PiHKAL: A Chemical Love Story. San Francisco: Transform Press, 1995.

—. TiHKAL: The Continuation. San Francisco: Transform Press, 1995.

Taylor, Timothy D., Mark Katz, and Tony Grajeda. Music, Sound, and Technology in America: A Documentary History of Early Phonograph, Cinema, and Radio. Durham, NC: Duke University Press, 2012.

Terranova, Tiziana. "Free Labor: Producing Culture for the Digital Economy." Social Text 63, no. 18 (2000): 33-57.

- Network Culture: Politics for the Information Age. Ann Arbor: University of Michigan Press, 2004.

Thayer, Alexander W. Life of Beethoven, vol. 3. Cambridge, MA: Harvard University Press, 1921.

Thoburn, Nicholas. Delewze, Marx, and Politics. London: Routledge, 2003. 
Thomas, Frank, and Olli Johnston. The Illusion of Life: Disney Animation. New York: Hyperion, 1995.

Turing, A. M. "Intelligent Machinery, A Heretical Theory," 1951. Reprinted in Philosophia Mathematica 4, no. 3 (1996): 256-60.

Vinge, Vernor. "First World." Omni, (January, 1983): 1.

von Neumann, J. "Zur Einfuhrung der transfiniten Zahlen," Acta Scientiarum Mathematicarum (Szeged) 1, no. 4, (1922-1923): 199-208.

Weaver, Warren, and Claude Shannon. The Mathematical Theory of Communication. Urbana: University of Illinois Press, 1949.

Weiming, Hu. "Survey on Visual Surveillance of Object Motion and Behaviors." Systems, Man, and Cybernetics 4, no. 3 (August, 2004): 334-52.

Wiener, Norbert. Cybernetics. New York: Wiley, 1948.

- The Human Use of Human Beings: Cybernetics and Society. New York: Avon Books, 1967.

Wiener, Norbert, Arturo Rosenblueth, and Julian Bigelow. "Behavior, Purpose, and Teleology," Philosophy of Science 10, no. 1 (1943): 18-24.

Windley, Phillip J., Devlin Daley, Bryant Cutler, and Kevin Tew. "Using Reputation to Augment Explicit Authorization." In $A C M$ Workshop on Digital Identity Management, Alexandria, VA, 72-81. New York: ACM, 2007.

Wittgenstein, Ludwig. Philosophical Investigations, Edited by P. M. S. Hacker and Joachim Schulte. New York: Wiley, 2010.

Wurtman, E. "Tyrosine: Effects on Catecholamine Release." Brain Research Bulletin 21, no. 3 (1988): 473-77.

Zheng, Rong, Li Jiexun, Hsinchun Chen, and Zan Huang, "A Framework for Authorship Identification of Online Messages: Writing-style Features and Classification Techniques." Journal of the Association for Information Science and Technology 57, no. 3 (2006): 378-93.

Zwick, Detlev, Samuel K. Bonsu, and Aron Darmody. "Putting Consumers to Work: 'CoCreation' and New Marketing Governmentality." Journal of Consumer Culture 8, no. 163 (2008): 163-96. 